\title{
HANNE LACEULLE
}

\section{- - - - - - - - \\ AGING AND \\ SELF-REALIZATION}

CULTURAL NARRATIVES

ABOUT LATER LIFE

\section{[transcript] Aging Studies Volume XVII}


Hanne Laceulle

Aging and Self-Realization

Aging Studies | Volume 17 
To Gert - in loving memory

The series is edited by Heike Hartung, Ulla Kriebernegg and Roberta Maierhofer.

Hanne Laceulle (PhD), born in 1975, obtained her doctorate "cum laude" at the University of Humanistic Studies in Utrecht, the Netherlands, where she currently works as an Assistant Professor of Philosophy of Life Course and Art of Living. In 2017, she received the European Network in Aging Studies (ENAS) award for the best PhD thesis. 
Hanne Laceulle

\section{Aging and Self-Realization}

Cultural Narratives about Later Life 
An electronic version of this book is freely available, thanks to the support of libraries working with Knowledge Unlatched. KU is a collaborative initiative designed to make high quality books Open Access for the public good. The Open Access ISBN for this book is 978-3-8394-4422-1. More information about the initiative and links to the Open Access version can be found at www.knowledgeunlatched.org.
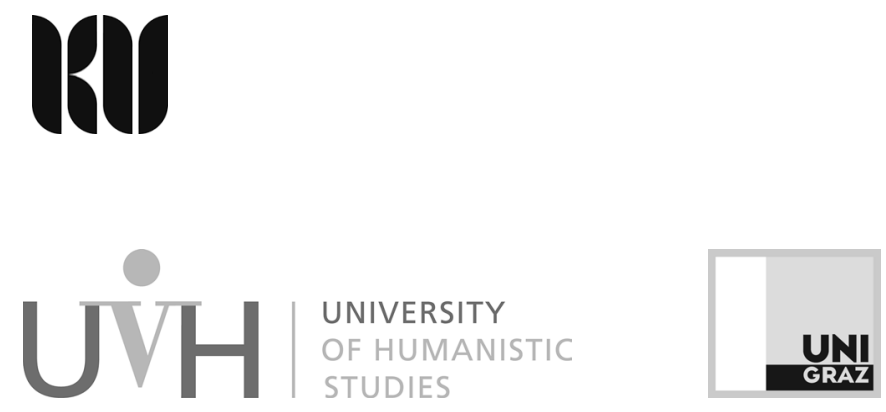

\section{Bibliographic information published by the Deutsche Nationalbibliothek}

The Deutsche Nationalbibliothek lists this publication in the Deutsche Nationalbibliografie; detailed bibliographic data are available in the Internet at http://dnb.d-nb.de

\section{(9)(1) $\Theta \Theta$}

This work is licensed under the Creative Commons Attribution-NonCommercial-NoDerivatives 4.0 (BY-NC-ND) which means that the text may be used for non-commercial purposes, provided credit is given to the author. For details go to http://creativecommons.org/licenses/by-nc-nd/4.o/

To create an adaptation, translation, or derivative of the original work and for commercial use, further permission is required and can be obtained by contacting rights@ transcript-verlag.de

Creative Commons license terms for re-use do not apply to any content (such as graphs, figures, photos, excerpts, etc.) not original to the Open Access publication and further permission may be required from the rights holder. The obligation to research and clear permission lies solely with the party re-using the material.

\section{(C) 2018 transcript Verlag, Bielefeld}

Cover concept: Kordula Röckenhaus, Bielefeld

Typeset by Francisco Bragança, Bielefeld

Printed by Majuskel Medienproduktion $\mathrm{GmbH}$, Wetzlar

Print-ISBN 978-3-8376-4422-7

PDF-ISBN 978-3-8394-4422-1

https://doi.org/10.14361/9783839444221 


\section{Content}

\section{Preface $\mid 9$}

\section{Chapter 1-Introduction | 11}

1.1 Prologue - An exemplar of "aging well" | 11

1.2 Introducing the thematic domain and background of the study $\mid 13$

1.2.1 Lack of meaning-generating narratives about later life $\mid 13$

1.2.2 Aging in an era of self-realization $\mid 15$

1.3 Objectives of the study $\mid 18$

1.4 A hermeneutic approach 19

1.5 Some terminological issues $\mid 21$

1.6 Positioning the study in the philosophical and gerontological field $\mid 26$

1.6.1 Positioning in moral philosophy $\mid 26$

1.6.2 Positioning in gerontology $\mid 27$

1.7 Chapter outlines $\mid 29$

\section{Chapter 2-Living and aging in late modernity $\mid 33$}

2.1 Introduction $\mid 33$

2.2 Late modernity, an era of self-realization? | 34

2.3 Features and dynamics of the late modern world | 35

2.3.1 A life of one's own: reflexive individualization $\mid 36$

2.3.2 Living in a post-traditional context $\mid 38$

2.3.3 A globalizing world $\mid 40$

2.3.4 Structural and systemic influences on individualized lives 41

2.3.5 Repression of meaning and morality $\mid 43$

2.3.6 The moral identity crisis of late modern man $\mid 45$

2.4 Implications for late modern aging | 46

2.4.1 A (much) longer life in a complex world | 47

2.4.2 Individualization and diversification: an old age of one's own? | 47

2.4.3 Third Age and Fourth Age $\mid 49$

2.4.4 Structural and systemic dynamics impacting late modern aging $\mid 52$

2.4.5 Aging well as an individual responsibility $\mid 53$

2.4.6 Existential vulnerability and the fragile experience of meaning $\mid 55$ 
2.5 Conclusion $\mid 58$

2.5.1 Ambivalences of self-realization in late modernity $\mid 58$

2.5.2 Reframing late modern self-realization discourse 59

Chapter 3-Cultural narratives and counter narratives about aging $\mid 6_{3}$

3.1 Introduction $\mid 6_{3}$

3.2 Cultural narratives and counter narratives $\mid 64$

3.2.1 Cultural (master) narratives and their role in identity-building | 64

3.2.2 Damaging effects of cultural narratives $\mid 67$

3.2.3 Moral agency and the importance of recognition 169

3.2.4 Narrative repair through agency-enhancing counter narratives $\mid 73$

3.3 Cultural narratives about later life $\mid 76$

3.3.1 Cultural and critical gerontology on the cultural positioning of aging $\mid 76$

3.3.2 Decline narratives $\mid 79$

3.3.3 Age-defying narratives $\mid 81$

3.3.4 Limitations of existing cultural narratives on aging $\mid 83$

3.4 Conclusion: In search of viable counter narratives about aging $\mid 86$

Chapter 4-Self-realization | 93

4.1 Introduction $\mid 93$

4.2 Introducing self-realization $\mid 94$

4.2.1 The purpose of self-realization $\mid 96$

4.2.2 The self in self-realization $\mid 101$

4.2.3 The practice of self-realization $\mid 106$

4.2.4 The timing of self-realization $\mid 109$

4.3 Exploring the best in us $\mid 112$

4.3.1 Selected historical and philosophical interpretations of the best in us $\mid 113$

4.3.2 Three threads: autonomy, authenticity and virtue $\mid 117$

4.4 Self-realization and aging $\mid 120$

4.4.1 Self-realization and the shrinking of the future $\mid 120$

4.4.2 Self-realization and radicalization of existential vulnerability $\mid 123$

\section{Chapter 5-Narrative identity and moral agency | 127}

5.1 Introduction 127

5.2 Introducing narrative identity $\mid 128$

5.2.1 Life and self as stories $\mid 128$

5.2.2 The relation between life and narrative $\mid 130$

5.2.3 Narrative integration and unified personhood $\mid 132$

5.2.4 Narrativity and aging | 134 
5.3 Three interpretations of narrative identity $\mid 136$

5.3.1 Marya Schechtman - Narrative self-constitution | 136

5.3.2 Hilde Lindemann - Narrative identity as a social practice 139

5.3.3 Kim Atkins - Narrative identity and moral identity $\mid 142$

5.4 From narrative identity to moral agency $\mid 145$

5.5 Conclusion: composing a definition of moral agency $\mid 153$

Chapter 6-Autonomy $\mid 159$

6.1 Introduction $\mid 159$

6.2 Introducing autonomy $\mid 160$

6.2.1 Historical roots of autonomy discourse 160

6.2.2 Harry Frankfurt: A dominant contemporary account $\mid 162$

6.3 Selected alternative accounts of autonomy $\mid 16_{3}$

6.3.1 Charles Taylor: Autonomy and the strong evaluation of desires $\mid 164$

6.3.2 Laura Ekstrom: Autonomy and the coherence of our value orientation $\mid 165$

6.3.3 Diana Meyers: Autonomy and the conditions of its practicability $\mid 166$

6.3.4 Relational view: Autonomy, interdependence, socialization and power 169

6.4 Autonomy in the context of aging $\mid 174$

6.4.1 Harry Moody: The communicative approach | 175

6.4.2 George Agich: The phenomenological approach $\mid 176$

6.4.3 Martha Holstein and colleagues: The relational approach $\mid 178$

6.5 Evaluation of the discussed accounts on autonomy $\mid 180$

6.6 Conclusion: Towards an individuating conception of autonomy $\mid 182$

\section{Chapter 7-Authenticity | 189}

7.1 Introduction $\mid 189$

7.2 Introducing authenticity $\mid 190$

7.3 Selected philosophical accounts of authenticity $\mid 194$

7.3.1 Jean-Jacques Rousseau and his Romantic heirs $\mid 194$

7.3.2 Existentialist views of authenticity $\mid 197$

7.3.3 Charles Taylor's ethics of authenticity $\mid 203$

7.3.4 Diana Meyers - Authenticity and intersectional identity | 205

7.4 Authenticity in the context of aging $\mid 207$

7.4.1 Spiritual perspectives on aging $\mid 207$

7.4.2 Existential perspectives on aging $\mid 209$

7.4.3 Art of living perspectives on aging | 210

7.5 Evaluation of the discussed authenticity accounts $\mid 212$

7.6 Conclusion: Towards authenticity as a social and moral practice $\mid 215$ 


\section{Chapter 8-Virtue 219}

8.1 Introduction $\mid 219$

8.2 Introducing virtue 219

8.3 Selected accounts of virtue ethics $\mid 223$

8.3.1 Aristotle: Virtue as 'nobility of the soul' | 223

8.3.2 Alasdair MacIntyre: Virtue as a remedy

for the modern "moral crisis" | 226

8.3.3 Christine Swanton: Pluralistic virtue ethics 229

8.4 Virtue in the context of aging 235

8.5 Evaluation of the discussed virtue accounts $\mid 239$

8.6 Conclusion: Towards virtue as attitudinal concretization of moral agency | 244

\section{Chapter 9-Conclusion | 251}

9.1 Introduction | 251

9.2 Recapitulation of the argument $\mid 252$

9.3 Advancing older people's moral agency | 257

9.4 Objections to the self-realization discourse 264

9.4.1 Elitism/demandingness objection $\mid 265$

9.4.2 Self-centeredness objection $\mid 266$

9.4.3 Social structure/social justice objection | 266

9.4.4 Western/masculine bias objection | 268

9.4.5 Moralism/paternalism objection | 269

9.4.6 Mental/cognitive ability objection | 270

9.5 Unanswered questions $\mid 273$

9.6 Final thoughts $\mid 274$

References | 277 


\section{Preface}

What does it mean to lead a good life? This question has puzzled moral philosophers for centuries. As is characteristic for all fundamental philosophical questions, it will never be fully answered. But finding the ultimate answer is not what matters; the continued quest for the meaning of a good life is of value because of the richness of perspectives it can open. In turn, these perspectives may inspire a variety of practices that are conducive to what Ricoeur (1992) has defined as the ethical aim of human life: 'a good life, with and for others, in just institutions'.

This phrase forms the heart of the mission statement of the University of Humanistic Studies in Utrecht, The Netherlands, a small university that in its research program focuses on the humanization of society, in order to enable individuals to lead a meaningful, dignified life of optimal human flourishing. This book is the culmination of five years of PhD-research in this unique academic community, where I had the privilege of participating in the research group Aging well. This multi-disciplinary group was founded in 2008 , and consists of philosophers, social scientists, historians and anthropologists. In its research program, this group aims to apply broad humanistic questions and thoughts about the good life to the context of aging. Contrasting dominant biomedical and sociological perspectives on aging, the members of this research group share an interest in the social-existential dimensions of aging (Baars, 2012a).

By narrowing down the question about the good life to the context of aging, we enter the field of humanistic and cultural gerontology. In recent decades, this field has been engaged in a vivid search to answer the question what it means to age well from different disciplinary perspectives, which has resulted in a mature and highly relevant (sub)field of the study of aging. Ever since the publication of the first handbook What does it mean to grow old? Reflections from the humanities by Cole and Gadow in 1986, humanistic and cultural gerontology offers much needed counterweight to the dominance of biomedical perspectives in the study of aging. The growing research interest in existential, moral and spiritual questions concerning aging, studied from a critical, context-sen- 
sitive perspective, offers hopeful and interesting perspectives on the meaning of aging well in our days. It also calls attention to the importance of having cultural resources available to help older people experience their existence as meaningful and socially relevant.

Each society, each culture has its own range of resources - stories, images, ideas, artifacts - that individuals can draw on in their own search for a good life. However, each socio-cultural context also harbors a variety of forces that may impede the optimal realization of a good, meaningful existence. As Edmondson (2015) has argued, cultural meaning resources for old age are by no means self-evidently available in contemporary modern Western societies. This raises the urgent question how to shape inspiring narratives and images of a good old age. In this book, this question is addressed from a philosophical perspective, inspired by the rich discourse about self-realization, or realizing the best in you. Since, with some exceptions, the contribution of philosophy to the study of aging has remained relatively modest so far, this study hopes to be a valuable addition to the field of humanistic and cultural gerontology.

This book could not have been realized without the help of others. Although it is impossible to mention everyone who has, knowingly or unknowingly, contributed to the creation of this study, some people deserve special acknowledgement. First of all, I am thankful to my colleagues of the research group Aging well at the University for Humanistic Studies. In particular, I would like to express my deep gratitude to Joep Dohmen, for his unconditional and loyal support at both the intellectual and existential level, and to Jan Baars, for sharing his broad knowledge of philosophy and gerontology and encouraging me to boldly start writing about my ideas. Second, I am very grateful to the European Network of Aging Studies, who has granted my work the first prize for Best PhD-thesis in 2017, in the aftermath of which the editors of the Aging Studies Series at Transcript Verlag kindly agreed to publish my work as part of their series. The University of Graz, the University of Humanistic Studies and the Dutch foundation for protestant elderly care VPSB generously contributed funding to support this publication. Finally, my own personal process of self-realization would be impossible without my beloved friends and family, whom I would like to thank for their continuous loving support in good and bad times of my life. 


\section{Chapter 1 - Introduction}

\subsection{Prologue - An exemplar of "Aging well"}

Whenever I am asked what it might mean to "age well", I think about my greataunt Antje. During my adolescent years, I visited her regularly and developed a very special bond with her. After my visits to her, I would feel enriched and privileged, as though she had conveyed some of her special life wisdom to me, even without explicitly giving me advice or telling me what to do. It would have been difficult for me to explain my feelings of deep connection with her, but her influence on my adolescent struggles to create a viable sense of identity for myself was certainly profound. My great-aunt died at the age of 92 , quietly in her own home, where I had always known her. Her passing away made me feel like I had lost one of my main anchors in life. Admiration or adoration would perhaps be wrong and exaggerated terms to describe my feelings for her, and yet, to me she represented an invaluable landmark of wisdom and life-experience.

Up to the present day, my great-aunt represents to me a prime example of someone who managed to lead a genuinely good life. Since I only knew her as an old lady, in my mind her living well also naturally extended to being an exemplar of aging well. Though I am sure she would resolutely have waved aside any suggestion of her being a moral exemplar, she certainly has been one to me. When I set out on the scholarly journey of exploring the theme of aging well, which has resulted in this philosophical-gerontological study, I realized that my implicit assumptions on what it might mean to age well had to a large extent been informed by my experiences with my great-aunt. What made her so special in this regard? Despite the fact that her life had not been easy in many ways (which I will not elaborate on here), my great-aunt always managed to keep a vital engagement with life. She had clear opinions on what mattered to her, and was never afraid to express them. Her character was that of an introvert, and she once with humor qualified herself socially as a "hermit by nature". Nevertheless, she had gathered a select number of true friends and companions. I suspect they loved being in her presence because they enjoyed her genuine interest in their lives, her sense of humor, her knowledge of literature, and her sometimes unconventional outlook on things. She kept a lively 
correspondence with a number of people, in her own very distinguished style of writing, inquiring about their well-being, but also lecturing them on what she perceived as shortcomings: failing to live up to one's principles or commitments, lacking loyalty to certain people or causes where this was required, or trying to influence people's choices in a moralistic or paternalistic manner. The biographical hardships she had survived in her life had made her a very resilient and opinionated woman, who wasn't always easy on herself and on others. With the passing of years, I think she grew milder towards herself, and she maintained an attitude of quiet enjoyment in the little things in her life observing birds and flowers in her garden, listening to books being read on tape when she could no longer read herself. In the end, I think she had learned the hard way to embrace life as it came, not always happy or thankful or with equanimity, but nevertheless with dedication and out of a sincere wish to make the best of it in her very own way. It was this attitude of humorous and loving self-acceptance, in combination with the vital involvement she maintained with the outside world, even when her mobility shrank due to age-related conditions, that for me embodied her wisdom, resilience and vitality. Looking back, these were the qualities which I strove to nourish myself with during my adolescent visits to her. I think it is also this combination of attitudes and characteristics that in my mind preserves her as an exemplar of aging well.

I started this study with the story about my great-aunt as my own personal exemplar of aging well, because aging well can be identified as the broad underlying concern that connects the themes of aging, self-realization and cultural narratives about later life which are central to this study. Rather than focusing on idiosyncratic stories of aging-well exemplars like my great-aunt, however, this study takes a more abstract and analytical, philosophical perspective on the topic. In this opening chapter, I first briefly introduce the thematic domain this study is engaged with ( $(1.2)$, which then leads to a formulation of the problem statement, the objectives aimed at in this study and the central guiding research question (\$1.3), and a short elaboration on the chosen approach (\$1.4). These sections are followed by a discussion of some terminological issues that require clarification in advance to enable a proper understanding of the perspective that is developed during the main part of this study (\$1.5). Finally, the positioning of this study in the fields of gerontology and moral philosophy is briefly considered (\$1.6). The chapter concludes with a short preview of the outlook and structuring of the rest of the chapters $(\$ 1.7)$. 


\subsection{INTRODUCING THE THEMATIC DOMAIN AND BACKGROUND OF THE STUDY}

This philosophical study about aging well in late modernity departs from two initial observations that are quintessential to understanding the background of its research objectives. The first observation pertains to a lack of satisfactory cultural narratives about later life in late modernity - satisfactory in the sense that they are able to provide individuals with the necessary resources to support a meaningful, positively valued identity as an older individual. The second observation pertains to the dominance of self-realization as a moral ideal in late modernity. Aging in late modernity is thus observed to take place against the background of a cultural ideology that strongly endorses a self-determined life shaped according to one's own choices and value orientation. Below, I will discuss these two observations in turn, working towards the formulation of this study's problem statement in $₫ 1.3$.

\subsubsection{Lack of meaning-generating narratives about later life}

"Lacking a culturally viable ideal of old age, our civilization does not really harbor a concept of the whole of life", wrote Erikson (1997, p. 114). This statement suggests that contemporary (Western) culture and society misses something vital, as long as it does not include an ideal of old age that is meaningful and even inspiring. Erikson's terminology of an "ideal” is interesting: apparently, what our culture is missing in relation to old age is an image of something to strive for. The term ideal is generally associated with an orientation towards values, which represent a horizon of possibly worthy perspectives to be attained in the future. Thus, Erikson's quote seems to express that our culture lacks attractive, inspirational and meaning-generating values, images and stories that are associated with later life. This implies that for individual persons, aging well is complicated by a lack of viable cultural resources on which to found their identities.

Besides the lack of inspiring and meaning-generating cultural ideals of old age implied by Erikson's observation, several authors in gerontology have expressed worries about the prevalence of negative or adverse cultural imaginaries about later life in our contemporary, Western, late modern culture (Gullette, 1997, 2004, 2011; Cruikshank, 2003; Andrews, 1999, 2012). In particular, these authors reproach the one-sided identification of later life with images and narratives of decline and deterioration. Experiencing later life as meaningful to a satisfactory degree - which is quintessential to aging well, I would contend will expectedly be further obstructed by such negative cultural associations. This situation has worrying implications for the existential life-reality of aging individuals in late modernity. 
The existentialist philosopher De Beauvoir concluded her seminal work La Vieillesse with an outcry, a fierce denouncement of the way contemporary society treats its older people. She asked the poignant question: "What should a society be, so that in his last years a man might still be a man?"1 (De Beauvoir, $1970 / 1972$, p. 542). Improving the material living conditions of the elderly, she stated, is not sufficient. The fundamental problem is the lack of a culture that provides aging individuals with the interests, roles, and responsibilities that are needed to experience life as meaningful. De Beauvoir's cultural-critical diagnosis that it is fundamentally a lack of meaning that haunts our aging discourses in contemporary society is echoed in the historical analysis of aging in the Western world by Cole in his study The journey of life. A cultural history of aging in America (1992). Cole argues that during the course of modernization, Western culture has become devoid of inspiring and visible images about the meaning and purposes of later life. This development results in a growing lack of sensitivity for the moral, existential and spiritual dimensions of later life (Cole, 1992; Cole, Achenbaum \& Carlin, 2008). Cole's historical analysis shows how gradually, aging has predominantly become a biomedical health issue, which enforces its association with decline, dependency and nearing death. These associations are all negatively perceived in Western modern culture. As a result, aging tends to evoke anxiety, pity, insecurity, condescension, and a general cultural mechanism of defense.

The situation is further complicated by the fact that the cultural neglect of matters of meaning and morality concerning later life seems to be reproduced by the scientific study of aging, which in its turn influences political and policy discussions about dealing with an aging population. We see a strong emphasis on biomedical issues of health, frailty, longevity, et cetera, as well as a focus on the policy measures and political interventions that are required to master the dramatic numerical increase of the global aging population (Phillipson, 2013; Baars, 2006a). By contrast, mainstream gerontology generally tends to leave questions of meaning unanswered (Cole, Achenbaum \& Carlin, 2008; Baars, 2012a). This lack of attention for the existential dimension of later life and the questions of meaning associated with it extends towards the political and societal discourse about aging. Cole, Achenbaum and Carlin (2008) argue that consequently, we are facing a profound "uncertainty about the roles, responsibilities, purposes and meanings of old age" in the late modern context (p. 241). Previously existing models of the "life cycle" that offered meaningful frameworks

1 Note that this formulation may unjustly raise the impression that De Beauvoir only spoke about older men; however, the whole context makes it clear that her analyses certainly applied to both older men and women alike. The original French citation reads 'Que devrait être une société pour que dans la vieillesse un homme demeure un homme?' (De Beauvoir 1970, 568). 
to situate our own lives in a broader intergenerational network of meanings cease to be relevant in late modernity, which has made a shift towards thinking in terms of an individual "life course" instead of an individual-transcending life cycle. This life course is perceived in terms of a "trajectory in which individuals choose their projects and plans" (Cole, Achenbaum \& Carlin, 2008, p. 242). Cole, Achenbaum and Carlin also note that transitions in this life course are typically accompanied by identity-crises, making the problem of how to uphold a viable, meaningful self-identity central to the lives of late modern individuals.

The potential effects of the observed lack of a culturally viable ideal of old age and the dominance of negative perceptions and expectations about later life in our contemporary culture are severe. For example, internalization of the adverse cultural imaginaries surrounding old age may lead to age-anxiety in individual cases. But the lack of viable cultural ideals of later life and the dominance of negative perceptions also expectedly influences how older people are treated by others, and impact which social roles and positions remain open to them in later life (Bolsenbroek \& Laceulle, in press). Moreover, the negative cultural perceptions of later life will expectedly influence how politicians and policymakers act to organize structural societal arrangements, which in turn have a profound impact on the lives of older people.

The problematic cultural dynamics surrounding aging that have been sketched above blur our view when it comes to acknowledging the potential gains of later life, for instance, in terms of personal growth, fulfillment in social relations, or meaning-generating experiences of deepening individuality. These are gains that can be observed in the life narratives of many older people, alongside the inevitable confrontation with the fragility of the human condition. Many of us know individual exemplars of aging well in our personal social circles. These are people like my great-aunt, who manage to live a vital, morally engaged life while integrating the hardships they suffer in their lives in a meaningful way. But the idea that old age may also be an enriching phase of life with potential for growth and development, that it can have a moral and spiritual value of its own, does not seem to extend itself in any convincing way to the late modern dominant cultural discourses on aging and later life.

\subsubsection{Aging in an era of self-realization}

Individuals living in late modern circumstances are facing a cultural context in which a self-determined, self-directed, self-chosen biography has become a dominant moral ideal. The somewhat enigmatical expression "becoming who you are", can be seen as exemplary for what underlies this moral ideal: developing an authentic, self-appropriated "life of one's own", in which we continuously keep developing ourselves towards more optimal self-fulfillment. Becoming who you are is seen as quintessential to navigating important life choices 
and dilemmas in an era where previously existing, traditional sources of moral authority are increasingly eroding and the responsibility for deciding what a morally good life is increasingly rests on the individual (C. Taylor, 1991; Ferrara, 1993, 1998). The philosophical discourse that underlies this line of thinking is taken up in this study under the heading of self-realization.

Self-realization, sometimes alternatively termed self-fulfillment or self-actualization, is a complex concept with a long and rich history in Western philosophy. However, in late modernity the concept of self-realization seems to have acquired a specific and increased importance. Due to the complex interaction of processes of individualization, de-traditionalization and globalization, the individual person is increasingly regarded as a prime source of morality and meaning in the late modern world (C. Taylor, 1989, 1991; Giddens, 1991). Consequently, in the quest for a good life that is experienced as meaningful, realizing one's own deepest aspirations and best capacities has become an almost inescapable call for the late modern individual. In spite of the unfathomable complexity and obvious uncertainty of the world in which we live, we are stimulated to perceive ourselves as moral agents capable of making important choices and decisions regarding what truly matters to us in life. As a result, self-realization has acquired a new urgency and a specific status as a guiding moral ideal in the late modern era. As Gewirth (1998) observes, "The ideal's prominence has waxed and waned at various periods of human history; but the present age has taken it up anew as a prime object of human striving, as a value that gives zest and meaning to the lives of the persons who adopt it as a central aim of their activities and aspirations" (p. ix).

The late modern individualistic exaltation of a life of one's own that has been analyzed by sociological thinkers like Giddens (1991), Beck (1992; Beck \& Beck-Gernsheim, 2002) and Bauman (2001, 2007, 2008), is typical for the pervasiveness of self-realization as a moral ideal in the contemporary world. These thinkers argue that in a post-traditional context where previously selfevident sources of identity have been eroded, the responsibility for leading a good life in terms of meaning and morality has increasingly been delegated to the individual agent. C. Taylor $(1989,2007)$ provides historical and philosophical background for this observation, sketching how during the process of modernization, the dominant cultural perception of the human being transformed from being a particle in an ordered cosmic universe transcending the scope of influence of the individual, to being an autonomous agent with the ability to control and master the external world. Although the late modern discourse of an authentic, self-determined life is highly influential and dominant as a moral ideal, it is important to note that there exists a considerable gap between the ideology of individual choice and selfdirection, and the empirical reality as it is experienced by many people, who see their opportunities for choosing impeded or blocked by the oppressive force 
of structural arrangements, or by adverse socio-economic conditions (Baars, $2006 \mathrm{a})$.

It is striking to note that self-realization, observed above to be one of the most dominant moral ideals of our times, revolves precisely around the notion of self-development and personal growth that is disregarded in cultural discourses about aging and later life. Apparently, this moral ideal is not regarded as an obvious or viable conceptualization of the good life for aging individuals. The predominantly negative and problematic cultural positioning of aging and later life, as discussed above (see $『 1.2 .1$ ), leads to the rather unsettling conclusion that the aging population seems to be excluded from participation in the dominant moral ideal of self-realization, especially once aging individuals become vulnerable and dependent.

Yet, given the shortcomings of existing cultural perceptions of later life, we might ask whether the self-realization discourse isn't an especially promising candidate to support a transformation of the problematically gloomy and less than inspiring cultural profiling of aging. Couldn't the late modern moral vocabulary of self-realization be translated to the context of aging in such a way that the negative cultural perception of old age is nuanced or refuted? Can the concept of self-realization provide a viable resource for cultural images and stories about later life that infuses this phase with the sense of meaning that seems to be problematically absent in its existing late modern cultural narratives?

On the one hand, this seems an exciting possibility worth investigating. After all, it would provide access to an influential ideal of the good life for aging individuals. Introducing self-realization to the aging discourse as a potential resource for challenging problematic cultural profiling of old age could then contribute to a welcome improvement and expansion of aging people's access to common goods and valued roles in late modern societies. On the other hand, serious doubts may be raised when pondering the application of the self-realization discourse to the context of aging and later life. For how does the typical late modern discourse on self-realization, with its emphasis on autonomous choice and authentic fulfillment of one's aspirations and capacities, relate to the existential reality of aging, in particular the fundamental fragility of the human condition and the growing vulnerability one is confronted with in later life? Even if we reject the one-sided cultural identification of aging with decline (Gullette, 1997, 2004), the fact remains that aging, for many if not all individuals, means a radical confrontation with the vulnerabilities that are generally intrinsic to the human condition, for instance through an increase in physical, mental and social frailty. In fact, the contemporary self-realization discourse may even complicate finding a satisfactory relation to these biographical encounters with existential vulnerability, because it implicitly relies on a typical late modern ideology of self-mastery and independence, which tends to 
denigrate decline and decay. As Cole, Achenbaum and Carlin (2008) observe, "Rather than acknowledge these harsh realities, we [modern individuals] pretend that we can master them, and we feel like failures when we do not, hence the elevation of physical functioning to the criteria of successful aging and the virulent fear and denial of frailty and dependency" (p. 247).

Despite these difficulties regarding the application of the self-realization discourse to the context of aging however, it is important to emphasize that the impact of the moral ideal of self-realization is probably felt in some form in the life-reality of all individuals in late modern society, including aging people. The ideal is expressed implicitly in many cultural artifacts, ranging from films and literature to advertising and newspaper articles. Moreover, it seems reasonable to expect that the influence of the self-realization discourse upon the life course of aging individuals will increase in the $21^{\text {st }}$ century, when the generations raised with the moral appeal of an authentic, self-determined life grow older. This further stresses the relevance of an exploration of the value of self-realization discourse in the context of aging - and in particular its potential value in the context of aging well.

\subsection{OBJectives OF the Study}

This study departs from two premises drawn from the sociological, philosophical and cultural gerontological observations briefly introduced above: 1 ) that people nowadays live their lives in a late modern context that celebrates (a certain interpretation of) self-realization as a guiding moral ideal, and 2) that this late modern context lacks satisfactory cultural imaginaries about aging and later life, a lack which complicates experiencing this life phase as meaningful. The study aims at answering the question whether the philosophical discourse of self-realization, that plays such a dominant role in late modern ideals of a good life, might be reframed in such a way that it can serve as a resource for cultural counter narratives about later life, forming a viable alternative for contemporary stereotyping and marginalizing cultural master narratives about aging. At the same time, this study wants to acknowledge the possible questions and doubts that can be raised by an attempt to suggest self-realization discourse as a viable meaning framework for aging well. This leads to the following formulation of research objectives and guiding research question.

The general aim of this study is to make a philosophical contribution to gerontology that concerns cultural and individual meanings of later life, thereby providing reflections on what it might mean to "age well". More specifically, this study targets the following objectives: 
- To remedy the observed lack of inspiring cultural narratives about aging and later life in the context of late modernity, by suggesting an alternative set of cultural narratives drawing on philosophical resources associated with the self-realization discourse

- To formulate a reframed account of self-realization, that enables us to criticize the shortcomings of the late modern self-realization discourse when applied to the context of aging

- To contribute a philosophical perspective on the opportunities for older people in our society to successfully practice their potential for moral agency (conceived in this study as the purpose of self-realization), as well as offer a reflection on how these opportunities for practicing moral agency may be enhanced

In light of these objectives, this study aims to answer, as its central guiding question, whether the late modern discourse of self-realization can be reframed in such a way that it can serve as a resource for meaning-generating cultural narratives about later life in late modern circumstances.

\subsection{A hermeneutic APPROACH}

In order to address the guiding questions and objectives stated above, the rich philosophical tradition of self-realization will be probed for relevant sources that can contribute to the reframing objective of this study. As such, this study strives to be a contribution to aging studies from a primarily philosophical perspective. Despite its philosophical orientation however, this study is not a purely philosophical project, since it also uses insights and literature from gerontological, sociological and psychological origin. The acquired insights are drawn together in an attempt to arrive at a new synthesis that hopefully contributes to the purpose of reframing the self-realization discourse from the viewpoint of aging.

My approach to this inquiry is a hermeneutic one, which implies that I aim to engage in a "dialogue" with the studied texts, adjusting and refining my own intuitions in the process. Generally speaking, philosophical hermeneutics arose as an attempt to provide an epistemological basis for the humanities that differed from the objectivistic take on scientific truth that is characteristic of the natural sciences - an objectivistic and naturalistic approach that the social sciences have traditionally tried to peer with. By contrast, the hermeneutic approach presents an intersubjective, dialogical perspective on truth that aims to offer a viable alternative scientific approach escaping the charges of both subjectivism and relativism (Gadamer, 1989). Thus, the hermeneutic perspective rejects the more "positivistic" approaches to scientific research. Reality is 
not out there to be studied as it is, because how it "is" is always perceived as a matter of interpretation. Moreover, the hermeneutic perspective principally acknowledges the possibility of multiple, equally valid interpretations of the same reality.

Specific to the hermeneutic approach is its emphasis on the situatedness of the researcher, whose prejudgments play a dominant role in the process of knowledge seeking. Knowledge and understanding are themselves perceived as situated, emerging from an intersubjective, dialogical practice between researchers and the "texts" (in the broadest possible sense) they study. I can only understand a reality from the perspective of my own situation, but I can alter my understanding by dialogically engaging with other interpretations and standpoints of the situation. Qualifying this study as a hermeneutic philosophical inquiry implies that I am not aiming to develop any final perspective or ultimate reality-claim regarding the theme of aging, self-realization and cultural narratives about later life. Instead, I aim to engage with the works of relevant philosophical and other thinkers in a dialogical way, confronting their work with my own initial ideas about the matter. Through this hermeneutic effort, I aim to provide an account of my research themes that in itself is open to continuing hermeneutic dialogue with other possible perspectives.

The openness and exploratory hermeneutic character of this study notwithstanding, it is important to emphasize that my approach also implies a normative philosophical engagement. In part, this engagement naturally follows from my own situatedness as a researcher/philosopher, which has equipped me with a horizon of certain intuitions, ideas, biases, preferences and the like. Thus, the fact that my personal normative engagement with the good of older people has informed my research project from the start is consistent with the chosen hermeneutic approach. Consequently, being trained as a humanistic thinker, I have inevitably been framing my research project from a humanistic inspiration that strives to advance a better, more humane existence for older people in our contemporary society. My study's underlying concern with aging well implies a certain advance preconception of the good, which precludes taking a neutral view to the issues of relevance to the research question. As will become clear, many of the theoretical positions I take are ultimately informed by this normative humanistic engagement.

I am aware that in some circles, taking such a normative position raises fundamental philosophical problems, for it can be seen as undesirable paternalism to prefer and advance a certain understanding of the good life over others. My standpoint on this issue is further addressed later on in this study. Here, it is important to point out that in my view, philosophical and scientific work always, to some extent, is and should be informed by the value orientation of the researcher in question. Rather than trying to bracket or exclude this value orientation from my work, my aspiration has been to put it to good 
use in this study. It is my contention that, as long as it is thoroughly reflected upon, my normative philosophical orientation sensitizes my thinking about the themes of this study. The normative philosophical engagement of this study should thus, in my opinion, be perceived as a potentially valuable addition to the hermeneutic understanding of what it might mean to age well, rather than a troublesome obstacle to scientific quality.

\subsection{Some terminological ISSUES}

This chapter started with the claim that the broad overarching theme of this study should be sought in the question what it might mean to age well. This terminology suggests that I am concerned with aging in a specific interpretation, which deviates from the biomedical, psychological and sociological approaches that play such a dominant role in the mainstream gerontological discourse. The perspective on aging that I develop focuses on its (experienced) meaning, both on the idiographic level of the individual agent's life and on the socio-cultural level. Baars (2006b, 2012a) provides a distinction between three different discourses concerned with aging that help clarify and illustrate the main focus of this study. First, there exists a discourse regarding senescence, i.e., the physical and biomedical aspects of aging. Second, there is a discourse regarding older people as a social category, focusing exclusively on the societal and economic effects of a growing population of older people, and the possibilities to manage these effects through (government) policies. Third, there is a discourse regarding aging as a social-existential process of living in time. This discourse focuses on questions of meaning and existential experiences of aging. According to Baars, the scientific and societal debate surrounding aging is dominated by the first two discourses, at the expense of the third one. By contrast, this study specifically aims to contribute to the third discourse.

Although the terms aging, existential dimension and meaning are applied frequently throughout this study, they are not explicitly conceptualized in the main argument. Since it is important to have a general idea of how these themes are understood in the context of this study, some consideration is given to them below.

\section{Aging}

In societal and scientific discourse, aging is usually assumed to present a phenomenon taking place during a specific phase or stage of life, with specific characteristics. One of the problems with this approach, however, is that the starting point of the phase or stage of aging is rather obscure and arbitrarily coupled to a certain chronological age, for example 65 or 70 . Baars (2012b) insightfully argues that this identification of aging with the fact that one has 
reached a certain chronological age is problematically one-sided, and therefore of limited use if we want to understand individual existential experiences of aging and the dimensions of meaning connected with it.

An alternative classifying criterion suggested by Baars (2006b) is the statement that people enter the phase of aging at the moment society (or culture) starts positioning them in terms of categories associated with old(er) age. This emphasizes the fact that aging is a socially constituted process (Baars, 1991). This social constitution of aging can be illustrated by the fact that during the course of Western history, different groups of people have been defined by culture or society as "old" at variable ages, depending on such divergent factors as gender, social class, (re)productive capacities or appearance. Thane (2010) further distinguishes three criteria along which people are socially constituted as "aged" or "aging": the chronological, the functional and the cultural. The chronological criterion is based upon people's calendar age. The functional criterion describes people as old depending on their capacity to perform certain tasks. The cultural criterion, however, classifies an individual as old according to the prevailing images and norms in certain cultural contexts, thereby implicitly expressing this culture's value orientation. It is this cultural criterion applied in the social constitution of aging which seems to be most usefully applicable to the understanding of aging in the current study.

This study thus interprets aging as a socio-culturally constituted process of living in time. In accordance with its orientation to Baars' (2006b, 2012a) third discourse, this study also explicitly perceives aging well to be concerned with the existential dimension of life, rather than with biological senescence or social status. It is important to realize however, that health issues, financial matters like pensions or insurance, and care arrangements at the micro-level of individual human lives also have an impact on experienced meaning. The meaning of later life thus cannot be interpreted as solely an individual existential matter. Meaning has the propensity for touching multiple dimensions, and it permeates questions situated at macro-, meso-, as well as micro-levels.

\section{Existential dimension}

In its most general sense, the existential dimension of life pertains to the basic human experience of "being-in-the-world". It relates to those elements of our lives that intrinsically belong to the human condition, such as our sociality, our vulnerability and finitude, our embodiment, and our inclination to strive for transcendence and meaning in our lives. Existentialist philosophers like Kierkegaard (1843/1959), Heidegger $(1927 / 1996)$ and Sartre $(1956,1948)$ have emphasized that people are "thrown" into a world without an inherent meaningful order, while at the same time, they have an incurable longing for experiencing life as coherent and meaningful. Since the world as such does not provide such coherence and meaning, people are destined to constantly search and create 
their own order, thereby taking agential responsibility for their own lives. Ultimately, the existentialists believe that people's freedom and well-being depends on their ability to relate to the different domains of reality of the human condition in an authentic way.

Van Deurzen (2002), an existentialist psychotherapist, presents the existential dimension of life in a four-dimensional model, applicable to the context of counseling. Her model has the advantage that it translates the rather abstract views of existentialist philosophers about the human condition to the concrete reality of human lives. In this sense, it may help us understand what is entailed when speaking about the existential dimension of aging, an attempt undertaken in this study. Each domain distinguished in Van Deurzen's model provides us with opportunities, challenges and tensions in our striving for selfrealization. Further, each domain has its own basic ideals and purposes that are strived for, but also its own threats, which have to be overcome in a viable way. It is in confrontation with these threats that people typically experience what in this study is termed "existential vulnerability".

The physical domain concerns our own bodily existence, as well as the material world around us. Applied to the context of aging, age-related ailments such as loss of hearing, sight, or mobility may confront us with the physical domain of the existential dimension of our lives.

The social domain concerns our relationships with other people, which are situated in a public domain determined by cultural norms, social conventions and power relations that influence and co-determine people's interdependent existence. Applied to the context of aging, this element of the existential dimension may show itself in loneliness due to the death of significant others like spouses or friends, or in finding a mode of relating to the growing dependence on one's caregivers, or also in deepening contacts with children and grandchildren.

The personal domain concerns our relationship with ourselves, situated in an inner realm of self-reflexivity and self-knowledge. Applied to the context of aging, the personal domain of the existential dimension of our lives relates to the deepening biographical uniqueness of human life, and may show itself when we reflect on our own finitude, or look back on our lives to see what we have become (Baars, 2016).

Finally, the spiritual or transcendent domain concerns the ideals, values and convictions that guide our life choices. Importantly, this transcendence need not be interpreted in a traditional religious sense, but may also pertain to our identification with guiding moral ideals or values that we believe are worth striving for. Applied to the context of aging, this domain of the existential dimension may show itself when we evaluate the purposes we have strived for in life and consider which purposes we still want to achieve, or when we contemplate what contribution we have made to the realization of those ideals and goals that 
we perceive as highly important. In the context of self-realization, the transcendent domain has heightened relevance, since self-realization presupposes, as we will see in this study, the ability to form a moral orientation and identify with ethical aims that are of utmost value to us. Existential vulnerability in the transcendent domain perhaps most deeply interferes with the striving for selfrealization, because it shows itself in feelings of meaninglessness, stagnation or withdrawal from life.

In sum, this study's interpretation of the existential dimension of life involves those elements and experiences that either enable or impede our realization of a satisfactory relation to the physical, social, personal and spiritual/ transcendent dimensions of life. According to my argument, what is considered satisfactory is decided by the opportunities that this relation offers for people to lead a good life with and for others, in accordance with their deepest aspirations and best capacities, as full participating members of society, the formulation used

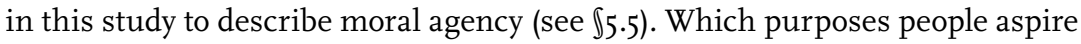
to, and which goals and values they regard as meaningful, may differ significantly depending on the situation, character disposition, social context and orientation of the individual, however. This underscores the moral importance of individual uniqueness and diversity that is a principal assumption of the self-realization discourse.

\section{Meaning}

In a number of ways, the philosophical argument of this study relies on ideas and assumptions about the importance, indeed, the existential necessity, of experiencing a certain degree of meaning in life in order to perceive one's life as good (which is presupposed by the engagement with aging well). Drawing from its humanistic inspiration, this study also implicitly assumes the need to enhance the socio-cultural circumstances of people to contribute to their optimal realization of a meaningful life, and to alleviate the circumstances that threaten to result in feelings of meaninglessness. Yet, what is understood by meaning is not explicitly conceptualized in the main argument, which necessitates paying some attention to it here.

First of all, this study is concerned with people's subjective experiences of meaning. These experiences of meaning in life should thereby be distinguished from metaphysical philosophical or theological discussions about the objective meaning of life. But what is required in order to experience this meaning in life? Psychological approaches mention several aspects that need to be present to some degree if people are to experience meaning in their lives. Examples of needs suggested by these approaches include a sense of purpose in life, efficacy or feeling "in control”, self-worth, moral worth, comprehensibility, connectedness, and transcendence (Baumeister, 1991; Derkx, 2011; Smaling \& Alma, 2009). It remains unclear whether high scores on one need could com- 
pensate for lower scores on other needs, or whether all needs have to be fulfilled equally in order to experience one's life as meaningful (which would of course significantly reduce the possibility of experiencing meaning).

Although such approaches based on psychological needs certainly are interesting and relevant attempts to provide a description of what underlies the experience of meaning, they have a rather functionalist orientation that relates problematically to the hermeneutic approach of this study. From a hermeneutic point of view, it seems too simplistic to reduce the experience of meaning to a quantitative addition of individual psychological needs for meaning that have been satisfactorily met, as Baumeister (1991) in particular, seems to suggest. For instance, approaches of meaning based on the presence or absence of fulfillment of individual psychological needs seem insufficiently able to address the influence that the socio-cultural position of people can have on the purposes that they are (or are not) able to formulate for themselves, or on their selfworth. Similarly, the psychological accounts make it hard to draw connections between questions of meaning and issues of social structure (Baars \& Phillipson, 2013). It remains unclear, for instance, how culturally and historically specific the suggested sets of needs are, and what the structural impediments are to fulfilling them. A viable approach to questions of meaning should therefore at least be complemented with a view of how the fulfillment of these needs is socio-culturally mediated, and which concrete conditions need to be present in order for people to answer their needs for meaning.

In accordance with the description of the existential dimension given above, this study therefore chooses to present meaning not in terms of a predefined set of needs, but as a dynamic property of experience that emerges when people succeed in finding a satisfactory relation towards the physical, social, personal and transcendent domains of life. In this account, what is experienced as meaningful interacts with both the fundamental embodied nature of human existence and the fundamental socio-cultural constitution of identity. Meaning is perceived as an experience rooted in and flowing from the dynamic, relational way in which we strive for the ideals and the good at stake in each of the existential domains, while trying to find a way to overcome threats and challenges impeding our realization of those ideals. In this view, experiencing meaning in life requires existential work aimed at constantly (re)finding balance between purposes and threats in all four domains of the existential dimension. This work may, for instance, take the form of inner reflection, dialogues with other people, or actions that make a difference in society. In a sense, we might say that this existential work required to experience meaning in one's life is exactly what underlies people's striving for self-realization. 


\subsection{Positioning the Study in the Philosophical AND GERONTOLOGICAL FIELD}

As indicated before, this study intends to make a philosophical contribution to the field of gerontology. Although its emphasis is on philosophical perspectives, insights from other disciplines, notably gerontology, are integrated in the argument. Given the multiplicity of existing approaches both in moral philosophy and in gerontology, however, it is clarifying to provide some explication of the positioning of this study in these fields.

\subsubsection{Positioning in moral philosophy}

In its broadest formulation, this study is concerned with the theme of aging well. Since I have defined aging as a socio-culturally constituted, existential process of living in time, aging well can be seen as a specification of living well. The ancient moral-philosophical question what it means to lead a good life is thus implicated by the research interest in this study. This interest already presupposes a certain interpretation of ethics and its central concerns, which is important to explicate here.

When situating self-realization in the moral philosophical debate, it is clarifying to introduce a distinction between two types of approaches. The teleological approaches to moral philosophy presuppose a substantive account of what it means to live a good life and to be a good person. The deontological, consequentialist or procedural interpretations of ethics, on the other hand, focus on rules and principles for acting in the (morally) right way. Teleological approaches assume that human beings strive for a certain purpose (telos) in their lives, which can either be seen as flowing from a cosmically given, meaningfully ordered plan (as in traditional Aristotelian virtue ethics, for instance), or as flowing from the self-appropriated value orientation of the individual (as is implied by contemporary forms of authenticity-ethics, for instance). By contrast, in deontological approaches to moral philosophy, the focus is on moral duties derived from following the moral authority of one's good will (as in traditional Kantian ethics). Alternatively, consequentialist approaches also qualify as procedural interpretations of ethics, such as utilitarianism, which measures the moral legitimacy of actions on the grounds of their contribution to the maximization of good. In both cases, the focus lies on the formulation of universally applicable, formal ethical rules and principles that are intended to distinguish between right and wrong courses of action.

It will come as no surprise that this study takes the standpoint that the most basic concern of moral philosophy is the question how we should lead a good life, and not the formulation of binding universal principles or guidelines for moral action. After all, this position is implied by the most fundamental 
assumptions that underlie all versions of the self-realization discourse. Self-realization, as observed later in this study, is basically about making the best of oneself that is possible given one's circumstances and capacities. This orientation towards moral self-development already presumes a teleological orientation, since self-realization aims at an ideal purpose (becoming who you are, realizing the best in you, et cetera) to be reached somewhere in the future. On the other hand, the account of self-realization that this study advances shows a significant focus on the importance of translating one's identity-constituting teleological orientation into action, by granting a central role to the concept of moral agency. Thus, while this study's main affinity is with substantive and teleological, rather than procedural, approaches to moral philosophy, and it certainly does not aim to come up with universal moral rules or principles, it does acknowledge the relevance of paying ethical attention to acting in a morally right way. However, this attention should always be embedded in the overarching ethical concern with the question what it means to lead a good life (Ricoeur, 1992; see also $(5.4)$.

In addition, the argument developed in this study sympathizes with those approaches in moral philosophy that take the context and situatedness of human beings into account, rather than developing a strictly theoretical abstract understanding of morality that is detached from the reality of people's daily struggle to function as moral agents. In this sense, the study should be positioned in the realm of what M. Walker (2007) has called the expressive-collaborative understanding of morality, which is presented as the opposite of so-called theoretical-juridical models (p. 7-14). Importantly, the expressive-collaborative view perceives morality as something that emerges and is continuously transformed in the context of human moral practices. A similar position on ethics and morality is defended in the reframed account of self-realization that this study develops.

\subsubsection{Positioning in gerontology}

Gerontology is the scientific study of aging in all its facets. Consequently, many disciplines co-exist in gerontology, with corresponding and sometimes conflicting perspectives on reality and very different approaches to acquiring knowledge. The third edition of the Handbook of theories of aging (Bengtson \& Settersten, 2016) gives a variety of scientific perspectives on aging, ranging across biological, psychological, social-scientific, practice and transdisciplinary perspectives. Note that humanistic perspectives are rather underrepresented in this overview. In the diverse realm of perspectives making up the field of gerontology, this study can best be situated in the field of cultural and critical gerontology.

According to Twigg and Martin (2015a), the field of cultural gerontology that has emerged in recent decades particularly focuses on four themes: 1) sub- 
jectivity and identity, 2) the body and embodiment, 3) representation and the visual, and 4) time and space. Cultural gerontology aims to "produce a fuller and richer account of later years [...] one that places the subjectivity of older people, the width and depths of their lives, at the forefront of analysis" (Twigg $\&$ Martin, 2015b, p. 2). This quote underscores the affinity between cultural gerontology and the perspective advanced in this study, which focuses on aging well, and thus on matters of meaning and morality, on those things people regard to be of fundamental importance in their lives. Cultural gerontology can be seen as the representative of a broader "cultural turn" in aging studies (Twigg \& Martin, 2015a). This cultural turn has both an epistemological side, which is based on poststructuralist theories and focuses on the many ways in which culture is constitutive of our identities and our social relations, and a historico-social side, which asserts that certain societal developments have made the constitutive role of culture in our identities and social relations much more prominent compared to earlier eras of history. Importantly, Twigg and Martin (2015b) state that the most distinguishing feature of cultural gerontology is its concern with meaning. In this sense, cultural gerontology is representative of the third discourse on aging distinguished by Baars (2006b, 2012a; see $\$ 1.5)$, which concerns itself with aging as a social-existential process, in contrast with the discourse on biological senescence and the discourse on old age as a societal issue, raising political and policy questions. The general concern with meaning presupposes a relatively large input from the humanities, which further underscores the importance of the cultural-gerontological perspective for the current, philosophically oriented study.

For the purposes of this study on self-realization and aging, cultural gerontology's occupation with the theme of subjectivity and identity in relation to its broader focus on meaning is of course the most important, although the other themes distinguished by Twigg and Martin (2015a) also have relevance. The focus on subjectivity and identity implies a shift of attention towards matters of agency, and away from dominant approaches in critical gerontology that tend to focus on social structures and the way they influence the life-reality of aging people (Phillipson, 1998, 2013; Baars et al., 2006). However, although the current study is best positioned in the cultural-gerontological field, critical gerontology has influenced the argument in this study as well. The awareness raised by critical gerontology about the impact of societal scripts and structures on people's agency is indispensable for developing an understanding of self-realization that is not naive about people's room for maneuver in formulating their own aspirations and value orientation in the complex and dynamic context of a late modern world.

Another reason to position the current study primarily in the realm of cultural gerontology is the fact that cultural gerontology (together with aging studies which seems to be its natural ally) brings into high relief the socio-cultural 
constitution of aging that is also assumed in this study. Cultural gerontology and aging studies have undertaken important work in recent decades to illustrate how aging is in fact not the value-free biological category connected with our chronological age upon which societal policy seems to be based, but a deeply normative, culturally influenced and socially constituted life process. We are being “aged by culture”, to use Gullette's (2004) words. As embodied, socially constituted and "cultured" creatures, we have internalized dominant cultural imaginaries about old age, which necessarily shape the expectations we hold regarding our own later lives, and the opportunities we perceive ourselves as having (Andrews, 2012). When these dominant cultural imaginaries are predominantly negative and based on assumptions of decline, it creates problems for experiencing later life as a meaningful and integral phase of our life, with the potential for development, progress or "becoming" (Gullette, 2004, 2011).

It is important to note, however, that this study does not share the strong social constructionist position that is taken by some representatives of aging studies such as Gullette $(2004,2011,2017)$. Socio-cultural constitution is perceived as a fundamental, but not the only influence that shapes our identity. Principally, a study about self-realization should always account for the important role played by people's individual agency, which enables them to relate to the ways in which they are socially and culturally positioned. Also, the role of our embodiment should be taken into account. Consequently, though this study shares the cultural gerontological view that our identity is fundamentally socio-culturally constituted, this social identity should always be perceived as formed in "an ongoing tri-partite relationship between social environment, human agency and the body" (Hockey \& James, 2003, p. 135). Despite the pervasiveness and the often stereotypical character of cultural images, there is a remarkable amount of diversity in the way these images mark people's existence and identity (Meyers, 2002). Importantly, it is in this individual diversity and the assumed capacity of individual moral agency to resist its own socio-cultural positioning that the seeds for the desired transformation of oppressive, marginalizing or stereotypical cultural narratives can be found.

\subsection{Chapter outlines}

This study is organized along the following complex set of argumentative steps: clarifying the background assumptions and concepts central to this study; providing argumentative underpinnings for the claims that are assumed in the guiding questions and objectives of this study (regarding the shortcomings of cultural narratives about aging and the shortcomings of the late modern self-realization discourse); and formulating a viable substantiation of the alternative set of cultural narratives this study suggests, as well as of the reframed 
interpretation of self-realization that such counter narratives can draw upon. A brief outline of the individual chapters follows below.

Chapter 2 gives an analytical sketch of the specific features of the late modern world that impact the life-reality of aging people in multiple ways. Drawing on both sociological and philosophical sources, it is argued that late modernity harbors a specific interpretation of self-realization that serves as one of its most dominant moral ideals - ideas about what it means to lead a good life. The typical features of this late modern interpretation of self-realization are summarized, and some problems that arise when this interpretation is applied to the context of aging are discussed.

In chapter 3 , a theory about cultural narratives and their function in identity is introduced. It is argued that in the case of identity-damage by marginalizing, oppressive or stereotyping cultural master narratives, cultural counter narratives are called for that enable people to restore their opportunities to exercise moral agency. Next, the discussed theory about cultural narratives is applied to the context of aging. Cultural gerontological discourse is probed to arrive at a categorization of two dominant contemporary cultural narratives about later life: decline narratives and age-defying narratives, which are then critically analyzed. Finally, a tentative outline of a new set of cultural counter narratives about aging and later life is suggested, called "narratives of becoming". This alternative set of narratives is introduced as an opportunity to remedy the suggested shortcomings of existing cultural narratives about aging and later life. The rest of the study is then dedicated to the question whether a reframed account of self-realization can be developed that might function as a resource for these narratives of becoming about aging and later life.

Chapter 4 sets out to formulate a broad philosophical understanding of self-realization, which is presented as a process of moral self-development in which people strive to become who they are by realizing their deepest aspirations and highest capacities. After an explication of the purpose, the underlying self-concept, the practice and the timing of self-realization, a short historical catalogue of philosophical accounts is discussed about what constitutes the "best" in human beings, which is at stake in self-realization. Overviewing the variety of philosophical accounts, it is proposed that the fabric of self-realization discourse is built of three interwoven threads: autonomy, authenticity and virtue, all of which need to be considered and reframed to answer the objectives in this study. The chapter concludes with a reflection on two potentially problematic issues that may arise when applying self-realization to the context of aging: the fact that one's future time-perspective is shrinking, and the fact that one is increasingly radically confronted with existential vulnerability in later life.

Before proceeding to a more detailed consideration of the three constitutive threads of self-realization identified in chapter 4 , chapter 5 will first consider in more detail which understanding of identity matches the reframed understand- 
ing of self-realization advanced in this study. I will argue that for several reasons, a narrative view of identity is most suited to the purposes of this study. One of the most important reasons for this preference is that the narrative interpretations of identity that are discussed provide the opportunity to illustrate the intrinsic connection between our identity and our moral orientation. This connection is vital to the reframed interpretation of self-realization developed in this study, the purpose of which is formulated in terms of an optimization of moral agency. Chapter 5 therefore concludes by explicating this study's account of moral agency, which forms a central link between the discussed theory about cultural narratives and identity, and the suggested reframed account of self-realization.

Chapter 6 explores the first constitutive thread of self-realization, namely, autonomy. First, a selection of relevant philosophical interpretations of this concept are discussed and evaluated in light of the aims of the current study. Then, it is discussed how gerontological discourse has so far included the concept of autonomy in its reflections about aging. Finally, based on the discussion of the strengths and shortcomings of existing views of autonomy, an alternative interpretation of this constitutive thread of self-realization is proposed, that can contribute to the objective of reframing self-realization for its application to the context of aging.

Chapter 7 discusses the second constitutive thread that weaves self-realization discourse, namely, authenticity, while chapter 8 focuses on the third constitutive thread, namely, virtue. Both chapters follow the same structure as the discussion of autonomy in chapter 6: first an overview and evaluation of a selection of relevant philosophical accounts, then a consideration of the way the thread has been applied in gerontological discourse so far, and finally a proposal for a reframed interpretation of the concerned thread.

In the concluding chapter 9, the overall argument of the study is shortly recapitulated in order to formulate an answer to the guiding research question. This is followed by a consideration of some relevant objections that can be made towards the self-realization discourse in general, and a discussion of their possible refutation by the account proposed in this study. Finally, some suggestions for further research are formulated, and the study draws to a close with an epilogue covering some personal reflections on the value of self-realization. 



\section{Chapter 2 - Living and aging in late modernity}

\subsection{INTRODUCTION}

This chapter intends to help us gain more clarity about the content and background of the late modern discourse on self-realization. This late modern discourse provides one of the starting points of this study, which aims to connect the theme of self-realization to the context of aging in order to explore its opportunities and serve as a resource for potentially inspiring cultural narratives about later life. Such narratives, as this study contends, are problematically absent in the late modern context.

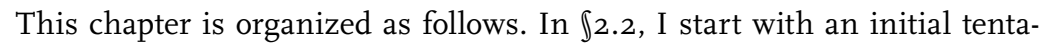
tive sketch of the late modern interpretation of self-realization that this study contests and aims to reframe. Founding this sketch are some influential sociological and moral-philosophical analyses of late modernity by thinkers like Giddens (1991), Beck (1992), Bauman (2001, 2007), C. Taylor (1989, 1991, 2007) and MacIntyre (1984). The typical elements they observe as characteristic of the late modern outlook are discussed in $\$ 2.3 .1$ through $\$ 2.3 .6$. My next step is to connect the general observations about late modernity that form the background of late modern self-realization discourse to the context of aging. In $\$ 2.4 .1$ through $₫ 2.4 .6$, a number of themes are discussed to elucidate some particular characteristics of aging in late modernity that are relevant from the viewpoint of this study. Finally, in $₫ 2.5$, after a recapitulation of the different facets of the late modern interpretation of self-realization, it is argued that aging provides an excellent case to illustrate the deep ambivalences that late modern self-realization discourse harbors. To preserve its value as a moral ideal for the context of aging, the late modern self-realization discourse needs to be reframed at some crucial points. This reframing entails an endeavor of refining, revising and redefining the late modern interpretation of self-realization and its constitutive concepts, in order to arrive at a view that better matches the context of aging. 


\subsection{LATE MODERNITY, AN ERA OF SELF-REALIZATION?}

The ambiguous wish may you live in interesting times, reportedly expressed to one's enemies in Eastern traditions, would certainly apply to the current era. But how can these interesting times in which we live be accurately described? The term late modernity to describe contemporary times is drawn from the work of Giddens (1991). Just like similar terms attempting to characterize our current era such as reflexive modernity (Beck, 1992), or liquid modernity (Bauman, 2001), choosing the term late modernity suggests that modernity is not so much "over" (as for example the term "postmodernity" would imply), but has entered a new phase. In comparison with premodern, traditional settings, the process of modernization has brought a major and fundamental transformation of the social circumstances in which the life of the individual takes place. Late modernity distinguishes itself from earlier phases of modernization by the unprecedented dynamism through which it continuously changes existing social practices (Baars, 2006a).

Following social theorists like Giddens (1991, 1994), Bauman (2001, 2007), Beck (1992), Beck \& Beck-Gernsheim (2002), and philosophers such as C. Taylor (1989, 1991, 2007) and MacIntyre (1984), late modernity is presented here first of all as an era with a typical focus on individual self-realization. In its late modern interpretation, self-realization pertains to the idea that a life considered "good" exhibits a self-chosen, authentic lifestyle, that is, a lifestyle in accordance with the good, purposes or value orientations one reflexively identifies with. As Beck and Beck-Gernsheim underscore, a "life of your own" seems to be one of the most dominant ideals strived for in the context of late modernity (Beck \& Beck-Gernsheim, 2002, p. 22). It is important to note, however, that this late modern focus on individual agents and their self-fulfillment also contains profound ambiguities, as is elaborated later on. Although the self-directed life is promoted as the best possible life, this ideal often seems to function as a disguise for a decisively de-individualizing ideology that is based on the dominant power constellations typical of market capitalism (Baars, 2006a).

The late modern interpretation of self-realization, that is the target of reframing in this study, can be characterized along general and rather tentative lines as follows:

- The late modern interpretation of self-realization lays strong emphasis on the good life as a life of one's own authentic choice. It conceptualizes living well typically in terms of a lifestyle, a set of personally appropriated habits and practices that assist people in the reflexive organization of life choices amidst the chaotic abundance of available options in late modernity.

- Late modern self-realization discourse assumes that the individual agent is a highly self-determined, atomistic and independent creature, who is 
emancipated from the restrictive traditional embedding of human lives characteristic of premodern times. It presents individual agents as the autonomous architects or directors of their own lives, who are capable of appropriating an authentic value orientation as the underlying motivation for their reflexive life choices.

- The late modern view of self-realization tends to neglect the constitutive and inescapable role that social context and relationships play in one's identity formation, focusing instead on the voluntary character of late modern social relationships.

- The late modern interpretation of self-realization is typically oriented towards obtaining mastery over one's life. This focus comes with a problematic neglect of the uncontrollable dimensions of human life that accompany the existential dimension of the human condition. Consequently, the late modern interpretation of self-realization has a hard time relating to confrontations with the inevitable vulnerability of human existence. This vulnerability, according to the late modern argument, necessarily compromises the success of self-realization.

This first brief sketch of the late modern interpretation of self-realization serves as the starting point of this study. This sketch is broadly based on a number of influential sociological and philosophical analyses of typical features and dynamics of life in late modernity, which will now be further addressed.

\subsection{Features ANd dynamics OF THE LATE MOdERN WORLd}

In this section, I first briefly elaborate on some characteristic features and dynamics of the late modern world. In succession, the themes discussed are in-

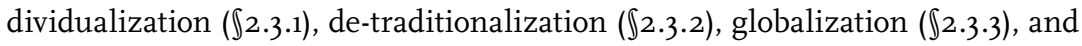
the expression of these broad tendencies in structural and systemic influences on individual lives (\$2.3.4). It will become clear how the sketched developments have resulted in an insecure and complex world, in which individuals are thrown back on their own resources when it comes to giving shape and meaning to their lives. These observations strongly influence late modern self-realization discourse's assumption that individuals are atomistic agents destined to navigate the complex circumstances of late modernity on their own. Next, I discuss how late modernity tends to repress matters of meaning and morality, by sequestering them in separate realms and emphasizing that the individual carries sole responsibility for them (\$2.3.5). At this point, the sociological analyses intersect with some influential moral philosophical analyses of (late) modernity, represented by the work of philosophers like C. Taylor $(1989,1991)$ and MacIntyre (1984). These philosophers focus on the demise of self-evident 
moral and spiritual frameworks and communities to fall back on, which in their view results in a moral identity crisis for late modern individuals (\$2.3.6).

\subsubsection{A life of one's own: reflexive individualization}

According to sociological thinkers such as Giddens (1991), Beck (1992), Beck \& Beck-Gernsheim (2002) and Bauman (2001, 2007), one of the most crucial processes giving shape to late modern culture and society seems to be its struggle with the implications of individualization and the resulting diversity and pluralism characterizing society. The late modern version of the self-realization discourse cannot be understood without acknowledging the fundamental influence of these individualization processes. According to the definition of Beck and Beck-Gernsheim (2002), individualization brings together two interrelated tendencies. On the one hand, modernization has brought the disintegration of previously existing, traditional social forms; modes of life that were ordained by religion, tradition or the state are breaking down and people are no longer automatically defined by traditional social categories such as gender or age. On the other hand, new demands are placed upon the individual, notably the requirement to lead a "life of one's own" (Beck \& Beck-Gernsheim, 2002, p. 22). Giddens has analyzed how the typical late modern "choice biography" replaces the traditional standard biography. He emphasizes however, that the demands associated with a choice biography are by no means less constraining for the individual, though the pressures are of a quite different kind (Giddens, 1991).

Although it seems to be a generally accepted truth that modernization is accompanied by far-reaching processes of individualization, it is important to realize that our interpretation of this phenomenon deeply influences our evaluation of its outcomes. Elliott and Lemert (2006) distinguish three different interpretations of individualization, representing rather different views on the characteristic changes in the relation between individual identities and globalizing late modern contexts. The perspective of manipulated individualism stresses the exploitative and dominating forces exercised by economic and bureaucratic structures, as well as by the dynamics of mass culture, on the individual life world. The perspective of isolated privatism focuses on the corruption of authentic individuality and the resulting narcissistic, hedonistic attitude of self-directed consumption and instant satisfaction of desires. Both perspectives seem to regard the individual agent as an isolated, powerless pawn, vulnerable to corrupting systemic influences, moved by invisible, structural manipulating forces which overrule any chance of truly autonomous control over one's life, or of the development of authentic individual capacities. Consequently, self-realization, as the path towards a good life, seems to be a rather illusory undertaking in these perspectives of individualization. 
The third perspective however, termed reflexive individualization, takes a different angle. It stresses the way in which the dynamics of late modern society and culture urge people to take their existence in their own hand, to become the architects of their own biography and realize their potential capacities as autonomously choosing agents. The late modern version of the self-realization discourse is most closely affiliated with the reflexive individualization-perspective. This perspective shares the observation that individuals are subjected to profound societal and cultural influences acting upon their lives. But importantly, in the reflexive individualization-view these influences strongly favor and even demand the development of individual capacities that are crucial for self-realization, such as autonomy competencies (Meyers, 1989). However, attaining these competencies is hardly a simple process.

Beck (1992) sketches how, due to the dynamics of reflexive individualization, the individual life loses the self-evident organization it had under more traditional circumstances. Although one might argue that individualization has come with an increase in autonomy, emancipation and freedom, it is equally true that the background of routines conditional for daily human activity as well as social interaction has evaporated into a cloud of possibilities. Late modern individuals live in a world infested with risks that form the flip side of this explosion of possibilities. In their striving for self-realization, they are forced to continuously reflect, calculate, adjust, negotiate and plan their lives. This suggests that the emancipation process inherent in individualization brings the individual life a set of freedoms that are precarious and vulnerable at best. The person has "no choice but to choose" (Giddens, 1991, p. 81), but there are hardly any reliable guidelines about which choices should prevail.

This brings me to the crucially important element of reflexivity which is regarded as characteristic of the late modern outlook by both Beck and Giddens. The term reflexivity points to the fact that almost all aspects of people's lives are susceptible to revision in the light of new information or knowledge. It applies both to institutions and to individual selves (Beck, 1992; Giddens, 1991). While late modernity offers access to an abundance of information and knowledge not available in premodern, traditional societies, this knowledge has at the same time lost its self-evident authority and certainty. Although there exist an abundance of "expert systems" offering their support in this process, none of them can claim to provide a definitive answer (Giddens, 1991). This leaves individuals "on their own", overwhelmed by complex situations requesting immediate and sound answers, but lacking any steadfast and reliable support for obtaining them. Only their own reflexive deliberation and choice can ultimately serve as guidelines in a "runaway world" (Beck \& Beck-Gernsheim, 2002, p. 22).

Thus, in their efforts to manage existence, late modern individuals are ultimately thrown back on the reflexive process of self-formation and can no longer rely on objective standards. Acquiring knowledge and making decisions is no 
longer a matter of taking an objectifying distance and applying determinate rules. The irony is that subjects are expected to be their own reflective rule-creators, while the features of the late modern world make this task very complicated. The fact that the world has become so complex that it cannot be overseen in a rational, detached manner calls for other forms of reflexivity than the rational reflection that underlies more traditional models of knowledge (Lash, 2003).

The sketched dynamics of reflexive individualization transforms individual biographies into personal "projects" of self-realization that are designed to express the individual lifestyle choices and value preferences underlying people's identity (Hendricks \& Hatch, 2009). The typical late modern reflexivity thus does not only pertain to questions of functional knowledge and choices, such as which medical expert to trust in the case of illness, or which food to choose for good health. It also concerns questions in the existential sphere, such as what makes one's life meaningful or what relationships one feels committed to, which are crucial to self-realization.

\subsubsection{Living in a post-traditional context}

The sketched processes of (reflexive) individualization are intrinsically connected to de-traditionalization, the tendency that traditional practices, sources of knowledge, religious and moral guidance and authority are eroding and losing their self-evident status in society. The two processes have a mutual causal connection: on the one hand, due to de-traditionalization individuals are thrown back on their own resources when it comes to finding reliable answers to matters of meaning and morality; on the other hand, individualization processes have strongly contributed to de-traditionalization and continue to enforce the demise of traditional institutions. In conjunction, both processes can be said to have increased the individual freedom to shape life according to one's own choice considerably, even if the realization of this freedom can be complicated by structural and systemic impediments (see $\$ 2.3 .4$ ).

Tradition has always been an important source of identity. According to Giddens (1994), there exists an important link between tradition and the individual's sense of identity; a link which is inevitably torn by the process of de-traditionalization typical of modernization in general. He expresses this link as follows: "Tradition [...] is a medium of identity. Whether personal or collective, identity presumes meaning; but it also presumes the constant process of recapitulation and reinterpretation noted earlier. Identity is the creation of constancy over time, that very bringing of the past into conjunction with an anticipated future. In all societies the maintenance of personal identity, and its connection to wider social identities, is a prime requisite of ontological security. [...] Threats to the integrity of traditions are very often, if by no means universally, experienced as threats to the integrity of the self" (Giddens, 1994, p. 80). This 
observation underscores that de-traditionalization can raise profound problems for the self-realization of late modern individuals, because it robs them of previously self-evident sources of identity.

Baars (2012a) argues that modernization processes have provided individual lives with an independent and unique "biographical dimension" (p. 16), instead of seeing them solely as parts of a larger traditional community. As a result, modern individuals increasingly see their lives as a future-oriented development of their unique qualities, according to their own choices, instead of as a standard trajectory already laid out for them by tradition, habit or convention. Obviously, this thought is strongly conducive to the late modern interpretation of self-realization. The flip side of the increased individual freedom, however, is a loss of self-evident, traditional, reliable certainties that the framework of the standard biography and the embedding in traditional communities could still provide. It is no longer self-evident that people spend their entire lives in the same location, choose the same profession as their fathers, marry someone from the same religious background, start a family, grow old and die after a life of hard work, et cetera. Life courses have become more diverse, for instance in matters of career development, patterns of personal relationships or education and learning, even though social structures tend to lag behind this development (Baars, 2012a; Riley, Kahn \& Fohner, 1994).

Despite the strong influence of de-traditionalization on late modern lives it is important to realize that moral and religious traditions have not disappeared. Rather, people living in late modernity have to tolerate pluralism and a diversity of different, contradicting sources of guidance. No tradition can claim to be the self-evident, dominant source of epistemological and moral authority anymore, and this is a profound and far-reaching change compared to earlier, traditional and (pre)modern contexts (C. Taylor, 2007). Traditions may still play an important role in how individual people and societal subgroups perceive themselves. But religious and moral pluralism increasingly urges people to reflect on their own position and take a stand. This process of appropriation may or may not succeed. It is often a cause of insecurity and raises the need for self-legitimization. For example, I find it striking how many older people I meet feel the urge to explain themselves if they regularly attend church services and, contrary to their children and grandchildren, have maintained a religious identity; whereas this would have been self-evident in other times.

The sketched developments confirm C. Taylor's observations, which read that late modernity no longer offers a self-evidently shared horizon of values and meaning. Rather, each individual is destined to search for their own value orientation (C. Taylor, 1989; 2007; see also $『 2.3 .6)$. On the one hand, this fact highly complicates processes of late modern identity-constitution and self-realization. It therefore situates "the problem of identity" among the most complex and pervasive problems confronted by late modern individuals (C. Taylor, 1989; 
McAdams, 1993; Baumeister, 1986). On the other hand, however, the sketched developments potentially offer chances for a deeper, more authentic and personalized relation to oneself and to one's social surroundings which can be conducive to self-realization.

\subsubsection{A globalizing world}

The societal and cultural outlook of late modernity is also deeply determined by the reality of the individualized, post-traditional lives having to be lived in a context of rapidly expanding forces of globalization. This means that late modern self-realization takes place in a complex global context which far exceeds the individual's scope of influence and control. Both the material and emotional impact of globalization on individual lives is profound and far-reaching (Elliott \& Lemert, 2006; Phillipson, 2009, 2013).

Broadly speaking, globalization is a process of pervasive, uncontrollable and continuous changes with a global scope, in the political and economic as well as in the cultural sphere. Clearly demarcated realms of influence based upon local authorities are evaporating. The nation state is struggling to maintain its traditional sovereignty. The so-called "radical" interpretation perceives globalization as a historically unprecedented social transformation, with revolutionary consequences for economy, politics, culture and society (Giddens, 1999; Phillipson, 2006).

Globalization processes tend to fundamentally transform the terms in which contemporary debates about the life course are formulated (Baars et al., 2006). Previously existing influential frameworks of analysis that have been developed to study and interpret socio-economic and political questions regarding the welfare state, such as those developed in critical gerontology and political economy perspectives (Estes, 1999; Estes \& Phillipson, 2003; Minkler \& Estes, 1999; A. Walker, 1980, 2006; Townsend, 1981; Vincent, Phillipson \& Downs, 2006), need to be adapted to a globalized situation.

In his discussion of the transformation of welfare arrangements, Phillipson (2006) distinguishes three aspects of globalization that are particularly relevant to aging. First, globalization exerts its influence upon the ideological assumptions underlying the way aging is socially constructed. Instead of being constituted as a burden to national economies, aging populations are now perceived as a worldwide problem, requiring nation-transcending solutions. Second, globalization enforces a particular construction of aging which perceives it in terms of a new sort of risk, the responsibility for which is delegated to the individual realm. Third, globalization plays an important role in creating and maintaining global inequalities in aging.

Although globalization processes have the potential to increase connections between people, for instance through the developments in information tech- 
nology, they may also lead to a loosening or even disintegration of social bonds. The transformation of welfare arrangements, for instance, puts high pressure on (intergenerational) solidarity (Phillipson, 2013; A. Walker, 1996).

On the macro-level of societal structures and political-economic arrangements, globalization makes large societal issues much more difficult to manage, since the traditional solutions offered by the structures and institutions of the nation state no longer suffice in a globalizing context (Baars et al., 2006). The resulting struggles can be observed daily in the newspapers, e.g., in reports on mastering the economic crisis, coping with the consequences of demographic developments like population aging on a global scale, or trying to manage global threats like environmental pollution, outbreaks of infectious diseases, or terrorist attacks. On the micro-level of individual lives, the reality of globalization can also be said to have a profoundly disorientating effect on people's lives. For instance, being unable to rely on welfare arrangements that used to be provided by the nation state not only puts people at risk of poverty when they are in vulnerable socio-economic positions, it also confronts them with existential questions about their societal value, the strength of their connections with others, and their human identity and dignity. This effect is reinforced by the fast pace at which their knowledge and skills get outdated as a result of the dynamics and complexity of a globalizing society and the immense and fast developments in science and technology.

\subsubsection{Structural and systemic influences on individualized lives}

People living in late modern circumstances are confronted with a highly ambivalent situation. On the one hand, self-realization, in its late modern disguise of the choice biography and of a life of one's own, is celebrated as the ultimate purpose to strive for in an individualized world. On the other hand, the late modern world harbors a variety of complex structural arrangements and systemic influences restricting or complicating people's opportunities to realize themselves. These influences can be traced at multiple, interacting levels: local, national and global, micro, meso and macro. Together with the influence of cultural master narratives on people's identity-formation that I will focus on in chapter 3 , these structural and systemic influences form a vast array of external forces impacting the life course; external forces that potentially complicate late modern self-realization profoundly. As a result of the impact of these external forces, the agential control over one's own life that is one of the presuppositions of late modern self-realization discourse has to be constantly negotiated while facing a diversity of structural and systemic influences. For example, in the Netherlands, obtaining professional care requires getting an 'indication decision' from the relevant bureaucratic organization, confirming that one is entitled to a certain kind and amount of care. On the one hand, the care provided 
supports people to lead their lives as they choose, thereby increasing their scope of agency and their opportunities for self-realization. On the other hand, the bureaucratic structures informing the indication procedure often do not match the specific individual situation. This then restricts people in their agential opportunities, by pushing them in a systemic framework that overrules their life-world reality.

Although choosing one's own lifestyle is heralded as a dominant moral value, late modern systemic structures and arrangements paradoxically also show a strong tendency towards standardizing people's life courses and fitting them into dominant societal "scripts". Such scripts present systemically framed models of "appropriate" social roles, age identities or modes of conduct for aging individuals (Hockey \& James, 2003; Baars, 2006a). While these scripts are not necessarily fixed or static - they have transformed considerably with the development of late modernity - they do present external systemic influences which are imposed on the life realities of older people. In this sense, a societal script is associated with a straightjacket, a framework aimed at fitting the divergent, the individual, the unique aspects of peoples' lives into unifying, standardizing and reductionist models. The enforced retirement at a certain age which is common in several European countries provides an example of such social construction of aging (Phillipson, 2013), as does the de-individualizing identification of the frail elderly with a dependent "sick role" (Cruikshank, 2003, p. 36). Needless to say, structural societal "scripting" can be expected to create tensions with the underlying assumptions of the moral ideal of self-realization, with its emphasis precisely on the authentic, uniquely individual aspects of a person's existence that it tries to standardize.

Late modern individuals seem to be drawn into a compulsive demand to engage with lifestyles that are in fact largely prescribed by the structural dynamics of late modern systems, for instance an economic system characterized by deregulation. A good example of the latter is provided by contemporary discussions in the Netherlands about what is called the "participation society", which aims to transfer responsibilities for care arrangements to individual people and their social network (Newman \& Tonkens, 2011). This transfer of responsibilities is presented as an ideal worth pursuing and naturally fitting the transformed life circumstances of late modernity. It supposedly enables people to gain more control over the organization of their lives. At the same time, however, this discourse of participation and individual freedom and responsibility functions as a cover for hardcore economic cost reduction. This puts people at risk of becoming the victims of imposed and restrictive images of the good life, instead of being truly empowered to realize their own appropriated views, developed in interaction and mutual connection with others. There is also a great risk that people in already vulnerable social positions, like psychiatric patients, disabled persons or older people lacking a satisfactory social network, will be 
victimized by this system because they can't live up to the implicitly expected standards of personal responsibility and independent agency.

It is important to note that many perspectives focusing on the structural and systemic impediments to the realization of a life of one's own seem to be based on the evaluation of individualization processes which Elliott and Lemert (2006) called "manipulated individualism". In this view, the individual agent is perceived as relatively powerless in comparison with the vast forces exercised by power structures and socio-economic arrangements. Individuals might be able to exert a modest amount of influence over their own life at the micro level, but the relation with structural forces is fundamentally unequal. Dannefer and Kelley-Moore (2009) for instance, emphasize that the relationship between agency and structural factors should be regarded as an asymmetrical one. However, this asymmetry does not necessarily lead to the conclusion drawn by the manipulated individualism-perspective distinguished by Elliot and Lemert (2006), which suggests that agency is basically an empty, illusory phenomenon that causes alienation rather than freeing people for a life of their own. Despite the asymmetry between agency and structure, resistance to oppressive forces is possible, and people's opportunities for exercising moral agency can in fact be enlarged, as is illustrated in the discussion about cultural narratives and counter narratives in chapter 3 .

\subsubsection{Repression of meaning and morality}

The societal scripting and standardization processes influencing how the individual's life course is organized are among the factors that expectedly influence people's experience of meaning in their lives. Regarding this influence, Honneth (2004) expresses worries about late modern consumer capitalism, which tends to use the language of self-realization discourse to strengthen its own purposes. The result is that instead of truly being facilitated to develop authentic lives that they experience as meaningful, individuals are subjected to standardization processes and the compulsive demand to experiment with lifestyles. This tendency is confirmed by Beck and Beck-Gernsheim (2002) when they describe individualization as "a compulsion, albeit a paradoxical one, to create, to stage manage, not only one's own biography but the bonds and networks surrounding it and to do this amid changing preferences and at successive stages of life, while constantly adapting to the conditions of the labor market, the education system, the welfare state and so on" (p. 4). Honneth (2004) argues that these lifestyles are in fact largely prescribed by the dynamics of a capitalistic economic system, which produces heteronomy rather than autonomy. What on the surface seems to be an authentic existence of self-realization is in fact only a shallow appearance camouflaging a deep dependency upon the capitalistic system. This concealed dependency undermines the moral stake 
of late modern self-realization discourse, and results in experiences of inner emptiness, meaninglessness and instability for the individual.

What is touched upon here is the existential and moral dimension of life, addressing people's relation to the physical, social, personal and transcendent dimension of existence (Van Deurzen 2002, see also \1.5). It has been discussed in $₫ 1.5$ that experiencing our lives as meaningful relies on developing and maintaining satisfactory relations with all those four realms. As is discussed later on in this study, finding a satisfactory attitude towards the existential and moral dimension is also crucial to my suggested reframed view of self-realization. Most analyses of late modernity agree that the late modern outlook gives rise to profound existential and moral questions, both for individuals and for societies at large. For instance, living in a de-traditionalized, secularized context, what is the meaning of one's spiritual and religious orientation? What is the purpose we should strive for in life, and how do we judge whether this purpose is sufficiently valuable in the absence of any broadly supported and shared common good? How should we perceive values like justice or solidarity in an increasingly individualized and globalizing situation? How do we deal with individuals and groups of people who deviate from the implicit norms of autonomous self-determination, independence and personal responsibility put forward by late modern self-realization discourse? These and many other pressing questions of meaning and morality urgently confront late modern individuals.

Sociological analyses particularly emphasize how existential and moral matters are typically repressed and delegated to the individual realm by the characteristic dynamics of late modernity. The latter's focus on risk management, control and individual responsibility causes uneasiness and tensions when confronted with the contingent, uncontrollable and often tragic existential dimension of life. Giddens speaks about the "sequestration of experience" (Giddens, 1991, p. 144): questions and dilemmas surrounding fundamental existential themes like death, aging, illness, insanity et cetera are being pushed away from sight, repressed and banned to specifically organized realms. Bauman's (2008) analyses of the late modern fear of everything that represents the "Other", also resonates this unwillingness and inability to address and deal with existential and moral matters. The potentially disturbing questions raised by these themes consequently disappear from the public realm and become the sole responsibility of the individual (Bauman 2008). At the same time however, Giddens underscores that the attempt to repress and control existential and moral matters never succeeds completely; the "repressed" returns in different disguises, raising new uneasiness and anxiety (Giddens, 1991). 


\subsubsection{The moral identity crisis of late modern man}

The position of matters of meaning and morality in late modernity has also been discussed from a moral-philosophical point of view. Although these moral philosophical perspectives take a different angle, they are closely intertwined with the sociological observations about the repression of meaning and morality discussed in \2.3.5. Two influential authors who have written extensively on the moral outlook of late modernity have been selected to feed the discussion in this section; C. Taylor (Sources of the self, 1989; Ethics of authenticity, 1991; A secular age, 2007) and MacIntyre (After virtue, 1984). An important advantage of their work, and the reason for selecting it, is that it presents an account in which the ideal of self-realization is put into a broader historical and moral philosophical perspective.

Broadly speaking, both authors describe and evaluate the moral and spiritual outlook of the contemporary Western world that has resulted from centuries of gradual modernization processes. Since Weber, it has become common to state that modernization is accompanied by a "disenchantment of the world", a characteristic process of rationalization and decline of transcendental sources of value (Weber, 1922/1989, p. 30). Weber's classic analysis plays a foundational role in contemporary analyses of the (late) modern world as a secular or post-traditional one (C. Taylor, 2007; Giddens, 1991). Terms like disenchantment or secularization describe how in the process of modernization, traditional sources of knowledge, religious and moral guidance and authority are eroding and losing their self-evident status in society. C. Taylor (1991) and MacIntyre (1984) share a deep concern about the moral uprooting plaguing late modern man, which has resulted from this process. As a result of complex historical, scientific, societal and cultural dynamics, they argue, we have lost contact with the sources underlying our identity and our conception of morality, which according to C. Taylor should be viewed as inextricably connected. This crisis of morality should be perceived as an identity crisis suffered by late modern individuals (C. Taylor, 1989). Bereft of a sense of connection with the sources nourishing their moral identities, individuals are at a loss when it comes to the legitimization of overarching value orientations and conceptions of a good life.

In the process of modernization, there has been a growing emphasis on procedural approaches to morality based on formal principles. MacIntyre (1984) argues that moral questions and disagreements are either solved by an appeal to impersonal and supposedly rational criteria such as "duty" or "utility", or they are considered principally interminable, because morality is reduced to a matter of personal emotional preference. Both C. Taylor (1991) and MacIntyre (1984) express worries about how morality is hereby separated from its traditional role of providing guidance in matters of value and good living. This leads to a general feeling of helplessness, relativism and even cynicism towards fun- 
damental ethical questions that haunt late modern individuals. Both authors are very critical about the atomistic anthropology of neoliberalism, which perceives the individual as an isolated, self-sufficient entity, whose autonomous development and self-realization forms the paramount goal to which all social interaction processes are made subordinate. It is important to realize that this is a very powerful image in late modern society and is also very influential in the dominant late modern interpretation of the discourse on self-realization.

MacIntyre in particular expresses worries about how the late modern emphasis on individual choice and personal authenticity risks losing sight of the way people are fundamentally embedded in a context of traditions, practices and social and moral communities, and are dependent on each other (MacIntyre, 1984, 1999). Correspondingly, we risk losing sight of the deeper meaning of the inter-human condition. Social relations are often solely interpreted in terms of mutual benefits or dependencies, and thereby reduced to superficial instrumental aspects. Alternatively, the way individual identities are socially constituted may be emphasized, but in such a way that the value and even the possibility of individuality is reduced or denied.

C. Taylor, on the other hand, emphasizes the lasting moral importance of the typical modern discourse of self-realization, despite his worries about the moral identity crisis of late modern people. He argues that, if re-interpreted in a different manner, the typical late modern culture of self-realization mirrored in what he calls the "ethics of authenticity" (C. Taylor, 1991) can still be a valuable ideal capable of providing moral guidance towards the good life. His attempt to explain the moral and spiritual outlook of (late) modern societies in terms of authenticity is highly relevant because it helps to legitimate the focus of this study on self-realization as a meaning-generating moral ideal (see further $\llbracket 7 \cdot 3 \cdot 3)$.

\subsection{IMPLICATIONS FOR LATE MODERN AGING}

In this section I explore how the discussed socio-cultural transformations associated with late modernity have had their impact on the reality of aging. In succession, I discuss the enormous increase in life expectancy and in the number of older people worldwide, with corresponding economic, political, social and cultural challenges (\$2.4.1); the typical individualization and diversification of aging trajectories (\$2.4.2); the distinction between the so-called "Third Age": the phase of later life associated with a fulfilling and vital lifestyle and embraced by consumer culture, and the "Fourth Age": the phase of later life associated with inevitable decline and nearing death, which is mostly en-

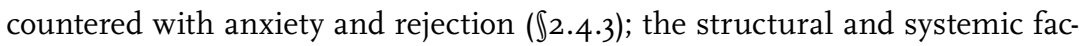
tors that force aging people into societal scripts that do not necessarily cohere 
with their individual aspirations and capacities (\$2.4.4); the dynamics through which aging well has increasingly become an individual rather than a collective responsibility ( $\mathbb{2} 2.4 .5)$; and finally, the unease that characterizes the late modern cultural response to the uncontrollable dimension of existential vulnerabil-

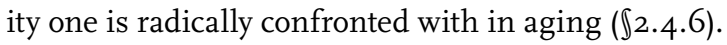

\subsubsection{A (much) longer life in a complex world}

When considering the impact of the discussed features and dynamics of late modernity on the reality of aging people's lives and identities, it is important to realize that these influences can be of very diverse kinds, some of them touching upon very basic life conditions, others relating to highly complex and elusive dynamics. One of the most basic and obvious factors influencing the typical outlook of late modern aging is the rise in life expectancy in the last century, at least in the Western world. Not only are people reaching higher ages, there is also a higher number of older people than ever before. This rise in life expectancy can be attributed to different factors, such as a decrease in infant mortality, an increase in hygienic circumstances, and an explosion of medical and technological possibilities that have transformed formerly deadly diseases into treatable medical conditions. Although it is important to realize that the concrete increase in life expectancy can still differ considerably depending on one's socio-economic position in society (Dannefer, 2003; Phillipson, 2013), the enormous extension of life expectancy at birth that has taken place in the last centuries has had a huge impact on the reality of aging in late modern conditions.

On the individual level, the fact that people in general live much longer not only raises a variety of biomedical questions (Westendorp, 2014), but also existential questions, since the extension of later life has opened up a rather long phase of requesting meaningful content (Moen \& Spencer, 2006; see \2.4.3). On the societal level, the increasing percentage of the population that consists of older individuals comes with profound socio-economic challenges for late modern societies, mostly related to how pensions and care should be financed (Phillipson, 2013; see also \2.4.5).

\subsubsection{Individualization and diversification: an old age of one's own?}

Hendricks rightly states that, "As the societal backdrop against which ageing unfolds undergoes change, so, too, will sense of self and perceptions of ageing actors" (Hendricks, 2010, p. 253). He goes on to argue that societal norms, social resources and collective ideologies concerning aging will inevitably influence how aging actors perceive themselves, their future life trajectories, and 
their social role and position. As the pace of change in this regard hastens and insecurities and complexities grow, a development characteristic of late modernity, the stability and consistency of people's identities will expectedly suffer.

In accordance with the general late modern transition from a standard biography to a choice biography, aging trajectories too are no longer pre-shaped along traditional lines. The fact that traditional models ordering the life course in three "boxes" or well-delineated periods of education, labor and retirement, have lost considerable ground, also affects older people's lives. Although there exists a structural lag in how societal arrangements organizing the life course are adapting to this new reality (Riley, Kahn \& Foner, 1994), the erosion of clearly delineated stages or boxes of life with a predictable timing and progression opens up new opportunities to shape one's later life as well. The result is an enormous diversification and corresponding individualization of aging trajectories and lifestyles (Hendricks \& Hatch, 2009).

In many aspects, there is an evident increase in freedom and autonomy to organize one's own life and old age. For instance, leisure and education patterns have shifted so that many activities previously reserved for younger people are now open to older people as well. The increase in choice options to organize one's later life can also be illustrated by the time, funds and energy that are invested in enhancing the possibilities for aging people to lead self-directed, independent lives, ranging from fall prevention programs to installing home automation systems monitoring people and their care needs from a distance. Admittedly, many of these inventions are stimulated with a cost-reduction agenda operating in the background, which causes skepticism about the value that could be ascribed to the moral language of autonomy with which these policies are justified.

The emphasis on a life of one's own characteristic of late modern self-realization discourse echoes in the implicit overarching ideology that underlies many living and care arrangements for older people. This ideology states that as far as possible, older people should have the opportunity to lead self-directed lives, travel, engage in volunteer work or leisure activities, follow education and undertake all sorts of activities contributing to a satisfying and fulfilling life according to their own standards. However, there is reason for a cautionary note if we want to apply the late modern ideology of choice and self-determination to the concrete reality of older people's lives. A variety of structural and systemic factors and societal scripts about aging restrict the opportunities to realize the envisioned old age of one's own (see $\ 2.4 .4$ ). Also, self-realization-related values such as the optimal development of personal capacities seem to have a stronger pull for the better-educated and younger members of society (Beck \& Beck-Gernsheim, 2002). Many older people nowadays still live relatively traditional lives, although this number can be expected to decrease fast as the baby boom generation ages. This suggests that the late modern discourse of self-re- 
alization does not automatically match these people's lives and should only be applied critically and with caution. Nevertheless, these people are living and aging in a world that increasingly endorses an ideal of individual self-realization as its dominant image of the good life. Expectedly, this will influence the cultural imaginaries and narratives about later life articulating what it means to age well in contemporary conditions.

\subsubsection{Third Age and Fourth Age}

Another typical characteristic of late modern aging is the emergence of a new distinction in the life course that subdivides later life into two phases; the Third Age and the Fourth Age (Laslett, 1989). The Third Age describes the rather long new period of life requesting meaningful content, created as a consequence of the dramatic increase in life expectancy (see $\$ 2.4 .1$ ). In most Western countries, the onset of retirement for most individuals has not kept pace with this increased life expectancy. As a result, a new phase in later life seems to have emerged between the age when one retires and the onset of age-related physical and mental decline. The length of this new period turns out to be considerable for many people. It may even equal the period of "normal", productive adulthood. This Third Age is generally associated with the enjoyment of an abundance of post-retirement leisure options and a still vital health condition. Typically, the concept is associated with baby boom retirees in relatively well-off material circumstances and still in good health, who are culturally positioned in the role of active and vital consumers (Gilleard \& Higgs, 2000). The ideology of the choice biography (with its corresponding pitfalls) is strongly present in the discourse of the Third Age as well.

According to Moen and Spencer (2006), the Third Age is a rather open life phase, offering lots of opportunities for individual design and activity. The exploration of these new uncharted territories of self-fulfillment can supposedly be performed in relative freedom from external constraints posed by the duties of labor and family life characteristic of earlier adulthood, due to the diversification of the life course and the loosening of traditional boundaries between boxes of life (see $\mathbb{2}$.4.2). However, as Gilleard and Higgs (2005) point out, the Third Age has also become the target of a consumerist ideology which unmasks this freedom as perverted by capitalist and economic values. After all, Third Agers represent an interesting target to sell all sorts of amenities and services to with promises of long-lasting vitality and youthfulness (Gilleard \& Higgs, 2005). One of the most striking features of the Third Age discourse is that it strongly stimulates older people to engage in anti-aging strategies. A whole industry has been harnessed to help people remain as youthful and active as possible, offering products varying from anti-wrinkle creams to Viagra. Aging well is increasingly identified with staying young. The corresponding 
anti-aging ideology can be argued to offer a one-sided and problematic image of old age which impedes the possibilities to infuse later life with an intrinsic meaning of its own (Baars, 2012a; see $\$ 3 \cdot 3 \cdot 3$ ).

Though critical gerontologists point to important limitations of the Third Age discourse, such as its disregard for the structural power factors influencing late modern aging; its conjunction with the stereotyping anti-aging industries; and its neglect of the social inequalities inhibiting a successful realization of the Third Age ideals, Phillipson (2013) nevertheless admits that the Third Age discourse "has played an important role in highlighting the possibility for people to shape their own 'ageing' in a way which was inconceivable for previous generations. And the idea of a 'Third Age' of freedom from the constraints of paid employment undoubtedly carries many attractions. [...] the idea of people choosing to manage and control their own aging is important, even while requiring significant social interventions if it is to be realized" (Phillipson, 2013, p. 49). From the perspective of this study too, the goals that the Third Age discourse typically engages with are valuable. These goals include, for instance, self-development; vital involvement in life; remaining active and healthy and socially connected; all purposes that deserve to be stimulated in light of self-realization, despite the obvious limitations of the Third Age ideology.

An interesting example of the merits of the Third Age discourse can be found in the Universities of the Third Age movement ${ }^{1}$ in which aging individuals join together to exchange skills and life experiences, and further their self-development by learning and teaching simultaneously. The Universities of the Third Age movement may also stimulate welcome investments in facilities for lifelong learning and intergenerational exchange. Phillipson sums up the many advantages associated with this interest in education: "Investment now in education [...] could have major benefits for individuals and for society: first, by playing a leading role in creating a new type of ageing for the twenty-first century, built around extended economic, family and citizenship roles; second, by supporting people planning the two decades or more beyond their main work careers; third, by unlocking mental capital and promoting well-being in later life; fourth, by supporting a range of professional and voluntary groups working on behalf of older people" (Phillipson, 2013, p. 160).

Initiatives like the Universities of the Third Age form a reminder of the many potentialities later life has to offer. These tend to be lost from sight in the context of societal discourses on aging that mostly emphasize the problematic consequences of an aging population. From the perspective of self-realization, these initiatives form a welcome correction of existing cultural imaginaries about aging. They may help people to develop themselves, but they may also

1 | See http://www.u3a.org.uk/ 
help societies to become more aware of the potentialities that older people have to offer, and stimulate making better use of them (see also chapter 3 ).

It is important to note however, that the attractiveness of the Third Age strongly relies on the contrast it represents to the so-called Fourth Age that follows it. This Fourth Age denotes the last phase of life and is associated with decline, deteriorating health and eventually death (Moen \& Spencer, 2006; Gilleard \& Higgs, 2000). Some gerontologists have criticized the fact that the interpretation of the Third Age as a period of self-fulfillment through leisure and consumption implicitly depends on the transfer of all aspects of aging that are perceived as negative to the Fourth Age. The positioning of the Third Age as a positive image of later life, a period in which one can freely engage in self-realization, presupposes the contrasting positioning of the Fourth Age as an almost exclusively negative, deplorable socio-cultural status (Gilleard \& Higgs, 2011; Grenier, 2012). This problematic positioning of the Fourth Age mirrors the general late modern tendency to meet existential questions with profound unease, and to isolate and repress anything confronting us with the uncontrollable, tragic dimensions of life ( $(2.3 .5)$.

There is no fixed moment for the transition from the Third Age to the Fourth Age; this depends on one's health condition. A vital 80-year old may still be in his/her Third Age while a 6o-year-old suffering a chronic disease has already entered the Fourth Age and lacks the opportunity to enjoy the freedom and possibilities associated with the Third Age. In stark contrast to the abundance of possible lifestyles that the Third Age offers to aging individuals, the options open to people in the Fourth Age seem to be restricted to images of need, lack and dependency (Grenier \& Phillipson, 2013). The responsibility for older people's identities, in terms of life choices, shifts away from the individuals themselves and is transferred to families or care institutions. One might thus argue that in the Fourth Age, people are no longer considered to be autonomous moral agents capable of shaping their lives according to what they value and who they want to be, but are solely identified by their impairments. Grenier (2012) addresses the possible detrimental consequences of this when she states, "The concern is that in recognizing the Fourth Age as characterized by impairment, older people in this category become socially and culturally 'othered' - both from society and within groups of older people" (p. 174). Whereas Third Agers can count on some socio-cultural valuation as active and vital consumers, Fourth Agers, by contrast, are placed in the socially deeply devalued role of being frail and vulnerable dependent "burdens", who only consume expensive care. Consequently, they are also excluded from the influential ideal of the good life that relies on self-realization.

However, it is important to realize that in the current study the notion of self-realization is developed in directions which diverge quite radically from the individualistic perspective typical for the late modern interpretation, a perspec- 
tive that underlies the individualistic Third Age discourse as well. The fact that in some cases (such as severe dementia) the transfer of responsibility for one's life choices to families or care institutions may be inevitable does not necessarily lead to the conclusion that the opportunities for exercising moral agency for frail and vulnerable older people should be as limited as they are usually perceived to be. It will be discussed in chapter 5 that applying a different perspective on the nature of the self and of moral agency that underlies the self-realization discourse may nuance our view and open our minds to possibilities for exercising moral agency even in the Fourth Age, that are usually overlooked by dominant cultural discourses about aging.

\subsubsection{Structural and systemic dynamics impacting late modern aging}

Despite the emphasis on aging in late modernity as an individualized trajectory (see $\llbracket 2.4 .2$ ), it would be very naïve to present it as a mere individualistic, self-determined project. In reality, many relevant factors influencing people's lives are the result of dynamics and circumstances far beyond the individual's control. This study focuses in particular on the influence of cultural imaginaries on the identity formation and the realization of moral agency by older people (see chapter 3). However, structural and systemic forces, as discussed in $\ 2.3 .4$, also have a profound impact on the life reality of aging individuals in late modernity. According to Hockey and James (2003), "the 'choice' and agency promised by postmodern accounts of ageing must [...] be tempered by the social inequalities of income and of health. These continue to produce considerable variation in the experience of ageing and thus offer rather different prospects for individuals with respect to the changing social identities which accompany the ageing process" (p. 109).

Importantly, the structural socio-economic inequalities that characterize the dynamics of late modern aging challenge the implicit assumption underlying the late modern self-realization discourse, that all individuals are the autonomous directors of their own life (Dannefer, 2008; Dannefer \& Uhlenberg, 1999; Dannefer \& Settersten, 2010). One's scope of self-determination is highly dependent on one's socio-economic status. The cumulative advantage-disadvantage theory (Dannefer, 2003; Crystal \& Shea, 2003) states that people who grow up in less privileged socio-economic circumstances experience growing disadvantages regarding health and economic position with aging. The disadvantages of a bad start in life tend to cumulate during the life course. The dramatic differences in (healthy) life expectancy and in the occurrence of diseases like obesity and diabetes between members of different socio-economic classes may serve as an example. The reverse is also true; people who are lucky enough to grow up in privileged socio-economic circumstances are more likely to age well 
than their less fortunate contemporaries. The influence of social inequalities on the lives of aging people implies that the characteristic changes and transitions of late modernity will have different impacts for different groups of aging individuals.

Another example of the influence of structural and systemic factors on the lives of individuals pertains to the structuring of the life course along the lines of "chronometric" (calendar) age, which is characteristic of modernization processes (Baars, 2007, 2012a, 2012b). While there has been a de-standardization

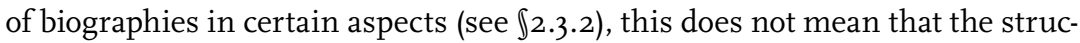
turing of the life-course according to chronometric age has lessened. On the contrary, especially in the domains of employment and education, there exist powerful institutionalized structuring influences based solely upon people's chronological age. This leads to a continuous process of de-standardizing and re-standardizing of the life course, depending on the prevailing political and economic realities (Baars, 2012a).

Rather than freeing individuals to organize their lives according to their own choices, the structuring according to chronometric age results in variations of the "standard" life course, for instance along the lines of socio-economic status. The envisioned life course of the well-to-do elite may include a prolonged Third Age with plenty of opportunities for consumption and self-fulfillment, whereas groups with lower socio-economic status face later life on the threshold of poverty, often with detrimental health consequences resulting in an early onset of Fourth Age problems.

A final relevant observation related to the structural and systemic influences on aging people's lives is that phenomena associated with aging (such as societal withdrawal after retirement) are also often "naturalized" by scientific theorizing. This legitimates them as self-evident situations, instead of acknowledging the fact that these phenomena are socially constituted (Baars, 1991). The influential but severely criticized disengagement theory in gerontology serves as a textbook example here (Cumming \& Henry, 1961). The fact that the "natural" tendency to disengage presupposed by this theory may be associated with the social institution of retirement at $\sigma_{5}$ is totally lost from sight. Such naturalization deflects attention from the influence of social and political forces and power structures that critical gerontology tries to analyze (Baars et al., 2006).

\subsubsection{Aging well as an individual responsibility}

An important consequence of the choice biography ideology that is typical for late modern self-realization discourse is that the risks associated with those choices have to be carried by the individual agent instead of collective institutions (Beck, 1992). As Settersten and Trauten (2009) argue: "Choices now seem greater, but these choices seem heavier and come with unknown consequences. 
Any fall-outs must be negotiated and absorbed by individuals and their families rather than by governments, markets, or other entities" (p. 457). This individualization of responsibility affects the lives of aging people profoundly. For instance, pensions and healthcare are increasingly transforming from a collective responsibility, taken on by the welfare state, to an individual responsibility. This contributes to social inequalities and puts pressure on solidarity (Phillipson, 2009, 2013; Polivka \& Longino Jr., 2006).

However, not only financial and healthcare decisions are transferred to the realm of individual responsibility. Existential and moral issues are also increasingly perceived as matters to be solved by individual deliberation and choice. A good example illustrating how increased choice options of late modernity interact with difficult existential and moral questions that have been delegated to the personal realm is provided by Kaufman's discussion of medical decisions surrounding death and dying. Due to biomedical developments and technological innovations, many conditions that would have resulted in death in earlier times have now become chronic conditions. This situation raises difficult ethical questions, for instance about continuation or ending of treatment, but also existential questions related to one's own finitude and one's relations with significant others. The responsibility for these kinds of questions and the dilemmas they invoke is mostly placed with the patients and their social surroundings (Kaufman, 2010a, 2010b).

The emphasis on individual responsibility in late modern aging discourse is also illustrated in dominant models of successful aging. These models focus on health, activity and social engagement and urge aging individuals to conform to the standards of a self-appropriated, active, vital lifestyle (Rowe \& Kahn, 1997, 1998; see also \$3.3.3). The underlying values of these models, such as autonomy, self-determination, activity, independence, et cetera, are obviously highly influenced by the language of the late modern self-realization discourse. Problematically, however, the focus on a self-appropriated, active and vital lifestyle presupposes that all things threatening the realization of such a lifestyle, such as sickness, vulnerability and death, are kept at a safe distance. It is clarifying to note again the parallels between this implicit urge of the successful aging movement to keep away from disturbing and uncontrollable existential realities associated with the vulnerability of the human condition, and the already discussed tendency of repression and "sequestration" of moral and existential matters perceived as typical of late modernity (\$2.3.5). Dealing with existential vulnerability too, has been turned into an individual responsibility.

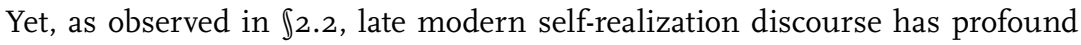
difficulties in integrating this dimension of existential vulnerability in a satisfactory manner. The inability to integrate existential vulnerability in a meaningful way can be expected to exert a highly complicating influence on people's chances to experience later life as a phase with value or meaning of its own. 


\subsubsection{Existential vulnerability and the fragile experience of meaning}

In gerontological discourse, the vulnerability of later life is often discussed in terms of frailty. Gobbens et al. (2011) define frailty broadly as "a process involving the accumulation of physical, psychological and/or social deficits in functioning which increase the risk of adverse health outcomes (functional disabilities, admission to an institution, death)" (p. 47). Frailty is not so much a state as a process whereby disabilities increase over time. It is an important advantage of this definition that it includes not only physical factors but also psychological and social factors. This is in contrast with more narrow definitions of frailty that tend to focus solely on physical health and functioning (Fried et al., 2001; Gobbens et al., 2011). Nevertheless, even in its broader definition the frailty discourse in general remains strongly oriented towards adverse health outcomes.

Importantly, however, it turns out that people scoring high on the frailty indexes do not necessarily perceive themselves as frail. In fact, people tend to give higher ratings to their own well-being than would be expected on account of their physical and mental impairments, a phenomenon also known as the "disability paradox" (Von Faber, 2002; Albrecht \& De Vlieger, 1999). There seems to be a compensation effect at work as well, because once people's physical disabilities increase, they tend to place higher value on social relations in evaluating their quality of life and well-being (Von Faber et al., 2001). Interestingly, although people tend to value their health very highly, social factors, such as the loss of a spouse, seem to be a more decisive reason for them to start perceiving themselves as frail (Verhoeven, Kooiker \& Van Campen, 2011).

This study prefers to use the term vulnerability instead of frailty. It focuses in particular on what I call existential vulnerability, to highlight elements of the human condition that are not always recognized in the predominantly health-oriented gerontological discourse that also underlies the frailty literature. The term existential vulnerability pertains to what Martha Nussbaum (2001) termed the "tragic" dimension of human existence, a dimension which we can never escape from because it intrinsically belongs to the human condition. To distinguish existential vulnerability from other kinds of vulnerability, it is clarifying to mention a taxonomy of three sources of vulnerability suggested by MacKenzie, Rogers and Dodds (2014). These sources include: 1) inherent vulnerability, which refers to those forms of vulnerability that are inherent to the human condition; 2) situational vulnerability, which refers to forms of vulnerability that are specific to the personal, social, political, cultural, or environmental situation that people are in; and 3) pathogenic vulnerability, which is a subset of situational vulnerability that specifically refers to varieties of situational influences that are troublesome in a moral sense, such as abusive relationships or social oppression and injustice. Of these three, what is described 
in this study as existential vulnerability shows most similarity with inherent vulnerability. By contrast, the remediable contingent forms of vulnerability caused by the structural and systemic arrangements influencing the lives of older people on the one hand (see $\ 2.4 .4$ ), and by oppressive and marginalizing cultural master narratives on the other hand (see $\mathbb{3} \cdot 3$ ), are comparable to situational vulnerability and in some cases deteriorate into pathogenic vulnerability. These contingent vulnerabilities influencing the life circumstances of older individuals in late modernity are not related to the inevitable fragility and interdependence of the human condition, but to social, structural and systemic factors that are in principle modifiable (Baars \& Phillipson, 2013).

Typically, these contingent vulnerabilities are relegated to the realm of individual responsibility, which is exemplary of late modernity's worrisome "tendency to inflate the idea of individual independence" (Baars, 2012a, p. 149). This tendency results in a denial of the many ways in which human beings live interdependent lives and are embedded in specific socio-cultural contexts, which in turn complicates acknowledging the potential for value and meaning that later life harbors. In this sense, contingent vulnerabilities can also have existential impact. As was discussed in $₫ 1.5$, the existential dimension of human life refers to four dimensions: people's relation with themselves, their relation with other people, their relation with the world at large and their relation with a realm of transcendence (Van Deurzen, 2002). Importantly, it is through their realization of satisfactory relations with these four domains of existence that people are able to experience meaning in their lives. Alternatively, everything that may threaten or impede the meaningfulness people experience through the formation and maintenance of satisfactory relations with these realms falls into the category of existential vulnerability.

Although there is certainly overlap between existential vulnerability and a broad conceptualization of frailty (the loss of a loved one, for instance, counts both as an instance of existential vulnerability and as an instance of social frailty), in its focus on health the scientific frailty discourse tends to overlook other important aspects of existential vulnerability, particularly when it comes to the aspect of meaning and the values that are constitutive of who we are. This is another reason for this study to prefer the terminology of existential vulnerability. Of course, not only elderly but human beings of every age are existentially vulnerable in the sense described above. Such events as illness, or the loss of a loved one, form an inescapable element of the human condition and are certainly not the exclusive province of later life. But although young people are not immune to instances of existential vulnerability, the probability of encountering such events nevertheless tends to increase with age, confronting older people more radically with the need for a meaningful integration of this reality in their lives (Baars, 2010). 
Settersten and Trauten (2009) have expressed the increase of vulnerability with age in their observation that later life has a "highly contingent quality" (p. 142). By this, they mean that the increased probability to live to a high age by no means guarantees how these added years will be experienced. An unfortunate fall resulting in a hip fracture may be the onset of a downward spiral of vulnerability. On the other hand, the birth of grandchildren may bring unexpected joy and strengthen or enrich contact with one's children, resulting in a flourishing phase of grandparenthood. The balance of experiences may turn out to be positive or negative, depending on what life events one encounters and how strong one's resilience to adversity turns out to be (Ryff et al., 2012). Much seems to depend on the successful integration of existential vulnerability and the attitude people develop towards it, as this study argues in later chapters.

Obviously, existential vulnerability as described above is a phenomenon of all times and not exclusive to late modernity or late modern aging. But it has been argued that as a result of processes such as individualization, erosion of traditional sources of meaning and morality and the increasing focus on controlling and managing risks, late modernity has a particularly hard time finding a satisfactory attitude towards the existential dimension of (later) life (Cole, 1992). In the absence of self-evident moral and spiritual sources of identity, relating to existential vulnerability can be expected to be a particularly complex task for late modern aging individuals. This study therefore advocates paying broader attention to existential vulnerability in the study of aging, and aims to make a contribution to this goal itself. However, it should be underscored that the contingent vulnerabilities confronted in later life that do not fall into the existential category remain in need of the dedicated attention of gerontology as well. It cannot be emphasized enough that contrary to existential vulnerabilities, the contingent vulnerabilities are principally open to repair, for instance, by improving the life circumstances of older people. Critical gerontology rightly keeps stressing the importance of scientific and political efforts to remedy adverse living conditions, such as global social inequalities (Phillipson, 2013; Baars et al., 2006). Cultural gerontology, on the other hand, focuses on the need to replace oppressive and stereotyping cultural narratives about later life with more inspiring counter narratives; this is an aim the current study also aims to contribute to (Gullette, 2004, 2011; Cruikshank 2003; see further chapter 3). 


\subsection{CONCLUSION}

\subsubsection{Ambivalences of self-realization in late modernity}

If there is one common element that can be distinguished in the diverse analyses of the late modern world that were broadly sketched in this chapter, it seems to be the image of individuals struggling to lead a good life, in a constantly changing, insecure, chaotic and confusing world. Not only has the individual acquired the morally highly valued status of free and autonomous agency in the course of modernization, individuals are also increasingly regarded as the only resource one can eventually turn to when it comes to creating a good life for oneself. In the context of an insecure, complex, globalized world, individuals are destined to find their own - temporary and constantly changing - answers to existential and moral questions and create and maintain a viable self-identity. Consequently, late modern conceptions of the good life that feed into the late modern discourse of self-realization present a strong inclination for individuals to develop their own life plans, projects and lifestyles. The image of people shaping their lives through an autonomous act of design and choice is typical of what is sketched in this study as the late modern version of self-realization discourse.

Yet the status of self-realization as a moral ideal characteristic of late modernity can only be deeply ambivalent. This ambivalence has two causes in particular. The first relates to the tension between the expectation of self-determining moral agency and the host of external forces exerting their influence on the individual; the second relates to the tension between the anthropological assumptions characterizing the late modern self-realization account and the reality of social embedding, interdependence and existential vulnerability that characterize human lives.

1. Late modern self-realization discourse implicitly relies on a strong and independent, self-determining image of the self. This self is expected to be able to reflexively consider (and constantly reconsider) its value commitments, aspirations and desires, and to act upon them in order to express moral agency in complex practical circumstances. However, as previously discussed, late modernity harbors a complex assembly of structural and systemic factors threatening the realization of such a strong self, an assembly of factors which has grown extensively complex in the course of modernization. Moreover, dominant cultural imaginaries and narratives provide an inescapable context that individuals have to relate to in their identity formation, as is discussed in chapter 3. The profound impact of both structural/ systemic and socio-cultural forces on the identity formation of individual agents suggests that the promise of late modern self-realization discourse 
is not as easily realizable as it seems. In fact, being the independent, self-determining architect of one's own lifestyle, on second thought, seems profoundly problematic. This raises doubts about whether self-realization is at all possible, at least as it is presented in the late modern interpretation.

2. The second source of ambivalence for late modern self-realization discourse relates to the implicit assumptions regarding the nature of the individual moral agent. The late modern view of self-realization relies on an account of human agency which can be argued to be very problematic and unrealistic. In particular, this account tends to disregard the socio-cultural constitution of human agency.

While the complexity of the late modern world confronts us with deep anxieties and uncertainties and forces us to acknowledge our interdependencies with others, paradoxically, the late modern moral ideal of self-realization suggests that we can and should take the position of an autonomous, independent, sovereign director of our individual lives. The late modern interpretation of self-realization seems unable to acknowledge the situated, socially constituted and interdependent nature of human lives. This inability also lies at the base of its difficulty to relate to the dimension of existential vulnerability (see $\mathbb{2} \cdot 4 \cdot 6$ ).

Despite these ambivalences attached to the late modern self-realization discourse however, it is important to realize that as a moral ideal, self-realization still provides us with an attractive image of what we could be, at our best. It provides us with an image of moral agents taking charge of their own lives, infusing these with value and meaning according to self-appropriated motivations and orientations. The force of this ideal, no matter how problematic its underlying assumptions, can be felt regardless of the question whether people actually succeed in attaining this ideal, or even whether it is at all realistic that they should do so. From the work of the sociological and philosophical authors that is discussed, self-realization arises as an alternative moral framework replacing the traditional sources of meaning and morality that have lost their self-evident status. This is all the more reason to take it seriously. However, the question relevant for the current study is whether it is a viable ideal to be applied in the context of aging.

\subsubsection{Reframing late modern self-realization discourse}

The case of late modern aging is highly illustrative of the way the discussed ambivalences of late modern self-realization discourse influence people's lives. From the discussion of characteristic elements of late modern aging in $\mathbb{2} .4$, we have learned that both ambivalences plaguing late modern self-realization discourse described above also impact the reality of late modern aging. 
- First of all, for older individuals, exercising competencies associated with self-realization such as self-determination and choice, is highly complicated by the structural and systemic arrangements organizing later life, as well as by the socio-cultural constitution of old age. Older people are often denied the agential capacities that are implied by self-realization discourse, which suggests that the possibility of self-realization seems illusionary in their case.

- Second, the problematic anthropological assumptions typical of late modern self-realization discourse poorly match the reality of vulnerability and frailty that is often radically confronted in aging. Consequently, late modern self-realization discourse seems to offer a rather insufficient model of the good life for older individuals, particularly because it falls short of providing resources for relating to the dimension of existential vulnerability in a meaningful way.

The ambivalences and tensions connected with late modern self-realization discourse that have been discussed above can reasonably tempt us to dismiss the value of self-realization altogether, and particularly its application to later life. Would it not be better to admit that self-realization, though an attractive idea, is in fact very unrealistic; and that a moral discourse based on this concept cannot possibly provide us with the necessary resources for developing more nuanced, inspiring and meaningful imaginaries and narratives about later life? Why try to uphold the moral value of an ideal that is obviously so problematic?

This study takes the standpoint that it would be unwise to give up on self-realization as a moral ideal. First of all, it would be undesirable if the ambivalences attached to the late modern version of self-realization discourse would result in the exclusion of aging people from this moral ideal. Even if the reality of many people's lives seems to negate the possibility for self-realization, I think, as a human society we are morally obliged to cherish its underlying goals of optimal human flourishing and fulfillment as something worthy to strive for, both on an individual and a cultural/societal level. Even those who take the standpoint that our primary scholarly efforts should be directed towards changing social structures in such a way that justice and social equality are enhanced, would be well-advised to probe the moral orientation underlying their engagement with these matters. This also underscores the relevance of the self-realization discourse, with its focus on the development of a viable orientation to identity-constituting values.

Furthermore, despite the formulated ambivalences, which are very real and should not be underestimated, we must not forget that late modern self-realization discourse draws upon a broader philosophical discourse of self-realization which may provide opportunities to help us solve the identified problems. It has become clear that a viable conception of self-realization applicable to the context 
of aging does need to address, and to some extent solve, two important issues related to the late modern view in particular. These issues need to be reframed to adapt the late modern self-realization discourse to the context of aging.

1. The problematically atomistic anthropology underlying the late modern view needs to be revised in order to acknowledge the contextual embedding and social constitution of individuals, and their mutual relation of interdependence with other people.

2. The problematic relationship of late modern self-realization discourse with the dimension of existential vulnerability, which is increasingly radically confronted in later life, needs to be remedied.

It is my contention that the rich philosophical discourse of self-realization, of which the late modern view represents only one appearance, should be probed for thoughts and insights that provide the opportunity to overcome the limitations of the late modern view, in particular, as they appear in the context of aging. My aim in the following chapters, then, is an exploration and reframing of self-realization and its constitutive concepts, in order to arrive at an interpretation able to provide backing for the inspirational image of "life as a whole" that Erikson (1997) found lacking in our contemporary world (see \$1.2). It is my hope that such a reframed interpretation of self-realization may bring us the needed resources to support an inspiring, meaningful, satisfactory image of what it means to live a good life as an aging individual. This hope illustrates the normative inspiration that underlies the current study, which is fueled by the humanist assumption that better lives are possible if people are recognized as moral agents. Such recognition implies that people should be able to influence their own lives in accordance with what they find valuable and worth striving for, and that they should have access to valued social roles. This humanistic inspiration requires upholding the conviction that moral agency is not an illusionary, redundant category, but a relevant ethical purpose to promote. Hopefully, my interpretation of self-realization in this study will convincingly underscore the importance, nature and conditions of such moral agency. 



\section{Chapter 3 - Cultural narratives and counter narratives about aging}

\subsection{INTRODUCTION}

"Living a life of your own"; "being your own person"; "marching to the beat of your own drum"; "becoming who you are"; contemporary self-realization discourse is replete with images and expressions that suggest a certain view of the self. Although rarely made explicit, this image of the self can broadly be described as self-reliant, independent, autonomous, atomistic and essentialist. It has already been pointed out that in contrast, the reframed understanding of self-realization that this study aims to develop presupposes the embedding of the self in a social and cultural context. Consequently, our identity is seen as a socio-culturally constituted phenomenon, rather than an essential inner "core self". Moreover, our lives and selves are perceived as intrinsically interwoven with those of others rather than atomistic and independent. In other words, who we are can only be understood against the background of the social and cultural context of our lives.

It follows from such a view of the self that the availability of sufficient social and cultural resources of identity is quintessential to a successful process of self-realization. As discussed earlier however ( $(1.3)$, this study is fueled by the observation that aging in late modernity lacks precisely those viable, inspiring cultural perspectives on later life that should provide aging individuals with resources for creating and maintaining a meaningful "age identity". Gullette (2004) defines this age identity as “each person's collection of 'information' about age and aging in general and stories about their own age and aging in particular" (p. 15). A further exploration of the relation between cultural narratives, identity building and aging forms the theme of this chapter.

First, a general theoretical perspective on cultural narratives and their role in identity building is presented $(\mathbb{3} 3 \cdot 2 \cdot 1)$. Also, potential identity-related problems associated with dominant cultural "master narratives" are discussed

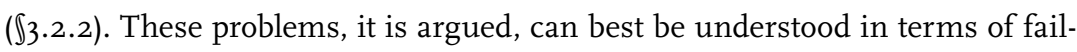
ure to recognize and accommodate people's moral agency in different ways 
(『3.2.3). Subsequently, ideas about how this identity damage caused by cultural narratives can be repaired by creating viable counter narratives are discussed ( $\sqrt{3.2 .4})$. The theory developed by Lindemann Nelson in her work Damaged identities, narrative repair (2001), complemented with some relevant insights that can be found in the work of Honneth on recognition (Anerkennung) and reification (Verdinglichung) $(1995,2008,2012)$ form the main basis of the discussion. The general theoretical insights on how cultural narratives and identity can be applied to the context of aging are discussed next ( $\$ 3 \cdot 3)$, drawing first on insights from cultural and critical gerontological thought (\$3.3.1). Two dominant contemporary categories of cultural narratives on aging are distinguished

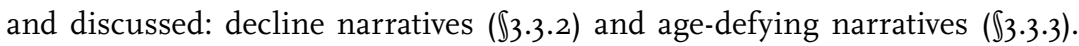
Following this, their problems and limitations are analyzed ( $\mathbb{3} \cdot 3 \cdot 4)$. The final section of this chapter is dedicated to an exploration of a set of possible alternative counter narratives about later life (\$3.4). In an attempt to repair the most important shortcomings of decline narratives and age-defying narratives, a tentative outline for so-called "narratives of becoming" is sketched. This outline foreshadows some of the important features of the reframed version of the late modern interpretation of self-realization that this study advances.

\subsection{Cultural narratives and coUnter narratives}

\subsubsection{Cultural (master) narratives and their role in identity-building}

In the context of this study, cultural narratives are defined as agglomerates of stories, imaginaries, meanings, representations, archetypes, views and stock images existing in a certain culture about a social group, for instance women, Muslims, gay/lesbian people, or aging individuals. This is a deliberately broad definition which includes, but is not restricted to narratives as traditionally understood stories with a beginning, middle and end. Most importantly, my understanding of cultural narratives presents them as carriers of meaning in the broadest sense. Cultural narratives are disseminated in a given culture through various means, and they pervade our lifeworld in a sometimes conscious, but also often largely unconscious manner (Lindemann Nelson, 2001; Meyers, 1994). They provide the horizon against which we situate our own life narratives (C. Taylor, 1989). They supply us with a reservoir of both narrative form and content on which to model our own identities. Other terms that emphasize this function of cultural narratives are "macro narrative environment" (Randall \& McKim, 2008), and “ideological setting” (McAdams, 1996).

From early childhood throughout life, we are constantly confronted with explicit and implicit cultural narratives about different aspects of our world. 
They come to us through fairy tales or comic books, advertisements, newspapers, TV shows, exemplary figures like parents or teachers, works of art and many other media. These cultural narratives give direction to our views and perceptions, inform our choices and judgments, influence which social roles are or are not available to us, and influence how we think and act in certain situations. Cultural narratives are thereby indispensable meaning-generating resources without which we cannot form a viable identity. Lindemann Nelson (2001) reminds us that "it's neither possible or desirable to extricate one's thinking to any great degree from all the clichés of one's culture, since these are the understandings we share in common. If a person were to dissociate herself from them completely, she would no longer be able to understand either herself and the people around her or the workings of her society" (p. 85). Despite their indispensable status as identity resources however, cultural narratives may also severely restrict the options that are available to members of a particular social group to form a certain identity. This is the case if they produce and reproduce prejudiced sets of images and expectations that are so pervasive that they are very hard to counter (Meyers, 1994). The expected result is marginalization and oppression. Members of social groups that are thus marginalized in a given culture are unlikely to have the same access to that culture's dominant ideals of a good life.

Any given culture harbors a diverse array of cultural narratives, but some narratives have a more dominant position than others. Lindemann Nelson (2001) describes these as "master narratives" (p. 6). She defines cultural master narratives as "the stories circulating in our culture that embody socially shared understandings" (Lindemann Nelson, 2001, p. 84). The role of cultural (master) narratives is expressed by De Medeiros (2005) when she defines them as "the stories (or story fragments) 'told' by a culture to communicate the values, expectations and attitudes of that culture" (p. 2). The quotation marks surrounding the word told in this definition emphasize that cultural narratives are very broadly perceived and do not only include traditional stories put into a coherent lingual form, but can also encompass more diffuse expressions, such as artistic expressions or media representations.

Cultural master narratives derive their pervasive force from the fact that they represent convictions and expectations shared by the majority of people in a given context. This grants them the status of self-evident truths. Any alternative narrative challenging this truth will have to go against the tide to convince the majority that what they perceive as the status quo is instead a prejudiced standpoint. Because this is very complicated, cultural master narratives are strongly resistant to change.

But cultural master narratives do not only shape our expectations about what is "fitting" behavior for people in general, they also influence our self-image and what we expect of ourselves. Even if we disagree with them consciously, 
our reactions may still unconsciously be influenced by these cultural narratives. Critical feminist gerontologists from De Beauvoir (1970/1972) to Gullette (1997, 2004, 2011) have underscored, for example, how the self-image of older women has become contaminated with cultural expectations about loss of sexual attractiveness and social invisibility. Being constantly confronted with either implicit or explicit confirmations of such a master narrative strengthens and consolidates this view and may result in internalization of the corresponding image.

Cultural master narratives that express socially shared understandings about a certain social group inevitably affect the identities of its members. People always belong to different social groups at the same time. Importantly, some group memberships are "found", such as our gender or our family, whereas others are "chosen", such as our profession, religious affiliation or membership of a sports club or choir. We all negotiate our current identities in interaction with both our found and our chosen communities. Communities of choice, however, grant us the opportunity to resist harmful or limiting socio-cultural positioning that we are subjected to by our membership of communities that are given (Friedman, 1992).

Although many master narratives are benign, some can be morally evil. The latter tend to "unfairly depict particular social groups as lacking in virtue or as existing merely to serve others' ends" (Lindemann Nelson, 2001, p. 152). One only need to think of the master narratives about Jews abounding in Nazi Germany to appreciate their potential for damaging consequences. Yet the identity-restricting influence of cultural master narratives can also be much more subtle and even exerted with the best intentions. For example, in cultures where girls are culturally positioned as subservient domestic creatures, expected to bear children and be obedient wives, it is often not perceived in their best interest to engage in a life outside the home. Consequently, elements that could constitute their identity associated with obtaining (higher) education or fulfilling a professional role are generally not available to them.

The range of identity resources provided by cultural narratives depends on a variety of factors, such as the historical and cultural outlook or one's social position. The analysis of late modernity in chapter 2 suggests that available identity resources have become more pluralistic and insecure given the fact that previously dominant grand narratives, provided by religious and moral traditions for instance, have lost their authority over us. Navigating this pluralism can be cause for identity confusion, but may also harbor opportunities for resistance. The availability of cultural identity resources also fluctuates during the life course. In youth and adulthood, one may have access to resources that become blocked in later life. Obvious examples include the values and social roles our cultures attach to paid labor, which escape our reach upon (mandatory) retirement. 
In light of their typical resistance to transformation, changing cultural narratives is a very complicated task. It can never be accomplished by the simple act of an individual, but always requires efforts by many actors at multiple levels (Lindemann Nelson, 2001). The fact that transformation of cultural narratives can be so difficult does not mean, however, that cultural narratives represent static entities, or that they always offer clear and unambiguous sets of stories, views and expectations that raise no doubts or conflicts. On the contrary, cultural narratives are dynamic, evolving and complex phenomena that exert their influence on our lives in many ways that are often difficult to trace.

\subsubsection{Damaging effects of cultural narratives}

Let me elaborate on how cultural master narratives may exert negative influences on people's identities according to Lindemann Nelson's (2001) theory. She emphasizes that malignant cultural master narratives tend to lead to a certain social positioning of a (sub)group (e.g., women, African Americans, Muslims, homosexuals, elderly, et cetera) that is damaging to their identities. Typically, the people belonging to this group become identified with a limited number of stereotypical characteristics. For example, women are supposed to be caring, elderly are expected to be slower, less flexible, or dependent, African Americans are perceived as lazy, et cetera. Other characteristics of (members of) the social group that do not fit the stereotypical image presented by the master narrative get lost from sight. This negates individual differentiation within the (sub)group, making individual differences (socially) invisible or irrelevant. It also results in exclusion from opportunities and social roles (Wolfensberger, 2013). According to Lindemann Nelson (2001), malignant cultural master narratives can exert their oppressive, marginalizing and stereotyping effect in four different ways. Firstly, they can exercise an expulsive force, whereby the subject of the narrative is driven out of the larger society. Secondly, they can exert a dismissive force, whereby the subgroup is tolerated in larger society but only on the margins. Thirdly, they can exercise a pressive force, whereby the subgroup is forced into a servile position towards the dominant group. Finally, they can exercise the preservative force, that positions the subgroup in such a manner that it represents the contrasting "other" necessary to maintain the dominant ideology (Lindemann Nelson, 2001, p. 113).

Lindemann Nelson distinguishes between two damaging effects that can be imposed on people by oppressive and marginalizing cultural (master) narratives.

1. Deprivation of opportunity (Lindemann Nelson, 2001, p. 23-28), which describes a situation in which people are excluded from certain roles, chances and options as a result of the stereotypical way in which they are presented 
by master narratives. Being a member of the group of "older employees", for example, all too often means being associated with diminished strength or speed. This may result in being deprived of the opportunity to solicit functions or tasks requiring these capacities, even if one's individual strength or speed are actually quite sufficient.

2. Infiltrated consciousness (Lindemann Nelson, 2001, p. 28-34), which does not operate from the outside, but from within the person itself. Dominant stories and images are internalized by individuals and influence their self-image and the opportunities they envision for themselves. I encountered an interesting example hearing my own parents and their friends say that for them, one of the challenges of retirement was "getting used to not being needed anymore". Note that this was expressed as a completely self-evident fact by people with rich social lives who are valued as parents, grandparents, friends, volunteers and so on. Apparently the dominant cultural narrative that being productive in the labor market gives access to a certain good (i.e., being needed in society) which is lost upon retirement is so strong that it is internalized as an inevitable fact of life. Characteristically, people are not aware of the harming effect of infiltrated consciousness, because it is experienced as the "normal" state of affairs. However, this makes its malignancy even more serious.

In order to free people from both categories of harm, it is required that their identity can be redefined in the context of alternative stories. One needs to be able to identify with alternative stories replacing the dysfunctional identification (in terms of infiltrated consciousness) with dominant oppressive or restrictive stories, a process Lindemann Nelson describes as "narrative repair" (p. 20). This presupposes (re)gaining access to resources for telling and confirming alternative stories, which should be provided by one's social and cultural communities. The two harms require repair in conjunction with each other; a redefinition of the self that challenges people's infiltrated consciousness may lead other people to perceive the people in question differently, which in turn may result in an increase in opportunities that mitigate the harming effect of deprivation. But it works the other way around as well, because efforts to increase people's opportunities are likely to influence their self-image and increase their self-respect as moral agents; this should have a positive influence on reducing the harm brought about by infiltrated consciousness. The overarching aim of the redefinition entailed by narrative repair of identities is always to reclaim and enhance people's moral agency. The next section further elaborates on the connection between this notion and the theme of cultural narratives and identity. 


\subsubsection{Moral agency and the importance of recognition}

The concept of moral agency plays a crucial role in my reframing of the late modern self-realization discourse. I define moral agency as the ability to lead a good life, with and for others, according to one's highest aspirations and best capacities, as full participating members of a society/community. The background of this choice of formulation is further elucidated in $\$ 5.5$. Although Lindemann Nelson's (2001) discussion of moral agency as the good that is reclaimed in the process of narrative identity-repair is not explicitly associated with the theme of self-realization, I think her understanding of moral agency shows sufficient similarities with the one advanced in this study.

In Lindemann Nelson's view, our moral agency is connected to a process of moral self-definition that is the target of identity-repairing counter narratives. Moral self-definitions can be either weak or strong. In the case of weak moral self-definitions, a group or an individual is constructed as basically morally competent. In the case of strong moral self-definitions, the moral competence of agents is deepened by connecting it to the identity-constituting commitments or priorities that give direction to the agent's moral behavior. These need not be the same as those of another moral agent, but are intrinsically connected with one's biography and one's self-understanding. Strong moral self-definition relates our decisions in concrete situations to who we want to be (or become), e.g., a good father, a reliable friend, or a senior maintaining a vital involvement with life.

An important implication of Lindemann Nelson's view is that moral agency requires recognition by others that one is morally worthy to perform one's desired actions freely. This condition is intertwined with the question whether one is given sufficient opportunities to act according to one's moral self-definition (cf. deprivation of opportunity). But importantly, moral agency also requires assessing oneself as morally able and trustworthy. The problem is that oppressive narratives may lead to an internalization of damaging images, so that the oppressive narrative affects one's self-image and in effect diminishes one's self-esteem as a moral agent (cf. infiltrated consciousness).

In order to gain a more refined understanding of the link between social recognition and the repairing of socio-cultural damage to people's identity and moral agency, the work of Honneth $(1995,2008,2012)$ can provide valuable additional insights that enrich and deepen Lindemann Nelson's (2001) account of moral agency. Inspired by Hegel as well as by the critical theory of the Frankfurt School, Honneth understands the dynamics of social conflicts directed towards social change in terms of what he calls a "struggle for recognition" (Honneth, 1995). He argues that it is a necessary condition for freedom, autonomy and self-realization that individuals feel recognized as beings whose aspirations, values and goals are legitimate and worthy to strive for. In 
Honneth's words, “Individuals achieve self-determination by learning, within relations of reciprocal recognition, to view their needs, beliefs and abilities as worthy of articulation and pursuit in the public sphere" (Honneth, 2012, p. 46). Honneth $(1995,2012)$ distinguishes between three levels of inter-human recognition, which are all perceived as equally essential, but pertain to different domains of human existence. The first and perhaps most fundamental and basic relationship of recognition is modeled on the unconditional love between mother and child. Through this recognition, we learn to perceive ourselves as subjects worthy of being loved and cherished independent of our efforts and achievements. If this initial relationship of recognition fails to be established in human life, our personhood or subjectivity is basically flawed (Erikson, 1963; Winnicott, 1965). Expectedly, this also impedes our ability to lead good lives which is fundamental to our moral agency.

The second form of recognition distinguished by Honneth $(1995,2012)$ is located not in the domain of primary relationships, but on the societal level. Essential for the ability to function as moral agents exercising our human potential for freedom and autonomy, is that we are recognized and respected as equal members of the societal legal order. This means being endowed with the status of citizenship that grants us access to fundamental human rights, i.e., being guaranteed a just, fair and equal treatment by the institutions of society. Whereas love is the form of expression of the first form of recognition, respect is the form of expression of the second.

The third form of recognition on the other hand, pertains to being recognized as a unique person, able and entitled to strive for self-appropriated goals in life. This form of recognition includes the optimal development of individual potentials and acknowledgment for the striving for self-realization. Whereas the second form of recognition requires that subjects are acknowledged as equals, the third form of recognition requires that subjects are valued in their diversity and individuality. This demands that people mutually acknowledge the legitimacy and value of each other's individual strivings for meaning and purpose in life, and are congenial to its realization. The corresponding form of expression associated with this third form of recognition is termed solidarity by Honneth.

Honneth's theory of recognition (1995) helps to clarify what is at stake in the narrative repair of the identity-damage inflicted by cultural master narratives. For example, a lack of the first form of recognition, love in primary relationships, may impede moral agency when parents are disappointed with the birth of a daughter, unable to provide her with the same love and support as a son under the influence of cultural master narratives that devalue women. A lack of the second form of recognition, equal respect in societal relationships, impedes moral agency when a certain subgroup in society is denied equal access to certain rights and goods, as used to be the case for the black population in the 
United States before the Civil Rights Acts of 1866 and 1968, or in South Africa during the Apartheid-regime (and sadly, some practices of lacking recognition for these groups continue to the current day). A lack of the third form of recognition, solidarity with other people's projects of self-realization, impedes moral agency by denying people the status of individuals with aspirations and capacities that deserve to be valued and supported. In such a case, a subgroup may enjoy the same formal rights and equal position as other groups in society, but be denied the opportunity to strive for certain goals because these don't match the dominant cultural expectations attached to the group in question. This can be illustrated by the case of older individuals who are forced into retirement although they still aspire to perform paid labor. Honneth's trichotomy offers a valuable perspective to arrive at a more refined analysis of how cultural narratives impede moral agency. It teaches us that restoring moral agency that has suffered from oppressive, stereotyping and marginalizing cultural master narratives requires the restoration of relationships of recognition at multiple levels. It sensitizes our mind to the question of which form of recognition is most urgently denied by certain cultural master narratives in a given situation, and at what level the moral agency of the concerned actors therefore needs repair.

Apart from his ideas about recognition, Honneth's (2008) analysis of reification (Verdinglichung) also helps to clarify certain damaging effects of oppressive and stereotyping cultural master narratives. This term describes human behavior in which fellow subjects are not treated according to their status as dignified human beings with the same emotions, desires, aspirations and rights as everyone else, but instead as objects or even commodities (Honneth, 2005). The link becomes clear if we notice that malignant cultural master narratives tend to treat people belonging to the oppressed group as objects rather than subjects or moral agents (Lindemann Nelson, 2001). The most obvious examples of reification can of course be drawn from the history of slavery, or from the context of industrialization in which people came to be treated as disposable anonymous laborers. But reification can also take more subtle and hidden shapes, by treating people as de-individualized creatures whose aspirations and rights are overruled. For example, the recurring political representation of older people as societal "burdens" weighing heavily on welfare and healthcare budgets could be interpreted as a case of reification.

Central to Honneth's (2008) analysis of reification is that it disables our engagement with the practices that form our reality from the perspective of a participant. Instead, it reduces us to the status of bystander, being excluded from those very activities, narratives and social roles that are essential in the constitution of a meaningful sense of identity. Being a participant does not necessarily presume an activist mode of behavior, but it does presuppose that people are fully recognized as agents who co-constitute the practices that make up their living context. The importance of being able to fulfill the role of par- 
ticipant can be illustrated by an interesting perspective drawn from the context of disability studies: social role valorization theory (Wolfensberger, 2013; Kendrick, 2008, 2009; Osburn, 2006; Lemay, 1999). Social role valorization theory reacts to the problem of social devaluation, or negative perception, of certain people in society. By creating new and positively valued social roles for people, or restoring their access to previously available roles, it is argued that people's chances to participate as full and equal members of society can be enhanced. This could contribute to the strengthening of their moral agency.

An inspiring story told to me by a social role valorization expert sketched the case of a retired carpenter who suffered from Alzheimer's disease. Although he was well taken care of in the care institution where he resided, he was utterly bored and fell into depression. His children, in an attempt to try and tackle his boredom and depression, managed to find a carpenter who had previously worked with him. Though many of the tasks of daily living presented him with insurmountable problems, he proved to still be capable of performing some of the operations that were familiar to him from his history of working as a carpenter. He could thereby provide valuable assistance to his colleague. With appropriate support, this man could thus regain access to a valued social role, which enabled him to function as a valued participant again instead of a passive bystander.

Honneth (2008) himself interprets the harmful effects of the phenomenon of reification in terms of a lack of relations of recognition, or rather a disregard for their fundamental role. Although an attitude characterized by reification can have advantages in some domains, for instance when it comes to acquiring knowledge or developing technological solutions for urgent societal issues, problems arise when the fundamental relationship of recognition preceding such instrumental knowledge relations are lost from sight. The implication of Honneth's view requires taking into account that relationships of mutual recognition are the transcendental condition for any viable human practice or society. Negating the importance of these relationships opens the door to morally harmful phenomena like social exclusion, discrimination, paternalism, oppression and neglect. If people, for instance the elderly, are excluded from participation, this will likely impede their moral agency. Good practices call for care institutions that give people their own say in how daily care is organized, for instance, with regard to bathing times or choice of meals. Conversely, care institutions where the systemic logic of efficiency decides about these issues, risk reducing people to "objects" of care, and thus bystanders in their own daily life. Besides consequences on the level of the individual life, reification may also have detrimental effects on society at large. After all, potentially valuable contributions that older people may have to make are overlooked. It follows that both society and aging people would profit from successful strategies to repair 
the damaging influences of dominant cultural narratives and enhance people's moral agency.

\subsubsection{Narrative repair through agency-enhancing counter narratives}

This section will proceed to discuss Lindemann Nelson's (2001) view about how identity-damaging cultural master narratives can be repaired. Transforming cultural narratives that are oppressive or marginalizing requires enduring efforts on multiple levels. Realizing this task is not easy, given the pervasive influence of stereotypical and devaluing images on the dominant mindset of people. Replacing such mindsets often seems a very unequal battle with discouragingly small chances of success. Wolfensberger (2013) aptly formulates the difficulty of this challenge when he states that, "One's experiences will usually have to contradict one's expectancies and stereotypes very powerfully, and almost always very consistently, in order for these latter to be defeated and reversed. On the other hand, it takes only few and/or weak confirmations of one's expectancies and stereotypes in order for them to become well-nigh irreversibly embedded" (p. 58). To repair the harm done by cultural master narratives that are oppressive, denigrating or marginalizing, Lindemann Nelson (2001) suggests the strategy of developing viable "counterstories" or counter narratives. A counter narrative is defined as "a story that resists an oppressive identity and attempts to replace it with one that commands respect" (Lindemann Nelson, 2001, p. 6). By providing alternative stories challenging the damaging identification with oppressive master narratives, a counter narrative can empower the concerned social group, by generating respect and social value for the people belonging to it. Although I share Lindemann Nelson's view about the importance of empowerment, drawing on the argument about Honneth's (1995) three types of social recognition I would add to her definition that counter narratives should not only command respect, but also enhance the opportunities for people to engage in primary relationships of love and care, as well as acknowledge and facilitate each individual's striving for self-realization.

It is important to emphasize that for Lindemann Nelson, it is not just any alternative story that qualifies as a counter narrative. To qualify as a counter narrative, a narrative has to represent a set of features: 1) it has to replace as well as resist an oppressive master narrative, 2) it should set out to rehabilitate damaged identities, 3) it should be directed towards freeing a person's moral agency, and 4) it should deliberately cause a shift in the cultural understanding of a certain group, rather than just reflecting one. Consequently, an alternative story that is just a different story from the dominant master narrative does not necessarily function as a counter narrative. Although it might be able to repair deficiencies in meaning on the individual level, it does not become a counter 
narrative unless it stretches out to the cultural level to challenge problematic socio-cultural positioning and actively present alternatives.

Lindemann Nelson distinguishes three possible levels of resistance: refusal, repudiation and contestation.

1. Refusal is usually limited to the individual level, when individuals deny that a damaging (for instance ageist) stereotype applies to them, and form their own alternative story to identify with. Since there is no necessity or guarantee of an extension of this alternative story to the cultural, collective level however, refusal stories cannot function as proper counter narratives; they remain incomplete and their reach is limited. For example, an individual older woman may resist the stereotype of diminished sexual activity or beauty associated with aging on the individual level, but it may still be very hard for her to shrug off the internalization of these stereotypes in all situations.

2. Repudiation goes a step further, not only implying identification with an alternative story, but also actively opposing the denigrating stereotypes in social contexts. The resistance remains a piecemeal activity however, limiting its scope as a counter narrative to what Lindemann Nelson (2001) calls "patchwork forms of resistance" (p. 171). The activities of the Red Hat Society $^{1}$, or the "Raging Grannies" (Caissie, 2011) might count as examples of repudiation of aging stereotypes. A danger of this type of resistance through counter narratives is that they result in the creation of alternative stereotypes. Because these alternative stereotypes can be easily ridiculed, the intended effect of repudiation is weakened and disarmed.

3. Contestation represents the full resisting potential of a counter narrative, by systematically and collectively challenging stereotypes in public. Resistance to aging master narratives on this level is worryingly scarce in our culture. However, the activities of the Gray Panthers, for instance, may serve as a promising example. This organization publicly refutes the implicit belief that turning $6_{5}$ means retreating to a passive role. Moreover, the organization strives to advance the opportunities for older people to lead good lives. The following phrase from their mission statement expresses a welcome sensitivity to the importance of focusing on the moral agency and self-realization of older people: "The concept of aging takes into account an individual's growth during their entire life span, from birth to death in personal development, social involvement, and self-fulfillment". ${ }^{2}$

$\mathbf{1}$ | http://redhatsociety.com

2 | www.graypanthers.org 
It is crucial that counter narratives transform both how other people think about the marginalized group and how members of this group think about themselves. The quintessential factor is the creation of new opportunities for identification and self-definition, which should ensure (renewed) access to socially valued goods and roles. As a result, components of meaning can be integrated into one's life and identity that were previously unavailable due to blocking by stereotyping, de-individualizing master narratives (Lindemann Nelson, 2001). Participant roles in valued and shared human practices can then be opened to people who were previously disregarded by these practices as morally inferior bystanders. In Honneth's (2008) terms, this implies becoming aware of and strengthening the constitutive relationships of mutual recognition that sustain human (or better: humane?) societies in order to remedy the adverse effects of reification.

Importantly, when people (or groups) are marginalized and lack recognition as full moral agents, this is often accompanied by social silencing. Feminist approaches in particular, stress that counter narratives should strengthen people's moral agency by making their voices heard (M. Walker, 2007; Meyers, 2004; Lindemann Nelson, 2001). According to these authors, narratives play an important role as instruments that give people a voice. This can take place at several levels, ranging from enabling people to tell their individual life stories to disclosing and presenting collective histories that have been suppressed in dominant cultural master narratives. M. Walker (2007) distinguishes between three interdependent categories of narratives: identity constituting narratives (who am I as a moral agent), narratives about relationships (with whom am I connected, for whom do I feel responsible, et cetera) and narratives about moral value (what do I regard as valuable, what is the meaning of my narratives, et cetera). Together, the three forms of narratives are fundamental to what $\mathrm{M}$. Walker terms our moral integrity.

In accordance with Lindemann Nelson's (2001) approach, M. Walker (2007) emphasizes that it is crucial that people are granted an "epistemological position" which gives them access to socio-cultural resources of identity. This means that people should be endowed with the status of legitimate sources when claiming knowledgeability about matters regarding their own lives. Their narratives about themselves have to be taken seriously by others in order for them to fulfill their potential for moral agency. For example, if older people are culturally perceived as a-sexual creatures, or if their sexuality is regarded as deviant or repulsive, their activities to engage in sexual relationships are likely to be regarded as ludicrous or sad, instead of taken seriously as attempts of moral agents to create viable narratives of identity and relationships for themselves. As long as people are denied epistemological authority regarding their own life orientation and choices, problems arise if they want to aspire to a self-determined life as moral agents. 


\subsection{Cultural narratives about later life}

\subsubsection{Cultural and critical gerontology on the cultural positioning of aging}

In this section, the discussed theory about cultural narratives is connected to the context of aging. One of the claims this study started out with was that existing cultural narratives about later life fall short in providing sufficient resources for meaning, both on the individual and on the societal level, by presenting aging in a problematic way. Initially, this claim was based on rather anecdotal evidence and observations, ranging from an old acquaintance repeatedly warning me "not to become older than 80 " because she was convinced that everything above that age would bring sorrow and misery, to the photograph of an old lady in a sexy bikini posted in a Dutch Facebook group entitled the New Aging, suggesting that the best way to age is to keep up with youth culture as long as possible. These personal and random observations are confirmed, however, by the research and analyses of cultural and critical gerontologists, which will be discussed below. First, however, it should be asked whether it makes sense to apply Lindemann Nelson's (2001) theory about cultural master narratives to the context of aging? Are older people in fact a culturally marginalized group in the sense her theory describes? My contention is that they are indeed, and that this justifies the focus on cultural (master) narratives about later life in the current study's analysis of late modern aging (see also Laceulle $\&$ Baars, 2014).

To begin with, according to Lindemann Nelson (2001) it is typical of being a member of a culturally marginalized group that one is identified with a limited number of stereotypical characteristics. For aging people this is often their calendar age (Baars, 2012b), but they are also identified with stereotypes like frailty, dependency, disability, lack of productivity, et cetera (Cruikshank, 2003; Grenier \& Phillipson, 2013). As a result of such identifications, it becomes difficult to acknowledge the high degree of individual diversity and heterogeneity that characterizes the aging population. Second, this identification with a limited amount of features tends to influence how people are encountered by others, but also how social institutions and policymakers treat them. This may lead to both deprivation of opportunity and infiltrated consciousness, the two harmful effects discussed by Lindemann Nelson (2001; see $\mathbb{3}$.2.2). In accordance with this, aging people's identification with stereotypical categories such as decline often leads to an overruling of their self-determination and a neglect of their own aspirations and life purposes, for instance in the organization of care arrangements (Agich, 2003). It proves to be very difficult to counter such stereotypical positioning. Third, aging people too are vulnerable to the dangers of internalization of stereotypical socio-cultural positioning sketched in Lin- 
demann Nelson's theory. The effect of this internalization on older individuals is illustrated by the so-called stereotype embodiment theory (Levy, 2009). This presents empirical research on stereotypes about aging which suggests that internalization of both positive and negative age stereotypes (defined as beliefs about older people in general) can have either beneficial, or detrimental effects respectively, even on supposedly "objective" factors such as cognitive and physical functioning. According to Levy (2009), "stereotypes are embodied when their assimilation from the surrounding culture leads to self-definitions that, in turn, influence functioning and health" (p. 332).

The three points discussed above, I believe, offer sufficient argumentation in favor of the application of Lindemann Nelson's (2001) theory to the context of aging. One important nuancing remark with regard to her strong emphasis on socio-cultural construction of identities needs to be made, however. Several gerontological authors emphasize that, although social and cultural constitution is vitally important and very influential to the experience of aging, living in an aging body cannot be reduced to socio-cultural construction alone (Cruikshank, 2003; Holstein, Parks \& Waymack, 2011). As Holstein, Parks and Waymack (2011) put it, "There are certain commonly shared experiences of having an aging body that cannot simply be written off as cultural norm: that one's body may begin to hurt, that it may no longer be able to do what we expect, and that its appearance may change over time cannot be eliminated by any cultural change, no matter how significant" (p. 50).

When applying the general insights on cultural narratives and their influence drawn from Lindemann Nelson's (2001) theory to the context of aging, one needs to understand how aging is culturally perceived and communicated in our current Western, late modern world. After all, it follows from this theory that our expectations and experiences concerning aging are inevitably colored by the prevailing cultural images and stories about later life. This theme has been addressed in several gerontological studies analyzing the cultural discourse about aging, from a mostly critical (and often feminist) point of view (De Beauvoir, 1970/1972; Gullette, 1997, 2004, 2011; Cruikshank, 2003; Featherstone \& Hepworth, 1995, 2005; Featherstone, Hepworth \& Turner, 1991; Andrews, 1999, 2012; Calasanti, 2008; Calasanti, Slevin \& King, 2006; Tulle, 2004; Hurd Clarke, 2001; Twigg, 2004; Katz, 2010; Biggs, 1997, 1999; Blaikie, 1999). Featherstone and Hepworth (1995) argue that cultural imaginaries about aging and old age have two functions: "first they are a cultural resource we draw upon to give meaning to later life [...]; and, second, [...] they provide important evidence of the kinds of cultural resources a specific society draws upon to give meaning to later life" (p. 30-31). This provides further basis to our claim that a discussion of cultural narratives about aging is highly informative regarding the meanings given to later life in our contemporary societies. 
Importantly, De Medeiros (2005) suggests a discrepancy between the cultural identities of aging individuals and the way they individually experience their aging process. Lack of attention to this distinction may lead gerontology to interpret certain narrative self-presentations as expressing something about the aging self while in fact, they are more properly interpreted as expressions of cultural master narratives about aging. She also cites Hazan and Raz (1997), who suggest that "narratives of elderly people, that is, interviews, life stories, and other utterances, are too often interpreted as authentic narratives of 'old age' rather than a 'reiteration of the discourse of aging' perpetuated by lifecourse and life-cycle perspectives" (as cited in De Medeiros, 2005, p. 7). In response, De Medeiros suggests a conceptual model in which a distinction can be drawn between the self as externally presented and constantly negotiated in relation to cultural expectations and norms, and the "complementary self", encompassing those aspects of our selves that are at odds with existing cultural narratives, or are silenced or suppressed by them (De Medeiros, 2005).

In general, the critiques of existing cultural representations of aging that are voiced by cultural and critical gerontology have two distinct targets. On the one hand, there is a critique against the cultural reduction of old age to a period characterized by decline and steady, inevitable deterioration into a state of frailty, dependency and misery (Gullette, 1997, 2004, 2011; Cruikshank, 2003; Andrews, 2012; Tulle, 2004). This critique focuses on the one-sidedness of this monolithic identification of old age and decline which results in an overlooking of "possibilities of growth, renewal, change, repair and healing" (Cruikshank, 2008 , p. 150) that may also be part of later life. On the other hand, critique is expressed against cultural perceptions of later life that implicitly express the message that in order to age "successfully", one should aim to stay young and avert decline as long as possible. This critique focuses, for instance, on the way aging people are falling prey to an anti-aging industry promising eternal youth, and points out that this strategy is ultimately self-effacing. It also targets the ideology that exalts the freedom and opportunities of the Third Age at the expense of the misery and dependency associated with the Fourth Age, which excludes Fourth Agers from what is perceived as "good" or "successful" aging (\$2.4.3) (Katz, 2005, 2010; Gilleard \& Higgs, 2005, 2011; Gullette, 2011; Twigg, 2004). In the context of this study, I have used these two broad strands of critique against existing cultural meanings about later life to reconstruct two categories of cultural master narratives about aging, which I propose to call decline narratives and age-defying narratives (Laceulle \& Baars, 2014). These will be further discussed in the next two sections. 


\subsubsection{Decline narratives}

Decline narratives equate the aging process with an inevitable and steady decay. They draw on the assumption that aging represents a biological process of inescapable deterioration. We gradually lose our physical and mental strengths and capacities. We have less purpose to strive for in our lives. We are confronted with loss and vulnerability. Eventually, we approach death. But the expected decline extends beyond the biological realm, since decline narratives often also presuppose a decrease in social relations and an increase in loneliness and dependency, as well as a self-evident loss of social roles. The classic gerontological disengagement theory (Cumming \& Henry, 1961) is based on such line of thinking, as it argues that it is "natural" and fitting for aging individuals to withdraw from society and gradually accept their decline when nearing death.

Cruikshank (2003) defines five different ways in which aging is socio-culturally presented nowadays. These provide a perfect illustration of the effects of decline narratives on contemporary aging discourse. In the first place, aging is heavily medicalized. Second, forceful stereotypes associated with decline influence the way the process of aging is conceived as well as experienced. Third, aging is broadly perceived as frightening and deterrent, both for individuals and for society at large. Fourth, aging is culturally perceived as genderless and sexless, as well as, fifth, regarded to be unrelated to class or ethnicity. Aging is, in other words, conceived culturally and socially as a "great leveler", erasing or making redundant all individual characteristics previously meaningful during the life course.

The socio-cultural constitution of later life that is typical for decline narratives thereby tends to reduce the identity resources of aging individuals to a limited amount of pitiable images and roles of sickness and dependency. Consequently, decline narratives fail to acknowledge the individual diversity of the aging population. As a result, they are unable to provide social recognition to people's aspirations of self-realization (Honneth's third category, see \3.2.3) needed to facilitate moral agency, because acknowledging individual diversity is a precondition for this type of recognition.

Importantly, decline narratives typically reinforce deep festering fears and anxieties about losing control over one's life that is often perceived as one of the typical characteristics of late modernity (Giddens, 1991; Bauman, 2001). The fact that the probability of being confronted with existential vulnerability increases with age seems to make aging an especially disturbing phenomenon for modern individuals socio-culturally "programmed" to strive for autonomous control over their lives.

The socio-cultural perception of what it means to fall victim to Alzheimer's disease or other forms of cognitive deterioration offers a good illustration. Alzheimer's disease seems to be the embodiment of everything late modern people 
fear about aging: loss of independence, autonomy, self-determination, control, and ultimately one's self. It is often presented as the ultimate counterexample if one dares to assume that later life can also be a period with potential for growth and flourishing, as I have experienced in several discussions about my work on aging and self-realization (see also $₫ 9.4 .6$ ). To avoid misunderstanding, there is no doubt in my mind that Alzheimer's represents a horrible disease, which often terrifies its sufferers in the way it disorients them and seizes the elements that were once constitutive of who they were. Being diagnosed with Alzheimer's disease is, bluntly put, an existential tragedy for the people concerned (both sufferers and their loved ones). However, experiential reports from Alzheimer's disease sufferers and the people working with them suggest that there are still possibilities for experiencing meaning in life, if one is willing to see them (see for instance, Kitwood, 1997; Sabat, 2001; Bruens, 2013). Sadly, these differentiating remarks hardly enter the common cultural perception of this disease, which remains one of massive misery and utter anxiety.

This perception of Alzheimer's, which can be seen as an example of a decline narrative, tends to reduce the person to the disease. Importantly, this reduction hinders the realization of the social recognition needed to advance people's moral agency. This happens, for instance, when the fact that people still have legitimate personal aspirations regarding their own future, and the potential to engage in certain valued social roles, is overlooked in view of the

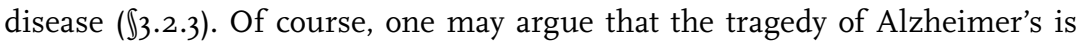
precisely that the disease destroys the person, leaving ultimately nothing but an empty shell. Although this may be true for the most advanced stages of the disease, it is often preceded by a gradual process of deterioration which, depending of course on how the condition develops, may still provide ample chances for self-realization and moral agency. It is my contention that under the influence of the anxious and grim image raised by decline narratives, sufferers of Alzheimer's (or any other feared condition associated with old age) are prematurely denied access to several cultural resources that could help them and their surrounding uphold a meaningful identity, including participation in valued social roles. By contrast, a viable counter narrative that contests the assumptions underlying decline narratives may be able to provide victims of Alzheimer's with a socio-cultural positioning that grants them more opportunities for moral agency for a longer time. This would require, at the minimum, showing that decline is not the only reality of later life in such cases, and that even suffering from a condition like Alzheimer's disease does not (or at least not for a long time) close off opportunities to lead a good life with and for others, according to one's own aspirations and capacities, participating meaningfully in one's society or community - in other words, moral agency as defined in this study.

To conclude, the most disturbing characteristic of decline narratives is perhaps that they reduce the diversity and potential richness of older people's 
life experiences to a saddening story of inevitable decay. Moreover, they rub it in that there is ultimately nothing we can do about our own decline. Decline is presented as an unfortunate fact of life that one should passively undergo, when the time comes. Before that time however, people are "advised" by contemporary cultural aging discourse to avoid decline as long as possible. This results in the other category of cultural master narratives I distinguish, termed age-defying narratives.

\subsubsection{Age-defying narratives}

Age-defying narratives oppose the exclusively negative associations connected with aging in decline narratives. Instead, they emphasize opportunities for prolonged vitality, social activity and resilience. It is typical of age-defying narratives that aging well is implicitly equated to staying young, or warding off the negative consequences associated with aging as long as possible. As Andrews (2012) puts it, "increasingly in western society, the old, and being old, have been identified by what they are not: young" (p. 388). Note that this position leaves the strong association that decline narratives assume between aging and decline intact.

Broadly speaking, the category of age-defying narratives can be divided into three sub-categories. All share in common the rejection of a "deficit perspective" on aging (as exemplified in decline narratives), and instead plead in favor of what Tornstam called a "resource perspective" focusing on the positive potentials of later life (Tornstam, 2005). However, their interpretation of what it means to "age well" differs.

1. The first subcategory focuses strongly on resisting decline, by emphasizing the importance of remaining active and productive, and taking all sorts of measures to ensure continuing health. This approach is exemplified in gerontological approaches advancing "successful", "healthy" or "active" aging (Havighurst, 1961; Rowe \& Kahn, 1987, 1997, 1998; Schulz \& Heckhausen, 1996; Ryff \& Singer, 2009; Knipscheer, 2010). These approaches lay a heavy emphasis on functional and health concerns (Depp \& Jeste, 2006). Rowe and Kahn intended their concept of successful aging to allow for more differentiation within the group of "normal", that is, healthy older individuals. They measured "success" in aging through three interrelated factors: the absence of disease, the maintenance of a high level of cognitive and physical functional capacities and the active (social) engagement with life (Rowe $\&$ Kahn, 1998). The scientific concept of successful aging also translates into more popular aging discourses. In a provocative article in The Atlantic published in October 2014, Ezekiel Emanuel described the activities a successful aging strategy may result in as follows: "Americans seem to be 
obsessed with exercising, doing mental puzzles, consuming various juice and protein concoctions, sticking to strict diets, and popping vitamins and supplements, all in a valiant effort to cheat death and prolong life as long as possible. This has become so pervasive that it now defines a cultural type: what I call the American immortal" (Emanuel 2014).

2. The second subcategory of age-defying narratives is more concentrated on successful adaptation to aging processes. These approaches focus on the importance of compensating for age-related losses. This can be achieved by maximizing one's remaining strengths and making optimal use of them, and minimizing the potential harms that can be caused by inevitable age-related losses. Examples include Baltes' Selection-Optimization-Compensation model (Baltes, 1997; Baltes \& Baltes, 1990; Freund \& Baltes, 1998) and the socio-emotional selectivity theory by Carstensen and colleagues (Carstensen et al., 2006; Carstensen, Isaacowitz \& Charles 1999). The bottom line of these psychological perspectives purports the idea that people maintain a sense of well-being and a positive self-concept despite loss and decline. In order to do this, people need to develop adaptive strategies, such as adjustment of aspirations and goals to fit new situations characterized by diminished levels of competency and mastery (Labouvie-Vief, 2009). For example, an inevitable loss of speed and physical strength in older workers can be compensated by the fact that accumulated years of experience have taught people to use their powers more effectively than younger workers. Other examples of adaptive age-defying strategies include programs of fall prevention in order to avoid physical dependency or memory training in order to delay cognitive deterioration.

3. The third subcategory of age-defying narratives focuses on the opportunities that later life - and in particular the Third Age - have to offer for self-fulfillment through leisure, consumption and education. Examples of this can be found in the abundance of cultural expectations that are communicated through advertisements of anti-aging products, senior travel, and retirement leisure options. All of these suggest that the prevailing associations between aging and decline do not have to be accepted as an unfortunate truth of life, but can - with the help of right products, of course - be reverted. This category of narratives tends to lead to so-called "commodification": older people are perceived primarily in their role as consumers, being subjected to pervasive temptation strategies of the anti-aging market. This market offers an endless variety of products and services aimed at warding off old age as long as possible. The main valued social roles left for aging individuals in these cultures are related to leisure and consumption (Gilleard \& Higgs, 2000, 2005; Katz, 2005). 
It could be said that generally, age-defying narratives are to be preferred over decline narratives, given their objection to the monolithic identification of later life with negative images of loss, decline and misery. Age-defying narratives have certainly helped to challenge ageist assumptions based on decline narratives. They have extended the horizon of what is deemed possible in later life to include opportunities that would have been unthinkable in earlier times. In contrast to decline narratives, age-defying narratives explicitly present later life as a period with many chances for living a rich, satisfying, flourishing life. In this regard, age-defying narratives can be perceived to offer much better opportunities to enhance the moral agency of aging individuals and enlarge their cultural repertoire of meaning and identity resources.

Nevertheless, there remain some fundamental problems attached to age-defying narratives that nuance this optimistic analysis and call for other alternatives. As Katz (2005) argues, "anti-ageism is not without problems of its own [...] the positive, political energies of the grey movement are dispersed and redeployed in the service of a commercial spirit of a senior's market culture" (p. 16-17). In their concern with the economic capitalist and consumerist issues connected to a growing elderly population (Biggs, 2001), age-defying narratives lack a genuine focus on the enhancement of people's moral agency that should characterize successful counter narratives. Or at least, they reserve it for a healthy and wealthy minority.

Age-defying narratives seem to replace the stereotype of the deplorable sick and dependent creature characteristic of decline narratives, with another, more positive stereotype: the healthy, active, productive, and self-fulfilling senior consumer. But as a stereotype, this image seems equally insensitive to differences within the aging population, and it can be equally oppressive. Moreover, age-defying narratives seem to transfer value frameworks belonging to youth and adulthood to old age, neglecting the possibility that later life may also have a value of its own (Cole, 1992; Atchley, 2009; Tornstam, 2005; Laceulle, 2013; Rentsch et al., 2013). Thus, although age-defying narratives set out to fight ageism and secure valued social roles for the elderly, they in fact celebrate a rather limited view of success and value in later life, that many older people are unable to live up to (Chapman, 2005; Holstein, 2011).

\subsubsection{Limitations of existing cultural narratives on aging}

Let me now briefly analyze some problematic implications that arise from the sketch of existing cultural master narratives about later life. This analysis will lead to a set of conditions that viable cultural counter narratives about aging should answer to. 
1. The equation of aging with decline - explicit in decline narratives and implicit in age-defying narratives - is so pervasive that it obscures other possible characteristics of later life. This effect is described by Gullette (1997) as the "default" position of decline narratives: "Culturally, default standing means that the subject feels an internal pressure to speak in decline terms, even when resistant experience or theory intervenes. [...] Alternative narrative doesn't feel as real” (p. 173-174). The association of decline with aging is so deeply entrenched in our cultural meaning system that we no longer tend to question it. As a result, profound tensions may arise between the meanings of aging that cultural narratives communicate and one's private experience. The influence of cultural narratives can even be so strong that our individual experiences lose their authority for us (Lindemann Nelson, 2001).

2. The stereotyping force of decline and age-defying narratives ignores the diversity existing among individuals within the aging population. Blaikie (1999) argues, "as each individual ages so the stock of their differentness from the next person increases - the older the cohort, the greater is the degree of diversity and individuality to be expected" (p. 7). By neglecting this fact, aging people's widely varying aspirations and capacities are also overlooked. This hinders the full realization of their potential for moral agency and precludes Honneth's third form of social recognition (1995; see $\$ 3.2 .3$ ). From the viewpoint of self-realization, acknowledging the unique potentials of this specific individual person for flourishing, creativity and resilience is of course crucial. It seems, however, that neither decline- nor age-defying narratives are able to accommodate this insight in a satisfactory way.

3. The implicit message that aging well is equal to staying young represents a severe impoverishment of cultural meaning resources. It suggests that later life has no value of its own, because apparently, whatever meaning can be given to later life has to be borrowed from youth-related frameworks. Again, in terms of Lindemann Nelson's (2001) theory, this poses a limitation on the moral agency of aging individuals, because it inhibits them from perceiving later life as a possibly attractive phase which harbors potentially valuable and enriching experiences and goals to strive for. To provide an example: the poetry volume Body bereft by Krog (2006) describing the subtle delights of an aging couple's sexuality raised protest in her country South Africa, because it was considered appalling and repulsive, not fitting the expectations one had of older women. Apparently, the culture was not ready to acknowledge deviations from the norms of youth. Consequently, the potential for meaning and identification such poetry could communicate to older people - a hopeful and beautiful message indeed - is blocked by the cultural prejudice that all good is to come from youthfulness, even in later life. 
4. Age-defying narratives stimulate and promote active and healthy lifestyles as an individual task and responsibility. In the process, however, these narratives paradoxically saddle older individuals with social stigmatization once they prove unable to live up to the corresponding standards and fall prey to frailty and dependency (Katz, 2005). As a result, the share of the aging population that is in fact experiencing frailty are further stigmatized as pitiable "losers". The irony is, of course, that given the biological reality of senescing processes, we will all fall into this category ultimately, which seems to prove that decline narratives are right after all. This makes the age-defying cultural narratives that dominate an important portion of the aging discourse in late modern societies eventually self-effacing.

5. Both decline- and age-defying cultural narratives are empirically flawed, because they disregard the fact that in reality, even people suffering age-related losses often manage to lead meaningful, flourishing, creative and inspiring lives (Ryff et al., 2012). Holstein, Parks and Waymack (2011) aptly formulate this problem when they state: "The anti-aging movement gains what momentum it has by means of denigrating the lives of our elderly as they in fact live. This, we think, rather than senescence and eventual death, is the real tragedy. We prefer to think that there can be, and indeed are, virtues that are possible in and appropriate to being elderly. If we lose sight of those virtues, we will all be less well off." (p. 100). The empirical inadequacy of existing cultural narratives is also illustrated by the "positivity effect" (Carstensen \& Mikels, 2005). This paradox expresses the fact that older people tend to have a functional bias towards positive experiences. This results in a discrepancy between what people subjectively perceive as satisfying and successful old age and the scientific criteria for successful aging. The strong emphasis that science places on health, productivity and independent functioning, for instance, proves to be less important to people than meaningful social relationships (Torres, 2006; Reichstadt et al., 2007, 2010; Phelan et al., 2004; Knight \& Ricciardelli, 2003)

6. Neither decline narratives nor age-defying narratives provide satisfactory resources for people to integrate existential vulnerability into their lives in a meaningful way. By integration, I mean the inclusion of an experience of adversity in one's life story in such a way that its reality is not disavowed, but neither does the situation lead to a permanent loss of vital involvement in life. Integration could be seen as the outcome of a process of grief over what is lost that restores one's sense of coherence in life. Whereas decline narratives generally encounter existential vulnerability with a strategy of passive surrender, age-defying narratives only have strategies of rejection to offer. Both strategies seem hardly satisfactory in this regard. Further, since existing narratives seem to offer no guidance towards a possible middle road between these strategies, people experiencing instances of existential 
vulnerability are poorly facilitated when they seek access to cultural meaning resources to enhance their ability to lead a good life (i.e. moral agency) in the face of the tragic dimension of existence (Nussbaum, 2001).

It can thus be concluded that both decline- and age-defying cultural narratives about later life ultimately fall short in providing satisfactory resources of identity to aging individuals. They function as stereotyping and restrictive models of aging which block our view of the value of its own that later life could have. Also, they neglect diversity and hinder access to valued social roles that could help aging people advance and express their potential for moral agency. This calls for the development of viable counter narratives about later life that are able to enhance aging individuals' moral agency and provide access to a richer array of cultural resources of identity and meaning. From the analyses so far the following desired features for such counter narratives can be deduced:

- They should resist the association of aging with decline and aging well with staying young that is characteristic of the discussed cultural master narratives

- They should offer a viable alternative that is able to:

- Acknowledge that later life can be a period with a value of its own, offering potential for growth and flourishing

- Acknowledge that later life is also a period in which one is ever more radically confronted with the existential vulnerability of the human condition

- Provide resources to meaningfully integrate this existential vulnerability into the narratives constituting one's identity, so that coherence is restored and vital involvement with life remains possible

\subsection{Conclusion: In Search of viable COUnter narratives ABOUT AGING}

In this final part of the chapter, I propose a tentative outline for an alternative category of cultural narratives about later life. These alternative narratives aim to meet the conditions defined in the previous section: acknowledging the value of later life and its potential for flourishing as well as its reality of existential vulnerability, and providing resources for the integration of the latter. My proposal will draw on ideas associated with the philosophical discourse on self-realization (Laceulle \& Baars, 2014; see further chapter 4). It thereby advances toward the intended formulation of a reframed discourse of self-realization that forms the theme of the coming chapters. Making a plausible case for a cultural counter narrative about later life drawing its resources from the self-realization 
discourse, will hopefully strengthen this study's overall argument that the ideal of self-realization can be fruitfully applied to the context of aging, as long as some crucial shortcomings of the late modern interpretation are remedied (see \2.5).

The term "narratives of becoming" that I choose to describe these alternative narratives serves as a prelude to the idea of self-realization as a process of moral self-development, or becoming who you are (see $\$ 4.2$ ). This terminology also conveniently underscores the continuing search for an equilibrium between engaging in activities purposively furthering our growth and flourishing on the one hand, while on the other hand, acknowledging the contingencies of life expressed in terms of existential vulnerability, which confronts us with the limitations of our purposive influence and control. Alternatively, Gullette (2011) proposes the term "progress narratives" in order to challenge the decline narratives that are so detrimental for an enriching and meaningful experience of later life. However, the notion of progress harbors an association with linear ascent that can misguidedly present old age as the ultimate culmination of development throughout the life course. Gullette does recognize part of this risk herself, when she states that, "Positive aging should not impose progress narrative on people, forcing them to deny their sorrows and the external facts that weigh on them. But neither should dominant culture impose decline narrative as the only possible truth" (p. 165). Katz (2005) expresses the same concern when he warns about a "tyrannical" positive aging culture. Apart from its congeniality to the self-realization discourse, this serves as an additional reason to prefer the term narratives of becoming over progress narratives in this study.

Broadly speaking, narratives of becoming suggest the following image of later life: on the one hand, they express how later life offers ample opportunities for self-realization, for instance, in the sense of growing in self-knowledge, improving our relationships with others, or acquiring virtues previously underdeveloped in one's life; on the other hand, they suggest that aging well means that we are able and willing to encounter the limitations we confront in our lives in a certain way. Instead of denying or rejecting our vulnerabilities, narratives of becoming suggest that we would do well to face them with an attitude characterized by realism and practical wisdom. This should not only enable us to see what we can do to improve the situation, but also what lies beyond our control and must be gracefully accepted.

Before proceeding to discuss the advantages that narratives of becoming may have to offer, let me begin with two concrete examples of what the associated image of aging well could look like in people's lives. The first example introduces an older woman I once met. On becoming a grandmother, she was delighted and aspired to engage in activities with her grandchildren that had been very important in her own life, such as supporting them in sports. But due to severe physical ailments, she was no longer able to do this. At first, this 
was a great disappointment to her, because she had always dreamt of being a vital, active grandparent and senior. The confrontation with her own physical fragility precluded this aspiration. However, by transforming her limitations in this regard into an attitude of quiet presence, she was able to provide her grandchildren with a peaceful and stable haven of calmness. This turned out to be most welcome to them, especially when it could not be provided by their busy parents. This realization made her aware of how her "activist" manner of raising her own children in the past had led her to neglect other equally important dimensions of being a good parent. She was able to speak about this with her daughter and it deepened and enriched their relationship. In the end, she told me that taking care of her grandchildren had taught her many things about her qualities and limitations as a mother in retrospect. It had deepened her self-insight and transformed her image of who she wanted to be.

The second example presents a man in his mid-seventies who had become a widower three years earlier. In a conversation, he admitted to me that this new social status had initially confronted him with some inconvenient truths about himself and his relationship with his late wife. He discovered how he had always taken for granted that she was the one maintaining their social contacts as a couple. After her death, it became clear to him that his character was still lacking in the qualities needed to nourish friendships. Because his wife had always been the one investing true attention in others, many of their mutual friends disappeared from his life after her demise. Being confronted with loneliness, at first he fell prey to self-pity and anger at the people who he felt had abandoned him. Gradually, however, he came to realize that the loss of his wife, however painful, offered him the opportunity to start working on acquiring the virtues of friendship that he had neglected in his life so far. So, by acknowledging his own limitations and the fragility of his social network, this man eventually gained self-knowledge and opened up new roads for moral self-development for himself.

What do these stories have to tell us about narratives of becoming? Which characteristics can be deduced from them?

- First, the term becoming suggests a continuous developmental process that encompasses the entire duration of the life course. The goal of development is to optimize one's ability to lead a good life with and for others (i.e., moral

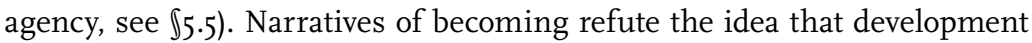
and growth is something reserved for youth and adolescence, and not for adulthood and old age. This also contributes to the rebuttal of equating aging well with staying young. In this sense, narratives of becoming express the idea that later life can also be a period of growth and even flourishing, that I have mentioned as one of the criteria for a viable cultural counter narrative for later life. From a self-realization perspective, the acknowledg- 
ment of growth potential is of course an essential aspect. It is not difficult to imagine how the absence of this has a negative impact on the possibilities to ascribe meaning to later life. Cruikshank (2003) has observed that in contemporary aging discourse, "Old women and men are seen in a utilitarian light of cost rather than potential. Who they can become is an unasked question" (p. 7; emphasis added). This further underscores the relevance of paying attention to the notion of becoming through the counter narrative suggested in this study.

- Second, the notion of becoming also expresses the dynamic character of moral self-development. Though it is important for identity to reach a certain degree of continuity $(\mathbb{\$} 4.2 .2)$, there is no stable and unchanging status quo position. Who one is remains constantly open to revision. The direction this revision will take highly depends on the individual value orientation that we have acquired during our lives. It also depends on whether our surroundings have a stimulating or restrictive influence. In other words, one's self-realization continues for as long as one lives and is always subject to socio-cultural influences that can either impede or facilitate moral agency.

- Third, the striving for moral agency that is advanced by narratives of becoming represents both a purpose and a means at the same time. In line with Lindemann Nelson's (2001) theory, I contend that counter narratives should aim at repairing moral agency; thus moral agency is the purpose strived for, the end result of a successful counter narrative. On the other hand, it seems clear that challenging dominant cultural master narratives involves, indeed requires, a strong level of moral agency to be successful. Moral agen$c y$ is then perceived as the necessary means to repair damaged identities or enlarge the possibilities for meaningful identification. The paradox here is that apparently, moral agency (or the potential of it?) already has to be present in order to realize moral agency. The same paradox is echoed in the expression becoming who you are that we encounter later in the discussion of the philosophical discourse on self-realization (see $\$ 7.3 .2$ ). Apparently, you already are someone, but at the same time, you are summoned to become yourself. The ambivalence of this expression emphasizes that self-realization requires a life-long process of work and practice, in order to transform qualities that are potentially available in one's personal outlook into lasting, durable attitudes, expressing vital characteristics of one's self.

- Fourth, narratives of becoming also advocate realism. They acknowledge that this developmental process need not always be easy, or proceed in the desired direction. While the term narratives of becoming does wish to emphasize the often neglected potentialities for growth that can feature in later life, it does not quite defend a teleological culmination hypothesis that assumes a linear ascent towards an ever more fulfilled and complete life. After all, this would present a one-sided optimism negating the ex- 
istential realities of vulnerability and loss that resembles the perspective of age-defying narratives. Instead, these realities need to be acknowledged and integrated if narratives of becoming are to supply a convincing meaning-generating view of aging.

- Fifth, through their dynamic and realistic character, narratives of becoming are able to answer the second criterion for a viable counter narrative about later life: offering guidance for the meaningful integration of existential vulnerability. These narratives acknowledge that our striving towards a good life always includes the possibility of failure; in reaching our goals, fulfilling our aspirations, becoming who we wish to be. We may frustrate our own purposes by succumbing to our weaknesses or following the wrong passions, but our self-realization can also be stymied by bad life circumstances beyond our control, from illness or accident to malignant socio-cultural positioning. By acknowledging the fact that our striving for a good life is inherently vulnerable, narratives of becoming emphasize how difficult it can be to navigate our social and cultural world in our aspiration for self-realization. However, by also acknowledging the moral importance of striving to become who we are, narratives of becoming escape the objection of falling prey to either passive surrender or active rejection of existential vulnerability. This was the critique made against decline- and age-defying narratives. The emphasis of narratives of becoming lies instead on developing an optimal attitude to whatever we may encounter in life and use these experiences in the service of a continuing process of moral self-development.

On what grounds should narratives of becoming be preferred over decline narratives and even the more positively oriented age-defying narratives? It is important to realize that this question touches upon a fundamental overarching problem confronting any philosophical argument that takes a normative stand. Who are we philosophers to prescribe to others how to live? Who are we to decide that an image that equates aging well with staying young is not as satisfactory, and even harmful, compared to an image proposing aging well as an ongoing and deepening process of becoming, of moral self-development? This issue, which also haunts the discourse of self-realization in general (see $\llbracket 9.4 .5$ ), is highly complex and may never find a fully satisfactory answer. Here, I restrict myself to the commentary that I believe we can safely say that any human being is basically trying to live a good life. Granted, this observation still offers room for many and possible contradictory interpretations of what this "good" life is, and does not provide criteria for an objectively justified choice between such interpretations. However, my definition of moral agency as the ability to lead a good life does suggest that cultural narratives that help to enhance people's moral agency should be preferred over cultural narratives that tend to restrict it. 
This accords with Lindemann Nelson's (2001) analysis about counter narratives and their role in strengthening moral agency (see $\$ 3.2 .3$ ).

Following this line of argument, it is important to realize that both decline narratives and age-defying narratives present us with problems when it comes to developing an age identity that is satisfactorily rich to infuse one's experience of aging with meaning and value. This can be detrimental to people's chances to develop and maintain their moral agency. By focusing on the importance of moral self-development, narratives of becoming aim to provide an alternative that does offer aging individuals the chance to acquire a sense of moral identity and the corresponding qualities of moral agency that will enable them to lead a good life (see $\sqrt{ } 5 \cdot 5$ ). Hereby, narratives of becoming present a distinct advantage over the other categories of cultural narratives that have been discussed.

In short, narratives of becoming express the moral importance of a lifelong process of working on ourselves in order to actualize our best potentialities. The developed qualities help us to function as moral agents. Importantly, this includes confronting existential vulnerability in a way that does not compromise our vital involvement with life. The term vital involvement is inspired by the classic study of Erikson, Erikson and Kivnick (1986) that illustrates the resilience of older people beautifully. Cruikshank (2003) aptly summarizes the attractive perspective this offers: "Learning to be old may be the last emotional and spiritual challenge we can agree to take on. While aging is shrouded in denial or shame, it will be seen simply as defeat. [...] The promise of other ways to age is exhilarating, though, if we can imagine late life as the time when we are most fully ourselves" (p. 7). Eventually, it can be said that narratives of becoming perceive aging well in terms of acquiring the kind of practical wisdom that is expressed in the well-known creed: the courage to change what you can change, the strength to endure what you cannot change, and the wisdom to know the difference. The idea that later life can be dedicated to acquiring this attitude, I argue, presents a welcome addition to current cultural narratives about later life, and offers potential resources to generate the resisting force that should characterize a true counter narrative. 



\section{Chapter 4 - Self-realization}

\subsection{INTRODUCTION}

In the two previous chapters, two broad claims have been made: 1) that a reframed interpretation of self-realization, provided it is able to remedy some of the problems attached to the late modern interpretation, remains a valuable moral ideal, also for aging individuals; and 2) that such a reframed discourse of self-realization could offer a fruitful resource for the development of a new category of cultural narratives about later life, namely, narratives of becoming, that can counter the adverse effects of existing dominant decline- and age-defying narratives.

In chapters 4-8 the outlines of such a reframed view of self-realization are sketched. The intention is, first of all, to make a plausible case for a view of self-realization that acknowledges the social embedding and constitution of human beings that is disregarded by the late modern self-realization discourse. Moreover, I explore whether the philosophical tradition of self-realization also enables coming up with an account that can relate to the reality of existential vulnerability in a more satisfactory way. It follows from the previous argument that both these issues are quintessential for the creation of an account

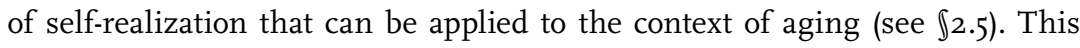
chapter makes a start with this endeavor. In $\$ 4.2$, the following questions are addressed. First, what can be understood by self-realization in the suggested interpretation $(\$ 4.2 .1)$ ? Second, who is the self that is involved in self-realization $(\$ 4.2 .2)$ ? Third, how does the process of self-realization take shape in practice $(\$ 4.2 .3)$ ? And fourth, when is self-realization manifested in people's lives $(\mathbb{4} 4.2 .4)$ ? From my discussion of these questions, self-realization arises as a process of moral self-development aimed at the realization of one's potential for moral agency, which necessitates identification with a certain image of who we want to be, or rather become. This presupposes that we have an orientation toward what is valuable and worthy to us.

Conceptualizing self-realization as optimal moral self-development implies that it relies on an image of what is "best" in ourselves. How this concept of "best" can be understood is discussed in $\$ 4$.3. Probing the historical and phil- 
osophical background of thinking about self-realization makes us aware of the variety of ways in which the best in human beings has been conceptualized by different thinkers in the course of Western history. In \$4.3.1, I discuss a selection of these views from philosophical history. In $\$ 4.3 .2$, I argue that from this brief catalogue of different conceptualizations of the best to be realized as part of self-realization, three main threads arise that together weave the fabric of the self-realization discourse as it is conceptualized in this study: autonomy, authenticity and virtue. These themes deserve more attention than can be given to them in the context of this chapter, and are discussed in separate chapters (6, 7 and 8 respectively).

Having thus provided a starting point for the reframing of self-realization, the final part of this chapter $(\mathbb{4} 4.4)$ discusses two themes that merit special attention because they may raise doubt about the application of the self-realization discourse to the context of aging. $\$ 4.4 .1$ focuses on the possible tension between self-realization as a future-directed endeavor, founding a teleological ethics, and the fact that aging confronts one with a shrinking time horizon; the reality that one's past is longer than one's expected future, and that the end of one's life is approaching. $\$ 4.4 .2$ focuses on the possible tension between the endeavor to realize oneself and the reality of existential vulnerability, which is associated with the human condition in general, but is increasingly radically confronted while aging.

\subsection{INTRODUCING SELF-REALIZATION}

Imagine a gardener. She tends the piece of the earth that happens to be her habitat year after year with effortful dedication. Her ultimate aim is a garden blossoming with flowers or offering rich harvests of fruits and vegetables. This aspiration is not realized by itself however; the gardener striving for a flourishing garden needs to work hard and put in her best efforts: pruning branches threatening to outgrow the others, digging and weeding, watering, preventing her plants from burning in the sun, et cetera. The work is never finished, because even after a good season there is always the next one, with new crops and flowers that await fruition. Nor is the success of this garden entirely in the hands of the gardener herself. Infertile soil, a particularly rainy or dry season, insects or snails that ruin vulnerable seedlings; all threaten the ultimate flourishing of the garden, and need to be dealt with by the gardener. Sometimes, some fertilizer or extra watering helps, but at other times, setbacks just have to be endured hoping for a better season next year.

This gardener, working to realize a flourishing garden, presents a metaphor to illustrate the purpose and process of self-realization. Generally speaking, self-realization pertains to the ideal that people should make the best of them- 
selves, i.e., strive for optimal flourishing by continuously aiming to become who they are. The individual agent works on herself to realize her potential for flourishing, just like the gardener cultivates the garden. The purpose, simply put, is to live the best possible life that one's talents and circumstances allow for. Ethical perspectives based on self-realization are therefore concerned with the fundamental question in moral philosophy: how to live well (V. Gerhardt 1999). The focus on this basic ethical question, combined with the engagement with realizing the best in ourselves leads me to the contention that self-realization is most fruitfully understood as a process of moral self-development, exemplified in the expression becoming who you are (see $\mathbb{7} 7 \cdot 3.2$ ).

Self-realization describes both an ideal state and the developmental process necessary to reach this state. Following a definition by Gewirth (1998), self-realization (or self-fulfillment, in his terminology) consists in "carrying to fruition one's deepest desires or one's worthiest capacities. It is a bringing of oneself to flourishing completion, an unfolding of what is strongest or best in oneself, so that it represents the successful culmination of one's aspirations or potentialities" (p. 3). Gewirth thus presents self-realization as a maximizing conception, aimed at superlatively formulated goals, representing the best, deepest, worthiest, et cetera, that people are able to accomplish.

Self-realization provides the basis for a so-called teleological conception of ethics, where human beings are perceived as striving towards a telos, or ultimate purpose. Self-realization discourse generally also reserves a special status for the individual moral agent, though not necessarily in the late modern atomistic, de-contextualized interpretation. The optimal fulfillment of the agent's potential is seen as conditional for a good life. The corresponding strand of thinking in moral philosophy has been interpreted as ethical individualism or eudaimonism (Norton, 1979). The emphasis on the good life as consisting in the optimal development and fulfillment of individual abilities for flourishing (eudaimonia) further underscores my claim that self-realization is best understood as a process of moral self-development.

Although what counts as a good life for us is deeply intertwined with the good of others, it remains important to realize that what principally underlies self-realization is the good of this unique individual. As Feinberg (1992) stresses, "My good is something peculiarly mine [...] Anything else that is good for me [...] is good because it contributes to my good, the fulfilments of my strongest stable tendencies [...] it is logically irrelevant to the question of what my good is whether my good is itself 'good' when judged from an external position." (p. 325). Thus, the good that is the purpose strived for in self-realization need not necessarily correspond to any universal conception of good.

At the same time, most philosophers writing about self-realization agree that actions and purposes that violate common "objective" standards of morality, such as the Golden Rule, are excluded as valid goals of self-fulfillment (Fein- 
berg, 1992). Also, as C. Taylor (1989) stresses, the good cannot be an individual creation, because we define what is good for us by positioning ourselves in relation to an individual-transcending moral horizon of culturally and historically developed conceptions of good. Which of these conceptions of good we choose to identify as ours, and how we respond to concrete situations however, remains an individual endeavor. As V. Gerhardt (1999) underscores, "Ich, dieses konkrete Ich, als das ich mich selbst erfahre, muss meine eigenen Gedanken zu meinen eigenen Problemen und Zwecken denken [I, this concrete I, as which I experience myself, have to formulate my own thoughts about my own problems and goals]" (p. 33, translation $\mathrm{HL}$ )

As stated before, this study aims to draw on the rich and complex philosophical discourse on self-realization to suggest an alternative to the late modern interpretation of self-realization. This act of reframing self-realization and its constitutive concepts should be able to remedy the problems that arise when applying the self-realization discourse to the context of aging (see $\$ 2.5 .1$ ). I will introduce this study's interpretation by considering four questions: 1) What is strived for and (ideally) realized in self-realization? 2) Who is striving to realize it? 3) How is it realized?, and 4) When is self-realization manifested in people's lives? These questions respectively address the purpose of self-realization

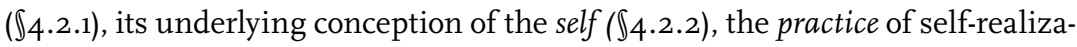
tion $(\mathbb{4} 4 \cdot 2 \cdot 3)$, and the timing of self-realization $(\mathbb{4} 4 \cdot 2 \cdot 4)$.

\subsubsection{The purpose of self-realization}

What is the purpose strived for in self-realization? The most obvious and simple answer is probably: realization of the self. But what might this mean? Given the fact that I have defined self-realization as a process of moral self-development, the purpose of self-realization can be broadly defined in terms of the optimal fulfillment of one's potential for moral agency. Moral agency is understood in this study as the practical expression of one's moral identity or self, and defined as the ability to lead a good life, with and for others, according to one's highest aspirations and best capacities, as full participating members of a society/community (see $₫ 5.5$ for further elaboration).

In the gardening metaphor, the purpose is a flourishing, blooming garden, yielding rich harvests of fruits, flowers and vegetables. But the purpose also includes the optimal development of the gardener herself as a gardener. In any case, the purpose represents an ideal picture, situated in the future. Its realization is hoped and strived for, and the gardener can stimulate it by putting her best efforts into it; but success can by no means be guaranteed. Analogously, in self-realization we strive to create an ideal self, the best or at least a better version of ourselves that we aspire to become in the future and bring to expression in our choices and actions. We may have dreams we identify with or aspirations 
to become a certain person, for example, a good teacher, a successful manager, a trustworthy friend, or a mentor others turn to for advice. Alternatively, our circumstances may prompt us to develop certain qualities in ourselves that were previously missing or underdeveloped, for instance, when we are confronted with a sick relative who needs our caring capacities, or when a situation of injustice requires the courage to stand up for our rights or those of others. Here too, we give the development of ourselves in the desired direction our best efforts, but success is not guaranteed and can be stymied by various factors. Within my presentation of the purpose of self-realization as the actualization of our potential for moral agency, it is clarifying to specify two different modes of self-realization, described as aspiration fulfillment and capacity fulfillment (Gewirth, 1998).

- Aspiration fulfillment pertains to the realization of one's deepest desires. Self-realization as aspiration fulfillment does not refer to any arbitrary desire, however. Instead, it is focused on our deepest aspirations, which relate to our desire to be a certain kind of person. This implies that it goes beyond having superficial pleasurable feelings or experiences. It pertains to what people consider as the most valuable among their desires, worthy of guiding their choices and actions. For instance, if it is my deep aspiration to be a good friend, my desire to be there for a friend in need when she calls should overrule my desire to sit on the couch and watch TV, or I will stymie my striving for self-realization.

It is crucial for aspiration fulfillment that one identifies with a certain image of who one wants to be, which then guides the choice of goals to strive for in self-realization - who one wants to become. Such identification presupposes the ability to make what C. Taylor has called "qualitative contrasts" and "strong evaluations" (C. Taylor, 1985a, 1989). With these terms, C. Taylor describes a process of ordering one's desires along the lines of their value, their representation of a certain higher good worthy to strive for. A similar thought is defended in V. Gerhardt's (1999) account of self-realization, which states that the ability to formulate "Grunde [grounds]", i.e. motives for action that are constitutive of one's identity, is crucial in self-realization. Consequently, in C. Taylor's and V. Gerhardt's accounts aspirations associated with a higher ideal of the self - for instance being a courageous or a caring person - are perceived as higher or more worthy than other aspirations or motivations that lack this identity-constituting value, such as making a lot of money or going on vacation.

Importantly, developing the aspirations to become a certain kind of person presupposes that we have access to cultural identity resources that we can identify with, such as inspiring stories, images and exemplars (see $\mathbb{3}$ 3.2.1). Even though our aspirations are authentically our own, we cannot form 
them in isolation from our socio-cultural context. It is this context that both provides us with the standards for strong evaluation (C. Taylor, 1989) and gives (or denies!) us access to certain options to identify with (Lindemann Nelson, 2001; M. Walker, 2007). Since both our self and our socio-cultural context are in a constant process of transformation, our identity-constituting aspirations are neither static nor monistic. Different aspirations may conflict with each other, and priorities among aspirations constantly have to be reconsidered. From the viewpoint of aging, it is also important to note that aspirations may change or alternate during our lives, either because our priorities change or because our socio-cultural context precludes certain aspirations for certain age groups (see $₫ 4 \cdot 4 \cdot 1$ ).

- Capacity fulfillment pertains to realizing the best or highest of one's capacities, 'the best that it is in you to become' (Gewirth, 1998, p. 59). Capacities are inherent latent potentialities that a person possesses, but that require actualization in practical contexts. Importantly, the capacities relevant here are those that are activated by the choice of the self, which excludes powers that escape our conscious control, such as breathing. These capacities enable us to bring about change, both in ourselves and in the world outside ourselves. Examples of such capacities include the ability for reason, the ability to learn things, the ability for compassion, aesthetic sensitivity, intuition, and the ability to care for others.

Like aspirations, capacities too relate to the ideal selves we strive to become. However, whereas aspiration fulfillment may vary from person to person and among different cultural contexts, Gewirth (1998) claims that capacity fulfillment pertains to more "objective goods or values" (p. 15). He defends a universalist conception of morality, which assumes that the ultimate criterion for evaluating the moral value of goals and purposes lies in their contribution to people's generic freedom and well-being. In his view, these values are of fundamental importance to all human beings, regardless of their social and cultural background, gender, ethnicity, age, and so on. Thus, he states that "[...] with regard to capacity-fulfillment as achieving the best that it is in one to become, what is best here is whatever is found by reason to lead to or consist in the fullest development of freedom and well-being, within the limits set by the universalist morality of human rights" (Gewirth, 1998, p. 112). According to Gewirth, human reason is the quintessential capacity that helps people to distinguish aspirations, choices and actions along the lines of their contribution to freedom and well-being. Consequently, he perceives reason as the "best" capacity involved in self-realization as capacity fulfillment. He claims that capacity fulfillment ultimately forms a higher mode of self-realization than aspiration fulfillment, because successful aspiration fulfillment depends on the capacity for reason, in order to evaluate 
one's aspirations along the moral standard of their contribution to freedom and well-being.

This study conceives of self-realization in such a way that aspiration fulfillment and capacity fulfillment both present valid modes to interpret the purpose of self-realization. I tend to agree with Gewirth in his contention that capacity-fulfillment is more fundamental because the formulation of aspirations depends on the possession of certain capacities. However, I do not follow him in his preference for a universalist interpretation of self-realization ethics that elevates reason as the most important capacity for self-realization.

Apart from universalist views of morality, Gewirth (1998) distinguishes particularist views of morality, focusing on interpersonal relations of love, friendship, loyalty and connection, and personalist views of morality, focusing on the capacities for flourishing as an individual (p. 52-55). In my view, all three of these views of morality can principally defend equally viable accounts of best capacities and aspirations of relevance to self-realization. Gewirth is right, however, when he warns that goals and aspirations furthered by particularist and personalist approaches can sometimes be at odds with basic universal moral principles, for example, if particularist considerations lead to xenophobic practices. In those cases, I agree that universal principles should function as a "sieve" to exclude immoral actions and purposes from the realm of self-realization (this roughly corresponds to the view of ethics and morality formulated by Ricoeur (1992; see $\left.\int 5 \cdot 4\right)$ ).

What precisely is the content of the best or highest capacities or aspirations that constitute the purpose of self-realization has been conceptualized in many different ways in the history of Western philosophy. I will further elaborate on this in $\$ 4$.3.1. This study takes the position that the purpose of self-realization should be seen in terms of a complex fabric of three interweaving threads, namely, autonomy, authenticity, and virtue (see further $₫ 4$.3.2). Each thread represents a distinct tradition of moral-philosophical thinking with its own claim to ultimate validity. A viable interpretation of self-realization in the context of this study, I contend, should not force us to choose between these three threads or place them in a hierarchical order of importance, especially given the context of late modern moral pluralism in which it should be applied. Instead, I claim that a satisfactory interpretation of self-realization should be able to acknowledge the value and legitimacy of the purposes suggested by all three threads. A choice between their claims, if necessary, should depend on the characteristics of the specific situation asking for our moral response. The question what to do when one's demented mother, unhappily housed in a nursing home, keeps asking "when will you take me home?" probably calls for the intuitions of particularist morality and the virtue-ethical discourse, and universalist principles associated with considerations of autonomy-enhancement for 
instance are of little use here. But the opposite can be the case when it comes to the question how many refugees a city should provide with housing and care in a situation of crisis, despite resistance from its inhabitants.

We could argue, in fact, that certain connections can be drawn between the three forms of morality distinguished by Gewirth and the three threads that weave the self-realization discourse according to this study. A universalist view seems most closely associated with the discourse on autonomy (see chapter 6), which traditionally strongly relies on the rational capacities Gewirth also emphasizes in his view of capacity fulfillment. On the other hand, the personalist view can be connected to the authenticity discourse, which brings aspirations and capacities associated with personal development into high relief (see chapter 7). Lastly, the particularist view of morality can be argued to emphasize considerations that show affinity with what underlies the virtue-ethical discourse, particularly given the latter's emphasis on how virtue sees the good of the self as intrinsically interwoven with the good of the community. Ideally, both "goods" should be balanced in striving for self-realization (see chapter 8).

It is also interesting to note that the three forms of morality as discussed by Gewirth - universalist, personalist, particularist - with their corresponding understandings of the highest or best capacities of human beings, can be connected with the three forms of recognition defined by Honneth (1995; see \$3.2.3). Thus, love and connectedness in primary relationships (the first form of recognition) corresponds to the good underlying particularist morality. Respect for one's rights and equal treatment as citizens (the second form) corresponds to the good underlying universalist morality. Finally, the opportunities to realize one's individual goals and potentials (the third form) correspond to the good underlying personalist morality. Since I have concluded that all three forms of recognition are indispensable for exercising moral agency (see $\sqrt{3} \cdot 2.3$ ), the different perceptions of the best capacities connected with the three forms of morality should be treated as equally valid according to the argument of this study. They depend on each other and should be strived for in combination.

In conclusion to this section, it is important to mention that the description of the purpose of self-realization in terms of realizing the best in ourselves may easily raise the impression that it is a highly demanding goal. In a sense, this is true. After all, realizing a "good life" is a serious moral goal that requires ongoing efforts and enduring engagement and perseverance. On the other hand, it would be a misconception to assume that special qualities are needed to strive for self-realization, or that only a well-situated, highly-educated and reflexive minority qualifies to partake in the striving for self-realization. On the contrary, both Gewirth (1998) and V. Gerhardt (1999) stress emphatically that the desire to lead a good life and to transcend the given facts of our natural existence by striving for self-realization is an inclination deeply entrenched in the human condition. This assumes that self-realization is a process that everyone 
in possession of the minimal capacities associated with humanness can be engaged with. Thus, though a small minority - for instance, people lacking basic consciousness of themselves, such as when they are in a coma or the end-stage of dementia - may be excluded from self-realization on this account, it remains a moral striving that is principally within the reach of the majority of people (see also $₫ 9.4 .1$ ).

\subsubsection{The self in self-realization}

Any interpretation of self-realization explicitly or implicitly draws on a certain understanding of the self. In chapter 2, it was discussed how the late modern discourse of self-realization relies on a problematically atomistic anthropology, presenting the individual agent as an autonomous, independent and sovereign director of their own life. By contrast, I argued, this study's reframed interpretation requires a conception of the self that acknowledges its situated, socially constituted and interdependent nature (see \2.5.2). In chapter 5, I argue in favor of a narrative conceptualization of the self, which seems most congenial to the purposes of this study. As a forerunner to this argument, this section will sketch some primary and more general considerations regarding how the self is understood in this study.

The self that underlies self-realization is described by Gewirth (1998) as "a continuing or enduring embodied entity that is aware of itself as a distinct person, that can anticipate a future for itself, and that has desires on which it can reflect" (p. 13). Gewirth also states that the self represents "a locus of powers or capacities that are primed for growth or development toward an inherent end, which is the good of the self" (p. 8). The idea that the self is an embodied "locus" of capacities and/or experiences, to be found in the inner realm of a person, is strongly prevalent in the history of Western modern philosophy, as illustrated by C. Taylor (1989). For example, Descartes' conception of the "cogito" emphasizes our capacity for rationality as crucial to who we are; Locke associates the self with our episodic memory; and Hume perceives it as a bundle of experiences. Importantly however, G. Gerhardt (1989) warns against the essentialist conceptualization of the self often associated with such ideas about localization. He emphasizes that the self is not to be seen as a clearly demarcated entity within ourselves, but should be perceived in terms of a relation to oneself and one's life. This relational conceptualization presents the self as being in constant dynamic transformation and without a specific locus. Thus, even though the self is associated with an inner realm, this does not imply that it needs to be purely self-directed or enclosed in itself. Returning to the gardening metaphor, we can see how self-realization presupposes a self with multiple levels: there is a currently existing self, with certain qualities and limitations (symbolized by the garden that demands cultivation); there is the self we aspire 
to become (symbolized by our plans and dreams for how our garden will bloom and flourish in the future); and there is the self that has the principal capacities to act upon itself in order to develop and grow in the desired direction (symbolized by the gardener). The self-realizing moral agent, we could say, is both the garden and the gardener engaged in a process of self-development which will hopefully lead to self-improvement or realizing the best within herself (see $\$ 4 \cdot 2.1)$.

These initial reflections already introduce some important themes relevant for an understanding of the self in this study, such as continuity or reflexivity. Some other themes however, need to be elaborated to further enrich our understanding. Below, I will briefly discuss six themes that are essential to an understanding of the self that matches the interpretation of self-realization advanced here. The themes highlighted are: reflexivity, temporality, continuity, embodiment, social and relational constitution, and ethical/moral aim.

- Reflexivity: In most traditional views, to be a self, in the sense of qualifying as a human agent and having a sense of personal identity, requires that one is able to reflect on one's own choices, purposes, feelings and actions. Reflexivity presupposes the ability to distance oneself from one's immediate inclinations and feelings, to take what is called a "third-person perspective" and look at oneself through the eyes of another. Frankfurt (1971) argued that it is crucial for human personhood that one can make second-order volitions; i.e., one should be able to evaluate one's own desires and decide towards which of them one wants to direct their behavior. The ability to reflect on oneself is often associated with the rational capacities of human beings, since it is by virtue of our reason that we are able to deliberate and make hierarchical orderings between our (first- and second-order) desires. But it can also be related to our hermeneutic and narrative capacities that enable us to interpret ourselves and bring meaningful order and coherence to the variety of experiences that make up our lives (Taylor, 1985b; see further chapter 5). In the latter case, reflexivity becomes a theme that not only concerns the third-person perspective, but also the second-person perspective, since narrative identity is principally socially constituted (see $\mathbb{5 5 . 3 . 2}$ and \5.3.3).

- Temporality: One is a self at a certain moment in time, but one is also always in the process of becoming another (version of this) self, that one aspires or has the capacity to be. Moreover, we relate to (several versions of) our past selves in formulating our current aspirations and evaluating our self-development. This presupposes that we are beings with a past, present and future that stand in a certain relation to each other. The role of temporality in the self is also mirrored in the fundamental concerns that Schechtman (1996) relates to our personal identity. The four concerns she distinguishes 
are 1) a concern for survival, i.e., whether or not one will continue to exist in the future; 2) self-interested concern, i.e., the type of interest in one's own future that is assumed to be rational for a person to have; 3) a concern for compensation, i.e., an interest in being personally compensated or rewarded for hardship or sacrifice; and 4) moral responsibility, i.e., being accountable for one's choices and actions. All these concerns assume that we can anticipate future versions of ourselves, and that we have an understanding of what characterized our self in the past and what characterizes it in the present.

- Continuity: The temporality of the self also presupposes a certain amount of continuity or constancy over time. In order to be able to envision a future self, the self we strive to become, we cannot experience our past, present and future selves as unconnected to each other. Correspondingly, Gewirth (1998) emphasizes that "The self is not to be atomized into a series of discrete entities. Rather, self-knowledge involves a continuous process wherein the later stage learns from what has been experienced at an earlier stage and modifies its aspirations and expectations accordingly" (p. 45). Thus, the notion of moral self-development inherent in this study's understanding of self-realization assumes an element of continuity, even though it acknowledges that our self is in a constant dynamic process of transition.

The fact that the purpose of self-realization presupposes that one identifies with an image of who one wants to become (see $\ 4$.2.1) also underscores the importance of assuming a certain amount of continuity in the self. In accordance with this, several thinkers have argued that our lives need to show some narrative integrity or constancy that underlies our self-understanding (C. Taylor, 1989; MacIntyre, 1984; Ricoeur, 1992; see also \$5.2.3). V. Gerhardt (1999) states that: “[...] dort, wo uns eine Entscheidung 'wichtig' ist, [steht] der ganze Erwartungskontext des eigenen Daseins mindestens im Hintergrund [in cases where we truly 'care' about a choice, the whole context of expectation derived from our own being stands in the background]" (p. 407; translation HL). Thus, identity-constituting choices and actions require a horizon that encompasses our life as a sufficiently integrated whole in order to be intelligible, both to ourselves and to others. What is sufficient in this regard depends on the situation and the personal outlook of the person concerned, as one person may be able to cope with more fragmentation and uncertainty than another. However, the view defended in this study assumes that a minimal amount of experienced integration, as a necessary (though not sufficient) condition of intelligibility and meaning, is presupposed for everyone.

- Embodiment: A satisfactory account of the self, in the context of the interpretation of self-realization suggested in this study, should also acknowledge the importance of our embodied being for our experience of self (Atkins, 2008). As phenomenological philosophers, notably Merleau-Ponty (1945/1962) have emphasized, we are pre-reflexively engaged with the world 
through our bodies. Before we are able to consciously reflect on ourselves, what we are and who we strive to be and become, before we are able to express who we are through language, we already have a relationship with the world around us through our bodily existence. Our bodies enable us to feel basic sensations like thirst, hunger, or cold, to grasp things, to touch, to move, to attract attention from our caregivers, et cetera. Our bodies are also the medium that enables us to relate to other people, who respond to us through bodily gestures as well. Our embodied being is therefore perceived as a constitutive condition of our personal identity, which precedes the reflexive capacity discussed earlier.

Our embodied selfhood thereby also enables us to give form and meaning to our lived experiences, and thus apply order and coherence to our world. However, the world should not be perceived as passively undergoing the ordering activity, because according to Atkins (2008), "embodiment also has an 'interrogative mode': the body explores and discovers a world that responds to its sensing and synthesis" (p. 42). In short, our ability to act and to interact, our agency, we might say, is rooted in our embodied existence. But our bodies are also inherently vulnerable, to illness, to assault from others, to accidents and natural disasters, and ultimately to death. Merleau-Ponty (1945/1962) has expressed our bodily relation to the world in terms of intentionality, which expresses a relation between the self and the (social and material) world characterized by mutual sensitivity and attunement. Only when this self-evident relationship with the material and social world is disrupted, as Merleau-Ponty illustrates using a case of brain damage, do we realize how deeply our personal identity and our navigation of the world depend on our embodied being and its intentional relations.

- Social/relational constitution: In contrast to late modern self-realization discourse (see $\$ 2.2$ ), this study stresses a view of the self that is embedded in social relations, and constituted by socio-cultural influences. Our opportunities for exercising and developing moral agency, i.e., for self-realization, fundamentally depend on the way we are positioned in this context (see \3.2.3). The social and relational element of our self has been interpreted along various lines, which all emphasize different, but equally relevant aspects of our social and relational constitution. I will briefly discuss some examples:

- Psychoanalytical authors like Erikson (1963) and Winnicott (1965) emphasized how a stable and healthy sense of self fundamentally depends on the availability of loving relations of basic trust with our primary caregivers in early childhood.

- Mead's (1934/2015) symbolic interactionist approach to human personhood stressed the importance of the embedding of the person in a context of social relationships. This can be illustrated by his distinction 
between the $I$ and the Me. Whereas the Me represents the self that is the product of social interactions, the $I$ represents the agential, creative response to this symbolic social constitution of the self. According to Mead's theory, the self emerges from social interactions, rather than being the precondition of these interactions. However, through the dialectic between $I$ and $M e$, identity is not totally socially determined, but has an important agential quality as well.

- Goffman's (1959) work on social roles argued that we perform our identities through the way we present ourselves to others and through the different social roles we play. This view implies that the self is not only socially constituted, but also a plural. It is thus more aptly described as a variety of context-dependent selves. After all, the way we present ourselves to our colleagues, or to strangers, may result in a very different social self than the way we present ourselves to our family and friends.

- Several philosophical authors have stressed the importance of the social and relational basis of our self for our moral relations with others, which Parekh (2008) interprets in terms of our human identity. This term relates to an awareness of particular unique qualities we possess as members of the human species, and the moral demands these qualities pose on our conduct and choices. The moral sensitivity to the demands of others as well as oneself, by virtue of one's shared membership of humanity, can be seen as crucial to the status of the person as a moral subject or a moral agent; i.e., someone who can be held accountable by others and accept responsibility for their choices and actions. Accountability, responsibility, or as Ricoeur (1992) terms it, imputability, all presuppose the existence of fundamental and constitutive moral relationships between the subject claiming a certain identity and the surrounding social world (see also $\ 5 \cdot 4$ ).

- Ethical/moral aim: The final relevant aspect of this study's view of the self is its intrinsic ethical or moral dimension. This expresses the connection between our identity - who we are and who we want to become - and a dimension of ethical and/or moral values that we identify with. Our identification with such ethical or moral aims is constitutive of our moral agency, which is understood in this study as the expression of our moral identity in concrete choices and actions. An account of the self that matches this study's reframed interpretation of self-realization presupposes that we are beings inevitably engaged with what Ricoeur (1992) has called the fundamental "ethical aim" of human life: "a good life, with and for others, in just institutions" (p. 172).

My account of the self as intrinsically moral follows C. Taylor (1989), who claims that we can only understand our existence as human beings situated 
in a moral space. C. Taylor assumes that our personal identity, i.e., our answer to the question of who we are, is inextricably linked to our conceptions of the good. Human beings can only acquire self-understanding by positioning themselves in relation to what is of deepest value to them. In C. Taylor's (1989) own words, "To know who I am is a species of knowing where I stand. My identity is defined by the commitments and identifications which provide the frame or horizon within which I can try to determine from case to case what is good, or valuable, or what ought to be done, or what I endorse or oppose. In other words, it is the horizon within which I am capable of taking a stand" (p. 27). C. Taylor's account of moral identity lays strong emphasis on the capability of the individual agents themselves to form moral orientations, and to appropriate through their choices and actions certain values that are constitutive of who they want to be. However, the normative, moral or ethical dimension of identity also pertains to our attitude towards - and relationship with others. The identity-constituting choices we make are embedded in and influenced by our social relations. They also have an inevitable impact on others. Our evaluation and moral legitimation of our choices and actions should consider this impact. Moreover, the social nature of identity suggests that there is always an element of the other included in the self, the influence of which is constantly negotiated in a dynamic dialogical relationship (Ricoeur, 1992; Lindemann, 2014; see also

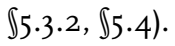

\subsubsection{The practice of self-realization}

How do human beings engage in self-realization? In other words, what does the practice of self-realization look like? Recalling the gardening metaphor, it is important to note that the purpose of reaching a flourishing garden is strived for by engaging in a variety of activities. On the one hand, bringing about the flourishing of the garden is a purposive striving, planned and chosen by the gardener because it is a goal she values. On the other hand, it is mainly through a variety of other activities, like sowing, planting, digging, watering, et cetera, that the gardener realizes this striving. Consequently, it is often complicated to point at one well-defined activity that constitutes the flourishing that is strived for. Moreover, the gardener's work is never finished, because she works with living nature, which is in continuous transition. This teaches us some important things regarding the practice of self-realization. First, self-realization can appear in human lives both as a purposive striving and as an epiphenomenon, a by-effect of other activities. In the first case, it is a practice undertaken intentionally and for its own sake, because one values the goal of self-development or making the best of oneself. In the second case, self-realization is the result of other activities. These do not have self-realization as their direct and intentional goal, but may nevertheless result in the actualization of one's potential for opti- 
mal flourishing. Second, the practice of self-realization cannot be reduced to an activity that is clearly delineated or marked in time. Instead, it has the features of a continuous process and is consequently never completed.

- Self-realization as purposive striving and/or epiphenomenon: Practicing self-realization can be an intentional purposive striving when one explicitly identifies aspects of self-fulfillment as crucial to develop in order to approach one's optimal self. For example, I may become aware of the fact that I constantly make the same mistakes, which obstructs my striving to be a good mother, spouse, sister, colleague, et cetera. From this, I may draw the conclusion that I lack self-knowledge and need to work on myself to attain better self-insight. When, as a result of this conclusion, I engage in activities explicitly intended to enhance my own self-knowledge, such as visiting a therapist or engaging in meditation on my own strengths and weaknesses, it can be said that I purposively strive to improve myself. Since this has the explicit aim of being able to lead a better life with and for others (i.e., enhancing my own moral agency), I am then, consciously and purposively, realizing myself.

V. Gerhardt (1999) claims that the ability for purposive chosen action (as opposed to unconscious, automatically occurring behavior such as breathing or falling asleep) is indispensable to define ourselves and communicate who we are as moral agents. Consequently, it seems that the practice of self-realization is necessarily mediated through purposive action. However, the purposive aim manifested in this action need not be self-realization as such, as is the case in the example given above. Our activities can also have another purposive aim and still contribute indirectly to who we want to become. In those cases, which I suspect are more widespread than the cases of intentional self-realization, the practice of self-realization appears as an epiphenomenon. This means that it proceeds through other activities such as working, caring, creating things, having relationships, fulfilling social roles, et cetera. These activities are not intentionally aimed at self-realization most of the time, but self-improvement or self-development may certainly be their outcome.

Reflecting on the practice of self-realization, it is crucial to note that in many cases our actions are only implicitly informed by who we strive to be. Further, this underlying motivation is not a matter of conscious reflexive choice. Yet, insofar as our activities contribute to the realization of the deepest aspirations or highest capacities that represent who we want to become, they contribute to the practice of self-realization. For example, by honoring my promise to accompany my friend to a doctor's appointment, I translate into action my aspiration to be a reliable friend, but this need not be a motivation I am reflectively aware of. It is important to note that it is not immaterial 
which actions figure in the practice of self-realization. In order to contribute to our self-realization, our actions cannot be destructive, damaging to ourself or to others, or otherwise morally illegitimate (Gewirth, 1998). After all, it is the purpose of self-realization to optimize our moral agency, which is defined in this study as the ability to lead a good life, with and for others, according to our deepest aspirations and highest capacities, as full participating members of society (see $\$ 5.5$ ). Any action that impedes this striving, for instance, by excluding other people from participation in society, by acting unjustly, or by failing to live up to one's potential as a result of laziness, indifference or selfishness, will also disable self-realization. The exclusion of morally damaging or illegitimate actions assumes that social processes of moral evaluation and self-legitimation are an intrinsic part of the practice of self-realization. V. Gerhardt (1999) stresses that it is implicit in our self-perception as moral agents that we grant other people the fundamental right to question our choices and judge our behavior. The social interaction involved in this dialogical process potentially plays a fundamental role in our further moral self-development (see also \$4.2.2). It enhances our self-knowledge and may cause us to revise our value orientations and the purposes we strive for. Again, it is only through the expression of our identity-constituting value orientation in actions that we are able to engage in these social processes of moral evaluation.

- Self-realization as a lifelong process: It can also be learned from the gardening metaphor that practicing self-realization is an ongoing process that is never complete or finished. This results in part from the fact that one's image of who one wants to be or become, expressed in the deepest aspirations and best capacities one strives for, is never static but will change over one's life. This constant transformation also changes the purpose one strives for in self-realization, although a certain coherence needs to be retained. In the optimal scenario, such changes prompt a person to appropriate new grounds and develop new aspirations or capacities that will then lead to flourishing in domains that were previously beyond one's reach. Ideally, this process of self-development is characterized by inner growth, an increase in self-insight and wisdom. The hoped for result is an enhancement of one's ability for moral agency, which exemplifies a successful process of self-realization.

However, there are also many cases in which the situation is less ideal. As a moral developmental goal strived for throughout life, self-realization is a process that will inevitably face ups and downs. The practice of self-realization can be characterized by severe struggles with oneself and/or one's surroundings. A beneficial outcome of growth and flourishing is certainly not guaranteed. 
The practice of self-realization is vulnerable to all sorts of threats, both external and internal to the self. For instance, if people are institutionalized in a long-term care facility, they may have to give up previously acquired discretionary space to decide for themselves what would contribute to the life they want to live and who they want to be. This loss can result in feelings of regret, sadness, anger or hopelessness, which, if they stagnate, impede the continuation of their process of self-realization. Alternatively, older workers may feel that their experience is no longer valued by their employer or colleagues. This can result in a loss of self-confidence, in frustration and withdrawal, so that they cannot make the contribution at work that would be in accordance with the kind of employee they want to be. It is important to emphasize that such situations need not automatically be the end of self-realization. In fact, our experienced defeats and losses in life can even be made a part of our self-realization if we succeed in finding a viable attitude towards them. But this does require an adjustment of one's self-understanding, an adaptation of one's strategies for realizing certain valued aspirations and capacities and maybe also of one's purposes.

This adaptation to a new situation doesn't always come easy. In each practical situation requiring a moral response, the constellation of aspirations and capacities contributing to the optimal exercise of moral agency has to be renegotiated. Moral self-development is a chance, but cannot be a certainty. Although some periods of our lives may be characterized by relative stability, there will always be the possibility of either external or internal disturbance of this equilibrium. When this happens, it necessitates a reconsideration of the resources that we use to safeguard the coherence and meaning we experience in our lives. In periods of equilibrium, our striving to become a certain kind of person is very often more like a silent background framework than a consciously experienced goal. This does not mean that our image of the best in us doesn't influence our behavior. But we are not necessarily consciously occupied with reflection on who we want to be all the time. It is typically in situations where we become a problem to ourselves, those moments of moral or existential crisis when our self-evident patterns of behavior and value orientations are challenged or found inadequate, that the striving for self-realization is suddenly felt as a moral task that we cannot evade; otherwise we will feel imbalanced, disturbed and out of sync with ourselves, our lives and the world (V. Gerhardt, 1999).

\subsubsection{The timing of self-realization}

The continuous and never-ending character of the self-realization process implies that there are no specific moments or phases in life that are reserved for self-realization. At the same time, the striving for self-realization may take a 
different shape in different phases of life. The account of self-realization I suggest in this study is that of a lifelong process of moral development. Its life-encompassing nature makes an ethics of self-realization particularly attractive when it comes to emphasizing that later life also harbors potentials for growth and flourishing. The gardening metaphor will again illustrate some relevant points. Gardening is an activity that never ends, but importantly, it does require different activities depending on the season. Some of these activities are flexible or repetitive, such as watering and weeding; others require a particular timing, such as planting certain crops. In spring, dead leaves and branches have to be removed, and new crops have to be sown. In summer, constant watering and weeding are needed, but summer is also the time to enjoy the blooming plants. In autumn, the time comes to harvest and to prepare for winter, when the soil rests and is restored for a new season, whereas the gardener quietly enjoys the fruits she has harvested and makes plans for crops and flowers to plant next year when the cycle of seasons starts anew.

From the perspective of timing, three observations stand out. First, there is a cyclical dynamics to gardening, which follows the rhythm of the seasons, in which active modes of being alternate with more retired and passive modes. Second, some activities of gardening require a specific moment in time. The ancient Greeks used the term kairos, meaning the right time for something. For instance, a crop planted too early may be destroyed by frost, but if planted too late, may not bear the desired fruits. Third, some aspects of gardening also show a linear dynamics of continuing growth and maturation. For instance, a rose bush will not carry many flowers the first year it has been planted, but its stems will grow over the years and develop into a strong and abundantly-blossoming plant, provided the bush is well taken care of and the circumstances are favorable. The gardener herself will also gain in experience and knowledge about gardening, which will expectedly contribute to the flourishing of her garden as well. Drawing on the analogy, I derive three relevant points about the timing of self-realization from these reflections:

- First, analogous to the cyclical character of gardening, self-realization is continuously of relevance throughout life, yet it may appear in different forms in different phases of our lives. We have already encountered the observation that aspirations and capacities may change over the life course $(\mathbb{4}$.2.1), which may cause a change in how we strive to realize ourselves through our choices and actions ( $\$ 4 \cdot 2 \cdot 3)$. Also, as was suggested earlier, certain life events or moments of moral/existential crisis may trigger a more active occupation with the question of who we want to be or become. At other moments, our striving for self-realization remains largely inexplicit. The ups and downs of life, with periods of active self-transformation alternating with periods of equilibrium and relative stability, suggest that the urgency 
felt to explicitly engage in self-realization will also vary throughout life, in the same way as the active preoccupation of the gardener with her garden.

- Second, the kairos aspect expresses that in some cases, self-realization requires choices to be made and actions to be undertaken at a specific moment in time, without postponement. It is detrimental to our growth and flourishing if we force ourselves to make certain decisive choices too early, for instance when a musically talented child feels forced into a career as a violinist at an age where other future options can be kept open. On the other hand, we cannot keep postponing the responsibility for our lives by refusing to make constitutive choices. This often occurs out of fear that other roads will be closed once we make a choice. Yet such postponement will probably impede our self-realization. In Either/Or Kierkegaard (1843/1959) makes the older judge Wilhelm warn his young protégé about the dangers of an aesthetic lifestyle that evades making ethical choices. The latter would require a steadfast engagement with a certain moral ideal of the self. As previously discussed, self-realization requires such identification with a certain image of who we want to become $(\mathbb{4}$.2.1). But our true engagement with an ideal of the self, demands that we remain true to what we care about even in difficult circumstances, by letting our value orientation guide our decisions at crucial moments. Otherwise we compromise our self, even more than our moral principles (Frankfurt, 1988a) and this can be expected to stymie our self-realization.

- Third, analogous to the linear character of gardening, self-realization indeed acquires heightened importance as we grow up and grow older. Most philosophical accounts of self-realization underscore that a certain amount of maturation is a condition for successful self-fulfillment. Aristotle's virtue ethics may serve as an example (Ethica Nicomachea; see $\mathbb{8} 8.3 .1)^{1}$. Young children first need to develop the relevant capacities to form aspirations about being a certain person before they can identify with them and translate them into action. Adolescents struggle to find models that they want to identify with, as Erikson (1963) suggested in his psycho-social model of development. Further, maturing into adulthood and old age ideally brings opportunities to deepen our self-insight and reflect upon what is truly important to us in our lives. This thought has led some thinkers, for example, Jung (1931/1995) to suggest that it is in later life that self-realization is most urgently of relevance. Jung stated that in midlife, we face a turning point in our development. Whereas the first half of life is dedicated to procreation and productivity, activities oriented towards the outside world, the

1 In citing Aristotle, this study will follow the common convention in philosophy to use Bekker numbers for literal citations. Translated quotes from Ethica Nicomachea are drawn from the edition by David Ross (1980) that is on the reference list. 
second half of life, according to Jung, should mark a shift inwards and an orientation towards personal growth, maturation and ripening/deepening of insight and wisdom. Of course, Jung relied on the traditions of ancient wisdom that also tend to couple self-realization to life experience and maturation, and thus, logically, to more advanced ages.

Although I disagree with the idea that self-realization is the exclusive province of later life or old age, let alone reserved for the Third Age, as contem-

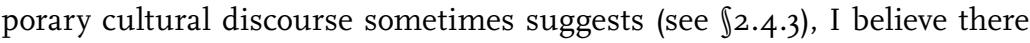
is something to be said for the idea that self-realization can gain a deeper urgency with aging. First of all, aging comes with life experience, and although experience certainly doesn't automatically culminate in more (self-) insight and wisdom, it does increase the likelihood of developing these desirable qualities that are conducive to self-realization. Second, as has already been stressed several times, the chances of being confronted with existential vulnerability increase with aging. These confrontations are likely to expose older people more often and with higher intensity to those very situations that call for explicit reflection on one's life, on who one has been, is, and wants to be or become, that underlie the practice of self-realization (see also $\llbracket 4 \cdot 4 \cdot 2$ ).

\subsection{EXPLORING THE BEST IN US}

In $\$ 4.2$, I have presented self-realization, broadly perceived, as a process of moral self-development aimed at the realization of the best within us. This expression is further explored in this section. To start with, I should emphasize that the best at stake in self-realization does not represent a static end to be achieved, or an unchanging character trait. Instead, it represents a dynamically developing process. As Gewirth (1998) puts it, "The best that is 'in you' is not in you as something that is preexisting or ready-made; [...] Rather, it gets developed out of preexisting materials that can be turned in different directions through autonomous choice and habituation" (p. 6o). Although the autonomous choice of the individual agent thus plays an important role, it should be mentioned that whatever is perceived as the best is also deeply influenced by socio-cultural factors, and always dependent on the particular situation and positioning of the individual. Note also that what constitutes the best is not meant to be a high bar, or static, universal standard against which people's lives are measured. What counts is that they strive for the best that is possible for them, given their individual qualities and specific situational circumstances. Of course, this should not be used as an excuse not to address and improve external conditions that form an obstacle to self-realization, as in the case of 
marginalizing and stereotyping cultural master narratives that impede people's moral agency (see chapter 3).

A cursory glance at the history of Western philosophy teaches us that the best in human beings has been interpreted in very diverse and often contradictory terms. All approaches share the idea that by developing the qualities advanced, one moves closer towards the realization of the overarching moral goal of a good life, however differently this is perceived. Below, I will briefly discuss a catalogue of historical and philosophical interpretations of what may constitute the best in human beings. Because the scope of this study did not allow for an extensive historical exploration of the genealogy of ideals of self-realization, I will draw upon work done in this regard by others, notably C. Taylor (1989) and G. Gerhardt (1989).

\subsubsection{Selected historical and philosophical interpretations of the best in us}

The evolution of thought on self-realization can be illustrated by considering seminal views and ideas that arose in the course of philosophical history about what it means to lead a good life as a human being. G. Gerhardt (1989) has provided a categorization of four historical lines, each exemplifying a specific interpretation of the best in human beings to be actualized through self-realization:

- The eudaimonistic line: This line conceptualizes the best in terms of the classical Aristotelian conception of happiness or eudaimonia. Self-realization involves the actualization of potentialities inherent in human nature, the capacity for reason being the highest among these.

- The naturalistic line: This line perceives human beings as most strongly motivated by their natural needs, which presents self-preservation as the best to be strived for. Reason, highly valued in the eudaimonistic line, is seen as functional but relatively powerless compared to the natural instinct for self-preservation. The naturalistic line also acknowledges that an individual's natural needs can be in conflict with the needs of others or with an indifferent or hostile environment.

- The aesthetic-pedagogical line: This line perceives the best in terms of the authentic expression of the unique individuality of the human being. Importantly, this line criticizes a one-sided focus on reason as the best human potential, and underscores the equally important role of affective and creative capacities.

- The historical-philosophical line: This line shares the pedagogical optimism of the aesthetic-pedagogical line, but focuses on humanity as a whole instead of on the unique individual. This line, exemplified by the works of 
Hegel and Marx among others, assumes an inescapable historical dynamics directed towards the moral perfection of the community of mankind.

Though G. Gerhardt's categorization offers a useful instrument to group different historical views about what constitutes the best in human beings in self-realization, his account also has its limitations. It remains a bit imbalanced because he uses his historical sketch of different views, mainly instrumentally, to confirm his own categorization of different forms of ethics. His account lacks the richness and nuance provided by C. Taylor in his magnum opus Sources of the self. The making of modern identity (1989). On the other hand, G. Gerhardt (1989) does address certain relevant perspectives that are not discussed by C. Taylor, such as the Aristotelian, eudaimonistic view, which adds to the value of his work relevant to this study.

C. Taylor (1989) analyzes historical ideas of what constitutes the best in human beings in terms of moral resources for our identity. Together, these images of the best, or "hypergoods", constitute the horizon against which we shape our selves, i.e., our moral identity. As elaborated in $\$ 2.3 .6$, C. Taylor believes that a conglomerate of tendencies associated with the process of modernization has resulted in a loss of access to these resources for modern individuals. This, he contends, has resulted in a moral identity crisis for late modern individuals. By exploring the gradual transformations of our modern self-understanding and the conceptualizations of the good or best that underlie it, C. Taylor strives to uncover fundamental identity resources that have disappeared from public moral discourse.

C. Taylor's work on the moral sources of our modern identity is highly erudite and rich, so that it is impossible to do full justice to all the developments he describes in the context of the current study. However, in light of the focus in this section on historical accounts of what constitutes the best in us with relevance to self-realization, it is important to highlight one specific theme of C. Taylor's analysis. This concerns his observations regarding the emergence, during the course of modernization, of the idea that human beings have an inner realm. C. Taylor perceives this development as quintessential to understanding the evolution of the moral sources of identity available to modern individuals. The inner realm is perceived as the seat of their selves or their "soul", the source of the aspirations and capacities that guide their self-realization (see \$4.2.1). Crucial to this development is what C. Taylor (1989) calls "radical reflexivity" (p. 131). This term describes human beings as capable of taking a first-person perspective, reflecting on their own life and the highest values they strive for. This radical reflexive first-person perspective was first introduced by early Christian thinkers such as Augustine, and was then carried forward in different directions by thinkers such as Locke, Descartes, Montaigne, Rousseau and Nietzsche. Ideas about radical reflexivity have profoundly influenced our 
modern self-understanding. As C. Taylor (1989) argues, since radical reflexivity became rooted in our collective self-image, "the road from the lower to the higher, the crucial shift in direction, passes through our attending to ourselves as inner" (p. 129). Consequently, regardless of how one interprets the best in human beings, self-realization can no longer be conceived without taking the inner realm of human beings into account.

From C. Taylor's and G. Gerhardt's views, a catalogue of historical and philosophical interpretations of what constitutes the best in human beings can be deduced. The selection of views discussed below certainly does not present an exhaustive overview. However, it illustrates that the fabric of self-realization discourse is rich and complex, and that its pattern is woven from different threads, that can be traced to their different appearances throughout philosophical history. This study will argue in favor of a distinction between three main threads that together form the purpose of self-realization as I interpret it: autonomy, authenticity and virtue $(\$ 4 \cdot 3 \cdot 2)$. Although the listing below of historical-philosophical interpretations of the best that is relevant to self-realization remains incomplete and brief, it does provide a starting point for a discussion of these threads.

1. Mastery of passion through reason: A catalogue of conceptualizations of the good in Western philosophy cannot escape starting with Plato. According to Plato (as cited in C. Taylor, 1989), human striving should be directed towards the mastery of our earthly passions and desires through reason. Reason is seen as our road of access to what Plato conceived as the eternal Good, of which our earthly goods are only incomplete adumbrations. Although Plato certainly did not locate the eternal Good in the individual realm, as C. Taylor (1989) shows, none of the later accounts of what constitutes the best in us can be properly understood without acknowledging the Platonic origins of thinking about the good.

2. Eudaimonia: More down-to-earth than Plato's account is Aristotle's (as cited in G. Gerhardt, 1989) ethics, which is perhaps the oldest explicit representation of a self-realization-ethics in Western philosophy. Aristotle presents eudaimonia (or happiness) as the ultimate goal of human striving. In this tradition, the best life is believed to be acquired by optimally fulfilling one's natural potentials as a human being. Aristotle's virtue ethics (Ethica Nicomachea) can be seen as the most well-known and influential approach advancing this idea.

3. Self-forsaking and self-transcendence: Early Christian thinkers like Augustine (as cited in C. Taylor, 1989) and Thomas Aquinas (as cited in C. Taylor, 1989) criticized the striving for flourishing in the context of earthly life. The best in human life could only be found in devotion to God. Virtues relevant in practical earthly contexts stressed by the Greek tradition (such as cour- 
age, justice and wisdom) were replaced by virtues believed to contribute to the union of the human soul with God, namely, faith, hope and love (Van Tongeren, 2012). Paradoxically, the road to self-realization was thus sought in self-sacrifice and self-transcendence, postponing ultimate fulfillment to the afterlife.

4. Rational mastery of the world: Descartes' (as cited in C. Taylor, 1989) strict separation between the knowing subject or cogito, and the world of objects, led to an ideal of rational detachment whereby human subjects, by virtue of their capacity for reason, acquired the status of sovereign masters of the world. During the scientific revolution of the $16^{\text {th }}$ and $17^{\text {th }}$ century, the Cartesian rational, detached attitude, ascribed to the subject as a sovereign locus of control, became imbued with the status of the best human potential.

5. Self-preservation: Thinkers such as Locke (as cited in C. Taylor, 1989) and Hobbes (as cited in G. Gerhardt, 1989) saw enlightened self-interest as one of the strongest and most fundamental human motivations. This nourished their idea of the social order being based on a "contract" between free and equal individual agents, installed in order to guarantee their maximal benefit. Striving for self-preservation by advancing and maximizing one's self-interest was thus added to the catalogue of views deliberating the best in human beings.

6. Self-knowledge: Another appearance of the modern radical reflexivity can be found in the work of Montaigne (as cited in C. Taylor, 1989). He stressed the importance of self-investigation, which should yield us insight into our own deepest motivations, inclinations, thoughts and feelings. The corresponding conceptualization of the best in human beings can be defined as the ability to view ourselves clearly and modestly, with all our limitations, to gain in self-knowledge; a virtue already valued by Socrates and the Stoics.

7. Self-determination: Enlightenment thinkers, most notable of them being Kant (as cited in C. Taylor, 1989), claimed that the ultimate source of moral authority is the moral law situated within us. The best in ourselves can be identified here in terms of our capacities for reason and autonomy. By replacing heteronomy and following authorities with autonomous rational "thinking for oneself", moral self-direction and self-determination become possible.

8. Expression of inner nature: Rousseau (as cited in C. Taylor, 1989) and his Romantic heirs criticized the Enlightenment emphasis on rationality and autonomy, focusing on our emotions and creative capacities instead. By learning to follow the compass of our inner nature, and expressing our authentic emotions and inclinations, our true potentials for moral agency can be realized. Following one's inner voice could thus be perceived as the best to be strived for in self-realization. 
9. Self-elevation: Post-Romantic thinkers such as Nietzsche (as cited in G. Gerhardt, 1989, and in C. Taylor, 1989) voiced their suspicion of human beings being self-evidently inclined to moral goodness. Instead, they perceived the inner realm as a dark and amoral domain. However, rather than concluding that self-realization as a moral striving was flawed, they saw greatness in transcending mediocrity by elevating oneself to a superior mode of being. Creative expression and authentic affirmation of one's life and self was introduced as a new and provocative conception of the best potential of human beings.

10. Radical freedom and self-choice: Existential philosophers like Kierkegaard, Heidegger and Sartre (as cited in G. Gerhardt, 1989) suggested that, being "thrown" into the world, human beings optimally realize themselves through radically exercising their freedom, by embracing an existence without any prior or intrinsic meaning. This radical freedom and self-choice were perceived as both inescapable fate and the highest purpose of human life.

11. Care: Though not discussed by G. Gerhardt (1989) and C. Taylor (1989), feminist ethics in the $20^{\text {th }}$ century introduced a moral focus on relations of care and responsibility that deserves a mention here as another perception of the best in human beings. Although not presented in terms of self-realization, the ability to care for others is seen as a very important virtue playing a fundamental role in maintaining human life and enabling its goodness (Tronto, 1993; Held, 2006).

12. Self-appropriation: A final item in the catalogue, also not discussed by G. Gerhardt (1989) and C. Taylor (1989) but relevant for my purposes, is the view represented by contemporary self-care or art of living perspectives, such as represented by Foucault (1984/1992) and his followers. They emphasize the moral importance of appropriating oneself, for instance one's purposes and motivations, without ignoring disciplining social forces. This approach values positive freedom, but precludes naïve assumptions about individual autonomy, authenticity and freedom that earlier thinkers believed in.

\subsubsection{Three threads: autonomy, authenticity and virtue}

The brief historical sketch of a selection of philosophical views about what constitutes the best in us to be actualized through self-realization, suggests that contemporary self-realization discourse draws on a very rich and complex set of ideas about what constitutes the optimal life for human beings. The catalogue of different views about what constitutes the best in human beings can be grouped or ordered in several ways, for instance, by focusing on the underlying assumptions about the world, or by distinguishing between self-directed 
or community-directed views, et cetera. For the purposes of this study, it is my contention that an ordering along the lines of thematic affiliation between the different conceptualizations is most clarifying. This results in the suggested distinction between three threads that weave the rich fabric of thought on self-realization, which are coupled to three ways of conceptualizing the moral agent. These threads are defined as autonomy, authenticity and virtue.

- Autonomy: The first thread focuses on the capacity of human beings to autonomously define, choose and appropriate goals, values and motivations that are concordant with the demands of reason. It celebrates freedom, mastery and choice, and perceives the purpose of self-realization in terms of a self-determined life. The corresponding image of the moral agent presents an autonomous, rational, independent individual, who has the freedom as well as the moral obligation to lead a self-determined life. In the catalogue of philosophical views about what constitutes the best in human beings $(\mathbb{4} 4 \cdot 3 \cdot 1)$, the ideas of rational mastery, self-preservation, self-determination, radical freedom/self-choice and self-appropriation all feed into the autonomy thread.

- Authenticity: The second thread focuses on the capacity of human beings to bring themselves, understood as their authentic, self-appropriated conception of who they want to be, to full creative expression. It celebrates self-knowledge, creativity, expressivity, sincerity and moral sensitivity. The purpose of self-realization is perceived in terms of becoming who you are, i.e., realizing your deepest aspirations to become a certain person, a more "true" or worthier version of yourself. The corresponding image of the moral agent presents searching, creative individuals, striving to obtain self-knowledge, making contact with their inner voice and optimally expressing their authenticity, as conditional for a fulfilled life that is genuinely one's own. In the catalogue, the ideas of self-knowledge, expression of inner nature, self-elevation, radical freedom/self-choice and in some sense also self-appropriation feed into the authenticity thread.

- Virtue: The third thread focuses on the capacity of human beings to develop their naturally given potentials into excellent character dispositions that are conducive to optimal flourishing, both of oneself and of the community one is a part of. It celebrates the practice of good habits, sociable and virtuous (for instance, just, courageous, temperate) behaviors, and wisdom. The corresponding image of the moral agent presents a virtuous, social and interdependent individual, who aims to develop good habits and excellent qualitative character dispositions. The good life is conceived as a life with and for others, as members of a community. In the catalogue, the ideas of eudaimonia, self-forsaking/self-transcendence, self-knowledge and care feed into the virtue thread. 
It is my contention that autonomy, authenticity and virtue are all valuable representations of the purpose underlying self-realization, and should not be plotted against each other. The moral pluralism of late modernity requires an interpretation of self-realization which acknowledges the rightful claims of each thread. All three of the constitutive threads in combination are required to arrive at my reframed interpretation of self-realization, which aims to function as a resource for narratives of becoming about later life (see $\sqrt{3} \cdot 4$ ). Each of these constitutive concepts of the self-realization discourse has given rise to an often highly specialist philosophical discourse of its own, whereby the link with self-realization is not always explicitly made. In chapters 6, 7 and 8, the three threads are discussed in more detail. However, my intention in these chapters is not to give full philosophical accounts of autonomy, authenticity and virtue, respectively. Rather, my focus is on the question which interpretation of these concepts matches the reframed interpretation of self-realization aimed at in this study. It is also the contention of this study that the fundamental ills which

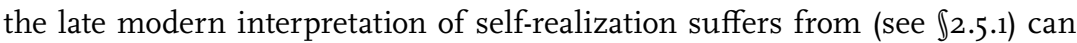
be largely attributed to its incomplete and sometimes perverted understanding of these constitutive concepts. For instance, late modern notions of autonomy have been criticized for presenting the individual as an atomistic being, only instrumentally engaged in relations with others, and attributed with an amount of rational control over the world that is not realistic for most people most of the time (M. Walker, 2007; see also chapter 6). On the other hand, modern notions of authenticity have been criticized as narcissistic and self-conscious (Lasch, 1979; C. Taylor, 1991; see also chapter 7). Interestingly, the eudaimonistic tradition focusing on virtue seems to be underrepresented in the typical late modern discourse on self-realization (see chapter 8).

As discussed in $\$ 2.5 .2$, these ambivalences of late modern self-realization discourse thrust themselves upon us when trying to apply this moral ideal to the context of aging. However, in my view, drawing on a self-realization discourse need not necessarily result in a defense of such problematic interpretations of autonomy and authenticity or a disregarding of virtue. The historical evolution of the self-realization discourse provides sufficient resources to generate alternative conceptualizations of these notions, which are able to underscore the moral importance of self-realization for us, as shown in chapters 6,7 and 8. In combination, the critical reconsideration of existing accounts of autonomy, authenticity and virtue in these chapters provide us with the building blocks for the reframed interpretation of self-realization. 


\subsection{Self-realization and aging}

Before proceeding to a more in-depth exploration of the constitutive concepts weaving the discourse of self-realization, let me conclude the current chapter with some reflections on self-realization and aging. As discussed in \$4.2.4, self-realization is an endeavor that continues throughout life, but also seems to gain an increased urgency with aging. Two issues merit particular attention however, because they may still give us pause regarding the applicability of the self-realization discourse to later life: 1) what are the consequences of the fact that the time horizon changes for older people, i.e., that their past is generally longer than their (perceived) remaining future lifetime? and 2) what are the consequences of the radicalized confrontation with existential vulnerability in later life?

\subsubsection{Self-realization and the shrinking of the future}

No one knows how long they will live of course, but it is evident that as we age, the proportion of years still to be lived shrinks in comparison to the years we have already lived. The commonsensical intuition that has also found its way into classical developmental life-stage models such as Erikson's (1997), is that old age is a time for looking back and evaluating one's past life, instead of looking forward to future goals one wants to realize. Since the self-realization discourse is intrinsically teleological - it presupposes a purpose (telos) in the future to be strived for - the shrinking of the future that characterizes later life raises questions regarding the application of the self-realization discourse to aging. After all, if future-oriented strivings become less relevant as one ages, what does this imply for self-realization, which is intrinsically a future-directed endeavor? A number of reflections are relevant here:

- First of all, it is important to critically assess whether the often heard assumption that younger and middle-aged people are predominantly prospectively oriented (i.e., oriented towards the future) whereas older people are more retrospectively oriented (i.e., oriented towards the past) is actually correct or, alternatively, rests on biased ideas about old age. Baars (2012b) argues that what is often overlooked is that all these groups - youth, adults, elderly - actually live their lives in the present. As Baars emphasizes, for older people "it can be quite annoying that it is apparently beyond many people's scope that older persons also live in the present, that these days are also their days, and that they might even be interested in the future" (p. 153). If time is perceived as a narrative and subjective category, rather than just a "chronometric" and (supposedly) objective one, it becomes clear that the experience of aging as living in time harbors a variety of individual varia- 
tions, and certainly does not exclude an orientation towards the future. The fact that this future is probably shorter does not have to diminish its importance. As a befriended older woman once told me, it remains important to "have something to wake up to in the morning, even if one is 83 ". This observation implies that the shrinking of the future that characterizes the life experience of older people need not derogate the value of one's striving for self-realization.

- Second, if we take into account that the approaching end of one's life may give people a heightened sense of the importance of living in the present and of realizing one's goals, it also follows that the teleological orientation of self-realization need not necessarily be in conflict with the shrinking time horizon of later life. The same effect is sometimes observed in people who have heard that they have a serious terminal illness and limited time left. They often report that their personal growth or moral self-development is experienced with increasing urgency due to their situation. It is further important to realize that for older people (and for others who know they are approaching death), attaining "closure" of certain issues in their lives may also be an important part of their self-realization. Even if this striving for closure indeed implies a heightened preoccupation with memories and people from the past, it can still constitute a purpose that fits into the framework of moral self-development that is presupposed by the self-realization discourse. Thus, though older people's future is indeed shorter and their orientation towards the past may dominate, their preoccupation with self-realization is not inevitably lessened by this fact.

- Third, although the shrinking of the future doesn't necessarily diminish the importance of self-realization, it should still be considered that it may possibly have an impact on the type of goals that people aim for. For instance, long-term goals connected with one's own achievement may shift to the background in favor of goals related to transcending one's self-directedness to contribute to the new generation, as Erikson (1997) described in his notion of generativity. To illustrate, it may be the aspiration of young scientists to become a respected authority in their field by publishing in high-impact journals and creating a large international network in order to realize these ambitions. By contrast, older or retired academics may rather focus on helping younger mentees find their way in academia, or, freed from the publication pressures, on writing books and articles that are more personal or unconventional, on themes they left out for instrumental reasons (such as chances for publication) earlier during their career. This difference shows that our aspirations regarding who we want to be or become can alter during our life. Note that this suggests that the shrinking of the future expectedly influences older people's aspiration fulfillment in particular (see $\ 4$.2.1). 
A difficult point in this regard pertains to the experienced necessity or pressure to let go of certain long-term goals, because one becomes aware that they will not be reached in the time one has left, or because others communicate that aspired goals no longer suit the socio-cultural norms of one's chronological age. It can be painful to feel forced to let go of deeply-valued aspirations. In such cases, replacing one aspiration (that is no longer conceived as a realistic possibility) with another, more manageable goal can initially feel like a disappointment or a defeat, as if one were settling for a consolation prize. If, after a period of adaptation, one does not succeed in genuinely appropriating the replacing goal as a worthy purpose of one's own, and one remains stuck in grief and resentment over what has been lost, self-realization will expectedly be stymied.

The assumption that there may be a connection between the type of goals people strive for and their perception of the remaining time horizon of their lives is confirmed in research based on the socioemotional selectivity theory formulated by Laura Carstensen and her colleagues (Carstensen, Isaacowitz \& Charles, 1999; Carstensen, 1991, 1992, 1995). The outcomes of this research strongly suggest that people who perceive the time horizon of their lives as shrinking tend to shift their life-orientation towards goals related to emotions, social relationships and existential meaning. In the words of Carstensen, Isaacowitz \& Charles (1999), "the knowledge that time is limited has direct effects on emotional experience. Appreciation of the fragility of life, recognition that the passage of time cannot be stopped, and heightened awareness of one's immediate surroundings directly alters the experience of emotions. We also expect that, relieved of concerns for the future, endings bring out the best qualities in people [...] As people approach the ultimate ending - death - lives are evaluated, and a search for existential meaning in life places emotion at center stage" (p. 169).

- Fourth and finally, it should be noted that the whole assumption that self-realization is complicated or loses importance as a result of the shrinking time horizon could at least partially be influenced by the limitations imposed by stereotypical and marginalizing cultural narratives on who people can strive to be or become. It has been argued before that access to cultural resources for identity, as well as the recognition that one is capable and worthy to strive for certain purposes, is quintessential for optimal exercise of moral agency (see $\sqrt{3}$.2.3). While growing older, I stated, people's access to possible identity resources can become more limited. I suggested that the influence of stereotypical social positioning and lack of valued social roles can play a crucial role in this regard. Again, the suggested tension between self-realization and a shrinking time horizon is then not something that arises inevitably, but is (at least in part) a socio-culturally constituted problem. As Markus and Nurius (1986) emphasize in their theory about the 
variety of "possible selves" that people may have, "the pool of possible selves [that an individual can create] derives from the categories made salient by the individual's particular sociocultural and historical context and from the models, images, and symbols provided by the media and by the individual's immediate social experiences. Possible selves thus have the potential to reveal the inventive and constructive nature of the self but they also reflect the extent to which the self is socially determined and constrained" (p. 954).

In sum, the assumption that the shrinking time horizon characteristic of later life should automatically reduce or problematize the importance of self-realization, turns out to be too simplistic. Although a shift in aspirations or purposes one strives for may certainly appear, self-realization can still be very relevant for older people. Moreover, my reflections show that other factors besides a shrinking time horizon, such as stereotyping cultural narratives and the corresponding lack of recognition of moral agency, may play a more urgent role when self-realization is stymied in old age.

\subsubsection{Self-realization and radicalization of existential vulnerability}

The second issue that merits attention regarding self-realization and aging relates to existential vulnerability. Existential vulnerability has been argued to be characteristic of human life in general, but is confronted more radically in later life (see $\llbracket 2.4 .6$ ). After all, the aging process tends to increase our vulnerability to all sorts of losses. Aging also strengthens our consciousness of the finitude of existence through the awareness that the longest part of our lives is behind us and death is inevitably approaching. This awareness in itself can be regarded as a form of confrontation with existential vulnerability.

I have described existential vulnerability in terms of anything that might threaten or impede the experience of meaningfulness that one derives from having a satisfactory relation with the physical, social, personal and transcendent dimensions of life (see \2.4.6). Existential vulnerability was distinguished from other, contingent and situational forms of vulnerability that pertain to the influence of external factors like structural and societal arrangements or cultural imaginaries. The effects of contingent situational vulnerabilities on the lives of older people deserve resolute efforts to accomplish social change and reduce social inequalities, in order to improve their life circumstances and increase their chances of experiencing a meaningful life. By contrast, I argued that existential vulnerability asks for a strategy of meaningful integration, since it is a category of vulnerability that is inescapable. It would be a misunderstanding of the basic conditions of human life to treat it as an unfortunate temporary condition that can be kept under control. 
The cultural decline- and age-defying narratives that were discussed in chapter 3 only seemed to offer two options to relate to the contingencies and existential vulnerabilities of later life: either passive surrender or active defense and/or denial. But in reality, when confronted with existential vulnerability one is forced to find a way to integrate it into one's life narrative, in order to maintain experiencing life as something meaningful and worth living. Neither surrender nor denial will be of much help regaining meaning in such situations.

The fundamental question that has to be faced here is whether self-realization, as it has been conceptualized in this chapter, is necessarily endangered or impeded by the confrontation with instances of existential vulnerability. Two issues deserve particular attention in this regard:

- First, it is important to consider which understandings of self-realization and vulnerability are implied in the assumption that existential vulnerability may create a problem for self-realization. The latter view implies that existential vulnerability compromises circumstances or capacities that are presumed to be necessary for self-realization. It is my contention that the implicit view we encounter here is based on precisely the late modern, liberal conceptualization of self-realization that the current study wants to criticize. In this view, we may recall, moral agents are presented as atomistic, autonomous individuals who independently make their own way in the world and strive to lead a fully self-determined life. Obviously, being confronted with existential vulnerability will threaten this independence and self-determination, which brings Hoffmaster (2006) to the conclusion that vulnerability is "antithetical to the ethos of individualism" (p. 42). However, this assumes several things, for instance that being dependent on others inevitably means being less autonomous, less self-determined, and therefore in a less favorable condition to realize oneself. What this view disregards however, is the fact that existential vulnerability is a fundamental feature of the human condition. It may not be equally pressing in everybody's life at any given moment, but we are all liable to be confronted with it. In this understanding, existential vulnerability by no means precludes forming aspirations to become a certain kind of person. Otherwise no one could ever aspire to self-realization, which seems an unreasonably crude assumption. This study defends a view in which social (inter)dependence is assumed as the default condition of human lives. It is argued later that this condition of interdependence need not be at odds with the underlying assumptions of my suggested reframed interpretation of self-realization. When following this line of thinking, growing older and being confronted with radicalized existential vulnerability, for instance, by experiencing physical deterioration due to senescing processes or social losses because one's spouse or friends die, are not automatically detrimental for self-realization. 
- Second, it is important to consider the possibility that not only do existential vulnerability and self-realization not exclude each other, but that the confrontation with existential vulnerability may even serve as a catalyst for self-realization. Although on the one hand some capacities traditionally associated with self-realization, such as self-determination or rational deliberation, may certainly become more fragile in later life; on the other hand, the confrontation with vulnerability may also prompt the development of other, new capacities, such as moral sensitivity or empathy. For example, after the loss of her husband, an older acquaintance found a new source of personal fulfillment in leading a church support group for recently bereaved people, which still greatly contributes to her self-realization.

As discussed in $\$ 4.3$, the best in us at stake in self-realization has been conceptualized in terms of a rich variety of ways, including our ability for self-knowledge, moral sensitivity, receptivity, creativity or care. Aligned with this, MacIntyre (1999) has argued that in order to flourish, human beings need both virtues that enable self-sufficiency and rational deliberation and what he calls "virtues of acknowledged dependence" (p. 126-127). The confrontation with vulnerability may teach us to (further) develop precisely those qualities associated with the latter category of virtues. Then, the existential vulnerability confronted in (later) life not only complicates self-realization in certain ways, but also offers opportunities to acquire new virtues that are conducive to our self-realization in later life. It follows that existential vulnerability is only an automatic impediment to self-realization when we follow the problematically limited interpretation of self-realization that only focuses on self-sufficiency and rational self-determination (see chapter 2).

The possibility that being confronted with existential vulnerability gives rise to the development of new virtues and capacities does presuppose however, that we have the courage and the flexibility to reconsider our identity-constituting aspirations in situations where our previous goals are no longer possible. Expectedly, if we follow too strictly the strategies typical of age-defying narratives ( $\mathbb{\$} 3.3 .3)$ and make "staying young" our main purpose in later life, we miss out on these opportunities. We need to steer between the Scylla of active denial and resistance of existential vulnerability and the Charybdis of passive surrender to existential vulnerability, if we want to profit from the opportunities for self-realization that later life confrontations with vulnerability may have to offer.

To conclude, let me briefly recall the reason for this study to engage with the philosophical self-realization discourse. As argued in $\mathbb{3} 3.4$, I turned to the self-realization discourse to find a viable resource for the suggested narratives of becoming. In order to serve as such a resource, self-realization discourse 
should be able to answer to both conditions that I have defined for such narratives: the acknowledgment of the potential for growth and flourishing in later life, and the support of a meaningful integration of existential vulnerability. I believe the analysis of self-realization in this chapter has made it clear that this philosophical discourse indeed harbors a strong and lively conviction that human beings principally possess the potential for growth and development. Moreover, it has been argued that the moral self-development underlying this study's interpretation of self-realization should engage human persons throughout their entire lives. Therefore, in my understanding of self-realization, the notion of growth and flourishing, of realizing the best that one is capable of, is by no means restricted to young people who have all of their lives ahead of them. This is an important advantage in the search for cultural counter narratives of becoming about later life that are able to acknowledge that later life may also harbor the potential for growth and flourishing.

Regarding the integration of existential vulnerability, I hope to have made it plausible that in this study's suggested interpretation, contrary to the late modern discourse, self-realization need not be a narcissistic endeavor, aimed at obtaining mastery over the contingencies of life and thus at the rejection or conquering of existential vulnerability. Instead, I suggested in the last section $(\$ 4.4 .2)$ that self-realization can also include the development of qualities that teach people how to find a satisfactory attitude towards these contingencies. In this sense, the second condition that was identified as necessary for viable cultural counter stories about later life - the enabling of a meaningful integration of existential vulnerability - also certainly finds resonance in my suggested reframed view of self-realization.

Now that we have gained an initial understanding of the philosophical discourse on self-realization, which has already broadened our view compared to the late modern interpretation of the concept, I can proceed to the reframing of self-realization that I argued was necessary to apply this moral ideal to the context of aging. This reframing will require developing alternative understandings of the constitutive concepts on which self-realization discourse relies. As might be expected from my argument in $\$ 4.3 .2$, it is particularly important to reframe the three threads that weave the fabric of self-realization discourse. Before I can proceed to an evaluation and reframing of existing views on autonomy, authenticity and virtue however, I first need to consider in more detail the themes of self-identity and moral agency, both of which are intrinsic to self-realization as it has been presented in this chapter. Understanding which conceptualizations of identity and moral agency are presupposed by the reframed conceptualization of self-realization that this study strives to develop, is conditional to enable further elaboration of the constitutive threads of self-realization. 


\section{Chapter 5 - Narrative identity and moral agency}

\subsection{INTRODUCTION}

In the previous chapter, the purpose of self-realization, i.e., the best in human beings that is developed in the process of realizing oneself, was conceived in terms of moral self-development. The latter is a process culminating in the optimization of one's potential for moral agency, defined tentatively in the context of human practices as the expression of one's moral identity in actions. The concept of moral agency has already been introduced earlier in the discussion of cultural counter narratives (see $\sqrt{3}$.2.3). But the notion of moral agency, particularly in the definition advanced by this study, still awaits further consideration. This is provided in the current chapter. Importantly however, this study's understanding of moral agency rests upon a specific view of personal identity that needs to be addressed first. As already mentioned in $\$ 4.2 .2$, a narrative conception of identity seems most aptly suited to the goals and assumptions fueling this study. However, this choice of perspective, as well as the content of such a narrative conception still await explanation. These are the other aspects covered in this chapter.

The current chapter is organized as follows. First, I present an argument in favor of a narrative conception of identity $(\mathbb{5} .2)$. This starts with a general introduction on the narrative view of identity $(\mathbb{5} .2 .1)$, followed by a consideration of the relation between narrative and life $(\mathbb{5} .2 .2)$, a discussion of the complex theme of narrative integration or unified selfhood usually assumed to be conditional for identity-constituting narratives $(\mathbb{5} .2 .3)$, and a justification of my preference for a narrative view in the context of aging ( $\$ 5$.2.4). Second, three selected philosophical interpretations of narrative identity are discussed and evaluated: the narrative self-constitution view by Schechtman (1996) (\$5.3.1), a view on narrative identity as a social practice by Lindemann (2014) ( $\$ 5.3 .2)$, and a view on narrative identity in its relation to moral identity by Atkins (2008) (\$5.3.3). Third, I discuss how Ricoeur's philosophy of identity (1992) offers the opportunity to relate the narrative conception of identity to moral agency ( $(55 \cdot 4)$. 
Fourth and finally, I draw together the arguments that result in my proposed definition of moral agency as the ability to live well, with and for others, according to one's deepest aspirations and best capacities, as full participating members of a society/community (\$5.5).

\subsection{INTRODUCING NARRATIVE IDENTITY}

\subsubsection{Life and self as stories}

Among the varied interpretations of personal identity, the narrative view stands out for its rich and nuanced, yet practical conceptualization of what it implies to answer the fundamental question of personal identity: Who am I? Instead of engaging in metaphysical and rather abstract reflections about what it means for an entity (person or otherwise) to be identical at two distinct points in time (see for instance Parfit, 1984), the narrative view focuses on what is seen as a fundamental feature of human life, namely the ability and inclination to engage in storytelling. The narrative view assumes that there exists an intrinsic connection between our lives, our personal identities, and the stories we tell about ourselves. In the process of narrating, arbitrary and unconnected experiences and events are transformed into a cohesive configuration, with a plot and characters and an ideological setting that enables us to experience meaning (McAdams, 1993). By selecting and interpreting, omitting and highlighting, we present a more or less coherent image of ourselves that we communicate to others through our stories.

Among the most interesting exponents of the narrative view of identity in philosophy are Schechtman (1996), Ricoeur (1991, 1992), C. Taylor (1989), MacIntyre (1984), Thomä (1998), Atkins (2008; Atkins \& Mackenzie, 2008) and Lindemann (2014). Additionally, McAdams (1993; McAdams, Josselson \& Lieblich, 2006) has provided an interesting account of narrative identity from a psychological point of view, whereas Gubrium and Holstein (2000) discuss the merits of a narrative account of identity in a postmodern context. According to these narrative thinkers, human beings are "story-telling animals" (MacIntyre, 1984 , p. 216). That is, they cannot help but understand and present their lives and selves in the form of stories. Stories are thus granted a constitutive function in our personal identities. We answer the question who we are by telling stories about ourselves. We make our life choices and our actions intelligible both to ourselves and to others by telling stories. We integrate the things that befall us in our lives by weaving them into our stories. All these stories can differ depending on who is listening, on the context of telling, on our socio-cultural position or the life phase that we are in. Identity-constituting stories are thus dynamic and constantly in flux. Yet they also safeguard the sense of coherence 
which we experience in our lives. That is, narratives enable us to see our lives in terms of more or less intelligible and connective unities. Following from this brief sketch, we can tentatively define the term narrative as a story (in the broadest possible sense) with a plot that brings together events and experiences we encounter in our lives, in a more or less ordered configuration that grants them intelligibility both in our own eyes as well as in the eyes of others.

As C. Taylor (1989), MacIntyre (1984), McAdams (1993) and many others emphasize, the narrative view presupposes an intrinsic connection between the coherence that narratives provide our lives with and our ability to experience meaning. It is assumed that the stories we tell about our lives order the events, experiences, relationships and feelings that make up our daily lives into a configuration that is meaningful to us. According to MacIntyre (1984), this is typically a story with a beginning, a middle and an end; but his ideas about the encompassing integrative function of narrative have been problematized (see $\llbracket 5.2 .3$ ). Disrupting events, such as illness or loss, tend to perturb our life stories. In response to such events, coherence needs to be restored by integrating the event into our narratives about ourselves, in order to experience them as meaningful again.

The narrative process of identity-constitution presupposes a dialogical, hermeneutic endeavor in which we interpret ourselves and our motivations and choices in light of our present and (aspired) future identity. This is a multivoiced process in which not only our self-evaluations, but also the way we relate to others and the way these others position us are implicated. A narrative, as MacIntyre (1984) reminds us, is never solely an individual creation. Instead, we are only the co-authors of our own life stories. This addresses the fundamental social character of narrative identity, but it also touches upon the theme of agency, since, as MacIntyre (1984) states, "I can only answer the question 'What am I to do?' if I can answer the prior question 'Of what story or stories do I find myself a part?" (p. 216).

An important advantage of a narrative conception of identity for my purposes is that it encompasses all aspects of the self of relevance to self-realization that have been discussed in $\mathbb{\$}$ 4.2.2. This makes the narrative view particularly well-suited to the reframed understanding of self-realization that this study aims at. Reflexivity is presupposed by the fact that in order to tell a story about our lives, we have to be able to distance ourselves from the immediacy of our experiences, look back at them and order them into a coherent narrative plot. Importantly, the intersubjective character of narrativity suggests that this reflexivity is not only a matter of the individual, but is something that arises in social interactions. Temporality and continuity are inherent in the very idea of life narratives because they stress the lifelong nature of the process of narrative self-constitution and focus on drawing connections between the temporal dimensions of past, present and future. Embodiment is implicitly covered by the 
fact that the narrative view takes the lived reality of people as its starting point, instead of abstract metaphysical assumptions and hypothetical scenarios (Benson, 1994). The social character of the narrative view of identity has already been emphasized by observing that narrative identity-constitution is something that engages other people as well - as listeners and co-constituters of our identities.

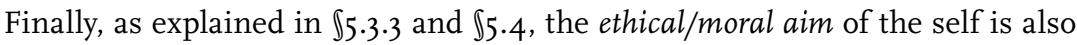
covered in the views of narrative identity that have been selected for discussion in this study, notably the accounts of Atkins (2008) and Ricoeur (1992). These views emphasize the fact that our narrative identity mediates our moral identity, and thereby enables our moral agency, through which we express this moral identity in our concrete choices and actions.

A narrative conception of identity also conveniently provides opportunities to make a connection with the theory about cultural narratives discussed in chapter 3 . By stressing the social processes influencing narrative identity-constitution, as well as the historicity of the self and the vulnerability of its narrative integration, the narrative conception of identity acknowledges the interaction between the individual self and its socio-cultural context. Ewing (1990) reminds us of the deeply social and culturally constituted character of the process of identity construction in itself: "[...] we can observe that individuals are continuously reconstituting themselves into new selves in response to internal and external stimuli. They construct these new selves from their available set of self-representations, which are based on cultural constructs" (p. 258). The insight that cultural narratives play a quintessential role in providing or denying access to identity-constituting resources is essential to understanding how our individual experiences of identity and meaning in life are enabled or impaired.

\subsubsection{The relation between life and narrative}

A particularly complicated question that has been much debated in narrative philosophy pertains to the relation between life and narrative. The most general way to formulate the connection between life and narrative is by saying that through telling stories (narratives) we bring a certain order to the experiences that make up our lives. In this process, we shape who we are by telling our stories. We understand our own past by interpreting it in narrative terms and we narratively project onto the future who we wish to become. Narratives enable us to place our different "possible selves" (Markus \& Nurius, 1986) in an intelligible framework. The famous saying by Kierkegaard (2007) that life can only be understood backwards but must be lived forwards, expresses some of the complexity of this narrative process of ordering our lives into a coherent and meaningful configuration that is capable of establishing our identity. Schechtman (1996) emphasizes the importance of the connection between life and narrative by stating that "the sense of one's life as unfolding to the logic of 
a narrative is not just an idea we have, it is an organizing principle of our lives. It is the lens through which we filter our experience and plan for actions, not a way we think about ourselves in reflective hours" (p. 113).

Yet the supposed connection between life and narrative also raises a lot of questions. Do we live our stories naturally as we tell them, or are our stories mainly post factum constructions, bringing artificial ordering to a life reality that is first experienced and then told? Do our identities coincide completely with the stories we tell about them, or are our narratives only partially capable of expressing who we are? Is telling stories an inescapable psychological mechanism that all human beings use to bring order and meaning to their lives and to understand who they are (McAdams, 1993), or is telling stories just an optional activity that we can also omit? Moreover, are lives and selves that are narratively configured somehow better able to safeguard a meaningful moral identity, as authors like C. Taylor (1989) have suggested, or are both the psychological, factual claim and the normative, philosophical claim regarding the necessary and inescapable relationship between life and narrative built on biased and faulty assumptions about how people (should) live their lives, as Strawson (2004) has argued?

Thomä (1998) has provided an insightful analysis regarding the relationship between life and narrative that covers some of these questions. He describes how on the one hand, the process of telling a narrative about ourselves implies that we become an "object" to ourselves. It requires the capacity to view one's life from a reflexive distance. On the other hand, we are, as subjects, deeply interwoven with the object of our story. We tell a narrative about ourselves, about our lives, and in this narrative we present what is important and valuable to us. This suggests that our lives and our narratives are both separate as well as intertwined. We might say that our narrative identity represents our own mediation of the relation between life and narrative, which is necessarily dynamic and flexible. Thomä perceives the activity of self-narration to take place in the so-called "autobiographic triad", a dynamic and dialogical structure which engages the narrator or the author of the story, the protagonist figuring in it, and the person leading the life that the story is about. But the relationship between the self as living person, narrator and protagonist on the one hand, and the actual story being told on the other hand, is highly complex.

Thomä argues that telling stories about our lives and selves not only helps us understand who we currently are, but that stories also express something about who we want to become. There is a constant tension between these different possible selves that our narratives try to reconcile. According to Thomä, we relate to this tension by engaging in a continuous narrative search for coherence, meaning and self-understanding. How we shape our identities and our lives fundamentally depends upon narrative structures, which suggests a strong connection between life and narrative. On the other hand, Thomä 
reminds us not to forget that the protagonist, the main character of our stories, does not cover all relevant aspects of the person who is living the life that is told in the story. Correspondingly, life cannot be totally identified with narrative. The role and function of narratives in life thus has its limits. Nevertheless, narratives play an important role, since they can help us relate to the situations we find ourselves in and to integrate the unexpected existential events confronting us in our lives.

\subsubsection{Narrative integration and unified personhood}

Another particularly complicated and important question raised by the discourse on narrative identity concerns the notions of narrative integration and unified personhood, which are formulated by authors like C. Taylor (1989) and MacIntyre (1984) as ideals. For instance, MacIntyre (1984) claims that narrative identity presupposes "a concept of a self whose unity resides in the unity of a narrative which links birth to death as narrative beginning to middle to end" (p. 205). But is it necessary that we integrate our experiences into such a full, life-encompassing coherent narrative unity? While most authors do not deny the importance of a certain form of narrative coherence in one's life story (Strawson (2004) being one of the exceptions), the idea that our lives should, or even could, form fully coherent narrative "wholes", or that such unity is a necessary condition for experiencing a meaningful life, is rightly questioned. Thomä (1998) for instance, rejects the idea that life and identity could be captured in one overarching, coherent narrative that ascribes meaning to them. There are always elements in our lives escaping the context and structure of the narrative. We are not only agents, narratively structuring our lives, we are also what Ricoeur (1992) calls "patients" of action, beings "suffering" or enduring things beyond our own control as narrative agents (p. 157). This implies that our lives also contain many contingent forces that disrupt or overrule the narrative organization of our lives. The news of a sudden illness, accidents and other blows of fate, confrontations with injustice, et cetera, all confront human beings with the limits of their agential scope of control. It can be difficult to integrate these experiences into our narrative self-understanding.

This vulnerability of human lives to existential contingencies implies, as Mackenzie (2000) notes, that as far as we can speak about an integrated or unified self, this integration cannot be seen as static, although it does imply a certain stability. Instead, she argues that "the process of self-integration is an ongoing and dynamic process precisely because of inevitable tensions and inconsistencies within the self and because the different elements of the self are constantly undergoing transformation. The notion of stability does imply, however, that an agent who is persistently internally divided or whose sense of self is seriously fragmented cannot achieve the kind of reflective equilibrium 
necessary for unified agency. By unified agency I mean the kind of practical unity necessary to deliberate, make decisions and choices, and act" (Mackenzie, 2000, p. 135). It follows from these reflections that our existential vulnerability as human beings which necessitates a flexible responsiveness in dealing

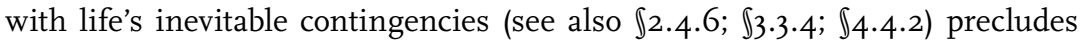
our ever arriving at a full life-encompassing narrative integration. Instead, our existential vulnerability necessitates that we find an attitude that Thomä (1998) has called "Selbstliebe [loving self-acceptance]" (p. 180). This attitude is characterized by the acknowledgment that our lives consists of both elements we can consciously control and elements that need to be endured. An attitude of loving self-acceptance is intended to help us ask and answer the question which Thomä (1998) formulates as "wie man mit sich selbst auskommt [how one gets by with oneself]" (p. 174). This attitude implies a more modest and flexible interpretation of narrative integration. When interpreted in this way, narrative integration is seen as a process of continuing attunement to oneself: who am I, how do my choices and actions relate to who I want to be, both to myself and to others? How do I deal with the things that befall me? How can I retain or regain a sense of meaning in my life in the face of adversities and existential contingencies? As discussed earlier $(\mathbb{\$} 4 \cdot 4.2)$, it is typically in moments of existential crisis, moments in which the coherence of our life stories is threatened, that such questions confront us most urgently.

M. Walker (1999a, 2007) has formulated another critique against a strong form of narrative integration. In particular, she responds to the views of $C$. Taylor (1989) on narrative unity, Williams (1981) on constitutive projects considered to be essential for a viable identity, and Rawls (1971) on the notion of a life plan. M. Walker's (2007) critical argument is that these type of ethics impose implicit standards of what a good life is on people whose life reality does not match these norms. These standards that are based on the archetypical "career self" associated with the dominant Western, male, white and affluent minority, fit "none of us at all times, and many of us at no times" (M. Walker, 2007, p. 22). The implicit norm of narrative unity can therefore be criticized for unjustly denigrating or dismissing the lives of people (often women or members of minority groups) unable to live up to its unrealistically high standards. Instead, M. Walker pleads for more sensitivity to the local and temporary forms of narrative integrity that characterize most people's life. A clarifying distinction drawn in this regard comes from Meyers (1989), who states that people direct and organize their lives both episodically and programmatically (p. 48). Whereas Meyers assumes that a coherent life plan is necessary to function as an autonomous agent, she also acknowledges that there are many situations in which it is not the overarching programmatic question how do I want to live my life that directs our actions, but the concrete considerations raised by a specific situation, which may differ from moment to moment. 
Contrary to the strong views of narrative integration by C. Taylor (1989) and MacIntyre (1984) cited above, the notion of narrative integration that I would suggest, following the critiques by Thomä (1998) and M. Walker (1999a, 2007), allows for the possibility that our lives and selves are built of multiple storylines. Some of them cover large parts of our lives, others only short episodes. Some of our storylines fit together harmoniously, while others may be conflictive. None of these storylines encompasses the entirety of who we are, our lives "from beginning to middle to end" (MacIntyre, 1984, p. 205). Still, in order to contribute to a viable sense of narrative identity, the different storylines that figure therein need to interact in such a way that enough coherence emerges to "get by with ourselves". Only then can narrative agents experience and present their life and self as a meaningful configuration. The resulting integration will always be a vulnerable, partial, fragmented and temporary constellation, but one that is nevertheless indispensable.

We seem to be confronted with a paradox then between the striving for some sense of order and coherence necessarily implied by the narrative conceptualization of identity on the one hand, and the fact that the result will always be an incomplete, partial and temporary unity on the other hand. Again, the conclusion should be that the process of narrative identity-constitution is never finished and always liable to failure. As Atkins (2008) puts it, "The unity of one's life is the product of a perpetual synthesis. However, narrative cannot guarantee a happy outcome and a coherent identity. It cannot guarantee coherent identity because it is a tensive, collaborative effort that can fail" (p. 77). At the same time, a sense of unified selfhood is indispensable if we want to realize our potential for moral agency. In Atkins' (2008) words “[...] unified selfhood is the condition of possibility for having a perspective from which to perceive, deliberate, and act. In other words, it is a condition of possibility of morality" (p. $6)$. I will return to this point in $\$ 5.4$.

\subsubsection{Narrativity and aging}

The narrative view seems to have a natural affinity with the theme of aging. This affinity offers an extra argument in favor of the narrative conception of identity over other alternatives in the context of this study. The close link between the narrative view and aging can be recognized in the fact that a narrative perspective has found particular resonance in the field of aging studies in recent decades. A whole new field of scholarship has arisen that can be described as "narrative gerontology" (Kenyon, Clark \& De Vries, 2001; Randall \& Kenyon, 2001; Randall \& McKim, 2008; Kenyon, Bohlmeijer \& Randall, 2o11; De Medeiros, 2014). In gerontological discourse, narrativity and aging are often connected because aging is associated with retrospection, looking back at one's life and drawing up the balance of one's experiences, typically in the form of 
telling or writing one's life story. Classic approaches such as Erikson's (1997) notion of ego-integrity, and Butler's (1963) life-review approach draw upon the link between narrative retrospection and aging, as do many contemporary interventions developed in narrative gerontology (Kenyon, Bohlmeijer \& Randall, 2011; De Medeiros, 2014). These approaches see reminiscence and memory as quintessential for our identity-constitution. It needs to be noted however, that this strong focus on reminiscence seems insufficiently capable of acknowledging other possibly important dimensions of the narrative view that will be discussed later. For instance, the focus on reminiscence problematically seems to presuppose a rather traditional, Lockean idea of identity that is based on the psychological continuity of memory. The narrative view of identity defended in this study on the other hand, presents a more embodied and socially embedded image. Also, the potential that narratives offer to connect our past, present and future selves is not given sufficient attention when the focus is solely on retrospection.

An important advantage of the narrative view in the context of aging is the fact that it presupposes a lifelong process of narrative self-constitution, thereby emphasizing the continuing potential for development in later life. This encompassing temporal scope is highly congenial to an approach of aging as a social-existential process of living in time (Baars, 2012a; see also $\$ 1.5)$. Moreover, it can be argued that the narrative perspective is particularly apt to address the dynamics of aging simply because, as De Medeiros (2014) emphasizes, "the more years one has, the more one has to draw on in the form of stories" (p. 18). In addition, the narrative perspective enables a study of aging from the perspective of meaning that offers a welcome alternative to more biomedical or sociological approaches in gerontology (De Medeiros, 2014).

The focus on meaning that the narrative view enables has two aspects that are relevant from the perspective of aging. First, as our lives extend through time (i.e., as we age), our stories also tend to get richer and more complex in layers of meaning. This process of enrichment ideally deepens our self-insight and our competency to navigate through our lives. As Randall (2011) puts it, as we age our stories are "continually thickening with potential for meaning" (p. 22). Cohen $(2005,2010)$ even suggests that the aging brain undergoes specific transformations that stimulate the drive to engage with one's life in an autobiographical manner, and thereby find new and creative ways to integrate painful or problematic experiences into the coherence of one's life story. Second, Randall (2011) suggests that the importance of meaning-making increases in later life, since "the older we get, the more meaning we require in order to cope with, and grow through, the losses and challenges (physical, financial, emotional) that later life can bring" (p. 24). The focus of the narrative perspective on meaning-making therefore suggests extra relevance when it comes to the integration of experiences of existential vulnerability, formulated as an important concern 
for this study's perspective on self-realization (see $\llbracket 2.5 .2$ ). It is important to mention however, that the urgency of creating viable meaning-making narratives in later life also makes us vulnerable. It has been argued that older people may suffer from narrative foreclosure (Freeman, 2000, 2011), a term describing a situation in which older people feel that their life stories are ended or stagnate while they are still alive. This phenomenon problematically impedes their experience of their life as meaningful and can result in passivity and depression. Narrative foreclosure can have many possible causes, including, of course, detrimental socio-cultural positioning through marginalizing cultural master narratives (see $₫ 3.3 \cdot 4$ ).

A final important point to mention regarding the connections between narrativity and aging concerns the recognition of later life's potential for growth and flourishing, one of the points emphasized as an important condition for this study's developing account of self-realization. The narrative view is particularly well-suited to acknowledge this potential. Randall \& McKim (2008) for instance, see the narrative engagement with oneself in later life as an important source of deepening wisdom and self-knowledge. Since the narrative approach focuses on the particularity and biographical richness of individual lives, it enables us to call attention to the uniqueness and value of the lives of older persons (Kenyon, Bohlmeijer \& Randall, 2011). An added advantage is that the attention to unique life stories of aging individuals can serve as an antidote against the adverse effect of stereotyping cultural images such as decline narratives (see $\mathbb{3} \cdot 3 \cdot 2$ ).

\subsection{THREE INTERPRETATIONS OF NARRATIVE IDENTITY}

In this part of the chapter, three distinct interpretations of narrative identity relevant to the context of this study are discussed. These three interpretations address, in succession, the views of Schechtman (1996), Lindemann (2014) and Atkins (2008).

\subsubsection{Marya Schechtman - Narrative self-constitution}

Schechtman (1996) defends what she calls a narrative self-constitution view, according to which "a person creates his identity by forming an autobiographical narrative" (p. 93). Schechtman argues that philosophical accounts of personal identity have a tendency to conflate two matters that should be distinguished. These two issues are termed the reidentification question and the characterization question. The reidentification question is concerned with "how a single entity persists through change" (Schechtman, 1996, p. 7). It takes a "time slice" approach to identity, in which a comparison of the person at time 1 and time 2 
decides whether the crucial features that enable us to speak of identity are present. The classic view of the person by Locke $(1689 / 1979)$ counts as an influential example here, as does the contemporary approach of Parfit (1984). Schechtman (1996) criticizes the reidentification approach for its reductionist image of the person. She contends that according to strong commonsensical intuition, it is what characterizes persons as they live through time in the rich practical contexts of their daily lives that is essential to questions of identity, and not their features at isolated moments of comparison. What characterizes a person through time is addressed by the characterization question, which investigates "what it means to say that a particular characteristic is that of a given person" (Schechtman, 1996, p. 73). Schechtman's own narrative self-constitution view provides the opportunity to address this characterization question.

The narrative self-constitution view contends that it is characteristic of human persons (as distinct from human individuals or human beings) that they organize their experiences and thus their life in a narrative manner. This implies that people understand and interpret their experiences by placing them in the context of a self-narrative, a story about their life that is able to provide a meaningful and more or less coherent background for their actions, choices, preferences, et cetera. According to Schechtman (1996), "individuals constitute themselves as persons by coming to think of themselves as persisting subjects who have had experience in the past and will continue to have experience in the future, taking certain experiences as theirs" (p. 94). The framework of the narrative or narratives enables persons to distinguish between what is and what is not essential to who they are. In our stories about ourselves, we select and highlight those experiences, choices, actions and value orientations that contribute most to how we perceive ourselves. For instance, if I am a person who deeply values freedom and independence, my life stories may emphasize how I stood up against the authority of my father and my teachers when I was sixteen, how I adventurously traveled the world on my own during my twenties, how my marriage is characterized by the joining of two equal partners with their own incomes and social lives, how in parenthood I strive to stimulate my children's assertiveness and independent thinking, and how the cancer that struck me in my fifties did not manage to break my fighting spirit and zest for life. On the other hand, if I am a person who values solidarity and justice, or love and care, the narratives I tell about my life will expectedly accentuate rather different highlights and experiences.

Schechtman (1996) emphasizes, however, that not just any narrative qualifies to provide a person with a coherent and meaningful sense of identity. Narratives that can function as identity-constituting do have to comply with certain constraints. In particular, she distinguishes the articulation constraint (p. 114) and the reality constraint (p. 119). These constraints respectively emphasize that it should be possible to articulate our identity-constituting narratives 
when required, and that they should sufficiently match both the objective facts of our lives and the narratives that others tell about us. Moreover, Schechtman claims that identity-constituting narratives should have a certain form that matches the linear narrative structure characteristic of conventional (life) stories (p. 96). They should also show sufficient coherence (p. 98). Mackenzie and Poltera (2010) argue that Schechtman's (1996) constraints are too restrictive. They think the formulated constraints unjustly assume that a self-narrative must be totally coherent and unified, and that a person must fully identity with it, for the narrative to play a role in someone's identity-formation. These demands neglect the possibility of internal conflicts, alienating experiences or emotional distance towards elements of the multitude of one's past or future selves. However, Schechtman defends her view by stating that her constraints do not presuppose that one is totally transparent to oneself, or self-consciously working on an autobiographical narrative all the time. Her account also allows for a variety of narrative styles. Moreover, she acknowledges that coherence and intelligibility are no "all-or-nothing" conditions, but rather matters of degree (Schechtman, 1996, p. 98). Her view does presume, however, that one has an implicit narrative organization of one's life story available. This account should be in accordance with reality and one should be able to articulate and clarify it upon request.

Besides the formal constraints that apply to identity-constituting stories, the narrative self-constitution view also presupposes that a person has certain capacities such as consciousness, reflexivity and the use of language, that are needed to form a narrative identity. Atkins (2008) has called the collection of such capacities narrative competence, which forms the basis of our narrative agency (Atkins, 2008; Atkins \& Mackenzie, 2008). Following Schechtman's (1996) account, lacking the basic capacities that contribute to one's narrative competence would mean that one does not qualify as a (full) human person and a narrative agent. This is characteristic of infants, for instance. They still need to develop the capacity to distinguish themselves from their surroundings and to perceive themselves as continuing entities with a recognizable identity encompassing a past, present and future. Lack of essential narrative capacities can also be recognized in adults suffering from certain pathologies. Dementia or Alzheimer's disease are examples of such conditions that are acutely relevant in the context of aging. Schechtman (1996) states that "those who suffer from dementia are robbed of precisely the ability to pull their lives together in a coherent story; they become terrified and confused because they cannot put the pieces together" (p. 147). Although Schechtman's description of the anxiety and confusion that befall people who are no longer able to put the pieces of their lives together in a narratively ordered coherent configuration will certainly be familiar to anyone having encountered people with dementia, her theoretical claim that such people can thus not qualify as (full) persons anymore seems 
rather bold. However, this claim may be influenced by the fact that her concept of the human person relies strongly on individual rational consciousness. In the next section, I present another view of narrative identity that takes a rather different standpoint in this regard.

\subsubsection{Hilde Lindemann - Narrative identity as a social practice}

Lindemann (2014) suggests a view of narrative identity that is able to recognize something often overlooked in mainstream philosophical accounts of identity: the fact that being human is an essentially interpersonal phenomenon. She contends that our personal identities are conferred upon us by the way others hold us in our personhood. Consequently, she describes our personal identity as a social practice which is expressed through narrative means. What Lindemann describes as the social practice of personal identity consists of four interrelated elements: 1) someone has the basic mental activity necessary to constitute a personality, 2) this personality is expressed in a human body, 3) this bodily expression is recognized by others, and 4) these others respond to the expression. Note that the first criterion is very basic and not modeled on the usual philosophical ideas of what it means to have a personality. For instance, speech or rational reflection are not necessary to this account. The ability to make eye contact or other non-verbal, bodily expressions of humanness can be sufficient to be held in personhood by others.

The focus on recognition and responsiveness in particular, distinguishes Lindemann's view from other narrative accounts of personal identity. Through our relations with other persons that are characterized by recognition and responsiveness, we are "initiated into personhood [...] and we simultaneously develop and maintain personal identities through interactions with others who hold us in our identities." (Lindemann, 2014, p. x). This initiation starts even before we are born, as a mother develops a relationship with her unborn child, and the process of holding continues after our death as long as "who we were" is preserved in the memories of those who have outlived us. Through our engagement in the social practice of identity, made up of continuous processes of recognition and response, a "narrative tissue" is created that expresses who we are, both to ourselves and to others (Lindemann, 2014, p. ix).

Narrative identity as a social practice involves both holding and letting go. By holding, Lindemann refers to a social process of weaving a network of stories around persons, stories that express who they are and what they mean to us. This weaving of storylines enables their admission to the realm of human personhood. The stories provide the resources for developing their identity, which is understood as a concretization of their personhood that is characteristically "them". Importantly, only beings equipped with the basic features of humanness can and should be held in personhood - the practice does not extend to 
animals or insentient objects, even though they can be very meaningful to us. In principle, Lindemann (2014) argues that we are morally obliged to hold everyone in personhood who can so be held, since "letting them go casts them out of social and moral life, and to live outside that is to have no kind of human life at all" (p. 120). The same emphasis on the importance of social recognition and being granted a participant status in moral life is encountered here that was discussed earlier drawing on Honneth's $(1995,2008)$ ideas $(\mathbb{3}$.2.3).

Holding someone in personhood can be done both well and badly. Good holding implies supporting the person in shaping and maintaining an identity that leads to personal flourishing and valuable social relationships. It can be said that good holding is an indispensable condition for actualizing people's potential for moral agency as it is defined in this study, i.e., that holding enables people to lead a good life with and for others, according to their own deepest aspirations and highest capacities, as full participating members of a society/community. Bad holding, on the other hand, means that people are being held captive in narratives that are damaging or restrictive. This has been illustrated in our discussion of oppressive cultural master narratives in chapter 3 .

No matter how essential holding is, in some cases, the social practice of identity may require what seems to be the opposite, namely, letting go. This applies for instance, when a certain identity from the past (e.g., the shy girl who hid herself in the closet whenever someone visited) no longer matches who a person currently is (e.g., the self-conscious mature woman who has overcome her extreme shyness, although she will never become an extrovert); it would be an injustice and morally faulty if we persisted in holding a person in their previous identity. But letting go may also be required when people have lost all mental characteristics on which their personhood could be based, such as when someone is in an irreversible coma or in the end-stage of dementia. Letting them go may then be the best possible way to honor our relationship with them.

In Lindemann's (2014) account, identity as a social practice need not necessarily involve the first-person perspective of an individual human agent. In some cases, people derive their personhood and identity solely by the fact that others hold them in it. Lindemann illustrates this with the example of her younger sister Carla who was severely disabled as a result of hydrocephaly and lived for only 18 months. Despite the fact that Carla never possessed any of the first-person competencies usually thought to be indispensable to qualify as an agent and acquire an identity (such as language, rational reflection or second-order desires), Lindemann argues that her sister was nevertheless held in personhood and invested with a specific identity from the third-person point of view of her parents, siblings and nurses. A similar argument could be made for people who do not yet or no longer possess relevant first-person competencies, for instance, infants and young children or people with cognitive disabilities such as Alzheimer's disease. The possibility that identity could be something 
one-sidedly invested on human beings from a third-person point of view, without an active contribution from the person itself, distinguishes Lindemann's account from many other philosophical views of personal identity, including the narrative self-constitution view by Schechtman (1996). Although Schechtman's account of narrative identity acknowledges that narrative identity-constitution is not done in social isolation, her view relies strongly on a first-person agential perspective. The fact that Lindemann (2014) takes a different position makes her view particularly interesting when thinking about cases in which processes of senescing gradually compromise or diminish our ability to exert a first-person influence on the world, such as in cases of dementia.

As seen, Schechtman (1996) problematizes the personhood and identity of sufferers from Alzheimer's disease ( $\mathbb{5 5 . 3 . 1 )}$. By contrast, Lindemann (2014) views such cases from a very different angle. She sketches a moving example of how caregivers hold a woman with Alzheimer's disease in the identity that she can no longer maintain by herself. This is perfectly imaginable when we realize that we start our lives in a very similar situation, argues Lindemann (2014): "When she was so young that she could not yet take part in the practice herself, [she] was held in personhood by the people who cared for her. Then, her ability to express frustration, pleasure, or other mental states gave her parents and other caregivers something on which to anchor their recognition and response they engaged in a one-sided practice of personhood. Now that she once again lacks the capacity for active participation in the practice, she may still retain enough mental functioning to be held in personhood by the other persons who touch her life" (p. 155-156). Not only are sufferers of Alzheimer's disease held in personhood by others, they also keep contributing to the practice of holding themselves, albeit, as Lindemann terms it, "clumsily" (p. 125). Note that Lindemann's account enables us to see how the loss of self usually associated with dementia and related conditions can be nuanced if this self is perceived as a social practice of holding and letting go. Having (or being ascribed with) a self is of course a necessary condition for the moral ideal of self-realization. But naturally, it is not a sufficient condition. The question whether being held in identity by others when one can no longer do so by oneself, also offers people opportunities for self-realization, is too complex to be addressed in this chapter dedicated to the theme of identity. Some thoughts on this matter are given in the final chapter of this study, where the merits and problems of self-realization discourse in the context of aging are drawn together (see $₫ 9.4 .6$ ).

The value of Lindemann's view is that it draws our attention to social facets of the practice of personhood, without denying the importance of individual human agency and the first-person perspective for our identities. She claims that the archetypical image of the self-sufficient human moral agent overlooks other equally relevant aspects of our identities that emerge from the social practices of personhood, and identities in which we are continuously involved. 
She contends that the "chosen" (representing our agency, free choice, will and self-determination, et cetera) and the "given" (representing our social context, relationships, the historical and cultural situation in which we are born, et cetera) should be granted equal weight in our understanding of what it means to have an identity, because "other things being equal, a self-understanding that values both these strands is better equipped to permit each of them to serve as a check on the excesses of the other" (Lindemann, 2014, p. 210). This standpoint makes her account highly relevant to the view of self-realization developed in this study, which aims for a similar position.

\subsubsection{Kim Atkins - Narrative identity and moral identity}

Atkins' (2008) account of narrative identity stands out because of the connection she draws between our narrative identity and our moral identity. Our moral identity is reflected in the value orientation that we appropriate (C. Taylor, 1989 ) but it is also expressed through our relationships with others (see $\mathbb{4}$ 4.2.2). Our moral agency can be regarded as the expression of our moral identity in practice. This underscores the importance of Atkins' view, connecting narrative and moral identity, in the context of this chapter. At first sight, Atkins' account of narrative identity seems rather similar to Schechtman's (1996) narrative self-constitution view, since she states that "selfhood is, essentially, an activity of self-constitution and self-understanding articulated narratively" (Atkins, 2008, p. 7). However, Atkins (2008) criticizes Schechtman (1996) for placing too much weight on the first-person perspective and the self-preservation of the individual agent through time. By contrast, Atkins (2008) proposes a more relational and phenomenological account, based on Merleau-Ponty (1945/1962) among others. Phenomenology emphasizes both our embodiment and our social embedding as fundamental to our identity. This implies that our identities are no individual creations, nor can they only be understood in cognitive or mental terms. The interventions or even sheer presence of others in our lives influence who we perceive ourselves to be. As Atkins (2008) puts it, "our interpersonal and social relations mediate our experience of ourselves and the world" (p. 44).

Atkins sees our identity as a narratively constituted, embodied continuity. She states that "Narrative identity is not simply a first-person report but a complex structure that interweaves first-, second-, and third-person perspectives into a semantic and temporal unity with a subject who attests to that identity and in doing so constitutes it as her own" (Atkins, 2008, p. 57). To this end, narrative competencies, i.e., late-developing cognitive, linguistic and communicative skills, are seen as indispensable, because they enable us to present and understand our lives as meaningful constellations of events, relationships, motives, circumstances, et cetera. According to Atkins (2008), our identity is best 
understood as an embodied, practical "unity of first-, second- and third-personal concerns" (p. 87). This is a complex formula that requires some elaboration. Traditional accounts of identity usually depart from the assumption that we qualify as human agents by virtue of our ability to take a first-person perspective. Through our ability to perceive ourselves as an "I", as exemplified in expressions such as "I can" or "I do", we see ourselves as the originator of actions. This agential self-perception is generally perceived to be a necessary condition for taking both practical and moral responsibility for our actions.

Besides the ability to take a first-person perspective, traditional accounts of identity also presuppose the ability to take a third-person perspective. This implies that we are able to reflect on our own choices, values and preferences as if we were seeing them from the perspective of a stranger, a third person outside ourselves. The (critical) evaluation of one's own motivations and choices that this perspective enables is traditionally believed to be essential to realize autonomous human agency (Frankfurt, 1971; C. Taylor, 1985a; see also $\$ 4.2 .2$, \6.2.2). The third-person perspective thus equips us to act as human agents by enabling us to make well-founded choices about our own actions and motivations. It also serves as a corrective to the self-deception that may characterize our first-person perspective.

Generally, narrative views of identity assume some form of dynamics between the first-person and the third-person perspective in the process of narrating one's life, although Lindemann's (2014) account suggests the possibility of a narrative identity being held by others in cases where a conventional understanding of the first-person perspective is absent. Traditionally, the first-person point of view represents the agent living the experiences in practice, i.e., the protagonist of the story, whereas the distance presupposed by the third-person point of view represents the narrator who organizes these experiences into a coherent plot. Atkins' (2008) view also stresses the importance of the first-person and third-person perspective in our understanding of identity. However, on two important (and interrelated) issues Atkins presents a different image of narrative identity that is of great relevance for the purposes of this study:

- First, whereas the traditional views situate our ability to take a first-person perspective in the cognitive realm of our mind or rational consciousness, Atkins emphasizes the constitutive role of our embodiment. In the phenomenological account, our first-person perspective is rooted in our embodied being, through which we are pre-reflexively related to and embedded in the world surrounding us. In this sense, Atkins' account seems to match well with Lindemann's (2014) perspective on the basic criteria someone needs to answer to in order to be a participant in the social practice of identity (see $\$ 5.3 .2)$. For Atkins (2008), our third-person perspective is only possible by virtue of our pre-reflexive embodied being-in-the-world. Although our 
narrative competency is regarded as quintessential in the creation of our identities, the emphasis on embodiment makes us aware that this competency is something we develop gradually. We are not born with narrative competence, and our ability to acquire it is rooted in our embodied relation to the world that precedes our reflexive and narrative self.

- Second, Atkins claims that if we want to fully understand the nature of our identity we should include a second-person perspective in addition to the firstand third-person point of view. This second-person perspective represents our concrete, practical moral relations to other people, which are rooted in our embodied being. For Atkins, the acquisition of a third-person perspective on ourselves is necessarily preceded by the second-person relations we are engaged in, as is expressed in the following quote: "to arrive at a conception of myself as a generalized other [i.e., the third-person perspective, HL], I must also be a concrete other for a concrete someone; that is, I must stand in a second-personal relationship. It is one's embodiment that lays the groundwork for this experience" (Atkins, 2008, p. 45).

Our second-person concerns describe our intersubjective moral engagement with other people. Similar to Lindemann's (2014) views discussed in the previous section, this implies that recognition and response to another person and their needs are seen as crucial for our identities by Atkins (2008) as well. Our recognition and responsiveness provide the fundamental basis for our moral relationships with other people. A resemblance can be found here with the work of philosophers like Levinas (2003) or Buber (1958). For them too, answering the second-person appeal of the other, forms the beginning of morality. What Buber calls an "I-Thou" relationship has a transcendent character that enables recognition of the invaluable particularity of the other person.

The aforementioned position suggests that the second-person perspective confronts us with a fundamental difference in relating to the world of objects and relating to another person. As Atkins (2008) underscores: "The presence of another person immediately affects the constitutive relations of my situation in ways that a mere object never does because I experience another person, not as an object, but as an agency within my world, a self-originating power of change within my world. The appearance of another person does not simply add to my perceptual field; he fundamentally alters the orientation of my world and the organization of my experiential field. [...] In this way my sense of own agency is affected by my interaction with another's" (p. 51). By engaging in second-person relationships, we honor what the other person means to us. At the same time we also establish and maintain our commitment to who we want to be ourselves. We principally open ourselves up to the possibility of being touched and transformed by our relationships with other people. A friend questioning my loyalty to her when I get too absorbed in my work calls for a practical response 
to her needs, of course, but can (and maybe should) also make me reconsider my priorities in life and decide that I need to change something. Thus, how I choose to react to the second-person appeal that others make on me expresses something about the relationship between myself and the other. It also expresses something vital about who I am and who I strive to be. My moral identity and my relationships with others are thus intrinsically interconnected. This indicates that my relationships with others exercise an imperatival force on my identity-constitution, and not just on my actions.

In addition to the first-person dimension and the third-person dimension of our identity, the second-person dimension draws our attention to the fact that our identities do not solely depend on our own rational choice or our ability for reflection; they are also created in and through our relationships with others.

Consequently, by introducing the second-person perspective in her narrative view of identity, Atkins (2008) not only acknowledges the social dimension of identity (which is also already partially included in the third-person perspective), but its moral dimension as well. The second-person perspective expresses our ability to be touched by others in an ethical sense, to take an interest in their well-being and to feel the moral appeal to respond to their needs. It is in the process of developing our narrative identity then, characterized by connecting the first-, second- and third-person perspective, that we realize our agency as a moral agency.

\subsection{From naRRative IDENTITY to MORAL AGENCY}

So far, I have argued in favor of a narrative interpretation of identity, because such interpretation appears to be an auspicious match with the account of self-realization that is developed in this study. One element of this match pertains to the congeniality of the narrative view with the concept of the self that has been defended in $\$ 4.2 .2$. A second element of this match pertains to the opportunity that the narrative view offers of drawing a connection between the selves we strive to realize and, broadly defined, morality. Given this study's interpretation of self-realization as a process of moral self-development aimed at the optimization of our potential for moral agency (see $\$ 4.2 .1$ ), this is highly relevant.

So far two relevant positions regarding the connection between our identity and morality have been discussed. Both views assume that narratives play a vital role in constituting this connection. The first is the view of C. Taylor (1989), who claims that in order to know who we are, we have to be able to articulate our position relative to the good (see $\mathbb{4} 4$.2.2). Importantly, this need for articulation is one of the reasons that C. Taylor prefers a narrative conception of identity. He believes that it is only through articulating our motivations and 
experiences in the context of a coherent narrative that we gradually arrive at a proper understanding of ourselves and what we regard as worthy moral goals to strive for. The second view that was discussed regarding the relationship between narrative identity and morality is that of Atkins (2008; see $\ 5.3 .3)$. Her addition of the second-person perspective as an intrinsic part of our narrative identity draws attention to another aspect of our moral identity, namely our relationships with other people. Both C. Taylor's and Atkins' accounts suggest an intrinsic connection between narrative identity and moral identity. However, a transition still needs to be made from these narratively mediated views of moral identity to moral agency. Tentatively, moral agency has been described so far as the way we express our moral identities in the context of human practices. Only by translating our identity-constituting orientation towards a certain good and our commitment to others into actions (or refraining from action), can we complete the process of moral self-development that represents our self-realization.

A philosopher who may help us understand the connection between human action, narrative identity and morality is Ricoeur $(1991,1992)$. His work is very rich in layers of meaning and its complexity far exceeds what can be discussed in the context of this chapter. Still, a discussion of some of his insights can enhance and deepen the understanding of the potential connections between narrative identity and moral agency. Ricoeur's view, even if it can only be discussed briefly and incompletely here, provides an invaluable bridge towards my own composition of a viable understanding of moral agency in $\$ 5.5$. In his impressive set of studies combined under the title Oneself as another, Ricoeur (1992) engages in what he calls a "hermeneutics of the self". He provides a sophisticated account of what it means to have an identity. His account aims to escape the pitfalls of both the "exaltation" of the individual subject characteristic of the Cartesian cogito (and its modern heirs), and the "humiliation" of the subject characteristic of the Nietzschean anticogito (and its postmodern heirs) (Ricoeur, 1992, p. 4). By suggesting a narrative view of identity that does not presuppose any core essential self, while at the same time stressing the ethical necessity of constituting a narratively unified selfhood, Ricoeur tries to find a middle road between these two extreme positions.

In order to understand the value of Ricoeur's account for the concept of moral agency, at least four elements of his view need to be discussed in more detail: 1) his distinction between identity as sameness and identity as selfhood; 2) his thoughts about the relationship between the self and other; 3 ) the mediating role that narrative plays between the realm of action and the realm of ethics; and 4) his distinction between ethics and morality, including his definition of what he terms the ethical aim of human life. 


\section{Sameness and selfhood}

Ricoeur (1992) distinguishes two meanings in which the concept of identity can be used. The first is identity as sameness, or idem-identity. The second is identity as selfhood, or ipse-identity. Though these two meanings may sometimes seem to overlap, they are not the same. Identity as sameness provides an answer to the question what the individual is. By contrast, identity as selfhood provides an answer to the question who the person is. It is in particular Ricoeur's concept of identity as selfhood that enriches our understanding, since it introduces an interpretation of the moral self that, though often overlooked in philosophical discourses of identity, is very congenial to the interpretation of self-realization.

Identity as sameness and identity as selfhood overlap at the component that Ricoeur calls permanence in time. He argues that permanence in time can be understood in two distinct ways, one corresponding to identity as sameness, the other corresponding to identity as selfhood. The first meaning of permanence in time is what is manifested if we speak about someone's character, defined by Ricoeur (1992) as "the set of lasting dispositions by which a person is recognized" (p. 121). These dispositions may be expressed in the habits a person has acquired, that have gained a certain "sedimentation" in the form of character traits. It is through these dispositions that the continuity of our identity through time is safeguarded. People recognize us by our character, and are surprised if we act "out of character". What is manifested in this meaning of permanence in time is comparable to what Schechtman (1996) describes as the characterization question (see $\$ 5 \cdot 3 \cdot 1$ ). With the second meaning of permanence in time we leave the realm of sameness and enter the realm of selfhood. This second meaning describes a very different concern than the continuity underlying our character. This concern is symbolized by Ricoeur in terms of "keeping one's word" or self-constancy (p. 118). Whereas the permanence of character (sameness) can in principle be described in generalizing terms (for example, someone is a shy person, or a quick-tempered one), the permanence of self-constancy (selfhood) requires an individual answer to the question who do I want to be? This question is suited for the concrete practical situation, and answering it calls for practical wisdom rather than the application of moral principles. Our answer is uniquely personal and cannot be generalized.

According to Ricoeur, our narrative identity is characterized by a constant dialectic between sameness and selfhood. Character and self-constancy stand in mutual connection and are constantly renegotiated in relation to one another. For example, frugality may be a defining feature of my character, something I value and something others recognize me by. But if I have made a promise to help refugees in need (a commitment that I need to honor in order to maintain self-constancy), I may be prompted to re- 
consider my own habit of frugality and generously spend my money on food and blankets. Both my habits and my ethical commitments are identity-concerns that deserve to be honored and taken seriously, but in the one case, we are dealing with identity as sameness (character) whereas in the other case, we are dealing with identity as selfhood (self-constancy). The required means to reconcile possibly conflicting tendencies in the dialectic between selfhood and sameness into a coherent identity is narrative. In our example, this may lead me to refine my narrative self-presentation in the sense that while I am normally characterized by frugality, I will set this habit aside when a cause I consider worthy requires so. Note that these reflections on self-constancy take us from the realm of moral identity to the realm of moral agency, and illustrate the intrinsic connection between the two. Our answer to the question who we are requires not only the ability to articulate our position in relation to what we regard as good (our moral identity), but also our commitment to live up to this moral orientation and act upon it in concrete practical situations (our moral agency). If we lack either the motivation, the ability or the opportunity to live up to our own ethical commitments, our self-constancy - our identity as selfhood - is inevitably compromised. From my perspective of self-realization as directed towards optimizing our ability for moral agency, this is a relevant observation. It emphasizes how important it is to be able to formulate purposes that represent a good life for us, as well as live up to these ideals in concrete practical circumstances. If there are causes that impede this striving, either internal or external to ourselves, these need to be overcome for us to realize the best within us and lead a good life.

2. Self and other

In Ricoeur's view, what we conceive as the good life is not an individual, isolated construction, but a dynamic ideal we share with others. We are engaged with other people in a continuing striving for a good life. Through our relationships with other people, we inevitably enter a moral field in which we aim to realize the good life in interaction with them. This is not to say, of course, that all our relationships are automatically morally valuable or beneficial. There are many possible relationships that are in fact morally detrimental to the people involved, such as relations between the oppressor and the oppressed, or relationships characterized by indifference or neglect. What is difficult to imagine following Ricoeur's account, however, are relationships that fall outside of any moral field. Identity as selfhood presupposes that there is always something at stake in our relationships with others. What is at stake, for instance, are the different forms of recognition (which can be either present or absent) that have been described by Honneth (1995, see $\$ 3$.2.3). The crucial role of recognition was also encountered in the views of narrative identity by Lindemann (2014) and Atkins (2008) 
discussed above (see $₫ 5 \cdot 3.2$ and $\ 5 \cdot 3 \cdot 3$ ). Ricoeur (1992) too, uses the term recognition to characterize what is manifested in what he terms the dialectic between selfhood and otherness, another of the fundamental "dialectics" involved in his hermeneutics of the self (p. 296).

It follows that our relationships can never be morally neutral and, consequently, neither can our identities. Our relationships make us enter a domain in which we strive for what Ricoeur (1992) has called the "ethical aim": "a good life, with and for others, in just institutions" (p. 172; see below). Ricoeur assumes that when identity as selfhood is manifested, the other cannot be viewed as something external, simply that which is different or distinct from the self. Instead, otherness should be viewed as something that is constitutive of identity as selfhood. As Ricoeur (1992) puts it, "the selfhood of oneself implies otherness to such an intimate degree that one cannot be thought of without the other, that instead one passes into the other" (p. 3). In his account of self-constancy or identity as selfhood, Ricoeur uses the analogy of friendship to describe the ethical commitment rooted in our identities that underlies the dialectic between the self and other. This seems to point to an Aristotelian inspiration. For Aristotle (Ethica Nicomachea, VIII-IX, 1155a1-1172a15) friendship was a very important virtue. In particular, the analogy of friendship underscores that for Ricoeur (1992), our selfhood is an essentially relational phenomenon.

Consequently, Ricoeur emphasizes that the faithfulness to our promises that constitutes our self-constancy is both a faithfulness to ourselves and a faithfulness to others. After all, self-constancy assumes that we are engaged in relationships with others to whom we feel dedicated enough to keep our promises. In this sense, Ricoeur rejects the suggestion that a concern for our own identity is a selfish concern. Instead, a concern for the other is always included in our concern for our own identity (as selfhood or self-constancy). What can be learned here from Ricoeur is that our identity is necessarily a moral identity, not only because of the fact that we position ourselves in relation to the good (C. Taylor, 1989), but also because our identities, in their very structure, presuppose an ethical engagement with the good of others that prompts us to act in a certain manner. According to Ricoeur (1992), the other is not an "externality" outside us, but is instead "enjoined as the structure of selfhood" (p. 354).

3. Narrative as mediator between action and ethics/morality

Narrative, for Ricoeur, has a mediating function between the realm of human action and the realm of ethics and morality. Actions are ordered and interpreted by placing them in a narrative configuration by a process that Ricoeur (1992) terms emplotment (p. 141-142). Through emplotment, we can integrate our actions, together with contingent events, characters, motivations, et cetera into a coherent narrative that provides the foundation for a 
unified experience of the self. As said in $\$ 5.2 .3$, a meaningful sense of identity requires a certain ordering of facts and events, which Ricoeur (1992) calls concordance. On the other hand, he acknowledges that our lives are in fact characterized by many forms of discordance, elements that challenge the continuity and coherence of our identity as sameness. Both the discordant and concordant elements of our lives need to be brought together in a narrative structure. It is this narrative that provides us with a sense of who we are, a viable sense of identity that we can rely on when we navigate our lives. As Ricoeur (1992) puts it, "It is indeed in the story recounted, with its qualities of unity, internal structure, and completeness which are conferred by emplotment, that the character preserves throughout the story an identity correlative to that of the story itself" (p. 143).

Importantly, it follows that narrative integration or unified selfhood are, in Ricoeur's view, not so much a transcendental condition of identity that describes an essential "core" of our selves or a life-encompassing whole - the view that rightly raises critique (see $\$ 5.2 .3$ ). Instead, narrative integration points towards a dynamic, unstable and fluctuating, but nevertheless indispensable pragmatic condition for upholding a moral identity, which in its turn is required for exercising moral agency. The importance and indeed the indispensability of a notion of unified selfhood is expressed by Ricoeur (1992) through the following rhetorical question: "How, indeed, could a subject of action give an ethical character to his or her own life taken as a whole, if this life were not gathered together in some way, and how could this occur if not, precisely, in the form of a narrative?" (p.158).

Through our narratives, we also articulate what constitutes a good life for us. From this emerges an orientation towards certain ends that we identify with and want to strive for. Our narratives not only hold a retrospective importance, by ordering experiences after the fact, they also prospectively help us orient ourselves towards future goals. This orientation implicitly forms the guiding principle in how we choose to act in the present, which further underscores the mediating role of narrative between action and our ethical commitments. As Ricoeur (1992) puts it, "Is not the choice among several courses of action a choice about ends, that is, about whether they conform more or less closely to an ideal in life-conform, that is, to what each person considers his or her aim of happiness, his or her conception of the 'good life'?" (p. 174). By virtue of its connections with our conception of the good life, a narrative can therefore never be ethically neutral, but functions as "the first laboratory of moral judgment" (Ricoeur, 1992, p. 140). We learn to distinguish between right and wrong, and formulate what is valuable to us, what we want to remain true to, by constructing our narrative identity through telling stories about our experiences and relating them to who we wish to become. For instance, if I have made a mistake which I regret, this 
causes tensions with my narrative self-image, because my action is not in sync with how I want to be. This situation calls for narrative repair. By articulating (to myself or to others) what I have learned from my mistake and how I hope to avoid it in the future, I accomplish three things: I restore the coherence of my self-image that was threatened by my mistake, I transform a disruptive experience into a purpose for the future, and I communicate this intention (either to myself or to others, depending on who I address my narrative to) which helps me keep it. Through our narratives then, we communicate our ethical commitments to others and, in dialogue with them, participate in a lifelong continuing common striving towards a good life. For Ricoeur (1992) it is the narrative that enables us to make connections between the descriptive level of our actions and the prescriptive level of morality and ethics (p. 170).

4. Ethics, morality and the "ethical aim"

Ricoeur makes an important distinction between the dimension of morality and the dimension of ethics. Usually, in moral philosophy the term ethics is simply understood to describe the study of morality, or ethics and morality are even treated as synonyms. But Ricoeur takes another perspective. Morality as he understands it represents the domain of rules, principles and rights that is dominant in many contemporary approaches to moral philosophy, for example, in Kantian deontological perspectives. Ethics, on the other hand, pertains to our common concern to lead a good life. This matches the teleological Aristotelian tradition in moral philosophy. As Ricoeur (1992) puts it, ethics is concerned with "that which is considered to be good" while morality pertains to "that which imposes itself as obligatory" (p. 170). It is ethics, then, that is concerned with the aim of a fulfilled or well-accomplished life, the best at stake in self-realization ( $\$ 4 \cdot 3$ ).

Ricoeur regards the ethical teleological dimension to have fundamental primacy over the moral dimension. He emphasizes, however, that our ethical concerns and considerations should pass through the sieve of norms and principles of morality in order to ensure their validity. This serves to test the actions and intentions that flow from our ethical concerns for their moral permissibility. Someone advancing an image of the good that involves morally illegitimate actions such as the oppression or extirpation of other people (as in the case of dictatorial regimes with an ideologically driven ideal of "racial purity", for instance) can be argued to hold a deluded image of a good that is not worthy to guide people's lives.

Moral norms, celebrated by the deontological tradition in moral philosophy, should be granted their rightful place according to Ricoeur, but they cannot have the final word. The teleological "ethical aim" is granted primacy. In cases where moral norms lead to impasses in solving concrete moral dilemmas in practice, we should take recourse to the Aristotelian tradition 
of practical wisdom, searching for the course of action that best contributes to the realization of the ethical aim of human life. This ethical aim is formulated by Ricoeur (1992) as "a good life, with and for others, in just institutions" (p. 172). However, what this broadly and rather vaguely formulated ethical aim of human life means for a particular human agent in a particular situation needs to be decided in the context of concrete practices, which have their characteristic internal good. This concretization requires what Ricoeur (1992) calls "moving back and forth between far-off ideals, which have to be made more precise, and the weighing of the advantages and disadvantages of the choice of a given life plan on the level of practice" (p. 177). Again, narrative seems to play an important role, since it is through narrative that we are able to make our choices and actions intelligible in light of our ethical commitments to what we perceive as the good life.

According to Ricoeur (1992), there is a sort of "hermeneutic circle" between our ethical aim of a good life and our concrete daily life choices in the context of human practice, where our actions should ideally be in accordance with our overarching ethical aim (p. 179). This requires a constant interpretation and reinterpretation of ourselves, of what we want to be faithful to. Narrative is, as previously observed, the perfect mediating instance for this hermeneutic activity of the self. The first part of the phrase Ricoeur (1992) uses to describe the ethical aim, the good life, is "for each of us, the nebulous of ideals and dreams of achievements with regard to which a life is held to be more or less fulfilled or unfulfilled" (p. 179). This formulation shows interesting parallels with how the purpose of self-realization is described in this study in $\mathbb{4}$ 4.2.1. It was argued there that the purpose of self-realization involves our "highest aspirations" and/or "best capacities" (compare with Ricoeur's "ideals and dreams"), the successful realization of which contributes to fulfilling the "best" that is within us (compare Ricoeur's "fulfilled or unfulfilled life"). The good life presupposes our identification with certain moral ideals, values, or aspirations, an identification that everyone is called to make on the level of their own individual life, against the background of a social and cultural horizon of meaning that provides the resources. The second part of the phrase describing the ethical aim, with and for others, points towards the fundamentally social and interpersonal character of the striving for a good life. In Ricoeur's view, the good life can only be good if we acknowledge that it is a life of shared goods that can only be constituted and realized through our relations with others, which he characterizes with the term solicitude. This term expresses a relationship of mutual concern for each other, which is founded on the fact that human beings are intrinsically vulnerable beings. Solicitude is modeled on an Aristotelian understanding of friendship, in particular the non-instrumental, non-hedonic type of friendship in which we strive with and for others for a good life. Friendship, 
argues Ricoeur, fills a lack at the root of human existence; we need each other to fulfill ourselves. This implies a mutual, symmetrical relationship between the self and other, which does not grant primacy to either one. In this sense, Ricoeur's account differs from both individualistic "egological" interpretations and from ethical accounts such as Levinas' (2003) who presumes an asymmetrical primacy of the other. It is through the mutuality of solicitude, which describes our relationship to others under the pretext of the ethical aim, that we become aware of both the irreplaceable value and the inescapable existential vulnerability of human existence. According to Ricoeur (1992), "Solicitude adds the dimension of value, whereby each person is irreplaceable in our affection and our esteem. In this respect, it is in experiencing the irreparable loss of the loved other that we learn, through the transfer of the other onto ourselves, the irreplaceable character of our own life. It is first for the other that I am irreplaceable" (p. 193).

The third part of the phrase describing the ethical aim, in just institutions, brings the ethical aim to the societal plane. It gives voice to the intuition that a good life needs to be shared with all members of a historical community, and should be safeguarded by just institutions, individual-transcending structures of living together that ensure equality for all. Thus, in the formulation of the ethical aim the individual, interpersonal and societal dimension of the good life are intrinsically connected.

\subsection{Conclusion: COMPOSING A DEFINITION OF MORAL AGENCY}

In this chapter a selection of narrative accounts of identity has been discussed, that may serve to clarify a specific aspect of the interpretation of self-realization developed in this study, namely its purpose, which I have defined as the optimization of one's potential for moral agency in $\$ 4$.2.1. Let me start with a short recapitulation of the relevance of the discussed views for our purposes.

Schechtman's (1996) view put us on a specific track that emphasizes how our personal identity should be seen as a process developing through time, which defines how people can be characterized. Narrative was presented as the means through which we constitute this evolving identity. Schechtman's focus on the characterization question is very valuable in drawing connections between self-realization and aging. After all, it emphasizes that narrative self-constitution is a lifelong process that connects the different temporal dimensions of existence. This also facilitates ascribing the potential for growth and development not only to youth, but also to later life. However, the fact that her account relies on a rather cognitive and rational image of the agent was argued to be problematic. Lindemann's (2014) account helped us overcome this limitation by offering an alternative image of personal identity as a social practice. Her view 
draws attention to something about our identities that appears to be so self-evident that it tends to be overlooked: the fact that we cannot form or maintain a personal identity without the contribution of others. If we disregard the social dimension of our identity-constitution and the way our self-narratives are connected with the narratives of others, we risk succumbing to precisely the problematically atomistic, self-sufficient image of the human agent that this study's reframed account of self-realization wishes to leave behind. Atkins' (2008) view too, is sensitive to the social dimension of identity. Her account emphasizes the pre-narrative foundation of our human being, rooted in our embodiment. But even more importantly, Atkins' view enables us to see the intrinsic connection between our narrative identity and our moral identity, by bringing into high relief our intersubjective engagement with others, through the introduction of the second-person perspective in addition to the first-person and third-person perspectives that figure in other accounts of identity and agency as well.

Ricoeur's (1992) view helps us raise the connection between narrative identity and the ethical or moral dimension of our lives to a different level. By introducing the distinction between sameness and selfhood he draws attention to an aspect of identity that could not be addressed through Schechtman's (1996) characterization question. His focus on selfhood and self-constancy underscores the importance of what we want to be true to in our lives. Besides drawing attention to our identification with certain values, aspirations or capacities that we regard as best or highest, Ricoeur (1992) also emphasizes that self-constancy prompts us to live up to our ethical commitments in the practice of daily life. This extends the scope of attention to include not only moral identity but also moral agency. Moreover, his formulation of the ethical aim of human life also emphasizes the crucial connection between the individual, social and societal dimension that is indispensable in our understanding of a good life. Ricoeur's distinction between ethics and morality is highly conducive to this study's developing view of self-realization, because it offers an account of ethics as fundamentally concerned with a good life, without taking a polarizing position towards more deontological or procedural accounts. Moral rules and principles are important, but they should be embedded in the broader ethical aim of human life. The resulting inclusive account of ethics provides a welcome match with the interpretation of self-realization that this study advances.

The philosophical positions discussed in this chapter have assisted me in composing a definition of moral agency as the purpose of self-realization - in this study's interpretation of that concept. Although moral agency is often understood as the ability to act according to the principles and rules prescribed by morality, I conceive it in a broader manner. Drawing on several intuitions and arguments encountered so far in my search for a viable reinterpretation of self-realization, I suggest a definition of moral agency as an ability that unites four distinct components: 1) to lead a good life 2) with and for others, 3) ac- 
cording to one's deepest aspirations and best capacities, 4) as full participating members of a society/community. Let me consider the four elements of this definition in turn.

1. First of all, making the phrase a good life central to my definition of moral agency expresses that this study's view of self-realization is rooted in an understanding of ethics as fundamentally engaged with leading a good life, instead of focusing on rules, principles and procedures for legitimating actions (see $\llbracket 1.6 .1)$. As seen, the good life also has a prominent place in Ricoeur's (1992) formulation of the ethical aim of human life. Defining moral agency broadly as the ability to lead a good life, however, raises the question what a good life is. The insights discussed in this and the previous chapter suggest that this is not for the individuals to decide by themselves alone. This is because in the first place we live our lives as fundamentally socially embedded creatures, as argued in $\$ 4.2 .2$ and also confirmed by Lindemann (2014; see $\$ 5$.3.2). A good life is a life shared with others, who have a say in what is perceived as "good". In the second place, ascribing value to something presupposes a cultural horizon of meanings that transcends the individual realm, as also argued by C. Taylor (1989).

On the other hand, my conceptualization of self-realization requires that maximal space is offered for individual appropriation and differentiation of the candidate goods that are available in a given social, cultural and historical context. Self-realization in circumstances of late modern moral pluralism requires that people can formulate and strive for their own deepest aspirations and best capacities. Being subjected to a conceptualization of the good that is not self-appropriated will impede one's chances for self-realization. Therefore, we should be very reticent about prescribing or imposing specific conceptions of the good as normative for everyone. The important exception to this reservation is, of course, that the individual appropriation of a value orientation is itself stimulated as necessary and valuable. This suggests a normative position in which a life with a self-appropriated orientation towards the good (however its concrete interpretation!) is perceived as better than a life without such an orientation. This normativity is legitimated in my view by the thought that it is a very fundamental feature and longing of human existence to aim for a good life, and that lacking any orientation (no matter how implicit it remains most of the time) is likely to undermine such striving.

Importantly, the criterion of self-appropriation of what is good does not necessitate an atomistic image of the human moral agent as fully self-sufficient. What we conceive as good in life can only truly qualify as a good if it can be intersubjectively legitimated. The insights in this chapter have highlighted that narratives play a quintessential role in this regard, because 
they help us to articulate what we regard as good, and communicate this with others.

2. The second part of my definition of moral agency with and for others, borrows from Ricoeur's (1992) formulation of the ethical aim, and underscores the social dimension of the self to be realized in self-realization. My formulation of moral agency thereby aims to provide an alternative to the late modern account of the purpose of self-realization which, as we have ob-

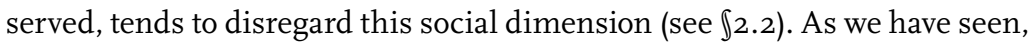
Ricoeur emphasizes that the role of the other in our identities is not restricted to concrete other people external to ourselves, but that the perspective of the other is also integrated in our own identities. Emphasizing that moral agency not only assumes that we strive for a good life with others, but also for others, implies that the best in human beings (the purpose to be realized in self-realization, see 4.2 ) includes the ability to engage with the good of others, and through this engagement realize our own fulfillment.

The phrase with and for others is not only meant to do justice to the social dimension of the self in self-realization, but also to its moral dimension, which has been discussed by Atkins (2008) through her introduction of the second-person dimension $(\mathbb{\$ 5} \cdot 3 \cdot 3)$, and by Ricoeur (1992) through his notion of solicitude ( $\$ 5.4)$. Importantly, it seems to be this moral dimension that confronts us with both the inalienable value and the intrinsic existential vulnerability of our existence. In this sense, the with and for others part of my definition of moral agency repairs one of the shortcomings that I observed in the late modern discourse of self-realization, namely, its inability to meaningfully integrate the dimension of existential vulnerability

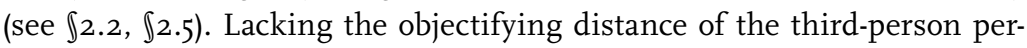
spective or the agential self-sufficiency of the first-person perspective, the second-person ethical commitment to answer to the appeal of others makes us aware of the fact that we may hurt or damage other people, or be hurt or damaged by them. We also realize that our commitment and engagement with other people makes us vulnerable to losing them - and thereby losing something of highest value in our lives, a part of ourselves. Paradoxically, the ability to lead a good life with and for others thus includes acknowledging the limitations of our own scope of agency, the insight that we are not only acting but also suffering beings (Ricoeur, 1992).

3. The third component of my suggested definition of moral agency, according to one's deepest aspirations and best capacities, refers back to the discussion of the purpose of self-realization in \$4.2.1, notably to Gewirth's (1998) distinction between aspiration-fulfillment and capacity-fulfillment. The phrase expresses that it is crucial for our moral agency that we have the opportunity to form the type of deep aspirations that are constitutive of our identities. As I have discussed in the current chapter, I propose an account in which 
these identity-constituting orientations towards certain purposes and values in life are formed along narrative lines. A strong parallel can be seen between Gewirth's notion of identity-defining aspirations, Schechtman's (1996) self-constituting narratives, and Ricoeur's (1992) notion of self-constancy, for example.

However, as I have observed in my discussion of the work of Ricoeur (1992), moral agency not only assumes that we develop aspirations and commitments that guide our identity-formation, it also presupposes that we have the capacities to live up to them. Translating our identity-constituting orientation into concrete choices and actions presupposes that we possess those fundamental qualities that are expressed in my definition of moral agency by the phrase best capacities. As has been discussed, opinions may differ on what our best or most crucial capacities are when it comes to self-realization. Gewirth (1998) has a preference for reason as a distinctive and superior human quality, whereas others criticize what they regard as a rationalistic bias, and suggest capacities of care and sympathy as more fundamental. The views discussed in this chapter seem to suggest a central place for what Atkins (2008) has called narrative competence, as conditional for articulating our ethical commitments, and for Ricoeur's (1992) notion of self-constancy as our capacity to be true to our word. These seem quintessential capacities in order to realize what is best in ourselves and actualize our potential for becoming a moral agent.

4. The fourth and final component of my definition describes an indispensable condition that needs to be fulfilled in order to optimally realize moral agency. The phrase as full participating members of a society/community is inspired by Lindemann Nelson's (2001) views about repairing identity damage and thereby enhancing people's moral agency (see $₫ 3.2 .4$ ). This repair necessitates restoring people's opportunities to strive for the lives they value and the purposes they appropriate. Enhancing moral agency assumes, however, that people are given maximal opportunity to participate in society as full and equally valued members. Without such opportunity for participation, we can expect that people experience problems with freely appropriating purposes that are valuable to them, or forming the relationships with others that are crucial to their flourishing.

Full participation relies on recognition on all three levels that were distinguished by Honneth (1995, see \3.2.3). Moreover, it also presumes the availability of what Ricoeur (1992) in his ethical aim calls "just institutions", which should "govern the apportionment of roles, tasks, and advantages or disadvantages between the members of society" (p. 200). Depending on these advantages and disadvantages, our chances for full participation in society are decided. Thus, to realize moral agency, everyone should ideally 
be given the support they need to articulate what constitutes a good life for them, and be given the opportunity to live up to what this requires.

Optimally realizing one's potential for moral agency as defined above is not an easy task. It requires enduring efforts on the part of the individual (which may fail), it requires the availability and accessibility of needed resources (which is certainly not self-evident), and it requires advantageous social conditions (but our relations with others are fragile and vulnerable to loss and break-ups). Self-realization emerges, once again, as a precarious striving which is susceptible to both contingent and existential vulnerabilities. However, it is the promise of a good life inherent in Ricoeur's (1992) formulation of the ethical aim that prompts me to keep underscoring the value of striving to enhance our opportunities for moral agency, even though they may never be completely fulfilled. 


\section{Chapter 6 - Autonomy}

\subsection{INTRODUCTION}

In $₫ 4.3 .2$, I argued that three dominant threads weave the rich and complex fabric of self-realization discourse: autonomy, authenticity and virtue. This chapter is dedicated to the first thread, namely, autonomy. The main question here is how autonomy is best interpreted in order to match the reframed account of self-realization constructed in this study. As Holstein, Parks and Waymack (2011) emphasize, "How we think about the self informs our understanding of the nature of autonomy" (p. 22). Therefore, what I am looking for is a conceptualization of autonomy that is in sync with the insights on narrative identity and moral agency discussed in the previous chapter. These insights include the fundamental social embedding of human beings and their mutual interdependence, as well as the narrative, embodied and moral nature of our identities. Moreover, since it is the underlying goal of this study to ultimately arrive at an understanding of self-realization that can serve as a resource for cultural counter narratives about later life, this chapter also connects the philosophical insights about autonomy to the context of aging.

The chapter proceeds to discuss these matters as follows. I start by introducing the philosophical debate about autonomy through a brief sketch of the classic historical view of Kant $(1785 / 2002)$ that many contemporary views explicitly or implicitly relate to (\$6.2.1). Next, I introduce one of the most dominant contemporary views, which focuses on procedural conditions for qualifying actions as autonomous: the so-called hierarchical account by Frankfurt (1971) (\$6.2.2). I then discuss some fundamental critiques that can be brought up against the Frankfurtian account (\$6.3). These critiques are exemplified by a brief discussion of the alternative views of C. Taylor (1985a) (\$6.3.1), Ekstrom $(1993,2005)$ (\$6.3.2), and Meyers (1989) (\$6.3.3). The final alternative account discussed is the relational view suggested by MacKenzie and Stoljar (2000) (\$6.3.4), which represents the most fundamental critique and aims for a true paradigm shift in philosophical thought about autonomy.

After discussing these philosophical accounts of autonomy, in $₫ 6.4$ the discussion zooms in on how autonomy has been understood and criticized in the 
context of aging. I thereby focus on three views from the gerontological realm: Moody's approach based on communicative ethics (\$6.4.1), Agich's phenomenological approach (\$6.4.2), and the approach by Holstein and colleagues based on relational views of autonomy ( $\$ 6.4 .3)$. I then critically evaluate the merits of the different accounts of autonomy in light of the purposes of the current study (\$6.5). Drawing upon the strong points of the discussed perspectives and adding my own considerations to complete the picture, in the concluding part of the chapter an alternative "individuating" conceptualization of autonomy is presented that is able to match the requirements that this study's evolving understanding of self-realization implies (\$6.6).

\subsection{INTRODUCING AUTONOMY}

\subsubsection{Historical roots of autonomy discourse}

The etymological origin of the term autonomy is derived from the Greek words autos (self, one-self) and nomos (law, rule, principle). The literal meaning of the word is thus best ascribed as self-rule or self-government. Feinberg (1986) distinguishes four closely related meanings in which the term autonomy has been understood. First, autonomy can be understood as the capacity to govern oneself; second, autonomy can describe the factual condition of self-government; third, autonomy can pertain to an ideal of character based on the notion of self-government; and fourth, the term autonomy can mean the sovereign authority to govern oneself. In this last meaning, personal autonomy is understood by analogy of the sovereignty of a political state, and intrinsically connected to the notion of a right. It is important to note the different statuses that these four meanings of autonomy have. The first two meanings, autonomy as a capacity and as a condition, are both matters of degree, above a minimal threshold, that vary among persons. The third meaning, autonomy as an ideal of character, indicates a dynamic developmental process that is never completed. The fourth meaning, autonomy as a right of sovereign authority over oneself, is by contrast either present or absent, and should be granted equally to all persons who meet the minimal threshold of the capacity for autonomy. In self-realization discourse, autonomy seems to be most explicitly used in the third meaning, that of an ideal of character. However, this use presupposes the presence of the capacity for autonomy in the agents involved. Moreover, self-realization discourse as this study understands it strives for sensitivity when it comes to the factual condition of self-government, which can be either conducive or impeding for the realization of autonomy as a character ideal. As Feinberg (1986) aptly puts it, "de facto self-government presupposes luck" (p. 31), i.e., the circumstances have to be favorable to exercise autonomy. 
Originally seen as a feature of political states of communities, autonomy as a term describing a feature of human persons gained currency around 1800 , largely influenced by the moral philosophy of Kant. He perceived human agents to be capable of following their own inner moral law on the basis of their capacity for reason. Central to Kant's view of autonomy is good will. It is by virtue of this will that human agents are capable of setting themselves moral laws. Autonomy does not mean acting randomly as we please or refusing to subject oneself to norms; autonomy means that the norms one follows are willed freely because they flow from our capacity for reason (Kant, 1785/2002). Kant famously urged people to "dare to think for themselves" (sapere aude) in his treatise on Enlightenment (Kant, 1784/2009). This capacity for independent moral judgment and self-legislation is crucial to the Kantian view of autonomy. His ascription of the autonomous status to the human moral agent has been of tremendous influence in our self-understanding as modern individuals. Since the Enlightenment then, we see the emergence of an increasingly dominant strand of thinking in moral philosophy that ascribes people with a unique potential for self-legislation. It is argued that reason enables people both to decide what the legitimate course of action in a certain situation is and to act in accordance with it. People's rational capacity enables them to free themselves from the false authority of conventions, traditions or other social sources of authority, and make their own moral judgments instead.

Autonomy in the Kantian sense is presented as the opposite of heteronomy - relying on the judgment of others, slavishly following conventions, being socially coerced into certain decisions or actions. A contemporary articulation of this position is voiced by Wolf (2005) when she states that an agent is autonomous, and can be held responsible for his actions "when, and only when, his actions originate from within himself, when nothing beyond or behind his self is forcing him to act as he does" (p. 261). In this sense, the traditional Kantian conceptualization of autonomy and its contemporary followers explicitly assume the typical internalization of moral sources characteristic of modernity (C. Taylor, 1989).

Although the Kantian concept of autonomy as self-government and self-determination was soon criticized for its optimistic reliance on human reason at the expense of other human faculties, it has nevertheless become a landmark concept in our modern Western self-understanding. The Kantian understanding of autonomy has been very influential, not only in moral philosophy, but also in political philosophy and applied ethics, for instance. In political philosophy, it infuses the very foundations of neoliberal societal theories that presuppose the independent autonomous individual as their cornerstone. Also, the Kantian concept of autonomy underlies typical modern interpretations of freedom, since it suggests that any limitation of our capacity for self-determination impedes our freedom as well. Thus, for neoliberalism, guaranteeing 
people's freedom and autonomy means safeguarding them from unduly external interference in their lives, unless their exercise of freedom interferes with that of others. This idea has famously been described by Berlin (1958) in terms of negative freedom. In applied ethics, neo-Kantian interpretations of autonomy have long occupied an almost unassailable status. This was greatly influenced by the "four principles" approach by Beauchamp and Childress (1984) in bioethics, who interpret autonomy in the medical context predominantly in terms of informed consent. Among these four principles, the dominance of autonomy as the ethical principle of "first among equals" is often interpreted as causally connected to the Western dominance of individualism. As I will discuss in $\$ 6.4$ however, this bioethical interpretation of autonomy is a poor match to the context of aging, particularly in long-term care (Agich, 2003; Holstein, Parks \& Waymack, 2011; Holstein, 2015; Moody, 1992).

\subsubsection{Harry Frankfurt: A dominant contemporary account}

Recent moral-philosophical interpretations of autonomy focus predominantly on the autonomy of persons with regard to their own desires, choices, attitudes, character dispositions, et cetera. The implicit underlying image of the person still resembles the Kantian rational moral agent, but most dominant contemporary accounts focus more explicitly on procedural criteria for autonomous actions. Thereby, the autonomy of a person's actions is generally measured by the way in which they flow from a properly reflected and authentically appropriated set of motivations (J. Taylor, 2005). Frankfurt's (1971) so-called hierarchical view provides one of the most prominent examples.

The term hierarchical pertains to the distinction Frankfurt makes between different levels of motivations. In order to qualify as an agent, Frankfurt contends that people should be able to reflect on their initial first-order desires and form second-order desires, which are desires about first-order desires. To be autonomous, one needs to appropriate one's second-order desires as one's own, willing them to guide one's actions. Frankfurt describes this in terms of (second-order) volitions. For instance, the volition to live healthy overrules the first-order desire to have that huge chocolate chip cookie for dessert. Thus, the ability to reflect on one's desires and promote some of them to the status of action-guiding volitions, freely and rationally chosen to guide one's conduct, is what defines the autonomy of persons and constitutes their agency (Frankfurt, 1971). One of the advantages of Frankfurt's approach is that it evades the discussion about determinism and free will that plagues the autonomy debate. The criterion for autonomy is not that one is totally "self-determining" in the sense of "free from external determinants", but that one identifies with one's higher-order desires and wants them to decide one's actions. Freedom of the will is 
therefore always conditional freedom and does not presuppose independence from determining (for example, social or cultural) factors (Bieri, 2001).

Frankfurt's (1971) account of autonomy does not concern itself with the substantive content of motivations underlying a certain choice. A choice simply qualifies as autonomous as long as the requirements of critical reflection and the resulting identification with one's action-guiding motivations are answered. The moral value (or lack thereof) of a given motivation is not considered relevant to judge people's autonomy. In this sense, Frankfurt exemplifies the category of what have been called procedural (as opposed to substantive) accounts of autonomy (Mackenzie \& Stoljar, 2000). The majority of contemporary philosophical accounts of autonomy can be described as procedural. Within the category of procedural accounts, Frankfurt's (1971) view represents a structural version, which takes what Mackenzie and Stoljar (2005) describe as a "time-slice approach to autonomy" (p. 15). This means that its assessment of the autonomy of the agent performing a certain action is based solely upon the occurring motivational structure at one given point in time. In contrast, historical versions of procedural theories argue that it is also important to consider the origins of the desires, beliefs and attitudes that have led to the agent's motivations. Historical versions of procedural theories have the advantage of enabling a developmental perspective on autonomy.

\subsection{Selected alternative accounts of autonomy}

Although hierarchical accounts such as Frankfurt's (1971) have been very influential in the contemporary philosophical debate on autonomy, there have also been some serious critiques. The more formalistic of these relate, for instance, to the threats of manipulation of desires and of infinite regress in explaining the authority of higher-order desires (J. Taylor, 2005). From the perspective of self-realization taken in this study, it is of particular importance to discuss four other objections that can be raised against the structural, a-historical and hierarchical approaches exemplified by Frankfurt's (1971) account of autonomy. All of these are illustrated below through alternative accounts of autonomy developed by different thinkers. The discussed views represent a continuum of critique that ranges from essential amendments to fundamental rejection of Frankfurt's philosophical-anthropological assumptions about human agency.

The first critique, represented by C. Taylor's view of human agency (1985a), questions the content-neutrality of procedural accounts. It points to the importance of a normative evaluation of the hierarchy of desires that is believed to constitute our autonomy. The second issue, illustrated by Ekstrom's view (1993, 2005) addresses the a-historical nature of Frankfurt's (1971) account. It suggests positioning autonomy more in the context of a coherent set of values that 
we identify with throughout our lives. The third issue, represented by Meyers' view (1989), relates to the conditions needed for the practical applicability of relatively abstract criteria for autonomy. It raises the question which competencies are needed to be able to execute one's capacity for autonomy. The fourth issue, represented by feminist relational thinkers (e.g., Mackenzie \& Stoljar, 2000), provides a critique against the fundamental anthropological assumptions about what it means to be a human person that underlie the traditional dominant accounts of autonomy. These accounts are discussed in turn below.

\subsubsection{Charles Taylor: Autonomy and the strong evaluation of desires}

In his account of human agency, C. Taylor (1985a) takes Frankfurt's (1971) original hierarchical interpretation of autonomy in terms of first- and second-order desires and volitions as his starting point. However, he argues that this misses an important element which in his view is fundamental to human agency (and thus to autonomy). To be human agents, we do not only have to be able to identify and endorse our desires by forming volitions about them, we also have to evaluate and order them according to their relative qualitative value.

Fundamental to C. Taylor's (1985a) view about agency and autonomy is the distinction he makes between weak and strong evaluations. Weak evaluations imply a weighing of desires, and choosing which one accords most with one's current preferences. Thus, for example, we can choose between having a snack or going for a walk. What we choose depends on our preference at that moment. However, our choice does not express a qualitative judgment about the value of snacking over walking or vice versa. Weak evaluations imply choosing between options that are in principal of equal value. What is missing from such choices however, is the evaluation of available choice options in terms of a hierarchy of values that motivate us. Strong evaluations, by contrast, do imply such a qualitative judgment, in terms of values that are perceived as indefinitely higher or deeper and therefore more worthy to guide our actions. C. Taylor calls these our "hypergoods" and regards our attempts to approach them more closely as essential to our moral identity formation (C. Taylor, 1989). Importantly, strong evaluations are coupled to certain ways of living that are considered expressive of who we want to be. For instance, I can choose a certain course of action, say, speaking up for a colleague who is being mistreated by our mutual superior, because I regard it as more courageous than the alternative, which would be to keep my mouth shut because of the risk that addressing this injustice might entail for my own job. My choice of action is then intrinsically connected to my evaluation of courage as a value. If I choose to speak up, this is an expression of my moral preference for a courageous way of living over a cowardly or indifferent one. In this sense, the capacity for strong evaluation is linked with 
my identity, because my strong evaluations and the choices based on them are guided by who I want to be. The ability to draw qualitative distinctions and articulate them in a value-laden language of what C. Taylor (1989) calls "qualitative contrast" is thus perceived as essential to what it means to be a human agent exercising autonomy.

It is important to note however, that the value-evaluations involved in making these qualitative contrasts are no individual preferences in which "anything goes". Instead, they have to be rooted in the cultural horizon of meaning that both embeds and transcends the individual life. The ability to make qualitative distinctions - and thus to exercise our strong evaluative capacity - is indispensable in acquiring moral identity and becoming a moral agent.

\subsubsection{Laura Ekstrom: Autonomy and the coherence of our value orientation}

The "coherentist" view of autonomy suggested by Ekstrom (1993, 2005) counts as an objection against the a-historical character of Frankfurt's (1971) approach, which focuses on presently existing desires and their hierarchy without connecting them to the broader narrative context of the person's identity. Essential to Ekstrom's $(1993,2005)$ view is that the autonomy of the agent relies on a sense of personal integration or coherence. Instead of focusing on agents' autonomy with respect to their desires, as the traditional hierarchical approaches do, she is concerned with the autonomy of agents with respect to their preferences. A preference is defined by Ekstrom (2005) as "a desire that has survived a process of critical evaluation - in particular with respect to an individual's conception of the good" (p. 148). For example, suppose I have a desire to eat fresh pineapple. But I have also seen documentaries that have taught me the environmental burden of a Western lifestyle, and stimulated me to make more sustainable choices in my life. Since I realize that growing pineapples and transporting them to Europe is not very environment-friendly, my momentary desire for the pineapple may then be replaced by the decision to eat a locally-grown organic apple. This will cohere with my preference for a sustainable lifestyle, which is crucial to who I want to be. It can therefore be regarded an autonomous choice in Ekstrom's account. A preference is, in other words, part of an attitude describing accurately one's identity, "what one is like”, which is formed by processes of (self-)evaluation in the context of one's pursuit of the good. In this respect, Ekstrom's view of a preference and its role in autonomy shows some important resemblances with C. Taylor's (1989) idea of strong evaluation and the importance of situating oneself in relation to one's hypergoods for identity. It also acknowledges the fact that our deepest aspirations (the ones relevant to self-realization) are connected to the kind of person we want to be (see \4.2.1). 
Ekstrom (2005) states that the autonomy of a person depends on the coherence of the set of preferences that is characteristic of the person's true or most central self. A consistent character disposition or set of attitudes has to underlie and justify one's actions in order to qualify as an autonomous agent. Having discussed the complications related to the idea of narrative integration and the concept of a unified self in $\$ 5.2 .3$, we could frown at this condition for autonomy. However, Ekstrom's perception of coherence is relatively modest. It does not require an inner core self in any essentialist metaphysical interpretation, but only a certain amount of coherence and durability through time concerning the set of motivational preferences underlying one's actions. Ekstrom (2005) formulates her account of a "true self" in the following terms: "the idea is that certain of our attitudes are more central to who we are in a moral or psychological sense than are other of our attitudes, and that it is in acting on these more central attitudes that we exert special direction over our lives" (p. 153). The preferences expressive of this true self need to be long-lasting, able to resist external challenges and be embraced wholeheartedly by the person.

Importantly, Ekstrom's approach does not deny the possibility of conflicts between aspirations, values and feelings that characterize most people's lives and identities. Her notion of coherence, she states, must not be misunderstood to exclude people struggling with such internal conflicts from the realms of autonomous agency. Instead, she states that her coherentist account of autonomy provides room for inner conflict and disorder. It just states that in order to qualify as autonomous, a person's motivating preferences must: 1) have undergone critical evaluation in light of the person's conception of the good; 2) be formed without being coerced by others; and 3) cohere with the person's other preference states. Such preference states support each other, creating a relative stability of character through time (Ekstrom, 2005, p. 154). In a later essay titled Identification and Wholeheartedness Frankfurt (1988b) too acknowledged the importance for autonomy of a certain durable engagement with what we authentically, wholeheartedly care about. These are the kind of commitments that Ekstrom (2008) describes as preferences that give our identity coherence. Both authors hereby implicitly affirm the need for the historical, narrative conception of the person and their identity as advanced in chapter 5 .

\subsubsection{Diana Meyers: Autonomy and the conditions of its practicability}

Meyers' (1989) work Self, society and personal choice provides yet another alternative approach to the autonomy question, which criticizes the abstract and de-contextualized nature of dominant structural views. Meyers understands autonomy in terms of the ability to act on the desires and preferences of one's authentic self. She shares Ekstrom's (2005) idea that a certain amount of coher- 
ence in one's personal character and set of preferences is an important criterion for autonomous agency. However, Meyers (1989) observes that a coherent personality can still be compatible with a lack of autonomy, if one's circumstances impede acting on what one really wants to do. Therefore, in Meyers' (1989) words, "a tenable account of autonomy must link the abstract desideratum of coherence to practicability” (p. 33).

The focus on practicability implies addressing the question of how people become disposed to engage in the self-reflexive consultation necessary to distinguish autonomous from heteronymous decisions and what capacities are needed in order to exercise autonomy in practice. For Meyers, autonomy is therefore best understood in terms of an autonomy competency. Her definition of competency describes it as "a repertory of coordinated skills that enables a person to engage in a complex activity" (Meyers, 1989, p. 56). Autonomy competency consists of a set of three such repertories: self-discovery, self-definition and self-direction. Whereas the emphasis in traditional accounts of autonomy usually remains limited to self-direction, Meyers underscores that self-discovery and self-definition are indispensable capacities for autonomy as well. The three capacities cannot be separated from each other, they function in mutual interaction.

Self-discovery implies the capacity to learn what one's true desires, values, feelings, and attachments are. I get to know myself by reflecting on my inclinations, reactions, judgments, et cetera. For example, I may observe in myself a growing unease with the materialistic, consumerist lifestyle that advertising tries to lure me into. I also feel moved when I see other creatures suffer as a result of my lifestyle choices, and appalled with what I see as the hedonistic, materialistic preferences of others in my surroundings. On the basis of the self-knowledge acquired through such reflections, I decide who I want to be and envisage a life plan on that ground. In the aforementioned example, I may decide I want to become someone with a modest and sustainable lifestyle, whose focus is on peaceful, non-harming relations with people, animals and the world. Such considerations about myself are implied in the capacity of self-definition. Finally, self-direction implies the capacity to act on the standards that are implicitly present in one's life plan and self-image. In my example, this could mean resisting the temptation to eat that delicious steak and choose a vegetarian dish instead, put effort into recycling my garbage, take the train instead of the car, turn the heat down a couple of degrees, enjoy a homemade dinner with friends instead of going out, et cetera.

Important to understand Meyers' view is the distinction she makes between moral autonomy and personal autonomy. Moral autonomy can be compared to the traditional Kantian idea of being able to apply universal rational criteria of right and wrong (Kant, 1785/2002). It is thus concerned with moral permissibility of actions (Friedman, 2000). However, Meyers (1989) underscores that 
autonomy has a broader scope and should also include paying attention to the choices and values that constitute people's authentic identities, which form the domain of personal autonomy. Though personal autonomy presupposes acting within the restrictions posed by the criteria for moral autonomy, it pertains to a different area of interest than the moral permissibility of actions, namely, that of people's unique and personal choices, values and identities. In this regard, Meyers (2000) draws a connection between autonomy and authenticity which makes her account particularly relevant from a self-realization perspective, in which both autonomy and authenticity are important threads (see also $\$ 7.3 .4$ ). I should highlight that Meyers' emphasis on authenticity makes her reluctant to provide substantive guidelines or norms regarding which concrete aspirations and capacities a person exercising autonomy competency should strive to fulfill. Her view remains within the realm of procedural approaches to autonomy in this regard. As Mackenzie and Stoljar (2000) emphasize discussing Meyers' (2000) approach: "Since individuals differ so significantly in their talents, capacities, character traits, values, desires, beliefs, and emotional attitudes, [...] there can be no blueprint for what constitutes an autonomous life" (p. 17).

Interestingly, Meyers' approach can accommodate both the importance of focusing on specific autonomy-constituting choices (as emphasized by Frankfurt's (1971) view) as well as the importance of a focus on the coherence of people's life (as emphasized by Ekstrom $(1993,2005)$ ). This is induced by the distinction she makes between episodic and programmatic self-direction, encountered earlier in my discussion of narrative integration ( $\$ 5$.2.3). Episodic autonomous self-direction pertains to a specific situation or episode, where agents confront a choice, decide what they really want to do by deliberating about the available options, and then execute their choice. Programmatic autonomous self-direction by contrast, has a much broader scope, and requires deciding what to choose in light of how one wants to live one's life in general. Programmatic autonomous self-direction particularly reflects Meyers' emphasis on the importance of personal integration for autonomy and living in harmony with one's authentic self.

An important advantage of the notion of programmatic autonomy is that it offers an opportunity to grant autonomous status to choices that are made spontaneously, i.e., without conscious reflexive deliberation in advance as traditional procedural accounts demand. As long as the choosing self is in possession of an autonomous life plan, spontaneous actions in accordance with the central concerns of this life plan may also count as autonomous, provided they accord with the desires of one's authentic self. The notion of a life plan that is crucial to the notion of programmatic autonomous self-direction may sound problematically static, ordered and restrictive. However, as Meyers (1989) emphasizes, "Life plans should not be pictured as complicated, highly detailed flow charts spanning a lifetime. Rather, a life plan is a largely schematic, par- 
tially articulated vision of a worthwhile life that is suitable for a particular individual. Life plans provide some specific directions and a great deal of general guidance. Agents amplify and refine them as they feel the need to do so" (p. 51). Life plans are thus flexible enough to accommodate for the contingencies confronted in life, for unforeseen situations and for continuous development and transformation of the self throughout life. It is not necessary to regularly question them or reflect on them under normal life circumstances. Still, they play an important role in people's perceptions of their authentic self. Consequently, Meyers argues that it is highly questionable if anyone can be called autonomous without having a life plan.

Nevertheless, as a feminist thinker, Meyers is very sensitive to the context in which the autonomy competency is exercised and authentic life plans are formed. She is acutely aware of the fact that the socio-cultural context in which people live offers rather different opportunities to different (groups of) people to actually be able to become autonomous and act accordingly, which is one of the reasons the notion of a life plan has been criticized (M. Walker, 2007; see also $\ 5$.2.3). For example, being socialized in the female gender role limits many women's chances to follow their own aspirations in life because - despite efforts to emancipate women - in reality they are still expected to take more than an equal share of care responsibilities. Even though Meyers (1989) maintains that authentic selfhood and the corresponding notion of a life plan are important, she acknowledges that autonomy (-competency) is thus always a matter of degree and can be severely impeded by how one is socially and culturally positioned (see also chapter 3 on the problematic effects of oppressive cultural narratives on people's moral agency).

\subsubsection{Relational view: Autonomy, interdependence, socialization and power}

The relational view presents the most far-reaching critique against structural hierarchical views of autonomy like Frankfurt's (1971). In particular, the relational view challenges the portrayal of the individual as a rational, independent, self-sufficient and atomistic creature that is typical for modern, neoliberal philosophical perspectives associated with the structural hierarchical account (compare also the underlying anthropological assumptions that, as I argued,

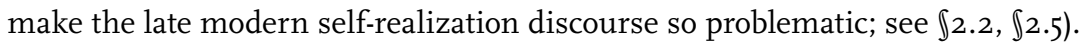
Relational autonomy is in fact an umbrella term covering views with several nuances. Their common ground however, is more important than their differences. In discussing the relational view, I will mainly draw upon an edited volume by Mackenzie and Stoljar (2000) titled Relational autonomy. Feminist perspectives on autonomy, agency and the social self, that unites the most important relational perspectives. 
The relational view of autonomy suggests a paradigm shift when it comes to the underlying notion of the person, compared to the previously discussed accounts of autonomy. Importantly, Meyers' (1989; 2000) perspective (\$6.3.3) also acknowledges the social embedding of the person; however, whereas her view of autonomy remains procedural, the relational perspective discussed in this paragraph argues for a more substantive content to be given to what autonomy amounts to. This implies that normative criteria are introduced to judge whether our decisions to act in a certain manner are motivated by inescapable and benign forms of socialization, or instead by oppressive and harmful forms of socialization (therefore rendering them not truly autonomous) (Stoljar, 2000; Benson, 1991; see further $₫ 6.6)$.

The relational view of autonomy draws upon feminist philosophical ideas about the social and relational embedding of human beings. In moral philosophy, these ideas have been most prominently defended by the ethics of care (Noddings, 1986; Tronto, 1993; Held, 2006). Care has often been presented as a typically "feminine" value, and the origins of the ethics of care are usually located in the famous debate between Kohlberg and Gilligan regarding the differences in moral development between boys and girls (Kohlberg \& Kramer, 1969; Gilligan, 1982). However, the ethics of care typically objects to the idea that care is a feminine domain, stressing that it should instead be seen as a fundamental feature of human life in general, permeating our existence from cradle to grave. Furthermore, a particularly strong feature of the ethics of care is its emphasis on the political and cultural opportunities for transformation. Tronto (1993) states that, "The values of caring and nurturance, of stressing the importance of human relationships as key elements of the good life, remain enticing possibilities in a culture that stresses, as its bottom line, an unlimited concern with productivity and progress" (p. 2).

Three points are particularly characteristic of the relational view of autonomy: 1) the relational view emphasizes that the individual is not an atomistic, independent and self-sufficient agent, but a socially embedded creature, involved in networks of relationships and responsibilities that highlight the fundamental interdependence of the human condition; 2) following from this relational conception of the individual, the relational view explicitly addresses the paradoxical connection between autonomy and socialization; and 3) the relational view exhibits a strong sensitivity to the consequences of social inequalities and power differences based on gender, socio-economic status, age, ethnicity and so forth, with regard to the development and opportunities to exercise autonomy. I will discuss these three points in some more detail below:

\section{Interdependence}

The first important contribution to the discourse on autonomy provided by the relational view relates to its strong critical implications for the phil- 
osophical-anthropological framework, particularly the assumptions about personhood, supporting traditional views of autonomy. The care-ethical perspective that forms the foundation for the relational account of autonomy makes it clear that interdependence is an inescapable reality of the human condition. Its influence is much deeper and more pervasive than can be recognized by the supposedly atomistic, independent status of an autonomous agent claimed by the traditional views. The relational view stresses that the dominant neoliberal conception of the individual should be regarded as an artificial abstraction, with only limited usefulness. It also seems to be a particularly Western conception, whereas the construal of the self in Eastern cultures seems to be more interdependent to start with (Markus \& Kitayama, 1991). Importantly, acknowledging the reality of interdependence denies the exclusive association of care with helpless infants or old, fragile and disabled people. It emphasizes that (inter)dependence and the associated vulnerability is a fundamental feature of human life, instead of a shameful and deplorable state of specific vulnerable groups. This affirms this study's reflections on existential vulnerability as an inescapable reality of all human lives (see $₫ 2.4 .6$ ).

Despite the importance and legitimacy of the fundamental critique on traditional notions of agency and human personhood, Mackenzie and Stoljar (2000) argue that the feminist critique has often been directed against a caricature version of individual autonomy. They describe this caricature as "the self-sufficient, rugged male individualist, rational maximizing chooser of libertarian theory” (Mackenzie \& Stoljar 2000, p. 5). While this particular caricature, which is deeply entrenched in the cultural imaginaries of modern Western societies, deserves continuing criticism, it would be unfair and undesirable to repudiate the whole concept of autonomy because of this caricature. The relational account of autonomy aims for a fundamental reframing of mainstream conceptions of personhood. This reframing intends to acknowledge insights about the fundamental interdependency of the human condition, the social nature of the self and the values of care, responsibility, solidarity, et cetera (Mackenzie \& Stoljar, 2000; Barclay, 2000; Code, 1991; Held, 2006). Moreover, the relational account also strives to acknowledge a richer variety of relevant faculties of agents to be considered in weighing their autonomy. Whereas traditional accounts focus mostly on the rational capacities needed for critical reflection on one's motivations, the relational approach stresses that agents are not only rational beings, but also embodied, desiring, feeling, creative and expressive beings (Mackenzie, 2000).

2. Socialization

The second important contribution of the relational view lies in its attempts to clarify how socialization and autonomy relate to each other. As we have 
seen, in traditional views of autonomy socialization is perceived as a source of heteronomy, and thus something to be overcome in the development of autonomy. The classic freedom-determination debate typically touches upon this matter. While modern structural views acknowledge the fact that freedom cannot exist without a certain form of social conditioning (Bieri, 2001), they still presuppose that autonomy requires being able to self-reflexively distance oneself from these influences and acquire an independent attitude towards them.

Through its emphasis on the social nature of the self, the relational view shows that socialization is inescapable and not something to be conquered in order to become truly autonomous and "free". Instead, the relational approach contends that one cannot even acquire the competences needed to exercise autonomy without continuing processes of socialization. As Barclay (2000) puts it, "the claim that social determinism undercuts the possibility of autonomy [...] is based on a misunderstanding of the notion of autonomy. [...] Autonomous agency does not imply that one mysteriously escapes altogether from social influence but rather that one is able to fashion a certain response to it" (p. 54). Code (1991) clarifies this point by drawing on a notion by Baier (1985) who stated that we are essentially "second-persons", relying for our personal development on relations of dependency with others - beginning with our caregivers in infancy and extending to a broader social realm throughout life. Self-knowledge and self-determination can only be realized by engaging in continuing, formative, dialogical social relationships with these others, not by reflecting on our desires and choices in self-dependent isolation. The fact that other people's values and decisions often differ from our own is not a threat to our autonomy. Instead, by challenging our views and actions other's alternative views help us define ourselves more clearly. Thus, other people play an indispensable role in what C. Taylor (1985b) has called our hermeneutic self-constitution.

At the same time, feminist thinkers are deeply ambivalent about processes of socialization, since the latter have also had severely negative consequences for the life opportunities and social freedom of women (as well as other groups that are traditionally disadvantaged in terms of societal power and influence) (M. Walker, 2007). A distinction thus needs to be made between necessary forms of socialization that are inevitable and should be welcomed to develop and exercise autonomy, and oppressive forms of socialization that impede this process (Benson, 1991). Consequently, Friedman (2000) argues that it is important to see that "socialization does not as such impede autonomy, whereas coercion as such does do so" (p. 37). Cultural master narratives that are stereotyping and marginalizing are an important factor in such oppressive and coercive forms of socialization given their effects 
of depriving people of opportunities and causing infiltrated consciousness (Lindemann Nelson 2001; see 『3.2.2).

Oppressive socialization can impair autonomy at three different levels, according to Mackenzie and Stoljar (2000): first, at the level of the formation of the agent's desires, beliefs and attitudes; second, at the level of the development of relevant capacities such as self-reflection, self-direction and self-knowledge; and third, at the level of the actual making of autonomous choices and performance of autonomous actions. Notice here the interesting parallel with the modes of self-realization (aspiration fulfillment and capacity fulfillment) discussed in $\$ 4.2 .1$, as well as the recognition that self-realization proceeds through acting in concrete practices (see $\$ 4.2 .3$ ). At each of these levels, oppressive socialization may thus impede self-realization.

3. Power

The third important contribution of the relational view to the autonomy debate is closely related to the problem of oppressive or otherwise problematic forms of socialization. The relational view raises our awareness of the simple fact that exercising autonomy requires social opportunities, or else it becomes a useless notion. Relational approaches stress that moral ideals like autonomy are always situated in a concrete, historical, social and cultural context. M. Walker (2007) emphasizes that marginalized groups can be denied access to the opportunities to realize certain moral ideals, because it is assumed that these are of no relevance to them. For example, women have long been excluded from higher education on the assumption that this would offer no added value for their typical life fulfillment as culturally perceived, namely, being housewives, mothers and caregivers. Similar paternalistic mechanisms stymie the aspirations of other social groups including elderly people - who are not given an appropriate voice in the existing dominant structures of our culture and society (see $\mathbb{3 3 . 2 . 2}$ ).

This point draws our attention to the power structures enabling and maintaining our social and cultural world. As a result of these power structures, there exist profound differences in the opportunities for people to live according to their own values, and even to formulate such values in the first place - what M. Walker (2007) has called their "epistemological position". It is also a fundamental insight of care ethics that all moral theories and concepts are influenced by a context of power relationships, which need to be taken seriously in evaluating their content and value (Tronto, 1993). Suggestions from the relational perspective for remedying this situation include a strong emphasis on the importance of social recognition of one's position as a moral agent, reminiscent of the arguments by Honneth (1995) and Lindemann Nelson (2001) discussed earlier (see \3.2.3). As long as people are not recognized as (potentially) autonomous moral agents, ascribing autonomy to them, be it as an anthropological characteristic or as a fun- 
damental human right, remains an empty, theoretical abstraction. Giving voice to marginalized groups should improve their epistemological, moral and social status as autonomous, relationally embedded subjects, and thereby enhance their autonomy (M. Walker, 2007; Meyers, 2002).

Although it is a great advantage of the relational view that it is able to acknowledge the fundamental social embedding of moral agents, it has two crucial shortcomings that merit specific attention. The first is a certain vagueness about the substantial content of relational autonomy. Despite the important critiques that the relational approach contributes to the autonomy debate, it seems to give far more information about what autonomy is not, than about what the suggested alternative relational conceptualization would in fact look like. The second shortcoming is that the relational view offers insufficient means to rethink the importance of the social practice of "becoming individual" for exercising autonomy (compare with the reflections on narratives of becoming in $\mathbb{3} 3.4$ ). Before the relational view can serve as a basis for an account of autonomy that fits the outlook of my conceptualization of self-realization, it needs to be enriched with a more explicit concern for what constitutes people's identity as selfhood, which underlies their moral identity and enables moral agency (see $₫ 5.4 ; \rrbracket 5.5)$.

\subsection{Autonomy in the context of aging}

Before proceeding towards an evaluation of the discussed conceptualizations of autonomy and their suitability for the narratives of becoming based on the self-realization discourse, let me first connect the theme of autonomy to the context of aging. Autonomy is an often highly contested value in the context of aging (Polivka \& Moody, 2001). Whereas some approaches to late modern aging - in particular those associated with what I have termed age-defying narratives - treat autonomy as an important flagship concept, other views have pointed out the difficulties in applying the notion of autonomy to aging, in particular because, as Moody (1992) puts it, autonomy in the conventional understanding seems "incompatible with existential facts about old age" (p. 40).

The fundamental critique posed against the dominant liberal conceptualization of autonomy with regard to aging is, according to Holstein, Parks \& Waymack (2011), that it "obscures the fact that we ultimately lack control over aging, illness, disability, suffering, and death. To admit this lack of autonomy is to admit that the human condition is beyond our control; to relinquish autonomy is to acknowledge our deep vulnerability, especially as we age" (p. 12). Besides this, the tendency of traditional conceptualizations of autonomy to favor independence leads to an unfortunate association of dependence with weakness, incapacity and loss of dignity. This has a particularly negative impact 
on aging individuals, whose dependence on others in executing daily tasks, such as bathing, dressing or eating, tends to increase once they become frailer. An identification of autonomy with independence, rational choice and freedom from interference, hinders a satisfactory moral consideration of issues confronted by aging people in their daily lives, especially when living in circumstances that severely restrict their opportunities to exercise autonomy in the traditional sense (Dodds, 2000). For this reason, autonomy critique in gerontological debate has strongly focused on the context of long-term care (Agich, 1990, 1995, 2003; Collopy, 1988; Moody, 1992; Polivka \& Moody, 2001; Cole \& Holstein, 1996; Holstein, Parks \& Waymack, 2011).

To illustrate how ethical problems surrounding autonomy in the context of aging have been addressed, let me select three suggestions by authors from the field of aging studies that approach autonomy. These include the communicative approach advocated by Moody (1992), the phenomenological approach suggested by Agich (1990, 1995, 2003), and the account put forward by Holstein and colleagues (Holstein, 2015; Holstein, Parks \& Waymack, 2011; Holstein, 2010a, 2010b) which applies the above discussed relational view of autonomy to the context of aging. What all three of them have in common is that they react against the neoliberal view of autonomy associated with Western individualization, a view that feeds into contemporary bioethical discourse in the form of

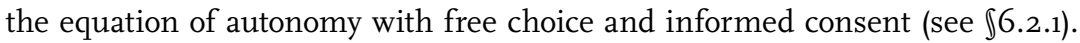
The discussed perspectives share a deep concern about the impoverishment of contemporary moral discourse and the detrimental influence that this has on the lives of older people. As Moody (1992) states, "The irony is that we want to uphold autonomy for the elderly at just the time in life when their condition makes autonomy least attainable and at a time in life when other human needs - for care, for respect, for meaning - are more pressing. Yet the poverty of our moral discourse is such that we can only offer to those in the last stage of life more autonomy" (p. 4).

\subsubsection{Harry Moody: The communicative approach}

In Ethics in an aging society, Moody (1992) suggests replacing the dominant bioethical informed-consent approach to autonomy with a communicative approach. Communicative ethics is based on the influential philosophy of Habermas (1984). His theory of communicative action underscores the importance of deriving valid decisions from an un-coerced dialogue between all involved agents, which should ideally lead to moral consensus. In Moody's (1992) interpretation, the communicative ethical approach suggests replacing the notion of informed consent by the notion of negotiated consent. Moral decisions are not to be made by an insular individual, but negotiated among the social network surrounding the person concerned. Moody argues that this has obvious advantag- 
es over the informed consent approach in the context of aging, especially when people have diminished cognitive capacities, for instance, because it involves a dialogue about the decisions to be made that can also involve family members and caregivers. Such a dialogical approach also provides better opportunities to acknowledge the social nature of human personhood discussed in chapter 5 .

An important aspect of communicative ethics is its sensitivity to the structures of power and influence that characterize the context in which communication has to take place. Moody particularly observes that, though autonomy as informed consent is highly valued in theory, the practice of many care settings tends to lead to a structured dependency of older people, thus aggravating their existential reality of vulnerability and dependency. For instance, signing a consent form or an advance directive means very little for people's actual freedom of choice in a vulnerable situation, if the whole care setting remains implicitly centered around the dominant authority of professionals and their expertise. Thus, the traditional autonomy discourse, in Moody's (1992) view, leaves older people with "a new myth promising us a fulfillment that is bound to leave us disappointed" (p. 40). Inevitably, Moody's preference for a communicative approach to ethics calls for making concessions to the promise of universally applicable rules assumed by bioethics. It emphasizes the fact that moral dilemmas in their complexity, often escape the uncluttered framework of clear principles suggested by bioethical approaches. However, the focus on communicative principles enlarges the possibility of honoring the different perspectives of all those involved in a situation of moral choice. This is a big advantage when we want to acknowledge the social embedding and mutual interdependence of human beings.

\subsubsection{George Agich: The phenomenological approach}

The second selected account from the realm of aging studies is formulated by Agich $(1990,1995,2003)$ who focuses on autonomy and dependence. He acknowledges the political and legal relevance of the neoliberal interpretation of autonomy that relates it to freedom of choice, independence and non-interference, but questions its applicability in the context of long-term care. Importantly, Agich observes that the neoliberal account of autonomy not only dominates politics and law, but has developed into a broader cultural ideal. In accordance with what was discussed in $\$ 2.5 .2$ and $\$ 3.3 .4$, Agich (2003) notes that the resulting problem in the context of aging is that "the cultural dominance of this model of autonomy creates a backlash against dependence of any sort, so that the frail and infirm old [...] are especially vulnerable to the pejorative meanings associated with dependence. They are seen and frequently see themselves as burdensome and less than full persons" (p. 10). As an alternative to the neoliberal view, Agich (2003) suggests a phenomenological view in which autonomy 
involves "a dialectic of independence and dependence that takes place within a social space characterized by interdependence" (p. 96). In this view, autonomy should be perceived in terms of a lifelong continuous process of development without a well-defined end-state.

Agich $(1990,1995)$ makes a relevant distinction between "nodal” autonomy, pertaining to the capacity for informed, free choice that is the dominant understanding in informed consent approaches, and "actual" autonomy, which refers to the process of enacting autonomy in everyday life. The latter view of autonomy seems to be the sort of autonomy that is primarily relevant to the life reality of people living in long-term care contexts. Actual autonomy underscores that autonomy can never be just about making a free choice between clearly delineated alternatives at a given point in time. Actual autonomy also implicates questions of value, relations and meaning that represent a continuous process through time which helps constitute who we are. Agich's notion of actual autonomy is therefore closely related to the conceptualization of narrative and moral agency discussed in chapter 5 .

In particular, Agich emphasizes that in order to contribute to actual autonomy, people should not only be able to choose, but also have options to choose from that are meaningful to them in the context of their personal lives, their relationships and their values. Most situations in which actual autonomy is implicated in a long-term care context may seem highly trivial, because they involve matters that most of us see as self-evident, for instance, having the freedom to decide what to eat, or having privacy in your own space. However, these things are far from obvious in a long-term care setting. In the liberal account, giving people more choice about their daily meals may be seen as an increase in autonomy. However, the choice between a pork chop, a sausage or clam chowder, for example, is hardly a meaningful, freedom-enhancing choice for people who have been vegetarians all their lives, or Jewish or Muslim for that matter.

Another important point made by Agich is that actual autonomy for frail or otherwise dependent people can be improved if they are supported by others who help them formulate or carry out the choices that are meaningful to them. In the conventional view, such help would limit people's self-dependency and thereby restrict their autonomy. However, being reticent about giving such support in a desire to respect elders' supposed independence may have the undesired result of compromising people's actual autonomy. A clarifying distinction made by Collopy (1988) in this regard is that between decisional and executional autonomy. Whereas the former represents the freedom of choice cherished by the neoliberal view, the latter expresses that one needs to be able to execute one's choices in order to experience actual autonomy. If people's decisional autonomy is sufficiently intact but frailty impedes their opportunities to exercise it, stepping in to support people in their executional autonomy will actually enhance their freedom. The bottom line of Agich's view is that dependence on 
the support of others to realize actual autonomy need not be compromising one's freedom, as long as it is conceptualized in a way that is different from the neoliberal account. Steering between the opposite poles of the neoliberal view and its communitarian critics, he proposes a contextual approach to ethics. This takes into account the many ways in which individuals are interdependent, socially embedded and vulnerable, without giving up the idea that their individuality, their choices and their aspirations truly matter and have a valid claim to being considered in ethical debates.

In Agich's phenomenological view, individuals are interdependently connected as social and embodied beings that share a common moral ground. Any viable account of autonomy in the context of aging needs to be sensitive to what is happening in this shared space. Obviously, this means that the phenomenological view paints a far more complex picture than the ideal type of autonomy in conventional accounts, because it deals directly with the "messy incompleteness and uncertainty" of the reality of everyday living (Agich, 2003, p. 92).

\subsubsection{Martha Holstein and colleagues: The relational approach}

Holstein and colleagues (Holstein, Parks \& Waymack, 2011; Holstein, 2010a, 2010b, 2015) suggest a perspective that applies the previously discussed relational view of autonomy to the context of aging (see $₫ 6.3 .4$ ). They share the previously discussed worries about the inapplicability of the neoliberal view of autonomy to the life reality of many older people, particularly those living in long-term care contexts. Holstein and her colleagues highlight three advantages of a relational approach to autonomy in the context of aging that are of particular relevance to this study:

- First, Holstein emphasizes that the view of the self that underlies the relational conception of autonomy is much more apt to acknowledge the fact that we are fundamentally embodied beings. This also includes the insight that reason is not the only relevant human faculty to be taken into account when talking about agency and autonomy. Feelings, desires, intuitions and imagination also belong to who we are and thus help constitute our agency. That we are embodied beings is true for our entire lives, of course; but when we get older, we tend to be more and more confronted with gradual bodily discomforts that make us acutely aware of how much our selves are intertwined with our bodies (Holstein, 1999, 2015; Holstein, Parks \& Waymack, 2011).

Both the development of our identities and the development of our autonomy competency (Meyers, 1989; see $\$ 6.3 .3$ ) are tied to our bodies. There is a mutual process of influence between the external experiences of our aging bodies (as informed by cultural decline narratives or age-defying nar- 
ratives, for instance) and the internal development of our autonomy competency. The relevance of taking embodiment into account when it comes to autonomy is further increased by the observation that our society tends to approach older people, especially women, predominantly as "older bodies". When older people start acting upon this implicit identification of who they are with their bodily appearance, it raises difficult questions regarding their autonomy (Holstein, 2015; Tulle, 2004). For example, if an older woman feels compelled to dye her graying hair or to stop wearing shorts in the summer as a result of the internalized cultural norm of youthfulness, the autonomy of this decision might be questioned.

- Second, Holstein, Parks \& Waymack (2011) emphasize that exercising autonomy - even relational autonomy - highly depends on the availability of autonomy-enabling societal structural arrangements. However, they are highly critical about contemporary social institutions and public policies influencing older people's lives. The way the pension and social security systems, or the health care system, are centered around norms of independence and individual responsibility excludes many older individuals from the realm of autonomous life choices, because their vulnerability precludes their living up to these implicit norms.

As Holstein argues, neoliberal societies tacitly assume that older people answer to the typical image of the Kantian rational man. However, this image has been unmasked by the feminist, relational discourse as a harmful illusion. This tendency is particularly damaging for older women as well as minority groups (Holstein, 2015). As Holstein, Parks \& Waymack (2011) aptly observe, "it is a long way from the paradigmatic Kantian rational 'man' to the 88-year-old woman with congestive heart failure, mild cognitive impairment, and osteoporosis" (p. 256). Although this is a noteworthy observation, it need not mean that the underlying ideal of autonomy ascribed to the paradigmatic Kantian man is of less relevance to the frail 88-year old. Her situation may even urgently call for the possibility to make choices that are well-informed and in continuity with the value orientation that has accompanied her identity throughout her life. But Holstein, Parks and Waymack are right to suggest that a proper interpretation of autonomy needs to transcend the caricature that is often made of the Kantian rational man in order to be of value to the context of aging.

- Third, and related to the previous two points, Holstein, Parks \& Waymack (2011) emphasize that a viable understanding of autonomy needs to be able to recognize people in their diversity and particularity. This implies acknowledging them not only as the vulnerable, interdependent human beings that they are, but also as moral agents with a deep interest in leading a meaningful life. Impediments to this social recognition, both on the structural societal level and on the micro-level of the social networks surround- 
ing the individual, will disregard the fundamental moral value of their life. Lack of social recognition will erode people's sense of identity, and thereby their opportunity to exercise autonomy, which is relationally embedded (see also $₫ 3.2 .3)$.

It follows that both formal and informal systems of care and support need to be sensitized to pay attention to older people's expressions of individual personhood, if autonomy is to be a meaningful category in the context of aging. This is particularly true in situations where the capacities usually associated with upholding a sense of identity begin to erode, such as in the case of dementia. As Holstein, Parks and Waymack (2011) emphasize, "Self-conception, identity, and self-esteem are all, to some degree, a social project [...] What happens then, as dementia progresses, is that we come to depend more and more on others to help maintain our identity" (p. 221). In their analyses about the conditions of autonomy in such situations of dependency and fragility, Holstein, Parks and Waymack confirm my contention that Lindemann's (2014) view of identity as a social practice (see \$5.3.2) is particularly well-suited to be applied in a reframed interpretation of self-realization for the context of later life.

\subsection{Evaluation of the discussed accounts on aUtonomy}

In this chapter, I have discussed a variety of conceptualizations of autonomy, both as developed in philosophical discourse and as applied in the context of aging studies. The question remains how these different perspectives should be evaluated in light of the search for a conceptualization of autonomy that matches the understanding of self-realization developed in this study. Recall that I proposed an understanding of the self that is embodied, socially embedded, reflexive and narratively creating a sense of continuity, against the background of the inescapable temporal horizon of human existence. Moreover, I argued for an understanding of identity and agency as fundamentally moral categories. This means that our identity presupposes an ethical commitment to certain values, aspirations and capacities that express something about who we want to be or become, and what we want to remain true to (see chapter 5). A satisfactory conceptualization of autonomy should match with these insights on narrative identity and moral agency.

The views of autonomy discussed in this chapter can be interpreted as constituting a spectrum ranging from predominantly individualist understandings to predominantly anti-individualist understandings. A first and rather obvious conclusion we can draw is that the traditional individualist understanding of autonomy represented by the structural hierarchical view (see \$6.2.2) cannot accommodate for most of the insights about narrative identity and moral agency 
described in chapter 5 . The traditional individualist interpretation of autonomy fails to acknowledge the social embedding, interdependence and fundamental vulnerability of the human condition. It also lacks the life-historical scope that is required from a narrative perspective and pays insufficient attention to the identity-constituting identification with values. In addition, I share the gerontological critiques discussed in $₫ 6.4$ that traditional individualist accounts of autonomy do not match the life reality of most older people.

Despite these objections, individualist accounts of autonomy should not be pushed aside too easily. Their emphasis on the agent as the source of uniquely individual desires, aspirations, motivations, capacities and actions remains of crucial significance from a self-realization perspective. Yet the problems raised by the classical structural hierarchical interpretation need to be solved if individualist accounts are to be integrated in this study's understanding of autonomy. The amendments made by C. Taylor (1985a), Ekstrom (1993, 2005) and Meyers (1989) to the mainstream interpretation of autonomy are a valuable start to enrich the traditional view of autonomy and adapt it to the account of self-realization developed here. As we have seen, C. Taylor's account sensitizes our view towards the importance of an identification with strongly held values positioning ourselves in relation to a moral horizon of (hyper)goods, for our agency and autonomy. Ekstrom adds a focus on the development of our desires and preferences over the course of our lives, and acknowledges the importance of continuity that we also encountered in chapter 5 . She thereby introduces a developmental life course perspective to the debate on autonomy that is very valuable, both from the perspective of self-realization and from the perspective of aging. Meyers, finally, contributes important considerations regarding the competencies that we need to practice autonomy in concrete circumstances. She also stresses the conditions of development of human moral agents which need to be beneficial in order to acquire such competencies. This addition is very important for this study's reframed account of self-realization, which requires sensitivity to the socio-cultural and structural factors that enable or impede people's striving towards the good life.

When combined, the views of C. Taylor, Ekstrom and Meyers, all situated on the individualist end of the spectrum of autonomy views, offer important ingredients to repair the discussed shortcomings of the structural hierarchical view. The relational view of autonomy, on the other hand, represents a view from the anti-individualist end of the spectrum. A distinct advantage of the relational view for this study's purposes is that it shares many assumptions with the understanding of self and identity as socially embedded, embodied, vulnerable and interdependent. This also explains its obvious appeal for the context of aging as we encountered in the discussion of gerontological views. Therefore, at first sight, it makes sense to say that the relational view presents a candidate conception of autonomy that is less problematic than the individu- 
alist accounts when applied to the context of aging. However, I argue that the relational account as it is, needs some amendments to arrive at a satisfactory conceptualization of autonomy in the context of self-realization as a resource for narratives of becoming about later life.

First of all, the account of autonomy that I am looking for should somehow combine the insights of the relational view about the social embedding of human beings with the most important benefit of individualist interpretations their focus on the moral status of the agent as a source of uniquely individual desires, aspirations, motivations, capacities and actions. Furthermore, this study's account of autonomy ought to be able to integrate the ethical dimension of our personhood, discussed in $\$ 5.3 .3$ and $\$ 5.4$. It is questionable whether either the individualist or the anti-individualist views of autonomy that I have so far discussed are sufficiently capable of integrating this ethical dimension. What is needed then, is to formulate a conceptualization of autonomy that answers to three conditions: 1 ) it values the moral status of the agent as a constantly developing individual with uniquely personal aspirations and capacities, 2) it acknowledges the relational embedding of these individuals, and 3) it is capable of integrating the ethical engagements that are essential for our moral agency and thereby for the purpose of our self-realization.

\subsection{CONCLUSION: TOWARdS AN INDIVIDUATING CONCEPTION OF AUTONOMY}

Let me call this alternative view an individuating conceptualization of autonomy. The term individuating is derived from the term individuation that was originally introduced by Jung (1971). Jung describes individuation as a complex psychological process of searching for your true, authentic self, coming to terms with the "shadow-sides" of your personality. Individuation, as elaborated by Jung, also implies freeing yourself from the pressures of outside conventions, in order to (re)connect with the deeper spiritual values and meanings of life. We could say that individuation represents Jung's perception of self-realization because it enables people to fulfill their deepest and truest potential for selfhood. More broadly speaking, the term individuation could be translated as becoming individual. It is mostly in this more general sense that I will apply the term when I speak about an individuating conceptualization of autonomy. This implies that individuating autonomy is seen as a developmental ideal that is part of the broader process of moral self-development. On a side note, it is interesting that individuation was understood by Jung (1971) to be a task particularly associated with the second half of life (see also Atchley, 2009; Hillmann, 1999). In combination with its linkages with the discourse of self-realization 
this association has also contributed to my choice for this particular term in the search for a satisfactory conceptualization of autonomy.

Though Jung seems to perceive individuation primarily as a process of inner spiritual growth, I stress that individuation as it is implicated in the notion of individuating autonomy, is quintessentially a social undertaking. Again, I am obliged to the suggestion made by Lindemann (2014) who argues that identity should be perceived in terms of a social practice. In order to enable people to realize the best within them, they need, in Lindemann's terminology, to be held in their identities by others (see $₫ 5.3 .2$ ). This position underscores that we cannot become who we are solely on our own.

Being autonomous in the individuating account is not a state people can attain once and then claim to possess for the rest of their life. It presupposes a continuous process of moral self-development, of attaining and refining an attitude towards oneself, others and the world in general that is conducive to the realization of a good life (see $\sqrt{5} \cdot 5$ ). Generally speaking, the individuating account of autonomy that I propose is individualist because it cherishes people's maximal freedom to choose and identify with the life plans, purposes and aspirations that they regard the most valuable, and in greatest coherence with their constantly evolving narrative selves. The individuating account emphasizes that people should be able to stand for what they value in life and act upon that orientation, even if it goes against convention or social expectation. At the same time, the individuating account is anti-individualist in its recognition that beneath people's autonomous competency to form such life plans, purposes and aspirations lies a deeply social interdependence with others. Part of the attitude presupposed by the individuating account is a deep awareness and acceptance of the dimension of existential vulnerability that is characteristic of human existence, and an acknowledgment of the fact that this dimension can restrict one's scope of self-determination.

A further important characteristic of the individuating account of autonomy is an openness towards a plurality of value orientations and an acknowledgment of the importance of people's freedom in this regard. Consequently, the individuating account refrains from being prescriptive about which values, motivations and aspirations people should choose to strive for. It principally values individual differentiation of goods and purposes that may contribute to a good life. In this sense, it strives to offer an account of autonomy that is congenial to the late modern situation of individualization and moral pluralism. But as has been suggested before, there seems to be one important exception to

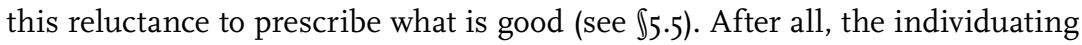
account of autonomy strongly emphasizes the importance of developing one's moral identity, which is a normative criterion. Despite its appraisal of a pluralism of values then, we might say that there is one normative criterion that the individuating account of autonomy does think people should adhere to: optimal 
moral self-development, i.e., striving to lead a good life, with and for others, according to one's deepest aspirations and highest capacities, as full participating members of a society/community.

The individuating account of autonomy requires then, that people identify with and appropriate a viable value orientation in life that is worthy of guiding their actions. What counts as a "worthy" value orientation conducive to such a good life is not objectively defined, but it certainly isn't arbitrary either. What does and doesn't count as worthy is seen as constantly negotiated in intersubjective, narrative and dialogical encounters with others about what constitutes a good life. These moral encounters are situated against the background of a cultural horizon of meaning and values that is created by humans, but transcends the individual preferences of any single individual. Worthy purposes can, for example, be freedom, or love, or care, or creativity, or humor, or justice, or courage, or soberness. But wriggling one's toes in the mud does not generally qualify as a purpose worthy of a good life (C. Taylor, 1989).

In sum, the individuating account of autonomy presupposes that it is crucial that people develop themselves in such a manner that they optimally realize their potential for moral agency as defined in $\ 5.5$. This calls for the appropriation of an ethical orientation with which they can identify, a translation of this orientation into action, and the development of an attitude of practical wisdom and loving self-acceptance towards those things in life that we have no agential control over. In Ricoeur's (1992) view, which inspires me here, a viable approach should allow us "to reconcile the idea of autonomy with (....) receptiveness, passivity, and even powerlessness” (p. 275).

We might say that when it comes to criteria to define autonomy, the individuating conceptualization is a weak substantive theory. Weak substantive views take an intermediate position between purely procedural accounts of autonomy on the one hand, and strong substantive accounts on the other hand (Mackenzie \& Stoljar, 2000; J. Taylor, 2005). Let me first clarify this distinction:

- For procedural accounts, for a decision to qualify as autonomous it suffices that one has followed the proper procedures to arrive at it. The substantive content of the decision does not matter from the viewpoint of judging its autonomy. So, for instance, a terrorist could make an autonomous decision to commit a suicide attack in a busy underground station, as long as he has reflected on his desire to do so and has made a free choice for this second-order volition to guide his action. His decision is morally censurable, for sure, but in the procedural view, it can still be autonomous.

- Strong substantive accounts, on the other hand, require that people's actions can be judged as defensible from the viewpoint of certain objective moral frameworks. A strong substantive theory may grant that the criteria suggested by procedural accounts are necessary conditions for autono- 
my, but they do not share the idea that these procedural criteria are also sufficient conditions. In addition to answering the procedural criteria for autonomy, strong substantive theories state that autonomous decisions should also answer to some non-neutral normative condition. This could, for instance, be an objective standard of rationality and/or rational criteria of right and wrong behavior (Mackenzie \& Stoljar, 2000). Importantly, the terrorist attack mentioned above could never qualify as an autonomous act in the strong substantive view because it is not rationally and/or morally defensible according to these criteria. In another example discussed by Stoljar (2000), a woman's decision to consciously neglect methods of reliable birth control cannot be autonomous when this decision to take a contraceptive risk is based on faulty assumptions about the value of women that she has internalized from a paternalistic masculine perspective. So for instance, a woman can be raised to believe that her value depends on her ability to give birth, and that her way to bind a man in a relationship is to get pregnant. From this perspective her decision to neglect birth control is in her own advantage and rationally defensible. Following the "feminist intuition" that Stoljar defends however, the internalized belief is wrong and harmful. Even though the woman's decision to take a contraceptive risk may answer to all procedural criteria of reflexive endorsement of a higher-order desire, in Stoljar's strong substantive account this decision nevertheless fails to qualify as autonomous.

Arguments in favor of adding a substantive criterion for autonomy are generally based on concerns about how our socialization affects our autonomy (Benson, 1991; Friedman, 2000; Stoljar, 2000). This is a particularly pressing matter from the perspective of relational autonomy that underscores the inevitable social embedding of human agents. It necessitates coming up with a criterion distinguishing autonomy-enabling relationships and forms of socialization, which should be valued, from autonomy-impeding relationships and forms of socialization, which deserve rejection.

- The intermediate position of weak substantive accounts comes down to the following. Just like strong substantive theories of autonomy, weak substantive accounts are concerned about possible autonomy-impeding effects of certain (not all!) forms of socialization. They equally seek criteria to decide whether a decision is based on motivations that flow from an autonomy-impeding source (like internalization of false or oppressive views about the social group to which one belongs; $c$. Lindemann Nelson's (2001) notion of infiltrated consciousness discussed in \3.2.2). However, as Mackenzie and Stoljar (2000) observe, "[a weak substantive account] places constraints on the desires, preferences, and values that count as autonomous, [but] abandons the content specificity of strong substantive theories" (p. 20). Typical of weak substantive criteria of autonomy is that they refer to norms that are 
based on a healthy psychological relation of moral agents with themselves, instead of norms based on objective moral criteria of right and wrong. Examples of weak subjective conditions for autonomy that have been suggested include, for instance, self-worth (Benson, 1994), self-respect (Dillon, 1992) and self-trust (McLeod \& Sherwin, 2000).

Following the categorization discussed above, qualifying my individuating view of autonomy as weak substantive means that it aims to set general benchmarks to qualitatively judge the genuineness of someone's (claimed) autonomy that are based on its criterion of optimal moral self-development. At the same time, contrasting what would be a strong substantive view, the individuating conception allows for maximal individual differentiation regarding one's choice of values, aspirations and capacities. The only restriction would have to be that they remain within the limits of conventional morality (i.e., respect the Golden Rule) and can intersubjectively be judged to contribute to a good life in the broadest sense - what Ricoeur (1992) has called the ethical aim of human life (see $\$ 5.4)$. The question remaining then is how the weak substantive criterion advanced by the individuating conceptualization of autonomy is best described.

Recall that at the end of $₫ 6.5$, I formulated three criteria that a satisfying account of autonomy in the context of this study should answer to. Regarding the first criterion, the acknowledgment of the relational embedding of human beings, we may gratefully integrate the anthropological position of the relational view of autonomy discussed in $\$ 6.3 .4$. The second criterion, the valuation of the moral status of the agent as a constantly developing individual with uniquely personal aspirations and capacities, seems to be well-covered by the amended versions of the individualist interpretations of autonomy by C. Taylor, Ekstrom and Meyers (\$6.3.1, 6.3.2, 6.3.3). What still needs to be added to my view is an element capable of accommodating the third criterion, i.e., the integration of the ethical engagements that are essential for our moral agency and thereby for the purpose of our self-realization. Drawing upon the argument in $\mathbb{5} .4$ and

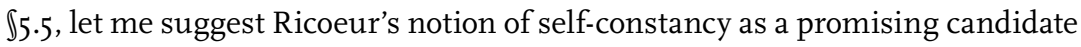
for the weak substantive criterion that we are looking for here.

Self-constancy or identity as selfhood has been formulated in terms of our answer to the question who we are or want to become. A viable answer to this question presupposes an ethical commitment with the aim of realizing a good life with and for others. The notion of self-constancy addresses the ethical dimension of our identity which is a crucial addition to the individuating conception of autonomy in two senses:

- First, it underscores the necessity of living up to the value orientation that is essential to who we want to be or become through our choices and actions in practice. This ethical commitment is developed and realized through our 
identification with and appropriation of things we want to be true to, for instance, values like love, care, justice or honesty.

- Second, self-constancy underscores our social embedding by sensitizing us to the fact that our commitment to others is an intrinsic part of who we are. Thus, self-constancy expresses something about our relationship to ourselves as well as our relationship to others. Suggesting self-constancy as one of the crucial elements of individuating autonomy implies that being autonomous requires the appropriation of an identity-guiding value orientation as well as the ability to engage in moral relationships with others, both aspects of realizing our best potential for moral agency.

These two senses of ethical commitment that are combined in the notion of self-constancy guide us in the moral choices we make and provide us with a durable and sufficiently coherent sense of identity. They also enable us to relate to others in a manner that is helpful to fulfilling the fundamental ethical aim of a good life with and for others. In this sense, I would argue that it truly is an indispensable substantive criterion for individuating autonomy.

Self-constancy does not necessarily come easy, however. It can require overcoming internal and external obstacles to remaining true to who we want to be, both in relation to ourselves and in relation to others. Self-constancy as a criterion of individuating autonomy calls for the development of certain virtues or attitudes that are indispensable to developing ourselves as autonomous agents. Some of these virtues resemble the attitudes that are also often associated with the condition of autonomy in the more traditional interpretation, such as self-reflexivity, integrity, authenticity, self-discipline, moral independence or responsibility for self (Feinberg, 1986). In addition, the individuating conception of autonomy also requires virtues like courage, perseverance, social and moral sensitivity, flexibility, self-acceptance and practical wisdom.

In sum then, people can be seen as autonomous in the individuating account when they satisfy the following criteria:

- They appropriate and engage with an authentic value orientation that is able to constitute their identity and gives them guidelines about which purposes to strive for in life

- They are able to uphold a satisfactory amount of narrative coherence in their set of value preferences and adapt their preferences flexibly and reflexively depending on what they encounter in life

- They possess the competencies and virtues that are needed to exercise autonomy in practice, such as self-knowledge, self-discovery, self-determination, reflexivity, integrity, courage, practical wisdom, et cetera.

- They are capable of acknowledging the limits of their self-determination that flow from the reality of human existential vulnerability, and integrate 
what escapes their own control in their existence as autonomous moral agents

- They answer to the ethical criterion of self-constancy, which enables them to stand for their identity-constituting value orientation in concrete practical circumstances, thereby honoring their ethical commitment both to themselves and to others, as well as acknowledging the fundamental interdependence with others that characterizes human lives

A few important closing remarks are in order regarding these conditions, however. All these conditions should be understood in terms of a developmental process that continues throughout life, not in terms of a normative end-state. In order to count as autonomous in the individuating view, it is not necessary to be some sort of perfect moral exemplar. Individuating autonomy is certainly not intended as an elitist goal. Thus, one need not have a totally comprehensive life plan and value orientation, a fully coherent set of preferences, perfectly developed autonomy competencies and virtues and a spotless ethical commitment without ambiguities, to claim autonomy on this account.

Matching the phenomenological orientation advanced by Agich (1995; 2003), individuating autonomy should be regarded as a socially embedded practice with many imperfections, because it relates to the actual messy daily reality of people's lives. It is therefore something that can never be completely or perfectly achieved. In principle, all human beings groping their way towards a good life qualify as candidates to claim individuating autonomy. As a process, individuating autonomy is always a matter of degree, and its successful exercise should be carefully assessed in light of all the relevant aspects of a concrete situation. What is crucial however, is that people's lives express an enduring developmental orientation towards a more fulfilled personhood, and an ethical engagement with approaching who we want to be, to ourselves and to others. Self-constancy requires maintaining a vital involvement with the ethical aim of human life, even if this requires struggling with the contingencies and vulnerabilities intrinsic to our existence. The ancient wisdom that it is the journey, not the destination that counts would certainly apply to the case of individuating autonomy. Stagnation, isolation, indifference, lack of commitment with one's own good life or that of others, inability to engage with meaningful goals and social relationships, and closing oneself off from relevant learning processes, all represent conditions that are likely to stymie individuating autonomy. These cannot be united with the purpose of developing moral agency that is intrinsic to the discourse of self-realization advanced in this study. 


\section{Chapter 7 - Authenticity}

\subsection{INTRODUCTION}

As discussed in $\$ 4.3 .2$, this study considers the philosophical discourse of self-realization to be constituted along three quintessential and interwoven threads: autonomy, authenticity and virtue. After having explored the autonomy-thread in chapter 6 , sketching its background and suggesting a viable interpretation in light of the intended reframing of the self-realization discourse, I continue with the next step in the argument by exploring the authenticity-thread in a similar way.

This chapter follows broadly the same structure as the previous one. I start with a general introduction of the concept of authenticity (\$7.2). Next, four relevant perspectives on authenticity from the history of modern philosophy are sketched. In $\$ 7.3 .1$, the view of Rousseau and his Romantic followers is discussed. Rousseau is often seen as the father of the notion of authenticity in Western thought. In \$7.3.2, I continue with a discussion of what could best be called an existentialist view of authenticity. This view was exemplified by Nietzsche and Kierkegaard in the $19^{\text {th }}$ century, with Heidegger, Sartre, Camus and De Beauvoir as their $20^{\text {th }}$ century heirs. In $\llbracket 7.3 .3$, C. Taylor's (1991) more recent view of authenticity is discussed, which aims to criticize authenticity's late modern perversions and calls attention to its historical roots as a moral ideal. Finally, in $\$ 7.3 .4$ I discuss Meyers' (2000) view connecting authenticity with the intersectionality framework of feminist philosophy.

Having thus introduced different relevant positions in the authenticity debate, in $\$ 7.4$ I consider how the theme of authenticity has found its way into gerontological thought. Although gerontological authors have been far less explicitly concerned with authenticity than with autonomy, I suggest three perspectives on aging that apply ideas which can be related to the authenticity discourse. These include the spiritual perspectives ( $\$ 7.4 .1)$, the existential perspectives ( $\$ 7.4 .2)$ and the art of living perspectives $(\$ 7.4 \cdot 3)$. To conclude this chapter, in $\$ 7.5$ I evaluate the different perspectives on authenticity, and suggest an interpretation that is able to accommodate my reframing of self-realization and its underlying view of moral agency (\$7.6). 


\subsection{INTRODUCING AUTHENTICITY}

Oscar Wilde made it sound so simple: "Be yourself. Everyone else is already taken". But being (or becoming) yourself raises a number of complex philosophical questions. These questions have been debated for the past centuries under the banner of authenticity. In its most general sense, authenticity means that something or someone is "faithful to an original" or is "of undisputed origin or authorship" (Varga \& Guignon, 2014). As one of the threads weaving the fabric of self-realization discourse, authenticity conceives the best within us that is to be realized in terms of being true to oneself, more particularly to one's most genuine, real or essential self (Guignon, 2004). Alternatively, becoming who you (truly) are is also often used as a phrase describing what underlies authenticity. Often, it appears to be difficult to give a direct description of what an authentic personality or mode of living amounts to in positive terms. Instead, authenticity is conceptualized as a critique against an inauthentic lifestyle that is perceived as untruthful and false (Golomb, 1995). In contrast to such an inauthentic life, authenticity implies originality, truthfulness, creativity and genuineness. It also assumes the development of an attitude towards life that is personally appropriated, instead of prescribed by one's social position, tradition or convention. People can be called authentic when they have not only created and appropriated their own "style", but also proudly carry the responsibility for it (Dohmen, 2014). In this sense, authenticity closely intersects with/depends on autonomy (competence) (Meyers, 1989; see also \6.3.3).

The formulae "being true to yourself" or "becoming who you truly are" seem to carry a commonsensical plausibility for many of us living in an era that promotes living a life of one's own as a moral ideal (see also \2.3.1 and \2.5.1). Beyond this commonsensical understanding, however, problems quickly arise if we try to fathom what underlies the moral ideal of an authentic life. After all, what should be understood as our "true" or "real" self? What is included and excluded by such a notion? Where is such a self to be found in the first place? Is it an essence to be discovered somewhere, or are we creating it throughout our lives? How can others recognize which appearance of our self is authentic and which is not? How can we even know ourselves? What if our true self turns out to include unpleasant, banal or plain evil characteristics that we don't want to be associated with? And how does such a true self, if it exists, relate to the outside social world without losing its "essential" quality? What does it mean to be "truthful", and how does this relate to different interpretations of "truth"? In short, the ideal of authenticity, on closer look, represents a very problematic discourse, and it may rightly be questioned whether it doesn't raise more problems than it solves (Guignon, 2004).

Several authors connect the rise of authenticity as a moral ideal with modernity and its characteristic "disenchantment" (C. Taylor, 1991; Ferrara, 1993, 
1998; see also \2.3.6). The decline of traditional sources of meaning and morality that are associated with this disenchantment, has left a void that authenticity is expected to fill. Although the modern interpretation of authenticity has often been criticized by neo-conservative thinkers as a purely aesthetic, narcissistic ideal, Ferrara (1993) argues that these critiques misconstrue the meaning of authenticity. He thinks that authenticity should instead be perceived as a moral ideal that offers a new reflexive value base for modern lives. During its rise as a characteristic modern moral ideal, authenticity also seems to have acquired a very specific meaning. To clarify the distinctive features of contemporary authenticity discourse, it is helpful to look at Trilling's (1971) distinction between sincerity as a typical early modern notion and authenticity as a typical late modern notion. Both sincerity and authenticity are concepts that touch upon the necessity of being true to oneself. But importantly, in the case of sincerity this is not perceived as an end in itself, but as a means to enable one's reliability towards others. One cannot be true to one's commitments to others without being true to oneself, i.e., without answering to the social expectation of being sincere. The evolution of the idea of being true to oneself in the modern understanding of authenticity, however, elevates it to an end in itself. It is no longer a necessary condition for one's social functioning, but something to strive for independently, for its own sake. Personal authenticity thereby gains the status of a moral character ideal. From a social virtue in the case of sincerity, being true to oneself becomes a personal virtue in the case of authenticity.

Even if one agrees on the status of authenticity as a personal virtue, many different interpretations remain possible. Ferrara (1998) has made some interesting distinctions that may help to categorize different interpretations of authenticity.

- First, he distinguishes between substantialist and intersubjective conceptions of authenticity, which depart from contrasting underlying concepts of the self. The substantialist perspectives of authenticity regard the self to possess an essential core which should ideally find expression in one's actions and interactions with other agents. Social institutions and social roles are perceived as forces that make us betray our essential core self, by having us adapt to the expectations and conventions belonging to these roles and institutions. The intersubjective conceptions of authenticity, on the other hand, stress that our identity should not be perceived in terms of an essential core self, but instead as a social practice which depends on different forms of recognition and dialogical, reflexive deliberation.

- Second, Ferrara distinguishes between antagonistic and integrative conceptions of authenticity. The antagonistic conception associates authenticity with breaking loose from restrictive and inauthenticating social expectations and conventions. The integrative conception stresses that social roles 
and institutions are not necessarily restrictive but are also needed, since they provide the building blocks for developing an authentic identity in the first place.

- Third, Ferrara introduces an opposition between a centered and a decentered perspective on authenticity. The former assumes that it is necessary to be able to express one's life in a coherent life narrative, with a hierarchical order of importance between the core storyline and more peripheral events and experiences. According to the centered conception, one's authenticity depends on the ability to constitute one's self along the lines of a unique life project guiding one's choices and actions. The decentered conception, on the other hand, assumes that any attempt to arrive at such a unifying narrative is in fact an instance of inauthenticity, because it means subjecting one's life to an external artificial ordering principle.

- Fourth, Ferrara distinguishes two different ways in which the notion of authenticity has been applied in political discourse. On the one hand, there is a nationalist perspective, which builds upon the Romantic, expressivist emphasis on the importance of a shared culture, history, language and tradition. On the other hand, post-modern thinkers draw upon a radical notion of authenticity to emphasize the importance of recognizing difference. Ferrara himself prefers an intermediate account of personal authenticity in reflective terms, emphasizing the way the individual negotiates its difference from others relative to the common and universal aspects of being human that are shared with others.

As is explained in $\mathbb{7 7 . 5}$, when examined using Ferrara's typology, the account of authenticity advanced in this study is both intersubjective and reflective, but takes an intermediate stand between antagonistic and integrative, as well as between centered and decentered views of authenticity.

Given the emphasis on being true to yourself, an authentic life is inextricably connected to an authentic personality. Ferrara (1998) discusses the features of such a personality. He derives these from a rich variety of psychoanalytical authors, who may have different ideas about decisive factors influencing processes of human development, but share some fundamental ideas that point towards four general characteristics of an authentic or fulfilled personality. These are: coherence, vitality, depth and maturity.

- Coherence stresses the importance of being able to understand the changes and transformations undergone in the course of one's life in terms of a more or less cohesive, continuous and demarcated life narrative. It stands opposed to fragmentation, discontinuity and indistinctness. Although we have already encountered the problems associated with some versions of the 
claim to coherence or narrative integration in $\$ 5.2 .3$, it is noteworthy that for authenticity, as well, some amount of coherence is indispensable.

- Vitality is described by Ferrara (1998) as the experiential counterpart of authentic self-realization, and defined as "the experience of joyful empowerment which results from the fulfillment of one's central needs, from a sense of the congruence of one's present state with the memory of who one has been, and from the sense of progressing toward becoming who one wants to be" (p. 87). Vitality presupposes a genuine involvement and engagement with life, and is opposed to an attitude of apathy and withdrawal.

- Depth refers to a person's capacity to fathom, at least to some extent, one's own psychic dynamism in a way that is sufficiently reflexive. That is, depth presupposes the ability to put the self-insight one gains to use in the continuous constitution of one's identity. The quality of depth, though indispensable for an authentic individual, is always a matter of degree, since obviously full transparency to oneself is not within the reach of most people.

- Maturity, the final characteristic of an authentic person, describes the quality of being able and willing to come to terms with the natural and social reality as it is. This is achieved in full awareness of the limitations of one's own control but without thereby disregarding one's own potentials to act upon oneself and transform unfavorable circumstances to some extent. Maturity presupposes a realistic sense of one's own strengths and limitations, a flexibility towards contingencies and a healthy sense of self-worth. Another term that is sometimes used to describe what is manifested here is wisdom.

To conclude this introductory section, it can be observed that generally speaking, two related issues stand out that continue to plague the authenticity debate:

- True self: The first set of problems that keeps returning, addresses the issue of how the "true" self should be conceptualized. Many interpretations of authenticity presuppose an essentialist view of the self, in which the true identity of the individual is opposed to the inauthenticity of social self-presentations. This is at odds with the idea that the self is socially constituted. In addition, the anthropocentric perspective that typically characterizes contemporary authenticity discourse tends to present the self as separate, self-sufficient and self-reliant (Guignon, 2004). However, as I have noted before (see $\$ 4.2 .2$ and $\ 5.3 .2$ ), such an understanding of the self has been criticized as profoundly problematic, which has implications for this study's perspective on authenticity.

- Social influence: The second set of problems is related to the concern that the authenticity discourse is unable to address people's fundamentally social nature and their need for belonging in a satisfactory way (Larmore, 
1996). Critiques have been voiced underscoring that we cannot disregard the social dimension in this manner. It is possible to conceive of authenticity in another manner, however. In fact, some interpretations stress that authenticity in fact relies on our embedding in social practices, because it is this social embedding that enables us to articulate and practice our identity-guiding value orientation in the first place. As Williams (2002) aptly formulates this insight, "We need each other in order to be anybody" (p. 200); and "being anybody", of course, is conditional to the authenticity ideal of being true to yourself.

The view of authenticity defended in this chapter agrees with authenticity thinkers who contend that neither set of problems needs to be insurmountable, but that authenticity needs to be carefully reformulated to accommodate the issues that are raised by each set (e.g., C. Taylor, 1991; Ferrara, 1998). However, before I can formulate a version of authenticity that matches this study's conceptualization of self-realization, we should first gain more clarity about what authenticity stands for as a moral ideal and discuss its origins.

\subsection{Selected Philosophical accounts of authenticity}

\subsubsection{Jean-Jacques Rousseau and his Romantic heirs}

Rousseau (1754/1984,1782/1996,1762/2003) is often seen as the originator of the modern discourse on authenticity in the Western world. Although he does not use the term authenticity himself, many of the guiding ideas underlying this notion are present in his work (Guignon, 2004). Even though Rousseau's social and political thought seems rather anachronistic to the late modern mind, in particular due to his boundless faith in restoring the "natural" state of goodness of human beings by excluding social and societal influences, Ferrara $(1993,1998)$ argues that Rousseau's philosophy still carries high relevance for contemporary life. Rousseau's philosophy teaches us that personal authenticity, especially in the reflexive interpretation that Ferrara advances, deserves an equal status in contemporary moral debates, besides more commonly used notions such as freedom, justice and equality. Rousseau's position on authenticity rests on a distinction between the natural state of man and its socialized version. While the natural state is perceived as inherently good, the socialized state is seen as the cause of most human, societal and moral problems. Instead of following the traditional Christian doctrine of original sin, Rousseau attributed any moral depravation of man to the influences of society. Due to the rise of a social order revolving around artificial and misguided sources of identity such as possession, competition and power inequalities, Rousseau (1754/1984) 
believed that as a result of this "social man lives always outside himself; he knows how to live only in the opinion of others" (p. 136). Thus, socialization results in inauthenticity, an irreparable corruption of man's natural authenticity. Moreover, this inauthenticity seems to coincide with heteronomy and a lack of free agency, because the opinions of others instead of our own convictions and inclinations steer our behavior.

The natural state of man, on the other hand, is pure and true and innocent, and lies at the foundation of the human potential for free agency. This state is often compared with the being of a child, who has not yet undergone the social influences that make many adults so artificial and inauthentic in Rousseau's eyes. He recommended turning inward and (re)gaining contact with the inner "voice of nature" (as cited in C. Taylor 1989, p. 357). However, although Rousseau claimed to present his own true and authentic self in the Confessions (1782/1996), he ran into problems almost immediately, because he noticed that his memory was flawed, his judgment clouded, and his self-insight and means of articulation only limited. Thus, even the father of modern authenticity discourse confronted a problem with the "truthfulness" of his self-account (Williams, 2002), which ultimately renders his view self-effacing. Nevertheless, Rousseau's account of authenticity as the only reliable road of access to the moral good, and thereby the condition for autonomy and freedom, has been highly influential in our modern self-understanding.

The realization of a flourishing, authentic life by human beings requires a special type of education, which Rousseau describes in his famous treatise Emile ou l'éducation (1762/2003). The educator is supposed to let pupils discover their own natural potential of knowledge, morality and character, undisturbed by any direct disciplinary influence of teachers or other adults. If given the chance to flourish properly, the natural state of man supposedly guarantees a healthy human moral agency in which self-love and concern for others, the two basic tendencies of human nature for Rousseau, are perfectly balanced.

As C. Taylor (1989) argues, Rousseau's work can be placed in the broader evolution of the crucial modern idea that our inner realm is a source of meaning, identity and morality. Following one's feelings was regarded as a more reliable road of access to the good than cognitive reflection, although Rousseau did not reject the value of reason (Guignon, 2004). C. Taylor (1989) notes that Hume, as well as moral sense philosophers like Shaftesbury and Hutcheson had already introduced the importance of feelings in moral philosophical debates in the $18^{\text {th }}$ century. But C. Taylor claims that Rousseau's views potentially go further than those of the earlier moral sense philosophers like Shaftesbury and Hutcheson. While these thinkers also believed our feelings enabled us to come into contact with the good, they still regarded this good as something universal and God-given. Rousseau, by contrast, provided the basis for the later Romantic view that the inner voice of our nature, our conscience, defines what 
is good. This transforms our inner nature to the principal moral source to draw on. This move enabled the rise of a new "ethic of nature" in the $19^{\text {th }}$ century, exemplified in Romantic expressivism (C. Taylor, 1989, p. 362). It is important to note, however, that Rousseau's Romantic heirs did not necessarily share his optimistic estimation of the natural goodness of humans and their feelings. Romantic thinkers such as Herder, Schelling or Novalis, who advanced this expressivist position, are much indebted to Rousseau. Their claim is that shaping one's life and identity in an authentic way can be compared to the way an artist creates a work of art. A crucial addition of the Romantic expressivists to the earlier views drawing on moral sentiment is that they assume that the realization of the natural good, to which we gain access through our inner realm, takes place through expression of ourselves. This expression implies an articulation in a certain medium, making feelings or thoughts manifest. However, in addition to this, the expression is also a way of creating something new, of bringing something to be that did not exist previously. This combination of expression and creation is the crucial contribution of the Romantic expressivist account of authenticity to the self-realization discourse.

The comparison of life with a work of art suggests that the chosen medium of expression is not solely instrumental to the work of art, or to the way of life, but that "being in the medium they are is integral to them" (C. Taylor, 1989, p. 374). By emphasizing that it is up to each individual to choose their own medium of expression, expressivism also adds the idea of originality: what it implies to be faithful to who you really are cannot be reached by following the model of someone else. In the end, for Rousseau and his heirs the ultimate purpose of self-realization is to arrive at a point of self-revelation (through self-reflection or through artistic expression). The self-revelation thus acquired has an almost spiritual meaning, because it involves recovering a sense of wholeness that was lost before, or creating it all anew. The true self is not perceived as a static entity to be discovered by rational reflection or scientific method, but is associated with a continuous search to unveil or create one's original, authentic self, thereby transcending base and inauthentic versions of oneself that result from the corrupting, heteronomous influence of others (Guignon, 2004). As the starting point in this study's exploration of authenticity, the account of Rousseau and his Romantic heirs illustrates both sets of problems associated with the authenticity discourse in general (see $\$ 7.2$ ): the problem of the true self, and the problem of social influence. In the next section, I will explore how existentialist thinkers offer an alternative account of authenticity, which in particular challenges the essentialist view of the person. 


\subsubsection{Existentialist views of authenticity}

The existentialist "pathos" of authenticity (Golomb, 1995) cannot be properly understood without taking into account the historical situation in which it arose. Typical of the late 19th century was the growing suspicion towards the optimistic promises of Enlightenment thinkers regarding the moral and scientific progress of mankind. Moreover, traditional sources of moral and spiritual authority were increasingly perceived as being unable to meet the need for guidance and meaning. Nietzsche's famous proclamation of the "Death of God" was the incisive distillation of a growing sense that no reliable source of morality existed in the outside world (The gay science, KGW III, 3, 125). Instead, it was up to the individual to provide life with coherence and meaning - man himself was the only remaining authority that could be acknowledged in the "disenchanted" modern world. Note that in general the existentialist thinkers in particular Nietzsche and Kierkegaard in the 19th century; Heidegger, Sartre, De Beauvoir and Camus in the 2oth century - did not regard this process of developing ownership of oneself and realization of one's human freedom as an easy task. Instead, human agents were perceived as condemned to freedom, and the only viable way to address this human fate was by trying to live as authentically as possible.

One of the main targets of the existentialist position on authenticity was the assumption, still present in Rousseau's work, that there is such a thing as an essential self, a clear, unambiguous inner core that speaks to us and guides us towards truth, meaning and value. In fact, existentialism challenges the whole idea of an "objective" truth, which seems to be presupposed by the essentialist conception of the self. According to Golomb (1995), "the heart of the existentialist revolution" consists in "the eclipse of 'truth' by 'truthfulness', the transition from objective sincerity to personal authenticity" (p. 8). Despite this difference, the existentialist position shares with Rousseau and his Romantic heirs the suspicion towards social convention, which is perceived to lead to self-alienation and an inauthentic way of living. Realizing one's human potential for freedom requires transcending the restrictions of existing moralities and finding one's own unique path to self-realization. Thus, Golomb (1995) states that "authenticity is not a 'moral authority', for it is contrary to the nature of authenticity to tell others what to do. [...] it is the mastery of one who freely creates the pathos of authenticity and strives to express and live it in the everyday" (p. 10).

Below, I explore a selection of $19^{\text {th }}$ and $20^{\text {th }}$ century existentialist views. Each of these adds its own emphasis, and contributes its own perspective to the authenticity discourse. The selection of thinkers to be discussed opens with the two main $19^{\text {th }}$ century thinkers who addressed authenticity: Kierkegaard and Nietzsche. Of the $20^{\text {th }}$ century thinkers, I focus mainly on Heidegger's 
perspective. His view has particular relevance in the context of aging, given his emphasis on the relations between being and time (Baars, 2012a).

\section{Søren Kierkegaard - Fateful choice}

In Kierkegaard's (1843/1959) view, the quest for authenticity begins with a moment of existential crisis, particularly a crisis involving a struggle with forces pulling us towards an inauthentic lifestyle. Such struggles make us question ourselves and reflect on who we "really" want to be or become. This represents an often painful process. We become acutely aware of the danger of self-betrayal if we lack the strength to choose an authentic life and instead submerge into an inauthentic limbo. For example, in Either/Or, Kierkegaard (1843/1959) focuses on the fateful moment of choice between an inauthentic or aesthetic lifestyle and an authentic lifestyle (the ethical and ultimately religious lifestyle that he advocates).

Kierkegaard's philosophy is exemplary for the quintessential importance of choice, which is characteristic of existentialist philosophy in general. This is not just any choice, however; the choice at stake here is an identity-constituting choice: who, out of all the possible selves I could become, do I truly choose to be? Lacking the courage to choose, the young protagonist of Either/Or is condemned to a continuous hectic bustle, looking for new experiences to satisfy his hedonic needs, but never finding true fulfillment. His lifestyle is qualified as "aesthetic". This is an existence full of unrest and the threat of dissatisfaction. In stark contrast, his fatherly friend Judge Wilhelm has chosen the "ethical life" of fulfilling his moral duties in the context of work, marriage and family life. However bourgeois this existence may sound, Wilhelm insists that his own choice for this specific life as his fulfillment makes it superior to the directionless wandering of his young protégé. Judge Wilhelm knows who he is and wants to be, and his life is organized accordingly.

Ultimately, however, Kierkegaard argues that the highest and most authentic lifestyle should transcend even this ethical mode of being. His ideal of authenticity eventually requires the self-transcendence of a religious conversion, a paradoxical risking of oneself in order to become oneself most fully. Eventually, for Kierkegaard authenticity assumes a leap into an unknown void, without the certainty of being captured or the guarantee of redemption. Freedom is about the courage to take that existential leap without knowing what to expect. This implies an acute confrontation with the uncontrollable, the dimension of existential vulnerability of human life that has been discussed earlier (see $₫ 2.4 .6$ ). The existentialist view of authenticity thereby introduces an element that is highly relevant for this study's purposes. Emphasizing the dimension of existential vulnerability as a crucial element of authenticity, suggests that finding a satisfactory attitude towards this dimension can paradoxically be an intrinsic part of self-realization. 


\section{Friedrich Nietzsche - Becoming who you are}

Nietzsche's view of authenticity can best be exemplified in the expression becoming who or what you are. This paradoxical phrase can be found at several points in Nietzsche's work (for instance in Schopenhauer as educator (Unfashionable observations 3), KGW I, 2, 1; The gay science, KGW III, 3, 270, 335; and Thus spoke Zarathustra, KGW IV, 1). As Golomb (1995) emphasizes, according to Nietzsche, "To become 'what we are' is not to live according to our so-called 'innate nature', but to create ourselves freely. To that end we have to know ourselves to distinguish what we can change in ourselves and in the external circumstances that have shaped us; we must realize what we have to accept as inevitable, and must do so in the heroic manner of amor fati (love of fate)" (p. 69). For Nietzsche, the heroism of authenticity lies in the effort to surmount ourselves, to become masters of our lives. We have to conquer many inclinations in ourselves that make us slaves: narrow-minded creatures full of "ressentiment" towards those that dominate us. We need the courage to follow the will to power that drives us to reign, to strive for domination of weaker souls, as Nietzsche has Zarathustra describe (Thus spoke Zarathustra, KGW IV). Ultimately, it is up to us, and only us, how we live our lives in a way that satisfies us. Inauthenticity lures us into succumbing to the temptation of following false authorities. As Nietzsche forcefully states in Schopenhauer as educator: "No one can build for you the bridge upon which you alone must cross the stream of life, no one but you alone. To be sure, there are countless paths and bridges and demigods that want to carry you through this stream, but only at the price of your self; you would pawn and lose your self. There is one single path in this world on which no one but you can travel. Where does it lead? Do not ask, just take it" (Schopenhauer as educator (Unfashionable observations 3), KGW I, 2, 1).

In the preface to Human, all too human (KGW II, 1), Nietzsche sketches a detailed process of several stages in which one may develop what he calls the "great health": a state of authentic freedom and self-mastery. This process of freeing one's spirit can be read as Nietzsche's description of self-realization. At the outset, one's spirit is still firmly bound, by duties, by one's social position and by convention. However, such a bounded soul may suddenly experience a desire to free himself, and feel the urge to go away on a journey to an unknown destination. In the next stage, this soul starts to revolt. He rejects everything familiar, all bonds, values and duties that previously decided his life. This revolting is compared to a disease by Nietzsche, but it is a necessary disease, since it provides the basis for the person to free his will, to start defining his own values as a self-determining agent. Inevitably, this process of freeing oneself results in temporary loneliness and withdrawal from the world. But this loneliness and struggle is conditional for the eventual great health, the ripe freedom of the spirit that for Nietzsche constitutes the purpose of authentic self-realization. Through a stage of gradual return to life, the stage of great health is 
eventually acquired. However, reaching this final stage may require years of wandering and healing, and only few people manage to attain the ultimate free and authentic life.

Nehamas (1985) notes that according to Nietzsche, our selves should not be interpreted as stable entities. Instead, they are in a continuous process of change and development. Nietzsche (as cited in Nehamas, 1985) does not assume the existence of one essential or core self, ready to be authentically expressed. Instead, his view presupposes a multiplicity of selves, in which different selves may occupy the dominant position governing our choices and actions, depending on the situation. This position makes the expression becoming who/what you are even more problematic and paradoxical, for "if there is no such thing as the self, there seems to be nothing that one can in any way become" (Nehamas, 1985, p. 172). It also raises the seemingly unsolvable question which of these selves is "in charge" when it comes to self-realization. Nevertheless, Nietzsche insists that it is possible and indeed desirable to shape the contingent variety of actual and possible selves into a coherent identity that can be qualified as expressing authenticity, a process he describes as giving style to our character. Giving style implies imprinting our personal stamp on the contingent and chaotic bundle of character features, thoughts, feelings and experiences making up our lives. In The Gay Science, Nietzsche urges his readers as follows: "One thing is needful. - To 'give style' to one's character - a great and rare art! It is practiced by those who survey all the strengths and weaknesses of their nature and then fit them into an artistic plan until every one of them appears as art and reason and even weaknesses delight the eye. [...] In the end, when the work is finished, it becomes evident how the constraints of a single taste governed and formed everything large and small. Whether this taste was good or bad is less important than one might suppose, if only it was a single taste!" (KGW III, 3, 290) .

Nietzsche is well aware that giving our character style and living authentically is by no means easy. As a result, in his philosophy "authenticity is a kind of regulative and corrective ideal rather than a manifestly viable norm" (Golomb, 1995 , p. 81). As a regulative moral ideal, becoming who we are is a process without an end. As long as we live we will always encounter new situations that necessitate revisiting our image of ourselves and possibly adjusting our strivings. What is of crucial importance, however, is that we learn to accept responsibility for all that we have become as a result of the mixture of choices, actions and contingent events that constitute our lives. This expresses Nietzsche's famous doctrine of "eternal recurrence" and life-affirmation, which Nehamas (1985) summarizes as follows: "To become what one is, we can see, is not to reach a specific new state and to stop becoming [...] It is to identify oneself with all of one's actions, to see that everything one does (what one becomes) is what one is. In the ideal case it is also to fit all this into a coherent whole and to want to be 
everything that one is" (p. 191; emphasis added). As with Kierkegaard, this view adds a welcome element to my reflection on self-realization, since it assumes that aspects of purposive choice connect with aspects of contingency in the life reality. It is crucial that we appropriate both in order to optimally realize our potential for moral agency.

Although some Nietzsche-interpreters qualify his view as aesthetic, it is important to note that authenticity has a strong moral importance for him. The way in which Nietzsche's views could be called aesthetic can in no way be compared with the meaning of that term in the philosophy of Kierkegaard, for instance. The way of life that expresses a unique and authentic individual style is promoted by Nietzsche not for its aesthetic value, but because he strongly believes that it constitutes a better life, more worthy of the best human potential. Although Nehamas (1985) is right to observe that a "stylish life" in Nietzsche's sense need not accord with what is promoted by existing moralities and may even contradict their rules and restrictions, it does not negate the moral significance of this ideal from Nietzsche's perspective.

\section{Martin Heidegger - Being-onto-death}

Heidegger's account of authenticity is located in the context of his sophisticated philosophical analysis of the ontological conditions of being, which he elaborates in his magnum opus Being and Time (Heidegger, 1927/1996). He frequently uses the word authentic (eigentlich) throughout his work. For Heidegger, there is a fundamental relation between authenticity and death. Humans are essentially creatures with an awareness of their own finitude; Dasein (Heidegger's term for human being or individuality that is difficult to translate) represents "being-onto-death" (Carman, 2005). It is by virtue of the awareness that we cannot escape our own death, and cannot "objectify" it as we can do with the death of others, that we become fundamentally aware of our existential vulnerability. The awareness of the finitude of one's being provokes a profound existential anxiety which one is inclined to flee from. The typical mode of escape is to merge into the anonymous, impersonal sphere of social convention, or what Heidegger terms the "They" (das "Man"). The result of this immersion is inauthenticity and self-loss, the inability to live up to our responsibility for our own being in the face of death.

By contrast, authentic being for Heidegger implies the courage to face this inescapable human condition. Only in the face of our own death can we investigate what it means to be. As Golomb (1995) puts it, "If authenticity is the sense of one's Being, in death one reaches the culmination of one's potential for authentic Being [...] Death enters life to conclude it, making possible its adequate explication. Each time we entertain the possibility of dying we undertake an assessment of our Being. In our anticipation we define our existence" (p. 106107). It is through this process of self-definition and gaining understanding 
about the ontological conditions of being in time that we acquire the ability to fully accept our responsibility for ourselves, i.e., attain authenticity. By associating authenticity with one's relation to one's own finitude, Dasein as being-onto-death, Heidegger fails to satisfactorily acknowledge that it can also be a social mode of being. Although other people certainly play a role in his view, they are mainly introduced as part of the inauthenticating "They". This stands for slavishly subjecting oneself to conventions instead of authentically appropriating one's own life in the face of one's temporal and limited human condition.

A characteristic of Heidegger's account of authenticity particularly relevant in the context of aging is its emphasis on the temporal dimension of human existence (Baars, 2012b). Authenticity is a continuous struggle to create and secure a sense of "own-ness" by countering the threat of alienation induced by existential anxiety. This struggle is a process that inevitably takes place in time. It requires appropriating one's past history, embracing one's present self, and carrying one's potential for authentic being into the future. If there are aspects of our past that we feel alienated from, that are shameful or that we would rather repress, this threatens our authentic being in the present as well as its realization in envisioned possibilities for the future.

Ultimately, it is the future that counts in Heidegger's account of authenticity, the realm of unrealized but aspired possibilities for more authentic selfhood. This can be compared to the discussion of Nietzsche's notion of becoming who you are, that also stresses the importance of realizing the potentiality for greater health that is intuitively sensed but not yet actualized. As Golomb (1995) puts it, "Authenticity reigns in the realm of possibilities not yet realized. The roots of authentic Being are in the future, because possibilities are never in the actual present. In other words, to Be is to be in time and history; it is to comport one's self to one's own Being in a time-consuming process of realizing one's potential for authenticity" (p. 118).

We may conclude that the existentialist position offers an account of authenticity that enables us to oppose the problematic essentialist assumptions about the authentic true self that plagued the views of Rousseau and his Romantic heirs. In this sense, the existentialist interpretation helps us to arrive at an interpretation of authenticity that is more in sync with the view of the self as constituted in narrative and social dynamic processes. However, with regard to the second set of problems haunting the authenticity discourse, which relates to the role of social influences, the existentialist account fails to offer a viable solution. The influence of others is still mainly presented as a source of inauthenticity that needs to be overcome. In the next section, I explore whether C. Taylor's (1991) interpretation of authenticity is able to address the issue of social influence in a more satisfactory manner for the purposes of this study. 


\subsubsection{Charles Taylor's ethics of authenticity}

Of the contemporary thinkers on authenticity, C. Taylor (1991) is no doubt one of the most influential, erudite and nuanced voices in the choir. C. Taylor acknowledges the moral value of the authentic mode of living according to one's own value orientation. He pleads for an interpretation of authenticity that acknowledges our dependence on an intersubjectively constituted horizon of social and cultural sources of meaning. Importantly, he argues that contemporary appearances of the culture of authenticity that are criticized for their egocentrism and narcissism are themselves at odds with the original meaning of authenticity as a moral ideal. In Ethics of authenticity C. Taylor (1991) starts by analyzing three "malaises" that haunt modernity:

1. The first malaise pertains to the worrisome effects of individualism. While individualism has enabled many of the great accomplishments of modernity, liberating people from the burdens of a life defined by the restrictions of traditions and community, C. Taylor argues that it has also resulted in a loss of self-evident access to shared sources of identity, meaning and morality. Individualism has created an ethics of self-realization that perceives individuals as atomistic, narcissistic and self-directed creatures, destined to create their own meaning in a context of value pluralism.

2. The second malaise of modernity is described as the "primacy of instrumental reason" (C. Taylor, 1991, p. 5). This primacy implies that everything tends to be calculated in economic terms like efficiency, cost-benefit ratio or maximization of gain. The problem C. Taylor discusses is that the typical logic of instrumental reason does not remain restricted to the economic domain, but also pervades other areas of human life, including politics, health care, social science and human relationships. The primacy of instrumental reason results in a problematic neglect of the value dimension intrinsic to these domains.

3. The third malaise of modernity discusses the implications of the first two malaises in the political domain, where it leads to a lack of engagement and a diminishing freedom. C. Taylor argues that the excesses of individualism and the primacy of instrumental reason have eroded people's sense of engagement with an individual-transcending whole. As a result, their political activity, their willingness to participate in the governing processes necessary for a healthy, resilient democratic society, is diminished. People become absorbed in their private lives, where it becomes increasingly difficult to feel connected to larger frameworks providing meaning. This development leads to a sense of moral uneasiness, and a loss of positive freedom. 
C. Taylor (1991) notes how influential neo-conservative thinkers like Lasch (1979), Sennett (1992) and Bellah et al. (1996) have deplored these malaises of modernity. They blame the typical modern culture of authenticity, which they regard as narcissistic and self-contained, for ruining communal engagement and moral values. C. Taylor shares their concerns, but he still maintains that we should acknowledge the ethical force that hides behind the contemporary authenticity culture. Instead of pleading to abnegate the ideal of authenticity, we should return to its sources and restore its original moral force. In fact, C. Taylor argues that authenticity is actually "unrepudiable by moderns" (C. Taylor, 1991, p. 23). Importantly, C. Taylor's position seems to be that nothing in the idea of authenticity as such necessitates its modern degeneration. On the contrary, he argues that the genealogy of our modern self-understanding shows authenticity to be a powerful source of identity, morality and meaning for modern individuals. For many people, the ultimate purpose of human life is no longer located beyond our earthly existence in some transcendent realm, but consists in authentic living in the present. However, as a result of moral relativism and subjectivism, modernity is uneasy when it comes to claiming the superior value of any mode of living over another. This also complicates acknowledging authentic living as a moral ideal.

The most important point stressed repeatedly by C. Taylor is that the typically modern localization of the source of morality in our inner realm, that we already found in Rousseau's work, does not necessitate moral subjectivism and relativism or an atomistic, essentialist conception of the human agent. Instead, C. Taylor argues that authenticity can only be a viable ideal against a broader horizon of meaning that precedes the individual life and extends beyond its duration. As C. Taylor (1991) puts it, "I can define my identity only against the background of things that matter. But to bracket out history, nature, society, the demands of solidarity, everything but what I find in myself, would be to eliminate all candidates for what matters. [...] Authenticity is not the enemy of demands that emanate from beyond the self; it supposes such demands" (p. 40-41). Moreover, only human beings intersubjectively related to others, in social bonds and communities enabling recognition and participation, can successfully realize an authentic life. We constitute our identities in dialogical relations with other people, in narrative processes of hermeneutic deliberation about the worthiness of the ideals we appropriate. Therefore, although authenticity is a facet of modern individualism, this does not mean that it cannot be accompanied by a social ethics of recognition, intersubjectivity and solidarity. It is a profound misunderstanding that the inward turn and the focus on either self-discovery or self-creation that lies at the bottom of the modern culture of authenticity precludes social constitution of identity. As C. Taylor (1991) observes, "My discovering my identity doesn't mean that I work it out in isolation but that I negotiate it through dialogue, partly overt, partly internalized, with 
others. That is why the development of an ideal of inwardly generated identity gives a new and crucial importance to recognition. My own identity crucially depends on my dialogical relations with others" (p. 47-48).

Although C. Taylor's view seems a promising candidate for a satisfactory solution to both sets of problems that plague authenticity discourse in general (see $\llbracket 7.2$ ), his account fails to explicitly address the fact that people's positioning in society (belonging to a dominant or a subordinate social group, for instance) strongly influences their chances for self-realization, as well as for their recognition as moral agents with a valid claim to authenticity and freedom. The possibility that authenticity may also require standing up to and distancing oneself from existing cultural horizons of meaning and morality is insufficiently covered by C. Taylor's view. In the next section, I discuss Meyers' (2000) view of authenticity, which addresses these topics.

\subsubsection{Diana Meyers - Authenticity and intersectional identity}

Meyers (2000) discusses the theme of authenticity in the context of her view of autonomy, for which she regards the possession of an authentic self to be a crucial condition. Meyers' position regarding authenticity is characterized by a feminist sensitivity for the role of societal systems of domination and subordination, of power structures, and of social inequality, that we also encountered in her view of autonomy (see $₫ 6.3 .3$ ). Oftentimes, critiques on oppressive social structures are associated with a worldview that denies the viability of autonomy and authenticity as moral ideals, and even doubts the plausibility of their existence. By contrast, Meyers argues that the fact that who we are is significantly influenced by social structures does not necessarily make it impossible to uphold an authentic self or to practice autonomy. In fact, she claims that it is quintessential for human agents to form an authentic self in order to navigate the abundance of social influences that affect their lives in a satisfactory way. Thus, she defends the value of authenticity (which she regards as conditional for autonomy), but suggests that we should "redirect our attention - away from the internal structure of the authentic self and toward the process of constituting an authentic self" (Meyers, 2000, p. 154).

Meyers situates her view of authenticity against the background of the framework of intersectionality. This term has been introduced by feminist scholars who wanted to sensitize the identity debate to the fact that different categories of diversity, such as gender, ethnicity, class and age, work together in determining people's identities. These influences cannot be studied in isolation from each other. Thus, one's opportunities to practice moral agency do not simply depend on whether one is a man or woman, or young or old. Instead, they depend on the intersection of these multiple sources of identity. The intersectionality framework emphasizes that being a young black man with 
a low socio-economic status is very different from being an older, well-to-do, white woman. It enables more fine-grained distinctions and raises awareness of the interconnections between these categories of difference, though it also complicates the analysis. Meyers argues that this intersectional positioning can be made a part of an authentic personality despite the fact that we do not choose this position freely ourselves. By successfully exercising our autonomy competencies (self-discovery, self-definition and self-direction) in our social interactions in the world, we are engaged in an ongoing and open-ended process of constructing an authentic identity for ourselves. Ferrara (1998) seems to express the same insight when he states: "All identities, in fact, authentic and inauthentic, are equally rooted in interaction. What distinguishes the authentic ones is something else, namely, the capacity to express a uniqueness which has been socially constituted through the interplay of the singularity of the formative contexts and the singularity of our responses to them" (p. 54).

For both Meyers (2000) and C. Taylor (1991) then, authenticity is not attained by overcoming the impact of external influences on the self. But Meyers emphasizes that these external influences are also not something we should uncritically accept at face value. Instead, authenticity in the intersectional view requires an active, agential attitude towards the socio-cultural forces that co-constitute who we are. As Meyers (2000) puts it, "accepting intersectional identity as a feature of one's authentic self does not entail clinging to a community of origin or capitulating to stereotypical group norms. Rather, it entails analyzing the social significance of one's community of origin, disclosing to oneself the ways in which associated norms have become embedded in one's own cognitive and motivational structure, appreciating how entrenched they are, and assuming responsibility for the ways in which one may enact them" (p. 159).

As C. Taylor's (1991) view suggests, we should for sure acknowledge the constitutive importance of our social and cultural horizon in our identity-constitution. But qualifying as authentic and autonomous means that we should also be able to criticize and possibly transform these constitutive horizons at points where they may impede our own or other people's moral agency. This is the point that Meyers (2000) adds. According to Meyers' view, authenticity and autonomy are intrinsically connected. We develop both in the context of our daily social practices. They will emerge easier and sooner in circumstances that stimulate people's moral agency. But as Meyers argues, this is not a necessity; both autonomy and authenticity can also be realized in unfavorable social situations. However, realizing "a good life, with and for others, in just institutions" which Ricoeur (1992, see also \5.4) formulates as the ethical aim guiding our moral lives, does seem to request of us to make an ongoing effort to ensure the actualization of a society that gives more people the opportunity to exercise their potential for moral agency in freedom. In Meyers' (2000) formulation, 
such an endeavor "would counteract moral anesthesia and motivate people to overcome cooptation and anomie. Apprehending one's intersectional identity that is, knowing who one is - may prompt resistance to unjust treatment - that is, moral and political autonomy" (p. 161).

A final important element of Meyers' view is the fact that she underscores that both autonomy competence and authenticity are lifelong learning processes situated in the context of concrete human practices. The result will never be complete or perfect, for, as Meyers (2000) emphasizes, "Piecemeal authenticity, I would urge, is the best that we murky, fallible human beings can hope for" (p. 174). Despite Meyers' acknowledgment of the complex and evolving character of authentic selves however, she maintains that selves should have a certain amount of unity or coherence. Personalities that lack this unification, that are, for instance, fragmented or compartmentalized, cannot exercise autonomy; nor can they qualify as authentic (Meyers, 1989). In this sense, her view matches

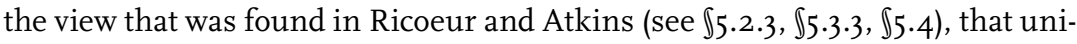
fied selfhood is conditional for moral agency.

\subsection{Authenticity in the context OF Aging}

As a guiding concept for aging well, authenticity is less explicitly present in mainstream gerontological discourse than autonomy. However, there do exist some perspectives that merit attention here, since they are concerned with authenticity-related notions like (spiritual) growth, ego-integrity, self-acceptance, et cetera. The fact that the term authenticity is not often used in these works does not mean that the underlying ideas do not cohere with the spirit of the authenticity discourse. I therefore present below some gerontological views which, in my opinion, defend a position related to the theme of authenticity. Three examples stand out in particular: 1) spiritual perspectives on aging, 2) existential perspectives on aging, and 3) art of living perspectives on aging.

\subsubsection{Spiritual perspectives on aging}

The most frequently occurring perspectives in gerontology that draw on the language of authenticity can be described as spiritual perspectives on aging. Examples can be found, for instance, in the works of Atchley (2009), Tornstam (1989, 2005), and Moody and Carroll (1999). An important similarity between spiritual perspectives on aging and the authenticity discourse is their emphasis on an (inner) development towards a truer, more fulfilled self. For instance, Atchley (2009) draws on several spiritual traditions that claim the existence of a pure core self that can be actualized by engaging in spiritual exercises such 
as meditation. This spiritual self is regarded as more genuine, more pure, and more true to one's nature, than the self we tend to show to the external world.

Spiritual perspectives understand an authentic attitude towards oneself to include the ability to relate to one's own finitude and existential vulnerability in a meaningful way. They suggest ways in which later life can be perceived as a period of growth and flourishing despite, or maybe even because of, the confrontation with vulnerability (Laceulle, 2013). This makes the spiritual understanding of authenticity relevant in our search for a new frame for self-realization that enables a meaningful integration of existential vulnerability. A good example of a spiritual gerontological perspective congenial to authenticity discourse can be found in the theory of gerotranscendence (Tornstam, 1989, 2005). Gerotranscendence is conceptualized as a shift in the metaperspective accompanying aging, which may pertain to one's self, one's social relations or the broader cosmic reality. Although empirical evidence for the claim that these forms of transcendence are exclusive to older people is rather thin (Tornstam, 1994, 1997; Braam et al., 2006), the merit of Tornstam's gerotranscendence theory is that it draws attention to the possibility that later life may also have a potential for growth and development, which is often neglected in Western culture (Laceulle, 2011). Gerotranscendence theory claims that later life harbors a specific potential for spiritual self-development. Importantly, one of the features of this development is that people turn away from the hustle of everyday life and the pressures of social expectations. The assumption that one connects with a more true or authentic self by loosening oneself from social conventions shows interesting similarities with the classical perspective on authenticity, in particular with Rousseau's views.

Moody and Carroll's work The five stages of the soul (1999), which also describes a process of spiritual development typical of people beyond midlife, introduces an element that shows similarities with the authenticity discourse as well. Moody and Carroll argue that it is crucial to spiritual development that at some point in life one hears "the Call"; standing at a crossroad, one feels the awakening of a sense of urgency to change things, to re-evaluate one's orientation in life. Hearing this call is followed by the desire to answer it and go on a search, a journey of self-discovery with an unknown outcome. The way this process of hearing and answering the call is sketched shows interesting parallels with the experience of crisis or "disease", that existentialist thinkers like Kierkegaard and Nietzsche saw as the quintessential starting point of realizing a more authentic existence. Interestingly, the way Moody and Carroll (1999) describe the characteristics of the searching soul also shows striking similarities with the features Ferrara (1998) distinguished as characterizing an authentic personality: coherence, vitality, depth and maturity. 


\subsubsection{Existential perspectives on aging}

The second example of the application of authenticity-related vocabulary in the context of aging studies is best described as existential gerontology. This term is not very prevalent, but it is used by some to accentuate their focus on matters of meaning related to later life (De Lange, 2007, 2008; Baars, 2012a). The term existential here solely indicates the focus on human existence and its meaning; its sources of inspiration are not restricted to existentialist philosophers. By using this terminology, existential gerontologists distinguish their own approach from predominantly biomedical or social-scientific discourses on aging that generally attract a lot more attention in the world of aging studies. They argue that aging should not just be regarded as a matter of biological senescence or as a demographical issue, but that more attention needs to be drawn to the existential dimension, i.e., the way people experience and give meaning to their own aging (Baars, 2012a; Baars \& Phillipson, 2013; Kruse, 2013).

A first relevant example of the existential view can be found in De Lange (2007). He aims to develop an existential gerontological perspective that transcends the consumerist, activist cultural paradigm of self-invention which has been qualified as an age-defying narrative (see $\mathbb{3} 3.3 .3$ ) in this study. Following Kierkegaard (1843/1959), De Lange (2007) argues that the existential reality of aging requires deeper and richer conceptualizations of the idea of personal growth or self-realization. These should be able to account for vulnerability, and be based on integrating and transcending limitations instead of conquering them. De Lange advocates a reading of self-realization as the "ethical engagement with one's own life course". He concretizes this aim by developing a model of five fundamental conditions that are needed in order to age well. These conditions include meeting one's natural needs, being a valued member of social communities, accepting moral responsibility for one's life, having the possibility to infuse one's life with meaning by connecting it to some higher dimension, and finding a satisfactory balance between all these conditions. The fourth condition implying a process of self-transcendence in particular, shows similarities with the accounts of authenticity that have been discussed above, with the view of Kierkegaard (1843/1959) in particular, but also that of C. Taylor (1991). The fact that De Lange's (2007) view is at odds with the classical essentialist, anti-social perspective of Rousseau $(1754 / 1984,1762 / 2003)$ and the Romanticists, makes his perspective all the more interesting for this study's purposes.

A second relevant example of the existential perspective comes from Kruse (2013). He suggests an "anthropology of aging" that highlights seven themes, some of which are very congenial to the idea of authenticity as an aspect of self-realization. For instance, Kruse focuses strongly on the theme of "Selbstgestaltung [self-design, or self-realization]", a term describing the motivation 
to consciously shape one's life and identity according to one's own values, purposes and desires. This theme is highly congenial to the underlying ideas of authenticity discourse such as becoming who you truly are. But Kruse adds important considerations that suggest that this process of authentic self-realization should include finding a satisfactory relation to the dimension of existential vulnerability and the finitude of human life. This suggests a strong resemblance with the perspective defended in the current study, which is even further enforced by the fact that Kruse also emphasizes the social embedding of human beings, and the necessity of taking moral responsibility for one's life.

A third relevant example from the category of existential gerontological perspectives can be found in the work of Rentsch (2013). According to Rentsch, the typical late modern ideology of self-constitution (becoming who we are) requires an ongoing process of maturation and deepening self-knowledge. In later life, this task gains in importance because of the more acute confrontation with finitude. We should be careful, however, not to assume that aging - reaching a higher age - in itself provides a guarantee for such character-development. However, the life experience one has generated throughout a long(er) life does in principle offer chances for growth and development not always open to younger people. These potentials are easily overlooked by dominant cultural discourses about later life.

In its emphasis on becoming who you are and the confrontation with finitude, Rentsch's view seems a close match with the existentialist perspective on authenticity discussed above, in particular with the views of Nietzsche and Heidegger. However, interestingly, Rentsch's interpretation is different and more in sync with ancient Greco-Roman views about self-realization, which may provide an interesting bridge to the third thread of self-realization - virtue - which has its roots there (see chapter 8).

\subsubsection{Art of living perspectives on aging}

A third relevant line of gerontological thinking that draws upon ideas acquainted with the authenticity discourse is affiliated with the recent revival in moral philosophy of Greco-Roman views about "art of living" or self-care. The later works of Foucault that focus on how we act upon ourselves through the appropriation and application of "techniques of the self" have been highly influential in this development (Foucault, 1984/1992; Kekes, 2002; Nehamas, 1998; Dohmen, 2002, 2008, 2014; Schmid, 1998). Hadot (1995) argues that in the Greco-Roman world, philosophy was perceived as a practice, a way of living centered around concrete sets of spiritual exercises. One of the important purposes of these practices was learning how to die, or developing a satisfactory attitude towards the contingencies, vulnerability and finitude of life. 
Lately, there have been some interesting attempts to connect these art of living perspectives to the field of aging studies. One of the most extensive and erudite recent works in this category is Aging and the art of living by Baars (2012a). Baars argues that late modernity is in need of a contemporary "art of aging", that perceives aging as a social-existential process of living in time. This art of aging should be perceived as an 'extended art of life' (Baars, 2012a, p. 201). Two themes stand out in such an art of living/aging: finding a satisfactory attitude towards the fundamental vulnerability of the human condition, and realizing one's unique potential as an individual human being. The art of living/aging perspective suggests that there is dignity and meaning to be found in an attitude of gracious and conscious acceptance of our existential vulnerability and our finitude, which we share with all other people. Importantly, our attitude towards finitude need not just pertain to (our own) death, even though thinkers like Heidegger (1927/1996) made a close connection between authenticity and consciousness of death. Baars states, by contrast, that finitude is at stake during our entire lifetime, a reality he describes by the term finitization. In fact, being aware of this may deepen the intensity with which we experience the events of our lives.

Baars (2012a) interprets Heidegger's account of authenticity as one that opens Dasein for its own authentic possibilities. This assumes a dynamic relationship to all dimensions of time: past, present and future. In this sense, Baars underscores that there is a deep connection between our finitude and the second theme in the art of aging: the realization of our individual uniqueness, which is a fundamental assumption of the authenticity discourse as well (Baars, in press). Regarding the latter, Baars underscores that aging can be accompanied by creativity and deepening individuality. Cohen $(2005,2000)$ makes an equally convincing empirical case for the creative potentials of later life based on his practice as a geriatrician. On this point, arguments from the art of living/aging perspective show important similarities with ideas from the authenticity discourse. Realizing one's potential for creativity and wisdom is seen as quintessential in the search for a good life. Ultimately, an art of aging should acknowledge both the vulnerability and the uniqueness and diversity of aging, ideally resulting in "a growing sensitivity for the unique qualities of vulnerable life” (Baars, 2012a, p. 201).

As a second example of the art of living perspective, Dohmen's (2013) sketch for a "moral lifestyle for later life" can also be interpreted as an authenticity perspective applied to the context of aging. To him, the term moral lifestyle assumes that people equip themselves with the relevant attitudes to engage in a "practice of freedom". Dohmen aims to give guidelines for such a practice that he believes are crucial in light of the life experiences of aging individuals. The dimensions of the moral lifestyle for later life that Dohmen suggests are the following: 
- Reflective distance: this dimension pertains to the capability to critically distance oneself from the diversity of expectations, images and directives about aging circulating in our socio-cultural context.

- Expropriation: this dimension pertains to the capability to recognize the ways in which our upbringing and socialization have disciplined us, and to discover and to a certain degree learn to oppose the expropriating forces characteristic of our particular lives.

- Appropriation: this dimension entails acquiring autonomy (as positive freedom) by identifying with certain values and goals in our lives.

- Orientation: this dimension pertains to the qualitative evaluation of our goals and purposes, relating them to the value horizon of the culture and tradition we form a part of.

- Engagement: this dimension suggests that, since people are not isolated, autonomous self-realizers but fundamentally socially embedded, we should engage ourselves with the web of relationships and responsibilities we form a part of.

- Integration and time: this dimension assumes that our moral identity, expressed in our moral lifestyle, is inherently bound to time. To connect the dimensions of past, present and future, a moral lifestyle requires a certain amount of coherence or integration.

- Serenity: this dimension suggests that a moral lifestyle for later life encompasses the acquisition of an attitude of resignation and serenity towards tragic aspects of life that are inevitably beyond our control.

- Finitude: this last dimension requires asking ourselves what sort of person we have been, what kind of life we have lived, what our value and contribution has been in light of the inevitable finitude of human life.

In sum, I conclude that although authenticity is not a common term in gerontological discourse, ideas associated with it have nevertheless found their way into gerontological reflections on how to age well. This fact provides welcome support for the ambition of this study to apply the self-realization discourse to the context of aging in a meaningful way.

\subsection{Evaluation OF the discussed aUthenticity accounts}

This chapter has discussed a selection of authenticity accounts. The understanding of authenticity for the purposes of this study should cohere with the insights on narrative identity and moral agency that support this study's reframing of self-realization. At the beginning of this chapter, I identified two sets of problems with the authenticity discourse: assumptions regarding true selves that underlie many interpretations, and the disregarding or rejection of 
social influences. A viable understanding of authenticity in the context of this study needs to provide a credible remedy for both problems. I will now evaluate the interpretations of authenticity discussed in this chapter for their ability to confront these issues.

- As we have seen, the views of Rousseau $(1754 / 1984,1762 / 2003)$ and his Romantic followers are problematically essentialist. The authentic self is perceived as a natural potential hidden deep inside a person, while the social context is exclusively presented as a source of grave trouble, obstructing the realization of authentic selfhood. The way I have conceptualized self-realization, narrative identity and moral agency does not match well with this interpretation. After all, I have repeatedly claimed that selves are best understood as socially embedded and narratively constituted, rather than essentialist. This view also implies that the influence of others is not perceived as inauthenticating, but as constitutive of who we are. Still, a valuable element to be retained from Rousseau for this study's view is his sensitivity to the fact that authenticity requires that we find a satisfactory relationship with inauthenticating influences, and that (moral) education plays a crucial role here. From the Romanticists, on the other hand, we can learn that our identity need not be seen as a given entity, but that it can be perceived as a creation that evolves dynamically. Although the heroic Romantic ideal of making an artistic creation of oneself is not how I would prefer to see authenticity, the idea of self-creation is also present in a different form in the view that we narratively constitute ourselves.

- The existentialist view challenges the problematically essentialist assumptions underlying Rousseau's account. This makes it relevant to this study. Another advantage of the existentialist view is its strong awareness of the intrinsic connection of authenticity with a dimension of finitude and existential vulnerability. From the perspective of this study, it is highly valuable that the existentialists emphasize how authentic self-realization presupposes finding a viable attitude towards this dimension. Moreover, the Nietzschean idea of becoming who/what you are is very congenial to our purpose of developing a perspective on self-realization that permits us to see moral self-development as a lifelong process. However, when it comes to the social embedding of human beings, the existential views remain unsatisfactory. Existentialist thinkers - with the possible exception of De Beauvoir (1947) generally assume an antagonistic perspective that opposes the self and the other. They present the individual moral agent as an atomistic, sometimes even solipsistic being. The individual is principally opposed to others, who are mainly perceived in negative terms as a cause of inauthenticity. Furthermore, though Heidegger's (1927/1996) phenomenological account seems congenial to our view of identity, his perspective ultimately leads us in a dif- 
ferent direction. Instead of focusing on the importance of intersubjectivity, Heidegger moves towards a view of authentic existence that seems highly self-contained, and excludes the possibility of relationships with others that are advantageous, indeed indispensable, for leading a good life.

- C. Taylor's (1991) view of authenticity is promising when it comes to tackling both the problem of an essentialist self and the problem of a negative evaluation of social influence for authenticity. His view of moral agents as embedded in a socio-cultural context that is constitutive of their moral identity shows close affiliation with this study's suggested account of identity. Moreover, his insistence upon the need to relate to individual-transcending horizons of meaning and moral value matches my view that the self manifested in self-realization is not a solely individual construction, but is formed in social practices with a background of cultural norms and values that cannot be ignored. However, C. Taylor's account may be questioned for its lack of sensitivity for the dangers of conformism to the status quo of a given socio-cultural horizon. Some situations may require standing up to existing value-frameworks and the practices that flow from them. Such situations call for moral agents who have the ability to resist their own social and cultural background. Importantly, this resistance presupposes that to some extent one separates oneself from one's embedding in socio-cultural practices. This is not to occupy the independent atomistic position presupposed by the neoliberalist inspired philosophical perspectives which this study has repeatedly rejected. Instead, it is to take a critical position against the status quo and engage in a search for alternative practices. The importance of such strong moral agency is in danger of getting lost from sight if our account of authenticity focuses too strongly on the intersubjective constitution and socio-cultural embedding of human life, as seems to be the case in C. Taylor's work.

- Finally, a merit of Meyers' (2000) view of authenticity is that she seems to remedy precisely this objection raised against C. Taylor's (1991) view. Contrary to C. Taylor, Meyers shows a great sensitivity to the fact that people are not just positioned against the background of a cultural horizon of meaning and morality as a given reality, but that their positioning strongly depends on the social categories they belong to, and is highly influenced by power structures. In turn, Meyers' view shows us that our socio-cultural positioning strongly impacts our opportunities to be recognized and to function as self-realizing, authentic and autonomous moral agents. The greatest merit of Meyers' view, however, is that her awareness of the influence of social structures does not cause her to reject authenticity and autonomy as viable moral ideals. Instead, she suggests that we should conceptualize them in a different manner, and focus on the competencies that we need to develop 
ourselves as authentic selves in the social and moral practices of everyday life.

\subsection{Conclusion: ToWARdS AUthenticity AS A SOCIAL AND MORAL PRACTICE}

In this final section, I attempt to provide a tentative sketch of the view of authenticity advanced in this study. It is my contention that, in order to match this study's developing reframed understanding of self-realization, authenticity is best conceptualized as a social and moral practice, a qualification that will be clarified below.

Let me begin by returning to Ferrara's (1998) typology of authenticity views (see $\$ 7$.2). I stated that my perspective on self-realization calls for an intersubjective interpretation of authenticity instead of a substantialist interpretation. Given all that has been discussed about this study's understanding of the person/moral agent in chapters 4 and 5, this choice should not be surprising. The same obviousness applies to the fact that the authenticity account this study advances should be seen as reflective in Ferrara's typology. However, regarding the opposition between an integrative and an antagonistic conception, as well as a centered and a decentered notion of the self, I take an intermediate position that merits some further clarification.

First, although this study shares the insight that our socio-cultural embedding is constitutive of who we are (as in the integrative conception), a satisfactory conception of authenticity should also accommodate the possibility that we stand up to this background (as suggested by the antagonistic conception). Second, as argued in $\$ 5.2 .3$, although the decentered view is right that narratives need to be flexible and open enough to accommodate unanticipated experiences, it does not mean that we can live with narratives that are totally fragmented and have no center. While a centered view of the self neglects the reality of things that escape the coherence of the narrative framework, a fully decentered view of the self may ultimately be no more than an academic abstraction (Guignon, 2004). Hence my contention that we should opt for an intermediate position between a centered and a decentered view of authenticity.

When analyzed in terms of Ferrara's (1998) typology, Meyers' (2000) view seems to be the closest match with the account of authenticity suggested in this study. Her view is intersubjective, reflective, and takes an intermediate position in the centered-decentered and the integrative-antagonistic dichotomies. However, the perspective of the current study suggests that there is still an element that needs to be added to my conceptualization of authenticity. This is not satisfactorily addressed in any of the discussed views so far, although C. Taylor (1991) does provide some leads. This additional element pertains to the 
dialogical moral relationship between our self and others, which is fueled by our identification with an ethical aim, a value orientation to which we want to remain true. In previous chapters, Ricoeur's (1992) term self-constancy was used to describe this dimension of our (aspired) identity (see $₫ 5.4, \llbracket 6.6$ ).

Drawing on the notion of self-constancy may, I believe, also be helpful to clarify my conceptualization of authenticity as a social and moral practice. Let me start with how the interpretation of narrative identity and moral agency based on Ricoeur's (1992) notion of self-constancy relates to the idea of being true to oneself which is quintessential to the discourse on authenticity. This can be clarified by recalling the difference made by Trilling (1971) between sincerity and authenticity (see $\$ 7.2$ ). As previously mentioned, Trilling presents sincerity as the early modern predecessor of authenticity. Both concepts address the topic of being true to yourself, but importantly, in the case of sincerity this trueness has an instrumental social function: it is a means to assure that one is also regarded as reliable by others, which is important for one's social position in the community. By contrast, authenticity approaches trueness as an end in itself, with a moral value independent from one's relation to others. Our analysis of fundamental concepts of the self-realization discourse so far discussing identity, (moral) agency and autonomy - strongly tends towards an account that emphasizes the equal and interconnected importance of the relation of agents to themselves (manifested in Trilling's idea of authenticity) and the relation of agents to other people (manifested in Trilling's idea of sincerity).

The advantage of Ricoeur's (1992) notion of self-constancy is that it addresses the relationship between the two forms of being true to oneself which Trilling (1971) discusses under the headings of sincerity and authenticity. In Trilling's analysis, it is theoretically possible to be authentic but to fall short of being reliable to other people. It is also possible to practice sincerity and still be perceived as inauthentic, as Trilling (1971) and Ferrara (1998) both admit. From the perspective of self-constancy, however, both situations would be experienced as problematic because they raise conflicts regarding people's moral identity. Self-constancy acknowledges that the self and other are engaged in a social and moral practice of holding each other in their mutual identities (cf. Lindemann, 2014, see also $\$ 5.3 .2$ ).

The distinction between trueness as a means and trueness as an end in itself evaporates here; in self-constancy trueness to oneself is both means and end at the same time, because the self and other are seen as standing in a dialogical relationship to each other. The notion of self-constancy acknowledges our intersubjective connectedness with others, while remaining aware of the importance of our status as individual moral agents: $I$ am the one making commitments and I am the one ultimately responsible for answering them. Acknowledging the constitutive importance of other people and of existing horizons of meaning, as C. Taylor (1991) advocates, does not diminish this moral 
responsibility for our selfhood. Introducing the notion of self-constancy to the authenticity discourse therefore enables conceptualizing authenticity as a social and moral practice in which we strive, together with others, towards a good life. This view has the following implications and advantages:

- By choosing the term practice, it is underscored that authenticity is enact$e d$ in concrete life situations. Although authenticity remains a quality of persons and not of actions, this quality is necessarily expressed through actions in concrete practices. For example, I assure a friend that I will give her my honest opinion on an important decision that she is about to make. I feel confident about making this promise because honesty is an important part of the ideal self I aspire to be or become. To qualify as authentic in this situation would require that I actually do tell my friend the truth when she asks me. Only then would I be true to the value orientation that makes me commit to honesty. Following Meyers (2000), this account thus focuses on the process of realizing the truthfulness that is traditionally implied by the authenticity discourse, instead of on the state in which one has supposedly realized it. This has the added advantage of escaping the essentialism-objection raised against authenticity discourse.

- By qualifying the practice of authenticity as social, I stress that qualifying as an authentic self depends on whether others recognize my authenticity. It makes no sense to make a promise to be honest if there is no one who cares that I will keep it. In the previous case this other is my friend, whose presence in my life makes me want to hold my word instead of betray my authentic self. This presumes that the claim to authenticity can only be made and honored in the context of what I have previously described, drawing on Lindemann (2014), as the social practice of identity (see $\$ 5.3 .2$ ).

- The conceptualization of authenticity as a social practice results in a perception of the other that seeks to avoid the instrumental and antagonistic perception of others in traditional accounts of authenticity like the views of Rousseau (1754/1984) or of the existentialists. Although the suggested view of authenticity certainly acknowledges the possibility of conflict between the self and other (for instance, my honesty may result in tension between my friend and me if the opinion I expressed is not what she thought I would say), it has the fundamental advantage of recognizing that the self and other need each other, for they are engaged in authenticity as a practice together.

- By presenting authenticity as a practice that is not only social but also moral, I underscore that being an authentic self inherently touches upon the ethical dimension of human existence (which conveniently precludes the charge of aestheticism sometimes raised against views of authenticity). The intention to live up to my word - actually being honest in the example sketched above - presupposes a fundamental moral engagement with the 
good of both myself and the other. As any interpretation of authenticity, this interpretation too presupposes an expression of who I truly am, as well as an ideal self that I strive to become. Authenticity is a moral practice because the ideal self I want to become assumes an identification with an ethical dimension (in this case the value attached to honesty) that I hope to realize or embody. What Ricoeur (1992) teaches us, however, is that my identification with what constitutes the good for me (the ethical dimension mentioned above) cannot be isolated from my engagement with the good of others. This underscores that in my view of authenticity, the social and moral dimensions are intrinsically connected. 


\section{Chapter 8 - Virtue}

\subsection{InTRODUCTION}

The complex fabric of the self-realization discourse has been presented in the context of this study as consisting of three interwoven threads: autonomy, authenticity and virtue. Having discussed the former two in the previous chapters, it is now time to explore the theme of virtue in a similar way.

As in the previous chapters, my aim in this chapter is to find out which conception of virtue forms the most appropriate match with the conceptualization of self-realization, self-identity and moral agency that this study wants to develop. I start with a general introduction to the theme of virtue and virtue ethics (\$8.2). Next, along similar lines as in our chapters on autonomy and authenticity, a selection of different perspectives on virtue are discussed. In $\$ 8.3 .1$ I start with the view of Aristotle (Ethica Nicomachea), who is generally regarded as the father of virtue ethics in the history of Western philosophy. Next, in $\$ 8.3 .2$ the view of MacIntyre is discussed, whose work After virtue (1984) has played a very influential role in the revival of virtue ethics in recent decades. Third, in $\$ 8.3 .3$ a more recent "pluralistic" view of virtue by Swanton (2003) is addressed. After this selective discussion of three relevant accounts of virtue, I proceed in $\$ 8.4$ to address the way in which the concept of virtue has found its way into gerontological discourse. As will be shown, the application of virtue-ethical thinking to the field of aging studies is surprisingly limited. The chapter concludes with an evaluation of the discussed perspectives in light of the aims of the current study (\$8.5) and finally a reflection on the most suitable interpretation of virtue in the context of the reframed interpretation of self-realization (\$8.6).

\subsection{INTRODUCING VIRTUE}

As discussed in $\ 4 \cdot 3.2$, compared to autonomy and authenticity, virtue plays a rather subordinate role in the rhetoric of late modern lifestyle and "a life of one's own", which underlies the late modern understanding of self-realization that this study aims to reframe. However, this lack of attention in the soci- 
etal discourse is offset by the fact that moral-philosophical debates in recent decades have reintroduced virtue ethics as a critical perspective against prevailing deontological and/or consequentialist strands of thinking. In contrast with the latter's focus on rules and universalizing principles, virtue ethics calls our attention to the importance of character dispositions and the practice of good habits. In this sense virtue ethics shifts our attention away from the question "what to do?" towards the question "who to be?" (Schneewind, 1990). This makes it a highly relevant perspective for a study on self-realization. Whereas deontological and consequentialist perspectives are alternative answers to the same basic question of ethics, virtue ethics, by contrast, asks a different question (Van Tongeren, 2012).

But what is virtue? Broadly reviewing the current literature on virtue ethics, there seem to exist almost as many definitions of what virtue is as there are virtue ethicists. In general, however, most virtue-ethical thinkers agree that virtue is an attitude or character disposition that strives for human excellence, and should result in optimal moral behavior, or at least behavior that can be qualified as the best given the circumstances. The development of virtuous attitudes is thus conceived as a process of moral self-development. In accordance with this, Van Tongeren (2012) qualifies virtue ethics as an ethics of self-realization. The virtue-ethical tradition in moral philosophy has seen a considerable revival in recent decades (for some seminal examples, see Anscombe, 1958; MacIntyre, 1984; Foot, 1978; Hursthouse, 1991; Hurka, 2001; Slote, 1992, 2001; Swanton, 2003). Broadly speaking, four characteristics of virtue-ethical perspectives can be distinguished that play a role in this renewed interest: 1) their critique on dominant moral philosophies that strive for universal rules and principles, which leads to a focus on the moral agent instead; 2) their opportunities to offer a remedy for the perceived "moral crisis" of modernity; 3 ) their acknowledgment of the fact that moral agents are embedded in a (complex and dynamic) social context; and 4) their recognition that this embedding of moral agency requires a responsive, flexible and context-dependent ethics. I will discuss these points in turn:

- First, the revival of virtue ethics is often explained as a critical reaction towards the two most dominant strands of moral theory since the Enlightenment: deontology and consequentialism (of which utilitarianism is one of the dominant representatives) (Crisp \& Slote, 1997; Statman 1997). For instance, in her seminal article Modern moral philosophy, Anscombe (1958) argues in favor of virtue ethics because it is capable of articulating a more satisfying moral psychology than deontology and consequentialism, with their one-sided focus on rules, principles and criteria for right actions. In a situation of eroding traditional foundations of ethics, Anscombe argues, we should turn to human flourishing (eudaimonia in Aristotelian ethics; 
see $\llbracket 8.3 .1$ as a more viable basis for morality than obligation. Consequently, virtue ethics focuses on moral agents and their lives, rather than on discrete actions (Crisp \& Slote, 1997).

We should note, however, that the distinction between virtue ethics and other ethical approaches is not as clear-cut as it seems. The revival of virtue ethics also harbors approaches aiming to formulate criteria for the moral legitimization of actions on the basis of virtue-ethical thinking (Slote, 1992; Hursthouse, 1991). To complicate things further, there are strands of consequentialist as well as deontological thinking which integrate a certain conception of virtue, such as Hurka's (2001) consequentialist account of virtue ethics.

- Second, the revival of virtue ethics has been motivated by concern regarding the moral outlook of (late) modern societies. MacIntyre (1984), for instance, saw virtue ethics as the much-needed remedy for the state of moral crisis he observed in modern societies. Interestingly, although MacIntyre criticizes moral individualism and builds his argument mainly along communitarian lines, it is also possible to argue in favor of virtue ethics for opposite reasons. After all, the virtue-ethical emphasis on the moral agent and his character development also seems to offer valuable directions to deal with contemporary moral individualism and pluralism without having to reject them.

- Third, the revival of virtue ethics mirrors the growing awareness in contemporary philosophy of the fundamental interdependence of human beings and their embedding in a social context. Aristotle's position on virtue, for instance, would be incomprehensible without taking into account his view that humans are fundamentally "political animals", creatures defined by their membership of the community or polis (Ethica Nicomachea, see 『8.3.1). MacIntyre's (1984) neo-Aristotelian account equally emphasizes that individuals are social beings, constituted by their social surroundings and by the traditions in which their life is embedded (see $\$ 8.3 .2$ ).

- Fourth, virtue ethics raises our awareness of situational and contextual influences on our moral conduct, and underscores the need for practical wisdom to confront these influences. Whereas deontological or consequentialist approaches depart from the assumption that morality should provide guidance regardless of the specific circumstances, virtue ethics emphasizes the importance of assessing the demands of a specific situation, and deciding which action is required on the basis of this assessment. Lifelong development and maintenance of virtuous attitudes or character dispositions is needed to enable this assessment and flexible responsiveness.

The discussed characteristics suggest that virtue ethics provides a promising perspective to accommodate the views of human identity and moral agency 
underlying the reframed version of self-realization developed in this study (see chapter 5). In contrast to ethical perspectives based on autonomy and authenticity, a virtue-ethical perspective is more naturally sensitive to the social and contextual embedding of human life. The fact that the development of virtue is perceived as a lifelong undertaking also conveniently corresponds to my emphasis in this study on the narrative, historical and temporal character of identity. Of course, the revival of virtue ethics has also raised criticism in moral philosophy. Critiques include, for instance, the vagueness of the notion of virtue compared to the universal rules and principles of other ethical approaches, the diverse and sometimes conflicting opinions of what relevant virtues are, or the self-centeredness that supposedly accompanies the virtue-ethical focus on the moral agent. Also, doubts have been raised about the ability of virtue ethics to provide guidance for action in concrete moral dilemmas. Moreover, given its concentration on long-term character assessment, virtue ethics has been criticized for being unable to evaluate the legitimacy of concrete actions (Louden, 1997). Finally, the so-called situationist critique voices skepticism about whether human action in fact depends on attitudes of character, or rather on situational characteristics (which would contradict the basic assumption of virtue ethics that character motivates moral behavior) (Harman, 1999, 2009; Doris, 1998).

In addition to these critiques, virtue as one of the constitutive threads of self-realization discourse raises two additional issues that deserve special consideration:

- First, some interpretations of virtue ethics harbor an image of the telos of human life that is rather naturalistic and essentialist. Such views are also often accompanied by objectivistic assumptions about truth and value, for example, when they assume the existence of a "common good". These naturalistic, essentialist and/or objectivistic views relate problematically to the highly pluralistic late modern moral context sketched in chapter 2 . Moreover, such views potentially cause tension with the social constitution perspective defended in this study, which regards categories like truth, value or the telos of human life not as pre-given or universal, but as socially-constituted. Furthermore, these categories are seen as diverse and plural, although this certainly does not imply that "anything goes". In the view of this study, the recognition of these goods as worthy, truthful or valuable is based on a constant intersubjective, hermeneutic process of deliberation instead of on a cosmic order or a tradition that offers "ready-made" goods, as it were. A viable conception of virtue in the context of this study will have to be able to accommodate late modern moral pluralism and the corresponding diversity of goods and purposes, as well as cohere with an intersubjective, social constitution perspective on truth and value. 
- Second, the sensitivity of virtue ethics to the social and contextual embedding of human moral agents is sometimes accompanied by a tendency of conventionalism and traditionalism. This tendency can be problematic when it comes to the potential for critical resistance that the theory of cultural narratives and counter narratives used in this study ascribes to- and requires from moral agents (see $\$ 3.2 .4$ ). Thus, a viable conception of virtue in the context of this study principally needs to incorporate the possibility to stand up to the status quo and criticize opinions or people who are traditionally seen as exemplary in a moral sense. Before I can attempt to formulate an interpretation of virtue that matches this study's suggested view of self-realization, it will be clarifying to discuss a selection of views illustrating how virtue has been developed and interpreted in the course of philosophical history.

\subsection{Selected accounts of Virtue ethics}

\subsubsection{Aristotle: Virtue as 'nobility of the soul'}

One of the most important and well-known sources of virtue ethics in the Western philosophical tradition is Aristotle's Ethica Nicomachea. The deepest roots of self-realization as a moral ideal depicting the good life can be found here. Self-realization in Aristotelian virtue ethics is perceived in terms of a lifelong developmental process of acquiring a virtuous, i.e., excellent, disposition of character. The good life for human beings is believed to be realized through "activity of the soul in accordance with virtue" (Ethica Nicomachea I, 7, 1098a16).

Aristotle's ethics and his understanding of virtue cannot properly be understood without considering his conception of the world as a meaningful cosmic order, his metaphysical biology/anthropology, and his ideas about society as a political and moral community. Importantly, Aristotle's philosophy teaches us that the individual striving for self-realization is interwoven with the good of the community - in Aristotle's case, the Greek polis. It thus has a moral relevance transcending the interests of the individual. This underscores that self-realization is not an atomistic undertaking. Instead, practicing the virtues has the potential of influencing the broader social and societal context of individual life. The virtue or excellence of an entity, according to Aristotle, is defined by its contribution to its optimal functioning. A hammer is a good hammer if it performs the function of a hammer well; likewise, human beings are good human beings if they live up to their natural function. In the worldview of ancient Greek philosophy, every entity - including human beings - has its own place in a meaningful cosmic order, from which its natural function flows. The 
good life is perceived as that life in which the natural telos or purpose of human life is optimally realized.

Aristotle thus presents a teleological ethics. The natural purpose for human beings, the telos strived for in the process of self-realization in virtue ethics, is formulated by Aristotle in terms of eudaimonia, or happiness. Eudaimonic conceptualizations of happiness contrast so-called hedonic conceptualizations that perceive happiness in terms of pleasure and absence of pain or unpleasantness (Ryff \& Singer, 2008; Ryan \& Deci, 2001). Instead, eudaimonic views perceive happiness in terms of a life well lived, a flourishing existence in accordance with the purpose or telos inherent to human nature, an existence that represents the best realization of the agent's potentialities. The faculties required for realizing eudaimonia are supposed to be potentially inherent in all beings, but need to be developed to become actualized. This implies a lifelong process of learning and maintaining virtues: excellent character dispositions, acquired through developing the right habits and performing good actions. For Aristotle, acquiring virtues takes place in concrete daily practice; one becomes a just person (i.e., acquires the virtue of justice) by performing just actions. Consequently, Aristotle's ethics conveys a life course perspective: one's virtuousness cannot be fully judged until life is completed. There is always the possibility that people who have made the right choices so far go astray in another situation, thereby compromising their virtuousness. Thus, Aristotle claims that "human good turns out to be the activity of the soul in accordance with virtue, and if there are more than one virtue, in accordance with the best and most complete. But we must add: 'in a complete life'. For one swallow doesn't make a summer, nor does one day" (Ethica Nicomachea I, 7, 1098a19).

Aristotle also thinks that children and young people cannot be called virtuous. They may have had some education, but they still lack the experience and training required to have developed virtuous habits. Practical wisdom, a very fundamental virtue for Aristotle, essential to obtain other virtues, is something that can only be developed in the course of maturation throughout life. These observations strengthen my surmise of a particular relevance of virtue ethics for aging. However, it should not be concluded that Aristotle automatically perceived older people as the most virtuous - in his Rhetoric, he was surprisingly negative about the elderly (Rhetorica II, 12, 1389a-1390a; Dohmen \& Baars, 2010). Although we all grow older, not everyone manages to become mature and acquire wisdom; this seems to be the sensible conclusion. Thus aging appears to be a necessary, but by no means a sufficient condition for virtue.

For Aristotle, the virtues exist in the proper mean between excess and defect of a certain trait. So, for instance, courage as a virtue is the proper mean, while fearlessness and cowardice represent the accompanying excess and defect states, temperance is the proper mean between self-indulgence and insensibility to pleasure, et cetera. Importantly, Aristotle acknowledges that both what 
counts as virtues and the concrete interpretation of their content depend on the context in which they are exercised. For instance, the virtue of good temper, which is the proper mean for the passion of anger, requires "to be angry in the manner, at the things, and for the length of time" that is required by the circumstances (Ethica Nicomachea IV, 11, 1125b32-1125b34). Reason is presented as the quintessential capacity to arrive at the proper mean in any given situation, for it enables thoughtful deliberation and steers our passions and emotions in the right direction. In this way, we ideally develop a virtuous disposition of character which we can rely on in future situations requiring our (moral) response. Note that the right mean envisioned by Aristotle is not an absolute mean, but a mean relative to us and to the situation. The intellectual virtue of practical wisdom is quintessential in deciding what a certain situation requires in terms of virtue as the right mean. Here, in these Aristotelian ethics, we strongly recognize the flexibility and context-sensitivity that is also characteristic of virtue ethics in general.

Aristotle's focus on excellence could elicit the conclusion that true virtue is attainable only for an elite minority. But in fact, his ethics harbors a strong awareness of the imperfection that characterizes earthly life for humans and the many contingencies and the existential vulnerability that influence our realization of eudaimonia. As Aristotle puts it, "Now many events happen by chance, and events differing in importance; small pieces of good fortune or of its opposite clearly do not weigh down the scales of life one way or the other; but a multitude of great events if they turn out well will make life happier [...] while if they turn out ill they crush and maim happiness; for they both bring pain with them and hinder many activities. Yet even in these nobility shines through, when a man bears with resignation many great misfortunes, not through insensibility to pain but through nobility and greatness of soul" (Ethica Nicomachea I, 11, 1100b23-110ob33). Thus, what Aristotelian virtue ethics suggests is finding the right attitude to deal with vulnerability, which relates significantly to this study's aim of composing an understanding of self-realization that is able to integrate existential vulnerability (see $₫ 2.5 .2$ ).

Crucial to the Aristotelian conception of virtue is making the right choices and doing the right thing based on the right, i.e., excellent attitude. But for people who cannot fully live up to this perfectionist standard, it still remains meaningful to strive for virtue and keep aiming to bring their passions under the control of their reason. There are many people, according to Aristotle, who know what is the right thing to do and struggle to make the right choices, against their emotional inclinations to do the opposite. Such people are in possession of "continence" rather than virtue. But this is still to be morally preferred over people failing to do the things they know are right, because they are unable or unwilling to control their wrong inclinations. Thus, everyone should be able to take part in the good life and reach a degree of eudaimonia 
that fits their capacities and situation. This part of Aristotle's view can serve to mitigate the supposed perfectionism his ethics has sometimes been criticized for, although his standards for true or "full" virtue remain quite high.

In sum, Aristotle's perspective on virtue has much to offer that is relevant in light of the account of self-realization developed in this study. In particular, its understanding of the moral agent as a socially embedded creature, its context-sensitivity, its life-course perspective and its suggestions for finding a satisfactory attitude towards inescapable existential vulnerability stand out in this regard. However, the question might be raised whether virtue-ethical ideas like Aristotle's are at all applicable to our lives in the complex world of late modernity. Isn't speaking about virtue these days rather archaic and strange? Doesn't it require the relatively ordered and organized context of the Greek polis, the context in which Aristotelian virtue ethics arose, and the corresponding metaphysical assumptions about the place of humans in a meaningful cosmic order that provides them with their natural telos? In the next section, I discuss the neo-Aristotelian view of MacIntyre (1984), who gives an account that defends the application of virtue ethics to the context of modernity.

\subsubsection{Alasdair Macintyre:}

\section{Virtue as a remedy for the modern "moral crisis"}

In \2.3.6, MacIntyre's (1984) dramatic estimation of the moral outlook of the modern world was already discussed. His remedy for what he perceives as the severe uprooting and moral crisis of modernity is a return to a neo-Aristotelian virtue-ethical perspective. This revival should restore our connection with the traditional sources of our moral intuitions and help us escape the modern dangers of relativism and emotivism. In MacIntyre's view, the process of modernization led to the loss of precisely those shared conceptions of common goods of the community and the individual that formed the basis of the traditional virtue ethics, together with the idea of a telos of human life. Admittedly, virtues have been reformulated in modern terms, but not in very helpful ways according to MacIntyre. On the one hand, modernity has conceptualized virtues in terms of their contribution to authentic self-creation, opposing the restrictions of conventional morality. This, for instance, is the view underlying Nietzschean philosophy, pleading for a strong, authentic, self-loving agent transcending the limitations of narrow, common morality (see \$7.3.2). On the other hand, virtues have been regarded as those dispositions that help people conform to the moral rules. This conformism is perceived as necessary to guarantee people's moral behavior in a world characterized by the unending struggle between atomistic human actors securing their self-interests and survival. This view underlies a wide variety of philosophical views, from Hobbes to contemporary communitarians. In both cases, however, MacIntyre observes that the context that 
originally provided virtues with meaning has disappeared. MacIntyre's own approach therefore defends a return to traditional Aristotelian virtue ethics, where individual virtuousness presupposed a context of shared goods, and the good of the individual automatically coincided with the good of the community.

MacIntyre (1984) defines virtue as, "an acquired human quality the possession and exercise of which tends to enable us to achieve those goods which are internal to practices and the lack of which prevents us from achieving any such goods" (p. 191). His account of virtue rests upon three important conceptual ideas: the concept of a practice, the narrative unity of human life, and the moral tradition. I will discuss his ideas about these concepts in turn.

- Practice: MacIntyre's (1984) understanding of virtue presupposes the context of a practice in which virtues are exercised. A practice is a mode of human activity in which certain common goods are at stake, goods that virtues help us to realize. However, not just any activity qualifies as a practice. The concerned activity has to be a social and collective undertaking forming a coherent unity which is meaningful to those involved. It has to aim at the realization of a certain good that is internal to the practice, a standard of excellence flowing from the practice itself. An illustration of a practice relevant to the context of aging might be caring, in which virtues like compassion, patience, helpfulness, modesty, kindness, thoughtfulness and generosity are exercised (Tronto, 1993; Held, 2006; Blum, 1994). Typically, a practice transcends the existence of the individual agent. It precedes the individuals involved in it, and will continue to exist after they are no more. Moreover, engagement in a certain practice requires the subordination of purely individual preferences to the authority of the history and tradition of the practice, and to those already experts in it. It involves a willingness to learn and to realize one's potentials in service of the realization of the common goods that are inherent in the practice.

- The narrative unity of human life: Although practices provide the necessary context for any virtue according to MacIntyre (1984), a practice does not in itself offer an overarching criterion to rank possibly conflicting or incompatible requirements posed by different virtues in the context of multiple practices. We thus need to choose between conflicting demands of a certain situation and decide which virtues will help us realize the overarching goal of a good life. Yet according to MacIntyre, our lives cannot qualify as good if they lack a unifying framework of meanings and values. Such an overarching picture of what matters most to us in our lives should help us make the proper choices and bring order into the demands at stake in a given situation. MacIntyre understands this framework of meaning in terms of an integrated unifying narrative. The problems associated with such a notion of narrative integration or unity have been encountered in $\mathbb{\$ 5 . 2 . 3}$. 
MacIntyre's assumption that life needs to be experienced as a unified whole is based on the Aristotelian premise that a virtue is a disposition that is supposed to be consistently present in one's actions throughout life, not just contingently exercised in a particular situation. Only in light of the narrative unity of our lives can we apply a hierarchical ordering to our values and strivings, and experience our lives as sufficiently coherent to count as meaningful. Although this view implies a strong emphasis on the narrative competence of the moral agent, it is important to note that MacIntyre perceives moral agents as only the co-authors of their own narratives, and not independent, self-determining authorities. Our lives are always embedded in a context (social, historical, cultural) and shaped by the tradition to which we belong.

- The moral tradition: According to MacIntyre, we can never decide solely as individuals what is the good life for us, or exercise the virtues in pursuit of such a life. Who we are and what we value and strive for, is mediated by social and cultural moral traditions. It matters for our own conduct and life choices whether we are born in a culture that values familial honor and loyalty over individual self-realization, or in a culture that values hard work, frugality and modesty, or in a culture that celebrates individual freedom. Our placement in the socio-cultural context in which we are born provides our individual life with its moral starting point. Our individual existence forms the embodiment of a social and moral identity (or several identities in different contexts) which has (or have) been shaped by the traditions that form the background of our lives. For MacIntyre, virtues play a key role in sustaining vital traditions that provide our lives with historical context and with the relevant common goods to be strived for.

MacIntyre is well aware that his view regarding the role of moral tradition is strongly at odds with the dominant individualism pervading our modern societies. He states: "From the standpoint of individualism I am what I myself choose to be. I can always, if I wish to, put in question what are taken to be the merely contingent social features of my existence" (MacIntyre, 1984, p. 220). This individualist standpoint is something MacIntyre strongly denies. We cannot detach who we are from our social and historical roles and the background of our moral tradition. We cannot even be called selves without acknowledging the fact that we are bearers of that tradition.

In sum, MacIntyre (1984) provides an account of virtue that is "modernized", insofar as it no longer presupposes Aristotle's metaphysical framework, which has become an anachronistic curiosity to the modern mind. His emphasis on practice is interesting, since it enables a concretization of how virtue is developed and sustained in human lives. However, his focus on the moral tradition and the quest for narrative unity are still relatively conservative and monistic, 
which makes a connection to the reality of late modern moral pluralism more problematic. I therefore proceed to discuss a view of virtue ethics that aims to accommodate moral pluralism.

\subsubsection{Christine Swanton: Pluralistic virtue ethics}

According to Swanton (2003), modern virtue ethics has been "rightly praised for taking seriously the richness and complexity of the moral domain, for its sensitivity to context and situation, and for its skepticism about the codifiability of ethics" (p. 9). Nevertheless, Swanton believes modern virtue ethics should enlarge its scope by incorporating pluralism in several ways. Swanton advocates a pluralistic understanding of the virtue concept itself, but her pluralism also extends towards an attempt to integrate insights from other strands of moral philosophical thinking that are usually perceived as mutually exclusive. The pluralism of her view seems promising when it comes to adapting virtue ethics to the context of late modernity. Four elements of Swanton's view merit particular attention for this study's purposes: 1) her focus on the responsive character of virtue; 2) her preference for a realistic rather than an idealistic or perfectionistic account of virtue; 3) her focus on pluralism at multiple levels; and 4) her suggestion of theoretical resources for the integration of existential vulnerability. I will discuss these aspects in succession:

\section{Responsiveness and virtue}

Swanton (2003) defines virtue as, "a good quality of character, more specifically a disposition to respond to, or acknowledge, items within its field or fields in an excellent or good enough way" (p. 19). In this definition, we see the notions of responding and acknowledging occupying a central place. The field(s) of virtue is (or are) interpreted in a broad way as the situation(s) requiring a moral response. Swanton argues that the good life has both "prudential" components, which pertain to personal flourishing and satisfaction, and components of "moral meritoriousness", which pertain to a "consistent appropriate responsiveness to the demands of the world" (Swanton, 2003, p. 59). These two types of components may be in tension, and the criterion for a virtuous life is that it succeeds in harmonizing the tension between the "demands of the self" and the "demands of the world". However, Swanton emphasizes that the gap between the two will not be closed completely.

A certain situation may require several, sometimes conflicting virtues at the same time. For instance, experiencing one's partner suffering from Alzheimer's disease places older people in a situation where multiple virtues are called for: care, patience, trust, respect, but also self-care and assertiveness. Some of the demands raised by this situation flow from the 
needs of the other or the outside world, others flow from the needs of the self. Both types of demands need to be acknowledged in order to arrive at the desired virtuous attitude in confronting a given situation. In Swanton's view, the criterion for virtue is an appropriate response to the demands of the world as well as the demands of the self. The adequacy of the response cannot be captured in any universal guideline for action, for it depends on the situation and needs to be decided upon in an intersubjective process of attunement requiring much moral sensitivity for the needs of others and of the self.

By emphasizing that the self is a relational entity, involved in a social world of multiple bonds and responsibilities that require a proper response, Swanton's (2003) analysis accords with my reflections on the role of socializing

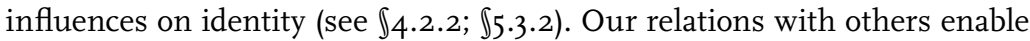
the process of development of virtue, but they can also stand in the way by placing contradictory demands or strains on the individual. Importantly, Swanton argues that the way in which we respond to the demands made by a situation defines who we are as an agent. The virtuousness (or lack of virtue) of our character disposition is manifested in the way we respond to the demands of the situation. This understanding of virtue related to identity echoes the previously discussed view that our moral identity and moral agency presuppose the desire to remain self-constant, i.e., to live up to our commitments to others and thereby to ourselves (Ricoeur 1992; see $\$ 5.5$ ). Swanton's (2003) analysis seems consistent with this analysis, because she underscores that our virtuous response to a certain situation is an expression of our motivation to be a certain person. As I understand it, this motivation defines what Swanton describes as the demands of the self. These demands need to be answered, but this process of self-realization has to be combined with a proper response to the demands of the world.

In the example sketched above, where someone is confronted with a partner diagnosed with Alzheimer's disease, this person may be dedicated to the promise to care for her partner "till death parts them". Expectedly, this commitment defines her identity and thus poses demands on her to honor it. But the situation may also make other demands; adult children, for instance, can argue that they have a shared responsibility to assure proper care for both parents, that motivations of protection or safety should prevail and that the sick parent should therefore be placed in an institution. Moreover, the demand to take into account the perspective of the sick partner/ parent and the need to respect his autonomy as far as possible also deserves to be reckoned with. Whereas the concerns of the patient and the children may be at odds with the demands of the self of the wife/mother, it is clear that they present legitimate demands that should be answered as well, if the situation is to be handled virtuously. 
Although Swanton (2003) emphasizes the importance of a virtuous motivation in moral agents, her account differs from the agent-centered account of Slote (2001), who argues for excellent motivation as the basic criterion of virtue. Swanton (2003) wishes to incorporate other factors besides motivation in her view, thereby aiming to do some justice to the situationist critique mentioned earlier (\$8.2). In Swanton's view, the criterion for moral rightness of action is whether the target of the relevant virtues is appropriately met. What the situationist critique teaches us, in Swanton's view, is that an excellent motivation is not the only relevant factor to be taken into account to assess virtue, because situational influences can sometimes outweigh motivations. The fact that in a practical context of action our virtuous motivation is vulnerable to being overruled by situational circumstances, however, need not deny the value of virtue ethics as such. Swanton just advocates a more modest and realistic view of how virtuous motivation and situational influences both decide how our moral behavior will turn out in a specific situation.

2. Realism and constraints on virtue

Since Swanton is well aware of the many difficulties people can meet in their search for virtue, she strives for a realistic, rather than perfectionist account of virtue. Generally speaking, Swanton advocates a view in which the criterion of virtue is seen as relative to the situation and the capacities of the agent. This has the advantage that no one is principally excluded from the realm of virtue; virtue is not something restricted to moral "saints" or "heroes". Swanton (2003) suggests a "threshold conception" of virtue (p. 63), in which the criterion is not some high idealistic standard of perfection, but the adequacy of the response to the demands at stake in a specific situation. What qualifies as virtuous and what is regarded as good may thus vary considerably depending on the context, according to Swanton's view. Life circumstances, expectations, value orientations, social relationships, external conditions, et cetera, all influence what can be called good in a certain situation. One of the interesting consequences of this view is that it allows for life-phase specific (constellations of) virtues and goods, which is a relevant point from the perspective of aging. Swanton herself points out that what is virtuous behavior for a younger person may not be so for an older one, and vice versa.

Swanton's realism implies that acquiring and exercising virtue can be complicated by many different factors. These factors include structural features of one's cultural and societal context, or parameters set by the social roles one is expected to fulfill, or a person's psychological outlook. For example, it would be more difficult to enact the virtue of generosity if one is not perceived by one's social and cultural surroundings as the kind of person who has something valuable to offer. Likewise, standing up against an injustice 
may require different types and expressions of courage from the position of a member of an oppressed minority than from the position of a well-meaning outsider. Finally, being very self-centered would complicate acquiring virtues like magnanimity or care.

Although Swanton argues for a realistic and context-dependent account of virtue, her view is not relativistic in the sense that any disposition can count as a virtue. Swanton suggests the application of a "constraint" on virtue, in which only agents showing a sufficient amount of psychological health and stability can qualify as virtuous. In her view, most contemporary accounts of virtue fail to offer a satisfactory understanding of the role of psychological factors in attaining virtue. She thus advocates an account of virtue that is based on acknowledging the complexity of human psychology. In order to accomplish such an account, Swanton suggests that virtue ethics should adapt to contemporary insights on psychological health and pathology. Swanton draws her inspiration for the criteria of psychological health which a virtuous agent in her view should possess from several psychoanalytic thinkers such as Winnicott (1965) and Horney (1950), but also from Nietzschean philosophy. These sources provide a much more complex and nuanced understanding of human nature than Aristotle's traditional naturalist metaphysical view, which is an advantage when it comes to adapting virtue-ethical thinking to the reality of late modernity.

Among the criteria for psychological health formulated by Nietzsche and post-Nietzschean psychologists that Swanton (2003) applies are, for instance, a realistic image of one's own strengths and weaknesses, the ability to maintain meaningful social relationships, the ability for life-affirmation and a sense of self-love. The latter is particularly important in Swanton's view, because she argues that a healthy form of self-love should be a part of the profile of every virtue. Swanton's "constraint on virtue" holds that, if an attitude or motivation does not spring from a sufficiently healthy psychological outlook along these lines (for instance, if it is associated with a narcissistic personality disorder, chronic resentment and hostility towards the world, or a pathological desire to harm others), it cannot qualify as a virtue.

\section{Pluralism}

Perhaps the most distinguishing feature of Swanton's account is her dedication to pluralism on multiple levels. In contrast to the classic eudaimonic view of (neo)-Aristotelianism, which regards the promotion of flourishing to be the sole and quintessential purpose of a virtuous life (see \$8.3.1), Swanton believes other goods besides human flourishing are relevant for virtue as well. Importantly, this means that Swanton aims to enrich her virtue-ethical perspective with insights from other moral philosophical approaches (such as Kantianism or Nietzschean ethics) that are usually perceived as conflicting or mutually exclusive. Though her focus remains virtue-ethical, 
she nevertheless wants to acknowledge the rightful claims of other moral theories. Any monistic conception of ethics is thus criticized by Swanton. A monistic conception of ethics bases what counts as right or virtuous on one single rationale, be it maximal promotion of value (in consequentialism), love or care (in forms of relational ethics), respecting moral status (in Kantian approaches), expression of authentic moral strength (in Nietzschean approaches), or contribution to human flourishing (in eudaimonic virtue ethics). Swanton's pluralism affirms my earlier statement that the three forms of ethics - universalist, personalist, particularist - distinguished by Gewirth (1998) (see $\$ 4.2 .1$ ), with their corresponding goods, all deserve to be given their proper due in my reframed interpretation of self-realization. In contrast to monistic theories, Swanton's (2003) view emphasizes that a virtue-ethical theory should not only be pluralistic regarding the goals to be strived for, i.e., bases of moral responsiveness, but also regarding the modes of moral responsiveness. In eudaimonist approaches, the only mode that seems to be acknowledged is promotion (of human flourishing). However, Swanton argues that a pluralism of goals also calls for a pluralism of viable modes of responsiveness. Depending on the characteristics of the situation drawing the response, other modes of moral responsiveness may be in order, such as respecting or honoring moral status, loving or being receptive of affective bonds, or expressing creative engagement with one's life. Every virtue has a complex profile, a constellation of multiple modes of moral responsiveness that are relevant to the situation.

An important implication of the pluralism Swanton advocates in her approach to virtue is that a good life does not automatically equal a flourishing life. The fact that other goods and strategies are also acknowledged to play a role in a virtuous life implies that life need not be (fully) flourishing to qualify as good (as eudaimonism implies). In fact, many situations in our lives may restrict our chances for flourishing. However, even a non-flourishing life can still qualify as meaningful or admirable, for instance, and therefore qualify as good. In the example of the woman whose partner suffers from Alzheimer's disease, her own well-being and self-realization are likely to suffer from the unfortunate condition of her husband, which will result in a less than flourishing life. But because she honors the demands of love and care constituted by her relationship with her husband in an excellent way, in Swanton's account her life can still be seen as virtuous.

4. Virtue and existential vulnerability

Swanton's sensitivity to the complications that confront moral agents striving to lead a good life makes her view particularly apt to offer a perspective on self-realization that acknowledges and integrates existential vulnerability. In formulating the point of departure of her account of virtue ethics, Swanton underscores right away that many possible obstacles threaten the 
ideal-type of virtue usually presented in moral philosophy. In this light, she argues that "[...] due to evil, catastrophe, and vulnerability, strategies for attaining the goals of personal self-realization and meeting the demands of the world cannot be assumed to coincide" (Swanton, 2003, p. 14). Swanton thus seems acutely aware of the way our lives are inevitably imbued with what I have termed existential vulnerability, which is inherent in human existence (see $\$ 2.4 .6)$. In my interpretation, her view rightfully acknowledges that moral agents are living in a world full of complexities and contingencies. Their striving for self-realization is fundamental to their good lives, but the demands of the world may complicate or impede this striving. Swanton's doctrine that virtuousness requires realizing a healthy equilibrium between seemingly opposing poles, suggests that living a virtuous, moral life is always a complicated balancing act. We cannot change or deny the fact that our lives are liable to existential vulnerabilities and other situational influences, but we can maybe develop an attitude that helps us deal with them in a satisfactory way.

Returning to my earlier example, being confronted with a diagnosis of Alzheimer's disease certainly qualifies as an instance of existential vulnerability, both for the person involved and for his partner or children. There are many emotional states that are possible in initial response; "negative" states such as denial, anger, sadness, despondency, but also more "positive" ones such as love, care, dedication, et cetera. It is likely that these states will all be experienced along the way of accepting and integrating the situation in one's life. What seems to matter is which states and inclinations define our response to this instance of existential vulnerability in the long run. It seems obvious that remaining stuck in anger or denial is not going to lead to a viable way of dealing with the situation. Yet, if we succeed in finding a livable balance between sadness, anger, injustice, care, love, acceptance of the inevitable, et cetera, this is likely to contribute in a positive way to our experience of the quality and meaning of life. This expectedly facilitates an "excellent or good enough", i.e., virtuous, way of responding to the demands of the situation. Having developed a virtuous character disposition may thus significantly increase this possibility, although no guarantees can be given of course.

In sum, Swanton's work suggests that virtue consists in finding an excellent or good enough way to respond to the demands placed by a situation. Her realistic perspective offers a welcome differentiation from Aristotle's supposed "perfectionism". Her acknowledgment of a diversity of goods, moreover, seems more capable of accommodating the reality of late modern moral pluralism than the more conservative approach of MacIntyre (1984) that presupposes a hierarchy of shared common goods delivered by the moral tradition. Nevertheless, an omission in her perspective is that it 
gives relatively little attention to the importance of a life-course perspective, and shows little sensitivity for the relation between our virtuous character disposition and the narrative coherence of our lives and identities. A satisfactory conception of virtue in the context of this study would do well to retain these two aspects from the views of Aristotle and MacIntyre, which are especially relevant from the perspective of aging, yet combine them with the realistic and pluralistic orientation of Swanton's account.

\subsection{Virtue in the context OF aging}

Throughout this chapter, I have repeatedly suggested that a virtue-ethical perspective has a specific relevance in the context of aging, given its focus on a life-encompassing process of self-realization and the openings it offers for integrating existential vulnerability in our lives in a meaningful way. Surprisingly, however, gerontological research applying the language of virtue to aging well, seems relatively scarce. I will focus on three examples here. The first is a chapter by May (1986) in the volume What does it mean to grow old? Reflections from the humanities (Cole \& Gadow, 1986). The second is a chapter by Ruddick (1999) in the volume Mother time. Women, aging and ethics (Walker, 1999). The third example is the quite extensive body of wisdom-literature in gerontology. Although not explicitly focused on virtue, this field of research can also be interpreted as congenial to the virtue-ethical discourse.

1. May (1986) discusses the virtues and vices of the elderly. He argues that older people should be taken seriously as full members of the community, which implies that they should also be treated as moral beings whose behavior may be approved or reproached in a moral sense. Although this may seem like an obvious statement, it is not. Particularly in the context of professional care, where there is an inevitable power imbalance between professionals and clients, all too often older people are consigned to the status of a passive recipient of caring services, rather than as full-fledged moral agents with an active responsibility for their own lives. This has an alienating effect, for the power imbalance between professionals and clients is not easily redressed, and can even be reinforced by what May calls 'the professional ethical ideal of philanthropy' (p. 45).

Instead of trying to secure the moral status and dignity of the elderly by proclaiming the importance of respecting their autonomy, ethicists and gerontologists should focus on questions of character and virtue instead, according to May. His argument for this is similar to the one about existential vulnerability advanced above; precisely because the elderly face 'the ordeals of sickness [...] infirmity, and fading powers' (p. 49), they need strength of 
character to endure them. Relevant virtues discussed by May include courage, patience, simplicity, benignity, integrity, wisdom, and finally, hilarity. The last mentioned virtue may sound odd and a little out of place given the 'ordeals' mentioned earlier, but describes a type of 'humored detachment' that can emerge in people who have been through a lot. May emphasizes, however, that none of these virtues develop automatically in the process of aging or are exclusive for elderly. Rather, they require perseverance and often struggle. But the effort of acquiring the virtues pays off because it enables people to address life's challenges, not as instrumental problems to be managed, but as existential events to be integrated in their life narratives.

2. Ruddick (1999) raises the question which virtues may be of relevance in the context of aging. This question could elicit two kinds of answers: it could be argued that some "classical", general (Aristotelian) virtues, such as temperance, courage, friendship, or practical wisdom, obtain a specific interpretation or substance in later life; or it could be argued that there are some special virtues that acquire relevance particularly in the context of aging. Ruddick argues in favor of the second option.

The concept of virtue that Ruddick uses is rather inexplicit. She only states that her conception of virtues is relational. This qualification implies that virtues are not seen as individual character dispositions, but believed to emerge from relations between interdependent and principally vulnerable people. Ruddick's view is based upon feminist insights about the fundamental importance of care relationships - such as those between mother and child - in human life. It remains unclear, however, how this view relates to the assumptions about individual self-realization and maturation that underlie most traditional conceptualizations of virtue ethics.

Ruddick highlights two examples of virtues that she perceives as particularly valuable from an aging perspective. The first is the capacity to forgive and let go of bitterness and regret, which she connects to the importance of "life review" and the Eriksonian goal of ego-integrity, or acceptance of how one's life has turned out. The second is the capacity for what she calls wise independence. This includes both upholding one's self-directing capacities and acknowledging one's limitations in this regard, and being able to accept needed assistance with an attitude of graciousness. Apart from these two virtues, Ruddick also mentions curiosity, capacity for pleasure and delight, concern for others, (self-)acceptance, appreciation, hopefulness and "energetic anger" as virtues that have a special or heightened importance for aging individuals. Importantly, Ruddick refutes the idea that it is overly demanding to expect virtuousness from older people. She does recognize, however, that virtues of older people commonly valued by others, such as productivity, independence or self-sufficiency, mirror the problematically stereotypical and ageist understandings of later life, also discussed in the 
context of cultural narratives in $\mathbb{3} \cdot 3 \cdot 4$. Ascribing these virtues to later life may have detrimental consequences for aging people, forcing them into a framework of productivity, health and activity that is burdensome for those unable to live up to its standards.

Ruddick also denies that age-related deterioration, a reality for many older people, makes it problematic to speak about virtues in the context of aging. While severe mental retardation can impede the capacities that make exercising virtue possible, this is only an expression of a vulnerability that is intrinsic to the human condition as such. The risk of diminished capacities thus threatens potentially all agents striving for virtue, not only older people. Moreover, mental incapacity connected with the aging process usually only endangers the efforts to exercise virtue slowly and gradually, which still makes it possible to speak of virtues in the context of aging.

3. Given the fact that the Aristotelian virtue-ethical tradition already saw (practical) wisdom as one of the most predominant virtues, it seems logical to present wisdom studies in gerontology as an application of virtue-ethical thought to the domain of aging. This field of study draws on a long history of ideas that associates wisdom specifically with later life. The connection between wisdom and old age occurs in different cultural, philosophical and religious traditions throughout the world. A notable example voicing this standpoint in the Western philosophical tradition is Cicero's De Senectute (1467/2002). However, it is generally agreed that aging (reaching a higher chronological age) as such does not provide any guarantees for wisdom. As Aristotle argued with regard to virtue, old age and in particular the life experience accompanying it should be seen as a necessary, but by no means a sufficient condition of wisdom.

Definitions of what wisdom amounts to are either based on (historical) exemplary figures that in most people's opinion could be considered wise, such as Jesus or Buddha, or extracted from a variety of wisdom traditions existing in human history, or constructed by probing people's opinion on what wise conduct would be in a particular (hypothetical) situation. Characteristics associated with wisdom that most conceptualizations have in common include, for instance, the capacity for tolerance, the capacity to accept uncertainty, the capacity for empathy and compassion towards one's fellow (human) beings, and the desire to transcend self-interest and contribute to the common good (Edmondson, 2015). These characteristics lend themselves easily to interpretation in virtue-ethical terms, since many of them are derived from classic virtue-ethical traditions like the Aristotelian. Much of contemporary wisdom research in gerontology has been done from a psychological perspective, for instance, by Baltes and his colleagues in the Berlin Wisdom Project (Baltes, 1991; Baltes \& Smith, 1990; Baltes et al., 1990; Baltes \& Staudinger, 2000), or by Ardelt (1997, 2003, 2011) who developed 
a three-dimensional wisdom scale consisting of cognitive, reflective and affective dimensions of wisdom. Generally speaking, these studies see wisdom as a personality characteristic rather than something that might vary from one context to the next. Wisdom is also treated as an ideal-type that in its full form is not expected to occur very frequently in practice. The studies by Baltes, Ardelt and their colleagues seem predominantly oriented towards measuring the psychological characteristics that individuals possess or may develop throughout life, which enable them to act in a manner that is considered wise. It is an important merit of the discussed approaches that they emphasize wisdom as a capacity that need not diminish with age, and may in fact even increase. However, the focus in psychological approaches to wisdom lies predominantly on improving the sophistication of measurement instruments, rather than on philosophical reflection about wisdom and its associated virtues.

By contrast, the perspective on wisdom that is presented by Edmondson $(2009,2015)$ seems to show more congeniality with the philosophical virtue-ethical perspective I have discussed. Edmondson (2015) conceives of wisdom in traditional Aristotelian terms as a set of "interlocking ethical, emotional and social practices, both tacit and explicit, making possible responses to other people, to oneself and to profound problems of human existence; questions without predetermined answers" (p. 91). Edmondson suggests a social understanding of wisdom in which it is not perceived as an individually measurable personality characteristic, but as something that emerges from a social, hermeneutic process in which people share their insights and life experiences to reflect on what would be wise to do in a given situation. Like MacIntyre (1984), she contends that wisdom is something that is embedded in human practices of daily life from which it cannot be isolated. This view has implications for her approach to wisdom research, which does not include measurement scales, but ethnography, observation, and listening to older people's life stories.

Edmondson's (2015) socially embedded conceptualization of wisdom presents it as something modest instead of spectacular, flexible instead of fixed, something that emerges from social interactions in the daily lives of people. Her view of wisdom is practical and dialogical, and strongly focuses on processes of deliberation. Acknowledging this wisdom that many older people have to offer, despite its modesty, could potentially have profound societal, cultural and even political implications for the position of older people. Such recognition could enhance the general status attributed to older people in our society, and give them the opportunity to participate fully as moral agents in the community. In this regard, Edmondson's perspective on wisdom and meaning in later life has much to contribute to the development of moral agency-enhancing cultural counter narratives. 


\subsection{Evaluation Of the discussed virtue accounts}

This chapter has discussed the third thread that weaves the fabric of self-realization discourse, namely, virtue. A selection of three different accounts of virtue(-ethics) have been covered. In this section, I evaluate the merits of these different approaches to virtue, to come up with an account that accommodates the reframed view of self-realization advanced by this study. As in the previous two chapters, this study's account of virtue will have to be able to fit the outlines of the view of narrative identity and moral agency on which my suggestion for a reframed account of self-realization relies. As mentioned in $\$ 8.2$, generally speaking, views of virtue are well-equipped to match the socially embedded, embodied, reflexive and narrative conception of the self that this study has taken as its underlying anthropological framework $(\$ 4.2 .2 ; \rrbracket 5.3)$. As observed in $\$ 4.3 .2$, the concept of virtue is undervalued in late modern self-realization discourse, with its one-sided focus on (problematical interpretations of) autonomy and authenticity. Virtue therefore has a particularly relevant contribution to make in light of my attempt to reframe the late modern understanding of self-realization. In particular, virtue-ethical views are more sensitive than traditional autonomy and authenticity views to the socially embedded nature of human existence. This means that the conceptualization of virtue needs less adaptation on that point to match the perspective of the current study. Further advantages of virtue-ethical thinking for this study's view are its flexibility and context-sensitivity, and its emphasis on a life-course perspective in ethics. A final important point to mention is that virtue-ethical perspectives appear to offer particularly important resources for an account of self-realization that is capable of integrating existential vulnerability in a meaningful way, another requirement I have formulated for the current study's interpretation.

Despite the merits of the virtue-ethical perspective, however, two potential problems with virtue, identified in $₫ 8.2$, need to be remedied for a satisfactory account of virtue in the context of this study. First, some interpretations of virtue ethics harbor a problematically essentialist, naturalistic and/or objectivist understanding of the purpose of human life and of the (common) good. Second, some accounts of virtue can give rise to conventionalism and traditionalism, whereas the view advanced by this study necessitates a perspective in which the given socio-cultural and moral horizon, the "status quo", can be critically encountered and, if necessary, resisted by moral agents striving for self-realization (see also $\$ 7.3 .4, \$ 7.5$ ). Let me now evaluate the three selected accounts of virtue for their strengths and weaknesses along the discussed lines.

- Aristotle, it was said in $\$ 8.3 .1$, provides my account of virtue with a valuable starting point, given his focus on moral agents who, embedded and situated in a moral community, strive all their lives towards realizing what, given 
their nature, constitutes the best life (Ethica Nicomachea). By virtue of its emphasis on the social embedding of moral agents, Aristotle's interpretation of self-realization offers an important argument against the critique that self-realization discourse implies a solipsistic self-absorption and is therefore unable to address moral issues. Aristotle's sensitivity to context is also shown in his emphasis on the right mean that separates the virtues from excesses and defects, which he sees as dependent on the practical circumstances in which the virtue is exercised. Moreover, his virtue ethics clearly has a life-encompassing scope, which as mentioned is important given this study's focus on aging and its narrative conception of identity. Perhaps the most important contribution of Aristotle to the concept of virtue advanced in this study, however, is his view of how virtues can help us relate to the inevitable existential vulnerability of life. In my reading, what Aristotle suggests is a manner of relating to inevitable existential vulnerability in a way that is different from both denial and rejection (characteristic of age-defying narratives, see $\$ 3.3 .3$ ) and passive surrender (characteristic of decline narratives, see $\mathbb{3}$ 3.3.2). "Nobility and greatness of soul" (in other words, virtue) apparently help people to endure adversities with graciousness without losing their soul or (in more modern terms) their character or selfhood. This suggests an opening towards finding a satisfactory way of integrating existential vulnerability in one's life, without compromising or having to give up on self-realization: namely, that developing and maintaining relevant virtues, as a way of self-realization, can be of assistance in this regard.

What distances Aristotle's virtue account from the view of virtue I am envisioning is of course his premodern metaphysical worldview, which means that the application of his views suffers from the first problem that I have identified above. He assumes that self-realization takes place in a cosmically ordered world, in which human beings have their naturally predefined place that defines the best possible life or highest moral purpose for them. An account of virtue presupposing such a naturalistic and pre-given conception of the good seems a poor match with the reality of the late modern world. After all, in late modern circumstances, what is considered good has become individualized. Moreover, people live in a situation of moral pluralism where the good has to be constantly intersubjectively negotiated, without a self-evident authoritative meaning-framework or moral tradition to fall back on (see $\llbracket 2.3 .2$ ). A satisfactory conceptualization of virtue in the context of this study will have to be able to take these points into account, but Aristotle obviously cannot assist us here.

- MacIntyre's (1984) view, not surprisingly given his intention to revive Aristotelian ethics in a modern context, shares many of the valuable characteristics of Aristotle's account. MacIntyre's rejection of the dominant mod- 
ern view that presents individuals as the autonomous, self-determining sculptors of their own lives shows close similarities with my own critique against such an atomistic self-concept (see $₫ 2.5$ ). By acknowledging the importance of social, contextual and historical embedding of the individual, MacIntyre's view seems to be concordant with the perception of identity

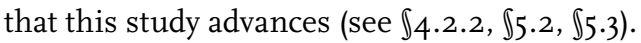

Furthermore, for my purposes, MacIntyre's emphasis on the narrative unity of a life provides a particularly useful angle to interpret the development of virtues. By focusing on the narrative coherence of a life, which he sees as a requirement for the development and exercise of virtues, MacIntyre's view seems a natural match with a view of aging as a lived experience through time (Baars, 2012a). Though his interpretation of narrative integration seems problematically oriented towards culmination, a view I would like to nuance (see $\$ 5.2 .3$ ), his focus on the relation between the identity-constituting and meaning-making function of narrative on the one hand, and virtue on the other, remains noteworthy. Also, MacIntyre's (1984) notion of a practice, although too complex to do justice to in my brief discussion of his view, has important merits for this study's purposes. His concept of practice in particular underscores that self-realization, as was also argued in $\$ 4.2 .3$, should be situated in the context of concrete human activities, which together form a meaningful framework that suggests which good to strive for in life.

Despite these strengths, however, MacIntyre's account suffers from both general problems that were identified above, which suggests that what this study's conceptualization of virtue may retain from his view needs to be complemented with other insights. First, with regard to the issue of essentialism/naturalism/objectivism, MacIntyre's idea of an intrinsic common good to be strived for in virtuous practices raises questions. For MacIntyre, like Aristotle, what constitutes a good is to a large extent given by something that transcends the individual. Granted, MacIntyre substitutes Aristotle's premodern idea of a cosmic order of the universe with the more modern idea of the moral tradition as the primary provider of the good. However, in an era that celebrates autonomy and authenticity as guiding moral values, a view of virtue that makes the (common) good dependent on a given cosmic order or tradition, seems to become increasingly problematic. Such a view seems to leave insufficient room for the good to be defined on the basis of individual aspirations and self-appropriated value orientations. The latter view, however, is an important premise underlying the autonomy and authenticity threads I have discussed in chapter 6 and 7. This study's envisioned account of virtue should be able to acknowledge the value of this premise. However, MacIntyre perceives individualism and individualization primarily as a danger to the moral outlook and social cohesion 
of society, not as something that could also potentially be valuable. In this sense, his account of virtue ethics is unsatisfactory for my interpretation of self-realization, since the latter also wants to do justice to the intuitions of the autonomy and authenticity threads (see chapters $6 \& 7$ ).

One might raise the objection that MacIntyre's notion of a moral tradition as the provider of the good can also be perceived in intersubjective rather than objectivistic terms. This view would imply that moral agents engage in constant deliberation and dialogue about what constitutes the good for them. Although this interpretation is certainly more in sync with the view advanced in this study, and MacIntyre's view in principle does not rule out such an interpretation, in the end his account still remains problematically prone to moral monism instead of moral pluralism. There is another possible counterargument to my charge that MacIntyre's view does not acknowledge the valuable intuitions of the autonomy and authenticity threads: namely, that MacIntyre's critique seemingly only targets the essentialist, narcissistic version of authenticity that has been rejected in this study (see \7.2; $\ 7.5)$. But even when authentic personhood is conceived as a social and moral practice (as this study suggests, see $\$ 5.3 .2$ and $\$ 7.5$ ) it seems hard to combine with MacIntyre's view that only the moral tradition, and not the individual as well, can be the source of moral good(s).

The second general problem concerns the charge of conformism or traditionalism. Because of his emphasis on the formative role of moral tradition, MacIntyre's view shows a lack of attention to the possible necessity of challenging or transforming the status quo of one's existing socio-cultural context. For this reason, the value of resistance against oppressive forms of practices that constitute our social identities, which is emphasized in Lindemann Nelson's (2001) theory about cultural (counter) narratives (see \3.2), is difficult to combine with the virtue account that MacIntyre (1984) suggests. My critique of MacIntyre's position in this sense echoes the one against C. Taylor's (1991) view of authenticity (see $\llbracket 7.3 .3 ;$;7.5), which also seems to underestimate the dangers of conformism.

- Compared to Aristotle (Ethica Nicomachea) and MacIntyre (1984), Swanton's (2003) view of virtue seems to offer a more useful point of departure when it comes to escaping the problems of essentialist, naturalistic and/or objectivistic interpretations of the good. Admittedly, Swanton develops a rather dense and sophisticated theoretical argument, which makes it difficult to assess the concrete consequences of her view in practical situations. Nevertheless, her argument that a viable conceptualization of virtue can be combined with a plurality of goods conveniently suggests that virtue need not be in conflict with purposes of self-realization that are suggested by autonomy and authenticity. For example, her view lays a strong emphasis on the basic importance of self-love for virtue, which can accommodate the 
Nietzschean value of self-affirmation ascribed to authenticity (see $\mathbb{7 7 \cdot 3 \cdot 2}$ ). Also, the fact that in her view this self-love should always be interpreted in conjunction with an equally valued concern for the other (called "universal love" by Swanton), supports my reflections about the necessity of self-constancy as a weak substantive criterion for autonomy (see 『6.6). Swanton's sensitivity to other goods and values, including those underlying authenticity and autonomy discourses, makes her view more favorable in comparison to MacIntyre's, whose conceptualization of virtue seems inimical to these discourses. Modeling my conceptualization of virtue on the pluralistic outline advanced by Swanton should therefore make it easier to arrive at a view of self-realization in which the threads of autonomy, authenticity and virtue all occupy an equally valued place.

As seen in $\$ 8.3 .3$, another advantage of Swanton's pluralism is that her recognition of a variety of goods besides optimal human flourishing enables us to see how lives that, due to confrontation with existential vulnerability, are not (currently) flourishing may still be called good or virtuous. This is an important merit because it suggests the possibility of an account of self-realization in which existential vulnerability is recognized and integrated as part of a good life. It also implies that Swanton's view could be particularly relevant when applied to aging. Her focus on a diversity of goods opens the possibility that an old age that is not "successful" in the conventional way may nevertheless be meaningful or admirable. In this sense, applying her ideas to the conceptualization of virtue and self-realization helps strengthen the critique against age-defying cultural narratives with their superficial and one-sided notion of success in aging (see $\$ 3 \cdot 3 \cdot 3$ ).

Regarding the issue of integrating existential vulnerability, Swanton's view has another (related) merit, which she shares with Aristotle. This is the fact that the realism and modesty of her view enables a great sensitivity for the uncontrollable contingencies and existential vulnerability we are confronted with in life. As discussed, she argues that virtue implies constantly refining our ability to respond in the most fitting manner to the demands of a given situation. This feature of her view is valuable because it suggests that a virtuous middle road can be found between the options of passive surrender to existential vulnerability (suggested by decline narratives) and denial or rejection of existential vulnerability (implied by age-defying narratives). The emphasis on responsiveness in Swanton's account of virtue may thus be a useful entry to a view of self-realization that enables a meaningful integration of existential vulnerability.

When it comes to the problem of conformism, Swanton's account remains too theoretical and abstract to properly judge her position in this regard. What seems important though, is her emphasis on how virtue-ethical self-realization can never solely be about the self and its inner states. Her 
view implies, in my interpretation, that we are inevitably engaged in a social practice with others. This embedding urges us to involve ourselves in a constant process of negotiation between demands of the self and demands of the world. What Swanton (2003) therefore advocates is a virtue-ethical form of "dialogic" ethics (p. 266), where constant deliberation among agents is required to decide how the demands of a situation are most virtuously met. It seems to me that such a dialogic ethics principally includes the possibility of conflict and resistance, which would provide at least some safeguard against the dangers of conformism and traditionalism.

Despite the valuable resources that Swanton's view offers for modeling my suggested conceptualization of virtue, it should be emphasized that compared to Aristotle and MacIntyre her view lacks the sensitivity for narrativity and life-course temporality that is highly important from the perspective of aging. In particular, it remains unclear how she perceives the development of virtues over time, which is an important aspect for my purposes, since I have presented self-realization as a lifelong process of moral self-development.

\subsection{Conclusion: Towards virtue as ATTITUDINAL CONCRETIZATION OF MORAL AGENCY}

After evaluating the merits and limits of the accounts of virtue, the time has now come to reflect on which conceptualization of virtue would be most suited to the reframed understanding of self-realization and its constitutive concepts developed in this study. Based on what has been discussed so far, the account of virtue that I propose should have at least the following characteristics:

- The understanding of virtue should retain the premise that moral agents are socially embedded, which is shared by all discussed accounts of virtue. This view also implies that the self-realization of moral agents is not seen as a self-centered, narcissistic undertaking but as a process shared with others and taking place in the context of social practices.

- The account should emphasize the fact that virtuous living implies a lifelong process of moral self-development, that acquires guidance from the value orientation underlying the narrative of a human life (as MacIntyre (1984) points out) and requires continuous attention and maintenance through practice (as Aristotle (Ethica Nicomachea) underscores). Virtue in its ideal-typical form is thus regarded in terms of a lifelong process of maturation and acquiring (practical) wisdom.

- It should offer room for a plurality of goods that are acknowledged as relevant for a virtuous, i.e., good life, including those associated with the auton- 
omy and authenticity threads of this study's conceptualization of self-realization. Monistic and perfectionist accounts of virtue should be replaced by a pluralistic and realistic interpretation, for which Swanton's (2003) approach offers welcome theoretical backing.

- The account should perceive virtue in a responsive manner (inspired by Swanton), which implies that self-realization should be conceived as a process of constantly refining our way of responding to the demands confronted in a situation. Virtue is then interpreted in terms of finding the right attitude towards whatever may cross one's path, including contingencies and instances of existential vulnerability.

- It should not answer the question of what is right or good by the application of any naturally given or objective standard. Instead, what is right or good should be context-dependent, and perceived as constantly negotiated and reflected upon in a hermeneutic, dialogical process. This hermeneutic process should either take place between moral agents or through self-reflection and internal dialogue within moral agents themselves.

- The understanding of virtue should acknowledge the moral value of individuality, while remaining aware of the fact that this individual is socially embedded. By insisting on the moral primacy of the individual, the deeper roots of the liberal spirit that gave rise to modern interpretations of self-realization are given their proper acknowledgment. At the same time, a virtue interpretation that acknowledges the moral value of individuality still remains able to criticize - in line with MacIntyre (1984) - liberalism's modern aberrations.

- Integrating the moral value of individuality in this suggested view of virtue includes valuing the particularity and uniqueness of each moral agent and their life story, recognizing and respecting their room for self-realization, and their authentically appropriated value orientation, which ideally finds its concrete expression in autonomous action.

- Acknowledging the moral value of individuality also implies taking into account that the relation between the individual moral agent and their socio-cultural context may be full of tension. In the view this study suggests, a virtuous life should include the possibility of distancing oneself from one's social embedding, of criticizing or rejecting the status quo of a given moral tradition and emancipating oneself from one's context by challenging the rules and norms of one's moral community.

What image of virtue can be extracted from the outlines of this envisioned view summed up above? It becomes clear that virtue, in the context of my reframed conceptualization of self-realization, is best regarded as the attitude, or set of attitudes, that people ideally develop throughout their lives which helps them realize the purpose I have defined for self-realization: the optimal fulfillment 
of our potential for moral agency, i.e., the enactment of our moral identity in practice. It thus seems most viable to advance an account of virtue as the concretization in practical attitudes of our striving for moral agency; the dispositions we develop to help us realize a good life, with and for others, in accordance with our highest aspirations and best capacities, as full participating members of a society/community. Developing virtuousness would then be seen as a process creating strong and resilient moral agents, able to confront the complexity and uncertainty of life, instead of being perplexed and impotent in the face of it.

What could such a conceptualization of virtue mean for aging? How could it contribute to the narratives of becoming advanced in this study? It is tempting, perhaps, to try to formulate a set of later-life virtues: an orderly catalogue of attitudes that one should develop throughout life in order to increase one's chances for aging well. It would not even be all too hard to suggest candidate virtues for such a catalogue, as Ruddick (1999) has attempted to do for instance (see 『8.4). Practical wisdom would probably score high for many people (including myself) as a virtue relevant for later life, as would loving self-acceptance, generativity, patience, equanimity, vital involvement, et cetera. However, the conception of virtue as the attitudinal concretization of moral agency, as defended in this study, should make us hesitant to formulate any such catalogue. The emphasis on responsiveness and pluralism that my account draws from Swanton (2003) implies that what is virtuous is ultimately decided in the context of a concrete situation that calls for our appropriate response. What the relevant virtues for later life are, cannot be decided by drawing up a catalogue, for without the context of a specific life situation to which an individual moral agent should respond, such a catalogue would always remain somewhat arbitrary. Defending a dialogic, hermeneutic form of virtue ethics, wherein what constitutes the good is constantly negotiated in an intersubjective process of deliberation, implies that the virtues that contribute to the practice of aging well in a given situation can only be decided by sensitively probing the characteristics of that person and that situation. Thus, how the suggested account of virtue as the attitudinal concretization of moral agency could work out can only be clarified by illustrative case examples, in full awareness that other case examples could emphasize other virtues, and that no definitive set of virtues for later life can be settled upon. Let me conclude with one such case example.

Imagine a woman who has struggled with the societal norms of feminine appearance all her life. Her mother taught her that taking good care of one's appearance was a sign of self-respect. As an adolescent, she was an introvert and insecure about her looks. She would always try to adapt as much as possible to how her peers dressed, spending a lot on clothes and make-up. During college, this pattern continued, although she grew increasingly uneasy about it, a feeling she could not put into words at that time however. She fell in love with a young man and after some time, they got married and started a family. When 
her children grew older she went to nursing school and started working as a nurse. Throughout adulthood, she kept putting great efforts into managing her physical appearance, which ensured her feeling of self-worth. At the same time, she developed a growing interest in feminism, which made her critical about the societal norms prescribing women to subject themselves to the dictates of the "male gaze". In her work, she decided to specialize on adolescent girls with eating disorders, whom she saw suffering from the pressures of societal beauty ideals. Under the influence of her engagement with feminist groups, she developed an increasing desire to devote less attention to her appearance and value herself (and be valued by others) for her other qualities. Yet in her relationship with her husband, she could not bring herself to lower her efforts regarding her looks. This caused conflicting feelings within herself that she found difficult to share with her husband or friends. When physical signs of senescence started to appear - wrinkles, spots, dry skin - these were hard for her to accept, even though she reproached herself for her own disgust of them. One day, she discovered a new spot on her skin, which proved to be a melanoma. Due to the medical treatments that followed, she developed severe facial neuralgia. Because of the pain, she could no longer cover up stains and wrinkles with facial creams and make-up. This initially made her feel uneasy and ashamed, but when she realized that other people did not approach her differently for it, she gradually learned to accept the situation, joke about it and relativize her lifelong preoccupation with beauty products. Interestingly, her relationship with her husband also changed following her illness. They were able to exchange thoughts and feelings that were of deep importance for them, which they had never spoken about before. She felt a deeper connection with her spouse than she had in many years.

From my perspective, this story can be seen as the enactment of a narrative of becoming at the level of an individual life, in which the three threads of self-realization as (re-)conceptualized in this study - individuating autonomy, authenticity as a social and moral practice, and virtue as the attitudinal concretization of the striving for moral agency - can all be detected. We encounter a woman who throughout life, in interaction with her social surroundings, strove to live in accordance with what she has gradually appropriated as valuable (a condition for both individuating autonomy and authenticity as a social/moral practice). Her value-horizon was in continuous development, however, and in each new life phase, context and situation, she had to navigate the demands placed upon her anew and find the best way to respond (which calls for virtue as the attitudinal concretization of moral agency). She encountered difficult conflicts between the good she endorsed (a well-cared for physical appearance as a sign of self-respect, emancipation and freedom from oppressive male norms, care for the victims of societal norms in her work with anorexic girls, et cetera.). The socio-cultural context in which her life was situated both restricted her 
moral self-development (for instance, through the norms of beauty she found it difficult to withdraw herself from) and enabled it (for instance, through the insights and reflections evoked by her work and her engagement in feminist groups). As a result of the existential vulnerability she encountered in her illness, she was stimulated to further explore what was of true importance for her, which led to an unexpected but pleasant transformation of her relationship with her husband and her friends.

Interpreted from the virtue-ethical perspective elaborated in this chapter, the crucial element of this story is how her striving to live a good life, in accordance with the aspirations and value orientations she gradually appropriated, depended on the disposition she developed in responding to what she was confronted with. In other words, what was crucially important for her living a good life with and for others was her attitude, towards herself, towards her (social) environment, and towards the broader socio-cultural context in which she lived. Inasmuch as she succeeded in her striving for self-realization, this occurred as a result of practicing and thereby constantly further developing virtues like self-knowledge, loving self-acceptance, attunement with others, assertiveness, independent thinking, mildness, humor, the ability to put things in perspective, et cetera. These virtues enabled a lifelong process of becoming herself.

To conclude my reflections in this chapter, let me recall that the initial purpose of creating a reframed interpretation of self-realization was to provide a viable resource that could support the creation of more satisfactory cultural narratives about later life. These cultural counter narratives are supposed to enhance people's moral agency (see $\mathbb{3}$ 3.2.4). In order to do so, it is important that older people are ascribed with the status of full moral personhood, so that they will be given the opportunity to participate as full and equal members of our society or community instead of estranged bystanders, as Honneth's $(2008)$ theory about reification helped to underscore (see $\$ 3.2 .3$ ). Realizing this participation is conditional on our perceiving older people as members of our moral community. This, however, is complicated by problematic cultural master narratives about later life that result in a dynamics of "othering", placing older people outside the realm of "normal" adulthood (see $\$ 3.3 .4$ ). The focus of virtue ethics on the interplay between the self and the world conveniently emphasizes the mutual interdependence of individuals in creating and maintaining a moral community. Incorporating older people as full members in such a community will greatly enhance their ability to realize their potential for virtue. It is my contention that this will not only benefit the lives and experiences of meaningfulness of the older people themselves, but also help society to make better use of the now often underused potentials older people have to offer.

This relevance of the virtue-ethical thread of self-realization discourse in the context of this study is beautifully illustrated by the following quote from 
Agich (2003), whose phenomenological account of autonomy was discussed in \$6.4.2. He states: "If frail or incapacitated elders appear powerless, they can be empowered precisely by acknowledging them as responsible persons. Taking elders seriously as members of the moral community of persons entails understanding their obligations and responsibilities as well as respecting their rights. Failure to criticize elders may subtly remove them from the realm of persons; unlike very young children who are not usually held accountable for their actions, elders are morally mature. To respect elders as moral agents, then, requires that we acknowledge and support the virtues and character traits appropriate to being old. Virtues involve not only the habits that allow us effectively to exercise our agency in the world, but comprise the strengths that grow out of adversities and sustain us through them" (Agich, 2003, p. 79).

In sum, in the attempt at remedying the shortcomings of the late modern self-realization discourse, and reframing this discourse so that it may serve as a valuable resource for much-needed moral agency-enhancing cultural counter narratives about later life, I contend that we would do well to integrate insights from the virtue-ethical discourse. The conceptualization of virtue I have suggested is able to contribute to both required conditions I formulated for such narratives: it lays strong emphasis on the potential for growth and maturation throughout life, and it suggests a viable way of dealing with existential vulnerability without succumbing to passive surrender or denial and rejection. 



\section{Chapter 9 - Conclusion}

\subsection{INTRODUCTION}

Every philosophical project, I presume, starts with surprise or wonder. One encounters a situation, observes its features, and asks oneself: how can this be so? Why and how did the current state of affairs come about? How can I analyze this in a fruitful way? What concepts and ideas help me improve my understanding?

As discussed in chapter 1, the initial experience of wonder fueling my interests in this study, began when I encountered the paradox between the negative cultural associations about later life during my first tentative exploration of the socio-cultural discourse on aging, and my own experience that older people often represent valuable exemplars of life experience, virtue, insight, resilience and wisdom. I was struck by the fact that on the socio-cultural level, late modern society seems to associate aging predominantly with physical or mental decline and the inevitable nearing of death, a period causing nothing but trouble both for individuals and for society at large. Where, in the existing cultural narratives and imaginaries that I encountered, were the possibilities for growth and flourishing in later life that I sensed in abundance in the older people that I knew personally? The absence of acknowledgment for the possibility of growth and flourishing in later life seemed even more pressing given how late modernity, as I knew it to be observed by many thinkers, tends to place such strong emphasis on a moral ideal of the good life relying on self-development and personal growth - the moral ideal that I have described in terms of self-realization in this study. Why, I asked myself, did the dominant moral self-realization discourse of late modernity not extend towards the cultural perception of aging and later life? Why were older people excluded from this dominant moral ideal of the good life? And, more importantly, could the late modern self-realization discourse be usefully reframed to serve as a moral ideal for later life, thereby possibly contributing to a remedy for this adverse socio-cultural positioning of older people? These were the questions that initially gave rise to this study. What followed was a journey through philosophical and gerontological resources, a journey which sometimes resulted in exciting discoveries and insights, 
and at other times led to frustrating bumps in the path and unexpected turns of the road. Having come to the final chapter of this study, it is now time to draw up the balance of this journey.

This chapter proceeds as follows. First, a short recapitulation of the line of argument presented in chapters 2 through 8 is given $(\mathbb{9} .2)$. Second, the conclusions that can be drawn in order to answer the questions raised in the problem statement in $\mathbb{1} .3$ are discussed ( $\$ 9 \cdot 3)$. Importantly, this study has predominantly been oriented towards making a case in favor of (a reframed version of) self-realization. However, the self-realization discourse in general tends to raise some diverse and important objections and critiques. Though these objections have implicitly been addressed at several points throughout the previous chapters, they deserve some more structured and explicit attention before the close of this study. Therefore, the chapter goes on to summarize six of the most dominant critiques ( $\$ 9.4)$, namely the elitism/demandingness objection ( $\$ 9.4 .1)$, the self-centeredness objection ( $(9.4 .2)$, the social justice/social structure objection ( $\$ 9.4 .3)$, the Western/masculine bias objection ( $\ 9.4 .4)$, the moralism/paternalism objection ( $(9.4 .5)$, and the cognitive ability objection ( $\$ 9.4 .6)$. As any scientific and philosophical endeavor, this study too, leaves important questions unanswered, asking for further attention from researchers in the future. Some of the most pressing of these unanswered questions are also discussed ( $\$ 9.5)$. The chapter closes with some final, more personal reflections on the theme of aging, self-realization and cultural narratives about later life ( $\ 9.6)$.

\subsection{Recapitulation of the argument}

This study started with the guiding question: Can the late modern discourse of self-realization be reframed in such a way that it can serve as a resource for meaning-generating cultural narratives about later life in late modern circumstances? (see 『1.3). This phrasing indicates the broad concern of this study with a combination of four themes: self-realization, aging, cultural narratives and late modernity.

In the process of philosophically investigating this question, several related sub-questions and issues had to be unraveled, discussed and answered.

- In the first place, a proper clarification of the guiding themes of this study was needed. Chapters 2, 3 and 4 were predominantly dedicated to the task of answering both descriptive and interpretative questions about these guiding themes.

- Second, it was necessary to provide sufficient underpinning for the claims assumed in the guiding research question and furthered in this study. The first claim, discussed in chapter 2 , was that the late modern interpretation 
of self-realization needs reframing on some crucial points, in order to be adapted to the context of aging. The second claim, discussed in chapter 3 , was that cultural master narratives about aging and later life fall short of providing people with satisfactory identification-models and need to be complemented with viable counter narratives.

- Third, the intended reframing of self-realization and its constitutive concepts had to be substantiated by exploring philosophical discourses about these themes, and clarifying and criticizing their limitations in the context of this study, thereby providing suggestions for better-matching alternative interpretations. This was by far the most complex and extensive task in this study, undertaken in chapters 4, 5, 6, 7 and 8 .

- Fourth and finally, my philosophical investigation needed to provide a viable argumentation regarding the claim that the suggested reframing of self-realization and its constitutive concepts can indeed serve as a resource for the meaning-generating cultural narratives about aging and later life highlighted in the problem statement. Chapters 3 through 8 have tried to provide the building blocks to underpin this claim. This concluding chapter will now draw the argument together in its final form (see $₫ 9.3$ ).

Importantly, these four sets of tasks had to be undertaken in conjunction with each other, because it was not always possible to separate them. Let me now briefly summarize the course of the argument developed during the investigation.

Chapter 2 sketched the background context of late modernity against which this study is situated. In particular, it attempted to clarify the characteristics of late modern living and aging, as well as the typical features of the late modern interpretation of self-realization. Late modernity was typified as an era advancing an interpretation of self-realization that focuses on the mastery that self-determining actors strive to exert over their lives, in order to arrive at the optimal realization of their self-chosen goals and purposes. Correspondingly, I argued that the good or successful life in late modern circumstances is identified with a life according to one's own choices and value orientations. The process of identity-constitution consequently gains heightened importance when it comes to infusing life with meaning. However, as was mentioned, late modern living is liable to all sorts of complex socio-cultural dynamics and influences, which makes the striving for self-realization a highly ambivalent and problematic undertaking. Subsequently, it was highlighted that in a context of individualization and de-traditionalization, individuals are thrown back on their own resources to search for sources of meaning and identity.

Chapter 3 explored the theme of cultural narratives that also forms one of the main elements of the overarching research question. Aided by Lindemann Nelson's (2001) philosophical theory about cultural narratives and counter nar- 
ratives, I discussed the impact of these narratives on the agent's identity-constitution, which proved to be both inescapable and potentially damaging. Importantly, we learned that repairing the identity-damage inflicted upon people by oppressive and stereotyping cultural narratives requires the creation of cultural counter narratives that optimize people's potential for moral agency. Next, I proceeded to apply the theory on identity-effects of cultural narratives and counter narratives to the context of aging. A dichotomy was suggested between two dominant cultural narratives in late modern Western culture with regard to aging and later life: decline narratives and age-defying narratives. I also discussed how these cultural narratives might impact people's (aging) identity. Eventually, I argued in favor of a third category of cultural narratives about later life that should be able to remedy the shortcomings of decline- and age-defying narratives. The category of narratives of becoming was presented as this study's preferred alternative account of what it means to age well in the late modern world. In particular, narratives of becoming were argued to aim at two important goals: acknowledging the potential for growth and flourishing that later life may harbor, and providing people with the resources for a meaningful integration of inescapable existential vulnerability - resources that were argued to be lacking in existing cultural narratives about later life.

From chapter 4 onwards, the discussion transitioned to more directly address the main aim of this study: reframing self-realization and its constitutive concepts so that a discourse emerges that escapes the problems of the late modern interpretation of self-realization. Importantly, this endeavor was undertaken specifically to explore whether the self-realization discourse could provide possible resources to feed into the suggested alternative cultural narratives of becoming. Given the goal to reframe self-realization in a certain direction, the first step needed was to gain more clarity about the philosophical history and background of the concept, in order to enrich our understanding of self-realization beyond the late modern discourse introduced in chapter 2 . The philosophical exploration in chapter 4 presented self-realization as a process of becoming the best that is in you, a process of moral self-development aimed at optimizing one's potential for moral agency. It was discussed that what constitutes this best in human beings has been interpreted in quite diverse ways during the course of Western philosophical history. This richness and diversity of interpretations conveniently provided leads for the reframing of self-realization undertaken in this study. Eventually, I argued that the self-realization discourse can best be understood as a rich and complex fabric of three interwoven threads: autonomy, authenticity and virtue. All of these deserve to be given their due importance in this study's reframed account of self-realization.

Before zooming in on each of the three constitutive threads of self-realization in chapters 6 through 8 , in chapter 5 I focused on first exploring a satisfying conceptualization of personal identity - the expression of the self un- 
derlying self-realization - and formulating an understanding of moral agency matching the purpose of this study. Moral agency arose as a quintessential topic both in the discussion of cultural counter narratives in chapter 3 , and in the discussion of the purpose of self-realization in chapter 4. Consequently, it was important to explore this theme in more detail and define a position matching the orientation of this study. My first step in chapter 5 was to argue in favor of a narrative conceptualization of identity. Expressing this preference for narrative views of identity can be seen as part of the reframing of the late modern self-realization discourse. After all, the narrative view provides a welcome alternative for the underlying anthropological assumptions of the late modern view that were analyzed to be problematic in chapter 2 . Choosing a narrative interpretation of identity proved to have several advantages, since it enabled acknowledging the social and contextual embedding of our identity, its temporal character, its reflexivity and its embodiment. In this study, I have particularly focused on those narrative views that helped to illustrate the connections between narrative identity and moral identity. It was therefore crucial to substantiate this link between identity and morality, given the conceptualization of self-realization as a process of moral self-development as presented in chapter 4 . The next step in chapter 5 was to connect my reflections on narrative identity and moral identity to the theme of moral agency, perceived in this study as the concretization of our moral identity-constituting value orientations into our actions. Using insights of Ricoeur (1992) and other discussed thinkers, I composed a complex definition of moral agency as the ability to lead a good life, with and for others, according to one's deepest aspirations and best capacities, as full participating members of a society/community.

Having thus delineated my own view of moral agency and its connections with narrative identity and moral identity, I could proceed to discuss in succession the three constitutive threads of self-realization discourse identified in chapter 4 in the following chapters: autonomy (chapter 6), authenticity (chapter 7) and virtue (chapter 8). In each of these chapters, the discussion of the thread in question followed broadly the same structure. After a general introduction, a selection of relevant philosophical views were discussed and then evaluated in light of the reframing purpose of this study. The chapters also explored how each of these threads has been translated to the context of aging by gerontological thinkers so far. Finally, I suggested an interpretation of each thread in the context of this study that tried to remedy the identified troubles with existing accounts. In particular, I argued in favor of an individuating account of autonomy, a view of authenticity as a social and moral practice, and a virtue-ethical account that perceives virtue as the attitudinal concretization of our striving for moral agency in practice. Importantly, these conceptualizations attempt to refute certain problematical connections that are assumed as self-evident by more 
traditional interpretations, such as that between autonomy and independence, between authenticity and anti-sociality, or between virtue and traditionalism.

- Regarding autonomy, the discussion in chapter 6 showed how dominant structural hierarchical accounts tend to disregard several facets of autonomy that are important given our conceptualization of moral agency. In particular, the narrative and contextual embedding of autonomous agents, their identification with a certain moral orientation and their relations of interdependence were suggested as vital additions to the autonomy discourse, particularly in the context of aging. The interpretation of individuating autonomy proposed eventually aims at combining proper acknowledgment of the relational and contextual embedding of the moral agent with a valuation of their "becoming individual", i.e., acknowledging the importance of moral self-development for autonomy. Ricoeur's (1992) notion of self-constancy provided a concept uniting both the acknowledgment of our moral relations to others, and of the importance of living up to our identity-constituting moral engagements. Both were argued to be crucial for a person in order to qualify as autonomous.

- Regarding authenticity, the discussion in chapter 7 identified two general problems confronting the authenticity discourse in general: its essentialist assumptions regarding the existence of an original "true" self that serves as the source of meaning and morality, and its negative attitude regarding social influences on our identity-formation. The interpretation of authenticity proposed in this study suggests we retain the valuation of the individual moral agent as a source of meaning and morality from classical views of authenticity, but reinterpret the authentic self in terms of a social and moral practice. Also, it underscores that authenticity requires both the acknowledgment of one's contextual embedding and social constitution, and the ability to criticize and distance oneself from social influences that are not beneficial to one's good life.

- Regarding virtue, the discussion in chapter 8 showed how virtue ethics provides a view of self-realization that acknowledges our embedding in social practices and communities. Moreover, it was underscored that virtue-ethical perspectives advance the development of certain attitudes in life, for instance, by focusing on practical wisdom. The emphasis on the right attitude towards what confronts us in life offers convenient possibilities for the meaningful integration of existential vulnerability, which is one of the focal points for this study. A potential shortcoming of the virtue-ethical discourse, however, proved to be a tendency towards conformism and traditionalism in some interpretations. The interpretation of virtue forwarded in this study aims to focus on a lifelong process of moral self-development, striving with and for others towards a good life. A plurality of goods is ac- 
knowledged to be valuable in this account, and its focus lies on the recognition of the moral value of individuality, while this individuality is still perceived as fundamentally socially embedded.

\subsection{Advancing older People's moral agency}

This study has been a search for an alternative to the late modern conceptualization of self-realization that forms a better match to the context of aging. In order to arrive at such an alternative conceptualization, I have been trying to reframe our understanding of self-realization and its constitutive concepts. I have intended to do this in such a way that the underlying moral ideal that fuels the self-realization discourse in general, presenting the good life in terms of realizing the best in oneself, remains intact, but is combined with a greater sensitivity for the social and contextual embedding of human lives and for the fundamental existential vulnerability of the human condition.

In order to evaluate the results of this study in terms of a reframing of the self-realization discourse that can serve as a resource for meaning-generating cultural narratives about aging and later life, it is useful to recall the desired conditions formulated for: 1) the suggested account of self-realization in the context of aging, and 2) the suggested cultural counter narratives of becoming. Regarding the conditions for a reframed account of self-realization suitable for the context of aging, I argued in $\$ 2.5 .2$ that the late modern interpretation of self-realization needed to be adapted so that:

- The characteristic atomistic anthropology of the late modern discourse would be replaced by a view that acknowledges the contextual embedding and social constitution of human persons, as well as their fundamental interdependence with other people

- The problematic denial or rejection of the dimension of existential vulnerability typical of the late modern discourse would be replaced by an attitude enabling a meaningful integration of existential vulnerability

The exploration of philosophical discourses on self-realization and identity in this study suggested that there are more possible interpretations of the self-realization discourse than just the late modern interpretation. During the argument in chapters 4 and 5, I hope to have made it clear that the idea of self-realization can in fact be made compatible with an understanding of the moral agent as a socio-culturally embedded being, inevitably involved in interdependent relationships with others, its identity co-constituted by a variety of social (i.e., relational, societal/structural/systemic, cultural and other) factors. Moreover, the argument in this study has repeatedly contended that the 
striving for self-realization need not be in conflict with the reality of existential vulnerability that we are increasingly radically confronted with in aging. Contrary to the late modern interpretation of self-realization which suggests a strategy of gaining mastery and control over one's life, I have claimed that the philosophical discourses of self-realization, in particular the virtue-thread and some interpretations of the authenticity-thread, provide ample opportunities to present the development of a satisfactory responsive attitude towards inescapable existential vulnerability as an intrinsic part of the striving for self-realization. Such an attitude, which I hope this study has shown to be plausible, provides us with valuable resources that are needed for a meaningful integration of existential vulnerability.

Regarding the suggested conditions for narratives of becoming, I argued in

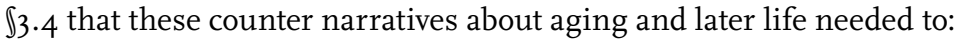

- Avoid both the equating of aging with decline (typical of decline narratives), and the equating of aging well with staying young (typical of age-defying narratives)

- Acknowledge both the potential for growth and flourishing that later life harbors, and its radicalized confrontation with existential vulnerability

- Provide resources for a meaningful integration of existential vulnerability in one's biography, so that the sense of coherence of one's life narrative(s) is restored and vital involvement with life remains possible

The question that remains to be answered is whether the suggestions for reframing self-realization and its constitutive concepts in the way described earlier are indeed capable of providing us with resources or insights that support the creation of narratives of becoming about aging and later life answering these three conditions summed up above. Not surprisingly, perhaps, given the line of argument followed in this study, I contend that the reframed interpretation of self-realization it offers can indeed be helpful here, which means that the guiding research question of this study can be answered in an affirmative manner. I will summarize my reasons for this contention below:

- First, the purpose of self-realization in my reframed articulation (i.e., a process of moral self-development aimed at the optimization of one's potential for moral agency), in combination with the emphasis on self-realization as a lifelong process of development, strongly underscores that growth and flourishing are morally relevant throughout our entire lives. The typical rhetoric of becoming who you are symbolizes this emphasis on continuous further self-development. The focus on moral self-development implies that my reframed articulation of self-realization is both capable of acknowledging the potential for growth and flourishing in later life, and of refuting 
the idea that aging should predominantly be seen as a phase of decline. Both features can be expected to be conducive to the creation of narratives of becoming, because they enable older people to access a dominant cultural ideal of the good life (i.e., self-realization) that remains closed to them when we follow dominant cultural master narratives.

- Second, the interpretation offered by this study presents the vulnerability of later life not as something to be remedied or rejected, but as something that can be integrated in our lives. The idea of self-realization as a process in which we strive for a good life with and for others is coupled with a narrative and moral account of identity, which emphasizes the importance of integrity, coherence and appropriation of an ethical orientation for a meaningful life. This combination implies that the approach to self-realization taken in this study enables a sensitivity for the importance of restoring coherence and vital involvement with life after being confronted with experiences of existential vulnerability. Restoring coherence and vital involvement is supportive of a meaningful integration of existential vulnerability in one's life, which I have defined as an important condition for narratives of becoming.

- Third, following from the previous point, this study perceives finding the proper responsive attitude towards existential vulnerability as quintessential to self-realization. Particularly the interpretations of virtue and authenticity defended in this study emphasize finding a satisfactory responsive attitude towards what confronts us in life. As a result, my reframed articulation of self-realization not only acknowledges existential vulnerability as an intrinsic part of the reality of living, but also perceives the confrontation with it as a potential catalyst for moral self-development, for instance, by increasing our self-knowledge and resilience or deepening our relations to other people. This study argues that with such an acquired responsive attitude, being confronted with existential vulnerability may in the end even contribute to one's growth as a human being, and, if not to one's flourishing, then at least to one's resilience. Of course, there is no guarantee that this will happen, but my reframed self-realization account certainly intends to keep this possibility open. In this sense, it also helps refute the idea that aging well is only possible within a framework of youth-related values, because it insists that value can also be derived from meaningfully dealing with those inevitable vulnerabilities and losses that our culture tends to associate with aging.

Together, these reflections illustrate the crucial importance of developing and maintaining the right attitude for the interpretation of aging well based on the self-realization discourse advanced in this study. Regarding the potential of growth and flourishing, emphasis is laid on the importance of an attitude of vital involvement with our own moral self-development and the identifications 
and orientations underlying it. It is also emphasized how our involvement with our good life should be translated into our concrete choices and actions, in our engagement with the ethical aims we have identified with, and in our concern for the good of others with whom we are interdependently connected. With regard to the meaningful integration of existential vulnerability, on the other hand, the emphasis has been on the importance of an attitude of resilience towards whatever confronts us in life, an attitude that escapes both passive surrender and active denial/rejection.

During the course of the argument, I have inserted illustrative case examples suggesting the value of specific attitudes and virtues like loving self-acceptance, mildness, hopefulness, independent thinking, modesty, self-respect, et cetera. In contrast, stagnation, indifference, intolerance and lack of engagement have been mentioned as counterproductive for realizing the purpose of aging well. Importantly, however, I have argued against the prescription of a catalogue of virtues that sets the standard for the desired attitude in any situation regardless of the context. Prescribing one specific attitude as a criterion for aging well would contradict the hermeneutic, dialogical ethical principles advanced in this study. Rather, what constitutes the "right" attitude in a given situation is decided in intersubjective hermeneutic practices involving continuous deliberation and attunement, both to one's own needs and to the demands and needs of others involved in the particular situation.

That said, however, the reframing of self-realization and its constitutive concepts advanced in this study does suggest a general direction in which the intended attitude for self-realization can be sought. I suggest describing this direction with the Aristotelian notion of practical wisdom, as an overarching virtuous attitude that helps us develop insight into ourselves and sensitivity to our situation, which in turn strengthens the hermeneutic deliberative qualities that we need in order to decide our response, and helps us seek the middle way between unwanted extremes in our reactions. Supported by the practical wisdom we ideally acquire in our striving for self-realization, we can hope to optimally realize our personal potential for growth and flourishing, as well as integrate experiences of existential vulnerability in our lives, without disavowing their reality and denying the pain they cause, but also without falling prey to a permanent loss of vital involvement in life.

What do these reflections imply for the actual formation of narratives of becoming about aging and later life? It means, most importantly, that the language of self-realization should be more explicitly welcomed and more actively applied in discourses where reflection on aging and later life takes place. These discourses, however, are highly varied and manifold. We can, for example, distinguish the following relevant aging discourses: 
- individual interactions and conversations between people where personal expectations and experiences regarding aging are exchanged. These social exchanges can either take place amongst the elderly themselves, or between individuals of different generations

- social positioning of older people, in which certain roles and possibilities are strengthened and affirmed while others are excluded. Examples of such positioning can be found, for instance, in implicit images of older employees by employers, norms regarding clothing or sexuality for older women, stereotypical expectations of dependence and complacency in fragile Fourth Agers, et cetera

- media representations of older people and their experiences, for instance, in the way newspapers and television report about them, or the way they are pictured in advertising

- artistic representations of older people and their experiences, for instance, in films or documentaries, novels, (auto)biographies, painting or sculpture, et cetera

- scientific representations of older people and their experiences, as illustrated by scientific papers and books, conference presentations, et cetera, but also exemplified in the subjects chosen as the dominant research focus by gerontologists and in the allocation of research funds (for example, favoring research on healthy aging, active aging, et cetera).

- political and societal representations of older people and their experiences exemplified, for instance, in policies regarding pensions or care-arrangements

All these discourses (and others not mentioned here) have their own way of presenting the reality of later life and thereby framing the lives of older people. The distinguished discourses are often interconnected or mutually influence each other. In their interaction, they decide which dominant images and meanings our culture recognizes as valid and credible cultural narratives about later life. Thus, following the terminology of this study, the dominance of decline- and age-defying narratives relies on a focus on certain themes (and not others!) in the variety of late modern aging discourses. Depending on the narrative, these themes may include illness, loss, dependence, anti-aging, activity, travel and consumption, et cetera. The combination of a certain set of themes mutually strengthens each other and enlarges the influence of the cultural narrative in question. For example, when gerontology focuses strongly on frailty, media predominantly show us pictures and stories about dependent older people in deplorable situations, and politicians and care-directors simultaneously warn about the costs of eldercare rising sky-high, these representations in combination strengthen (in this case) the force that decline narratives exert on the lives, minds and souls of older individuals. 
Consequently, the effort to challenge and replace adverse cultural master narratives by moral agency-enhancing counter narratives (see chapter 3) requires adjusting the aging discourse on multiple levels, targeting all of the relevant sketched discourses about later life in their mutual interactions. This effort to transform existing discourses, as may be expected, is by no means an easy process. However, experiences with social groups whose moral agency suffers from adverse positioning through cultural master narratives show that, while the result may never be completely satisfying or finished, the effort to challenge existing cultural master narratives and replace them by more viable counter narratives certainly isn't useless or doomed to fail either. Importantly, it is where master narratives show cracks and inconsistencies that the chances lie to confront them. Such confrontation should lead to the replacement of negative elements of the narrative by more satisfactory ones, a process of transformation that can ultimately lead to a strong counter narrative contesting the status quo (see Lindemann Nelson, 2001 for some interesting case examples).

In my view, we should be realistic, but nevertheless hopeful about the opportunities to transform existing problematic cultural narratives about aging and later life in the direction suggested by my plea for narratives of becoming. But given what has been discussed above, this will require substantive efforts on multiple levels. After all, multiple discourses have to be made aware of the merits of using the language of self-realization (in the reframed interpretation proposed here, of course) to arrive at a more viable image of aging well in late modern circumstances. It depends on which of the aging discourses we target, I presume, what the most promising strategy is to influence them. Generally speaking, the goal is to enrich existing ideas and meanings about aging with the ideas and meanings derived from the philosophical self-realization discourse advanced in this study. How precisely this should be done and what strategies will be successful are questions that can unfortunately not be answered here. In this study, I have just aimed to provide a (hopefully sufficiently convincing) philosophical underpinning for the relevance of my reframed version of self-realization. Its translation into practice has to wait for further research (see also $₫ 9 \cdot 5)$.

In anticipation of the results of such further research, it seems to me, however, that inspiring examples and role models, as well as good practices of how older people's moral agency can successfully be enhanced are relevant and needed at all levels of discourse. We thus need pioneering individuals and practices that teach us new and previously unthought-of options to enhance older people's opportunities to live "a good life, with and for others, according to their deepest desires and best capacities, as full participating members of society/ community" - in other words, we need exemplars of moral agency that show us the way towards the creation of narratives of becoming that strive to optimize moral agency for the rest of us. 
From the recapitulation of the argument of this study in $\ 9.2$, advancing and optimizing people's potential for moral agency emerged as a shared central purpose for both the account of self-realization as well as the account of narratives of becoming suggested in this study. The concept of moral agency is thus a kingpin of my argument. Based on the analysis in this study, I can now formulate four crucial conditions to enable the optimization of moral agency. The first two of these conditions, identification and orientation place emphasis on efforts undertaken by the individual person to become a moral agent, whereas the other two, recognition and participation require efforts on the socio-cultural and/or societal level to facilitate individuals in their striving to become (and remain) moral agents.

- First of all, I have repeatedly emphasized the need for moral agents to identify with a certain image (or rather a dynamic set of images) of who they want to be or become. This identification with a "possible self" or set of selves is essential for our identity as selfhood and our self-constancy, to use the terminology of Ricoeur (1992) that has inspired my view of moral agen-

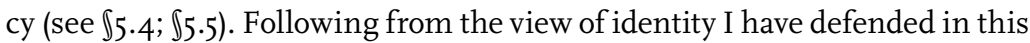
study, the identification of relevance here does not result in a static fixation of oneself on one predefined image of identity, but is a dynamic process that gradually and organically takes shape in our lifelong evolving narratives about ourselves, narratives that are intersubjectively co-constituted in our relationships with others.

- Second, this identification both enables and relies on a moral orientation, a positioning of oneself relative to a horizon of values, as C. Taylor (1989) puts it. This orientation enables us to form our aspirations and articulate our purposes. The orientation we have appropriated is also what guides us when we define for ourselves what we want to remain true to in our lives, which is where our orientation interconnects with the identification discussed above. The truthfulness to our identity-constituting orientation, as encountered particularly in the discussion on authenticity, is an indispensable ingredient of self-realization and therefore crucially important for moral agency.

- Third, arriving at a viable identification and orientation presupposes that we are socially positioned as able and worthy moral agents. That means that our moral agency crucially relies on processes of social recognition, as

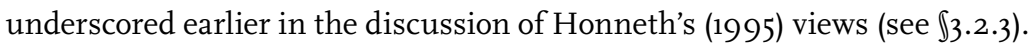
The context in which we live our lives should harbor persons, practices, systems and structures that are willing and able to acknowledge our valid claims to love, respect and solidarity (the values at stake in Honneth's three levels of recognition), which are indispensable for the ethical aim of a good life with and for others that underlies moral agency. A context in which 
one or more of the forms of social recognition is (are) absent or flawed will expectedly be an obstacle to the optimization of the development of moral agency.

- Fourth, because self-realization also pertains to the actual translation of the value orientations one has identified with into practice, moral agency also requires that people are engaged in society and granted the opportunity to participate as full members of the communities to which they belong. The discussion of Honneth's (2008) views about reification (\$3.2.3) taught us how important it is that people are treated not as mere bystanders in their own lives. Instead, they should be treated as participants in a shared practice of striving for a good life together with others. As participants, they are granted the ability to influence their own lives, which is crucial in order for their potential for moral agency to come to full bloom.

In conjunction, identification, orientation, recognition and participation form the necessary conditions for moral agency, and thereby for the understanding of self-realization defended in this study. In order to contribute to the creation of viable counter narratives, we should thus strive to influence the opportunities for moral agency in all four of these domains. Importantly, identification and orientation are individual tasks, the success of which rely for an important part on the opportunities for recognition and participation that precede their exercise. Therefore, initiatives and projects undertaken to optimize older people's moral agency would perhaps be most efficient if they start out by improving the chances for recognition and participation first.

\subsection{OBjections to the SELF-REALIZATION DISCOURSE}

There are several objections that can be directed against the self-realization discourse in general. These objections need to be briefly discussed here, in order to evaluate whether this study's reframed conceptualization of self-realization is able to answer them in a satisfactory manner. Six main objections to the self-realization discourse are discussed below: that it is elitist and overly demanding, only attainable for the "happy few" (\$9.4.1); that it is self-centered and overly individualistic ( $\$ 9.4 .2)$; that it neglects the fact that a good life is highly dependent on how social structures organize our lives, and whether or not the society we live in harbors a practice of social justice ( $\$ 9.4 .3)$; that it is biased by Western and male-oriented values (\$9.4.4); that it is moralistic and paternalistic, prescribing individuals a specific moral lifestyle instead of respecting their own choices and preferences ( $(9.4 .5)$; and that it advocates an ideal of the good life that presupposes mental health and cognitive ability, thus excluding people 
who experience disability in this regard, for instance, people with dementia or Alzheimer's disease ( $₫ 9 \cdot 4 \cdot 6)$.

\subsubsection{Elitism/demandingness objection}

The elitism/demandingness objection accuses the self-realization discourse of defending a "high bar" moral ideal, which is believed to be only relevant to a minority elite. Thus, only people who are healthy and wealthy, reflexive and intellectually highly developed, can afford to engage themselves in activities that are conducive to self-realization. Along similar lines, this objection argues that self-realization is too demanding for "ordinary" individuals. After all, it requires many capacities (reflexivity, autonomy competencies like self-direction, self-knowledge, et cetera) that - it is assumed - are not normally found in the majority of people.

In response to this objection, I would like to emphasize first of all that the suggestion that self-realization is not suitable for "normal" people has always sounded slightly condescending to me - indeed, the elitist objection seems to occupy an elitist position itself in this regard. Though I grant that most people would probably not formulate their engagement with existential questions and their search for meaning and a good life in terms of an abstract philosophical concept like self-realization, this does not mean that the underlying concerns expressed by this discourse do not concern them. A basic assumption underlying this study is loosely inspired by existentialist philosophy, which states that people have no other option but to engage themselves in a lifelong search for meaning and a good life, even if it is acknowledged that the universe they live in is not intrinsically meaningful itself. Consequently, what is fundamentally at stake in the moral discourse of self-realization - a good life with and for others, according to one's deepest aspirations and best capacities, as full participating members of a society/community - is considered relevant for all human beings.

I should grant those who raise the elitism/demandingness objection, however, that self-realization discourse makes significant demands on individuals which some people in some situations may be unable to answer. However, if we consider what is at stake - a good life in the broadest sense of the term - it should not really surprise us that the demands are high. After all, a good life is something that requires effort, at least if it is conceptualized as transcending a superficial sense of "well-being" in terms of positive affect, as used in some hedonistic conceptions of the term (Ryan \& Deci, 2001). In this study, by contrast, a good life is considered to be a complex process of self-development, as has also been underscored in eudaimonic conceptions of well-being (Ryff \& Singer, 2008). The interpretation of the self-realization discourse advanced in this study, in particular the virtue-ethical thread, therefore implies a process of continuous development and practice. It is fully acknowledged that the striving 
for self-realization takes place in a complex and imperfect context. What counts is that the result of one's strivings to respond to the demands of the situation is optimal given the restrictions of the situation. This criterion should serve to illustrate that according to my proposed reframing, though self-realization indeed makes demands on people to further their development and continuously strengthen their moral agency, it is nevertheless within the reach of many more people than the elitist objection would have us believe.

\subsubsection{Self-centeredness objection}

The self-centeredness objection fears that focusing on self-realization will lead to moral egoism or a narcissistic self-centeredness, whereby individuals are only concerned with creating the circumstances that further their own flourishing. Consequently, it is argued, there is a lack of attention to moral questions that require our engagement with the interests of others. This objection therefore considers the self-realization discourse to be insufficiently capable of acknowledging the fundamental relational embedding of the human condition, by focusing exclusively on the individual capacities for growth and flourishing.

The self-centeredness objection is addressed at the supposed underlying anthropological assumptions of the self-realization discourse. However, as seen earlier, the reframed discourse on self-realization that is advanced in this study is equally critical of the image of the self-sufficient, atomistic human agent. It follows that in my suggested reframing, the agent striving for self-realization is never solely concerned with the self, because this self is situated in a social and cultural, historical context. Moreover, as I have argued in chapter 5, this study defends a view of identity which is intrinsically moral in two senses. First, I have claimed, following C. Taylor (1985a, 1989), that our identity presupposes the appropriation of a value orientation relative to the moral horizon that forms the inescapable background of our lives. Second, following Ricoeur (1992), I have claimed that our identity as selfhood always intrinsically presupposes an ethical engagement with the good of others. Both arguments make it clear that the self-centeredness objection is refuted by the way this study has reframed the late modern interpretation of self-realization, to which the objection more rightfully applies.

\subsubsection{Social structure/social justice objection}

Related to the self-centeredness objection, but addressing it from a different angle is the social structure/social justice objection. It argues that our moral concern should not be primarily directed at the individual self, as is assumed by the self-realization discourse. How could we legitimize a focus on individual flourishing, when the world around us is on fire and requires structural mea- 
sures to remedy gross injustices and inequalities? Doesn't self-realization seem an insignificant, self-absorbed and elusive undertaking compared to solving "real world problems"? Shouldn't morality be concerned with the question how social justice can be furthered, inequality diminished, and solidarity created, thus improving the life conditions of the less privileged in society?

This objection has a legitimate point, insofar as the self-realization discourse indeed places moral primacy on the individual moral agent. This does not mean that matters of social justice or the potentially damaging influence of social structures are considered unimportant, however. As has been repeatedly discussed, this study's reframed interpretation of self-realization strongly emphasizes the socio-cultural constitution of the individual person, and its embedding in a social, historical, cultural and societal context. Hence, this account is perfectly capable of acknowledging the importance, indeed, the necessity, of creating favorable circumstances under which people are able to strive for self-realization, as the emphasis on recognition and participation also illustrates.

Nevertheless, it remains true that the principal focus of the perspective defended in this study is on the development of individual moral agency, not on changing social structures. In defense against the charge that the self-realization discourse has faulty priorities, however, I argue that the focus on moral self-development is legitimized based on the following line of thought. Challenging and transforming social structures that damage or impede people's chances to lead a good and fulfilling life are rightly underscored as important moral goals by the social structure/social justice objection and deserve to be taken seriously. However, realizing any social change or transformation requires people who take the lead. Structures are created by people, and can only be changed by people. The desired transformation in the direction of more humanizing social structures and arrangements requires first of all that people are willing to engage with ideals that are representative of the desired "better world". In order to do this, they need to be capable of appropriating an identity-guiding value orientation and act upon it. It is exactly this process of identifying with a value orientation and expressing this moral identity in actions that was argued to be the foundation of moral agency.

Thus, in order to change and transform damaging social structures, we need strong moral agents. Only strong moral agents can unite forces to challenge adverse social structures, unjust practices and oppressive cultural narratives. The perspective focusing on social structures tends to reduce moral agents to powerless pawns subjected to the overwhelming force of systemic powers. I believe this does a fundamental injustice to the potential of human persons, paradoxically a potential that is vitally needed to reach the very goals the social structure-perspective aims at. The reframed interpretation of self-realization proposed in this study emphasizes precisely the development of the 
potential for moral agency in individuals that is a "sine qua non" of social change.

\subsubsection{Western/masculine bias objection}

This objection states that the self-realization discourse is based on values and capacities that betray a bias towards Western, masculine values. The bottom line of this objection is that the self-realization discourse pretends to represent a moral perspective with a universal value, while in fact its assumptions are based upon the life reality of Western, male, white and upper class persons. Consequently, it is argued, the situation of this minority group gains a normative status, while there are many other people whose lives have very different features. The latter's claim to a good life is denied or marginalized because it supposedly does not match the criteria of self-realization.

The background against which the argument about self-realization in this study is situated is the context of late modernity. This undeniably presumes a Western, individualized context, since the features that are characteristic of late modernity do not apply to more traditional or community-oriented societal contexts. In this sense, it is fair to say that the moral discourse on self-realization advanced here is predominantly applicable to the Western context, and therefore, in a sense, biased. Expectedly, however, the experience of aging itself will also be very different in other cultural contexts, mainly because different cultural narratives about aging abound there. It seems to make little sense to try to formulate one overarching moral ideal that could accommodate all these very different experiences of aging. The reframing of self-realization advanced in this study therefore does not claim universal validity, but aims to provide a foundational concept that is capable of stimulating the creation of more nuanced and richer cultural narratives about later life in a Western, late modern context.

With regard to the accusation of a masculine bias, it is important to emphasize that this objection seems to be directed mainly against the late modern interpretation of self-realization, which has also been criticized by this study. By contrast, my proposed alternative conceptualizations of identity, autonomy, authenticity and virtue explicitly strive to accommodate the feminist critique regarding the negative influence of neglecting the relational and vulnerable dimensions of human existence. Since the interpretation of moral agency that is advocated in this study does not resemble the more traditional accounts of agency that have been accused of a masculine bias, I believe this study's reframed interpretation of self-realization largely escapes this objection. 


\subsubsection{Moralism/paternalism objection}

The moralism/paternalism objection touches upon a very deep and fundamental critique that can be made against all normative philosophical projects. It is intrinsic to a normative philosophical project that a certain way of living or a certain understanding of the good is presented as superior to others. The moralism/paternalism objection questions the legitimacy of such superiority claims on principled grounds: it argues that there is no good reason to impose the particular preferences of one philosopher or one philosophical orientation on others, for this will restrict their freedom to choose for themselves. The moralism/paternalism objection accuses the self-realization discourse of imposing moral self-development on people as a criterion to measure the moral quality of their lives. This normative prescriptiveness is perceived as undesirable paternalism, which paradoxically also contradicts the fundamental underlying principles of the self-realization discourse itself. After all, this discourse highly values making one's own authentic life choices and stimulates one's own reflexive appropriation of an identity-constituting value orientation.

In a way, the moralism/paternalism objection is understandable and maybe even partially legitimate. After all, the self-realization discourse does explicitly promote a certain lifestyle aimed at moral self-development and optimization of moral agency. Such a life is perceived as ranking higher on the continuum between admirable and flawed lives than a life with no moral focus or direction. However, as I already suggested in defense of this study's preference for narratives of becoming over decline- and age-defying narratives (see $\$ 3.4$ ), taking a normative stand can be prescriptive in weaker or stronger degrees, which influences its susceptibility to the moralism/paternalism objection. This study defends a weak substantive normative view (see $\$ 6.6$ ), which promotes that people strive to form an authentic moral orientation and act upon it, without prescribing in detail what this value orientation should precisely aspire towards. Within certain constraints that are suggested by the moral horizon of our culture (such as the so-called Golden Rule that restricts the aspirations and purposes that are morally acceptable to strive for; see $\$ 5.5$ ) this study makes a principled choice to advance maximal freedom for individual choice between different identity-constituting values, and for the appropriation of an authentic lifestyle in correspondence with what the individual agent values most deeply.

Defending a weak substantive normative position assumes a focus on transcendental conditions of self-realization, instead of on the prescription of concrete, strong substantive value orientations. For instance, the self-realization discourse presupposes that leading a good life requires certain basic competencies, such as identification with a moral image of who we strive to become, or appropriating a certain value orientation. When we assume that leading a good life is, in principle, of interest to all human beings, for it would be self-effacing 
for them to strive for anything that is not good, the "prescription" that people acquire the necessary competencies that enable such a good life acquires legitimacy. Following this, however, people ought to have the freedom to "individualize" their self-realization trajectory in their own autonomous, authentic and virtuous manner. Consequently, my suggested (re)interpretation of the self-realization discourse is indeed, in a sense, moralistic, but this need not lead to paternalism that forces a specified conceptualization of the good upon people, as would be the case in a strong substantive approach.

\subsubsection{Mental/cognitive ability objection}

The mental/cognitive ability objection expresses doubts whether people are always capable or in possession of the necessary capacities to engage in self-realization. This objection is of particular relevance when it comes to applying the self-realization discourse to the context of aging. If basic cognitive abilities start to fail, for instance in the case of Alzheimer's disease, is it still credible to speak about self-realization - or even about the presence of a self? It cannot be denied, of course, that Alzheimer's disease and other such forms of cognitive impairment deeply affect abilities we tend to regard as essential to human personhood. If we would follow the more traditional accounts of human identity, we would have to take the standpoint that people whose cognitive abilities are deteriorating lack the constitutive capacities for identity, and thus the indispensable preconditions for moral agency. Consequently, people with cognitive impairment would be denied access to the moral ideal of the good life that is represented by the self-realization discourse, since the latter strives for optimization of moral agency. Ultimately, we would then fall back upon the decline narratives that we wanted to challenge in the first place by suggesting self-realization as a resource for counter narratives of becoming. We would be forced to conclude that in this case, self-realization discourse cannot provide the desired perspective on later life, able to integrate both the potential for growth and the fundamental existential vulnerability of the human condition, of which Alzheimer's disease presents an unsettling example.

As argued in $\$ 5.3 .2$, however, the view of identity as a narrative, social practice endorsed in this study enables upholding the idea that people with Alzheimer's disease, despite their cognitive deterioration, still qualify as persons with narrative identities, because they are so held by their social surroundings (Lindemann, 2014). In this account, when people lose the capacity to keep their own narrative going, it does not mean that their identity-constituting life story ends. Others too can help people tell their life story; they can conserve valuable memories that slip away from the person originally possessing them. People can be recognized for the valuable roles they have played in the past, or be supported in occupying or maintaining other social roles in the present. Their 
social networks can engage in dialogical processes aiming to secure, as much as possible, the acknowledgment of who they used to be and who they are now, and can strive to help them organize their lives correspondingly.

Naturally, this will remain an imperfect and incomplete process. This imperfection and eroding cohesion of identity is surely one of the losses that cognitively impaired people and their social surroundings will have to deal with. But perceiving identity in a wider sense than the strictly individual cognitive perspective enables us to see that, though some fundamental capacities underlying the personhood sadly disintegrate in the process of Alzheimer's, other identity-constituting elements remain intact, such as the embodied, affective or social dimensions of identity. If we view identity as a social practice, these elements can provide enough basis to grant people suffering from Alzheimer's disease a continuing narrative identity.

Yet, claiming that people with Alzheimer's disease can still qualify as human persons or selves does not automatically mean that they are capable of self-realization as well, of course. It is deeply problematic and may even be perceived as presumptuous to describe the lives of older people surrendered to progressive mental deterioration in terms of moral self-development or the optimization of moral agency. After all, doesn't applying the language of self-realization in this case negate the life-reality of people who suffer from Alzheimer's disease, as well as the experience of their loved ones who have to watch them "fade away", as it were, progressively loosing grip on life and on everything that used to constitute their identity? I do not deny these problems. Still I wish to contend that it would be wrong and unjust to use them as legitimization to automatically exclude people with Alzheimer's disease (or other cognitive disabilities) from the realms of self-realization completely. The following two reflections elaborate on my reasons for this contention:

- First of all, the narrative conception of identity as a social practice suggests that our self-realization does not only rely on our first-person ability to uphold an identity or our third-person ability to reflect on who we are. Others can assist us in upholding our identities and help us strive for what is important for us from their second-person narrative engagement with who we are and have been throughout our lives. Importantly, the view of

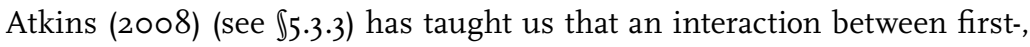
second- and third-person perspectives is characteristic of everyone's identity. For people whose first- or third-person perspective is weaker, the balance of the narrative identity-work underlying the striving for self-realization could be covered to some extent by a larger contribution from the second-person perspective.

People with Alzheimer's disease have a lifelong history of relationships and commitments that have made them who they are. They often have a his- 
tory of moral self-development which we can draw on to decide the best direction in which to further their chances to lead a good life with and for others. It takes great creativity and engagement from family, friends and caregivers to figure out which purposes or aspirations are valuable for patients of Alzheimer's. But if we take the time and effort to involve ourselves in their life narratives, we will probably be able to learn a lot about who the person is, and what choices, roles and activities would be most consistent with who they are. Further, we could help them practice these roles and activities, adapting our strategy through trial and error if it turns out that the chosen road is not advancing people's experienced quality of life. This implies that there are still possibilities to continue a lifelong process of self-realization and exercise moral agency even in conditions where people suffer from mental or cognitive disabilities. In fact, I think this is precisely what many family-members, friends and caregivers try to do in practice, in order to include their loved one in the shared practice of striving for a good life as long as possible.

- Second, it is important to reflect on the four conditions of moral agency that I have discussed before (identification, orientation, recognition and participation) in light of the objection that mental/cognitive deterioration automatically diminishes the chances for self-realization. It appears to me, namely, that there is much to be improved when it comes to enhancing the social recognition and chances for full participation for people with Alzheimer's disease or other age-related vulnerabilities in contemporary late modern societies. Anecdotal evidence from my own experience and the stories I have heard from caregivers suggests that more often than not, people with Alzheimer's disease are prematurely denied moral agency, for instance, by being treated like children or not being spoken to or consulted directly about their wishes and aspirations. Also, the cases in which we see people with Alzheimer's disease participating in valued social roles in "normal" social life are worryingly scarce. Investing in securing valued social roles for these people (or even creating new valued roles for them) would greatly enhance their opportunity to exercise moral agency, even if they are increasingly dependent on the support of others for their identification and orientation in the social practice of upholding a moral identity. I suspect that, with sufficient time and effort, with an ethical commitment to honor and preserve the uniqueness and diversity of people's life narratives, and with some creative out-of-the-box thinking aimed at enabling a more inclusive society in which everyone can fully participate according to their own aspirations and capacities, there would be many more possibilities for people with (cognitive or other) impairments to realize moral agency than is usually assumed. This should at least nuance the claim of the mental/cognitive 
ability objection that as soon as mental deterioration sets in, self-realization sadly becomes a closed book.

\subsection{UNANSWERED QUESTIONS}

As any scientific and philosophical study, this study too leaves many important questions unanswered. I will summarize some unanswered questions below that, in my view, would be valuable research domains for future investigators:

- Although the current study provides plausible philosophical underpinnings for the claim that the suggested reframed self-realization discourse might serve as a valuable resource for narratives of becoming about aging and later life, the question of how such counter narratives can be effectively created still remains open. This calls for interdisciplinary, explorative empirical work tracking down the characteristics of good practices and exemplars of moral agency that contribute to challenging existing dominant cultural narratives.

- While the primacy of the moral agent is defended with full conviction on a theoretical level, the actual voice of aging/older moral agents is missing in this study. Given the complexity of the philosophical argument I was unable to include their perspective in the study, with the exception of some anecdotal illustrations from my own experience with older people. Nevertheless, I strongly feel that the project of this study remains unfinished as long as it has not been brought into much closer connection with the living narratives of older people striving for a good life, with and for others, according to their deepest aspirations and best capacities, as full participating members of a society/community. This calls for narrative research connecting the individual life narratives of aging individuals to my theoretical/philosophical argument. Interesting questions to pursue would be, for instance: How do older people experience existing dominant cultural narratives about aging in practice? Which virtues and values do older people cherish and strive for? How does their autonomy take shape in practice? How have they searched for authenticity in their lives? How do they deal with existential vulnerability? Which obstacles and dilemmas confront them in their search for a good life? These and other questions deserve more attention, from age scholars and narrative ethicists alike.

- I have argued above that remedying the troubles identified with existing cultural (master) narratives about later life through the creation of narratives of becoming requires that the multiplicity of existing aging discourses is sensitized to the vocabulary of the self-realization discourse. It would be a valuable direction for future research in a more practical or applied setting 
to develop and test concrete interventions based on such vocabulary in the context of elderly care or specific domains of policy aimed at older people, for instance. One could think of interventions using artistic means to make care professionals and managers aware of the potentials for growth and flourishing among their elderly population, or projects raising awareness in organizations of the underused potentials and experiences of their older employees.

- On a more theoretical level, more research is called for on the relations between individual, cultural and societal/structural factors that impact people's striving for moral agency or self-realization. The focus in the current study was mainly on the interaction between individual and cultural identity-constituting factors. The impact of societal and structural factors has been indicated in chapter 2, but has further remained in the background during the main argument of the study. It would be important to devote more time and thought to how societal and structural arrangements influence the process of moral agency-development as conceptualized in this study, both on the meso-level of organizations and institutions, and on the macro-level of politics and economy.

- The focus of this study on social recognition and participation in a society/ community as crucial conditions for moral agency suggests a certain societal ideal, that has remained largely untheorized in this study and thus deserves further exploration in future research. I would suggest that theoretical and practical perspectives focusing on the need to realize an inclusive society can be a valuable road to explore in this regard, both in theoretical and practical or applied research projects (compare for instance, my reference to social role valorization theory in $\mathbb{3 3 . 2 . 3}$ ). The ideal of an inclusive society pleads for equal participation opportunities for all people regardless of their social, cultural or ethnic background, their gender, their age, their health status, et cetera. In my perception, the ideal of an inclusive society could provide a valuable match with my reframed interpretation of self-realization and its constitutive concepts in this study. In particular, the advanced view of moral agency, the view of identity as a social and moral practice and the suggested interpretations of autonomy, authenticity and virtue seem to accord very well with the ideal of an inclusive society .

\subsection{Final THOUghtS}

I have come to the end of this study connecting the themes of self-realization (including moral identity/moral agency), aging and cultural narratives about later life. In a normative philosophical endeavor such as this, it seems less uncommon then in other realms of scientific investigation to include a personal 
note; so let me end with a few personal reflections that pertain to my own, I now dare to admit, ambivalent relation to the concept of self-realization. Among philosophers, I have often heard the joke that we tend to choose as our professional focus precisely those themes that we struggle with in our personal lives. I must admit that I am no exception. The task to lead a good life (what do I consider good?), with and for others (which others do I reckon with? what if significant others die or disappear from my life? how can I mean something for others?), according to my deepest aspirations and best capacities (what are these in my case? and how can they be meaningful to myself and to others?) as full participating member of a society/community (to which community do I want to belong? and what if I am by nature hesitant to participate?) has often puzzled me deeply.

Yet the fact that I keep asking myself these questions, that I keep struggling with them in my personal life, is also proof of my authentic engagement with the moral ideal of what I have called self-realization in this study. Apparently, I have some important personal issues to digest relating to the theme of moral self-development, which I have been discussing from a comfortably detached, theoretical perspective in this study. Of course, it is precisely my struggle with these questions and with my own self-realization that has fueled my scholarly engagement with these matters in the first place.

I will not return to the arguments in favor of the self-realization discourse discussed in the more formal part of this study, for they have hopefully been made sufficiently clear above. I will end instead with two reflections regarding the meaning of self-realization that arise from my personal point of view:

- First, what is the use of striving for self-realization in light of the transiency of everything in human life? If you don't believe - as I do not - in an ultimate purpose for your life, in some gratification for earthly struggle to be acquired after one's death.... If life has made you aware - as happened to me - of the fact that who and what you love most is never here to stay "forever and always", then why take the trouble to keep striving for self-realization? To return to the gardening metaphor introduced in chapter 4 when clarifying what is at stake in self-realization: why put in all the effort to strive for a flourishing garden, if eventually everything that was blooming withers away and dies? Feinberg (1992) has made this point in a more sophisticated manner by pointing out that the whole undertaking of self-realization may seem intrinsically pointless and absurd, comparable to the ancient myth of Sisyphus, pushing his rock to the top of a hill ad infinitum only to see it fall down again on the other side.

Despite these thoughts, however, I have eventually come to the conclusion that for me there is value in the striving for self-realization after all. My own experience and confrontation with existential vulnerability has convinced 
me that eventually, we human beings cannot help seeking meaning and fulfillment in our lives. We will always long for the joys of a flourishing garden, no matter how far away this goal may seem at moments of despair. To me, the value of the self-realization discourse and its focus on a continuous process of moral self-development is therefore that it sensitizes me to the importance and intrinsic worth of activities in the here and now, which are undertaken with dedication, attentiveness, care, enthusiasm and determination. Striving for self-realization against all odds enables me to keep feeling a vital involvement with life even at times when this seems most difficult.

- Second, one of the reasons for my personal ambivalence towards the theme of self-realization is that oftentimes, who I am, my "self" that I am supposed to develop according to the self-realization discourse, seems rather like a burden to me. I can be deeply dissatisfied with myself - with my insecurity, my laziness, my anxiety, my workaholic tendency, et cetera - and I am quite sure I am not the only one. But what my struggle with the theme of self-realization in this study has taught me, an insight that has deeply contributed to my eventual appreciation of this discourse, is the indispensable need for a loving acceptance of who I am, with all my imperfections. Importantly, self-love and self-acceptance also imply struggling with the feeling that I have not chosen to be this particular person. Feinberg (1992), again, puts this into words in a way that resonates with my own feelings by stating that, "self-identity can be conceived as a kind of arranged marriage (I did not select the self that was to be me) that in a stable person ripens into true love, but in an unstable one sours into rancor and self-destruction" (p. 326). This self-love, the incomparable value of which I have come to appreciate through my involvement with the self-realization discourse, is not of the heroic kind advanced by Nietzsche, however, but of a rather more modest type. This self-love or loving self-acceptance is a virtue of realism regarding my own strengths and weaknesses, an attitude that couples an intention to make the best of myself in life with a certain mildness and forgiving attitude towards my faults and vices, and to the many moments at which I fail in my strivings. Without an attitude of loving self-acceptance, I feel like my striving for self-realization becomes an insurmountable burden. But with such an attitude, the task of "becoming who I am" seems less daunting and even - dare I say so? - attractive to pursue. 


\section{References}

Agich, G. (1990). Reassessing autonomy in long-term care. Hastings Center Report 20 (6), 12-17.

Agich, G. (1995). Actual autonomy and long-term care decision making. In L. B. McCullough, \& N. L. Wilson (Eds.), Long-term care decision: Ethical and conceptual dimensions (pp. 113-136). Baltimore, MD: Johns Hopkins University Press.

Agich, G. (2003). Dependence and autonomy in old age. An ethical framework for long-term care ( $2^{\text {nd }}$ rev. ed.). Cambridge: Cambridge University Press.

Albrecht, G.L. \& Devlieger, P.J. (1999). The disability paradox: high quality of life against all odds. Social Science \& Medicine 48, 977-988.

Andrews, M. (1999). The seductiveness of agelessness. Ageing and Society 19, 301-318.

Andrews, M. (2012). Unexpecting age. Journal of aging studies 26, 386-393.

Anscombe, E. (1958). Modern moral philosophy. Philosophy 33 (124), 1-19.

Ardelt, M. (1997). Wisdom and life satisfaction in old age. Journals of gerontology: Psychological sciences 52B, 15-27.

Ardelt, M. (2003). Empirical assessment of a three-dimensional wisdom scale. Research on aging 25 (3), 275-324.

Ardelt, M. (2011). The measurement of wisdom: a commentary on Taylor, Bates, and Webster's comparison of the SAWs and $3 \mathrm{D}-\mathrm{WS}$. Experimental aging research 37, 241-255.

Aristotle (1980). The Nicomachean Ethics (transl. David Ross). Oxford etc.: Oxford University Press.

Aristotle (1991). On rhetoric. The theory of civic discourse. (transl. George A. Kennedy). New York: Oxford University Press.

Atchley, R. C. (2009). Spirituality and aging. Baltimore: Johns Hopkins University Press.

Atkins, K. (2008). Narrative identity and moral identity. A practical perspective. New York: Routledge.

Atkins K. \& Mackenzie, C. (Eds.) (2008). Practical identity and narrative agency. New York/London: Routledge. 
Baars, J. (1991). The challenge of critical gerontology: The problem of social constitution. Journal of Aging Studies, 5(3), 219-243.

Baars, J. (2006a). Beyond neomodernism, antimodernism, and postmodernism: Basic categories for contemporary critical gerontology. In J. Baars, D. Dannefer, C. Phillipson \& A. Walker (Eds.), Aging, globalization and inequality. The new critical gerontology (pp. 17-42). Amityville, New York: Baywood publishing company, Inc.

Baars, J. (2006b). Het nieuwe ouder worden. Paradoxen en perspectieven van leven in de tijd (2nd ed.). Amsterdam: SWP.

Baars, J. (2007). Introduction: Chronological time and chronological age: problems of temporal diversity. In: J. Baars \& H. Visser (Eds.), Aging and time: multidisciplinary perspectives (pp. 1-14). Amityville, New York: Baywood publishing company Inc.

Baars, J. (2010). Philosophy of aging, time and finitude. In T.R. Cole, R. Ray $\&$ R. Kastenbaum (Eds.), A guide to humanistic studies in aging. Baltimore: Johns Hopkins University press.

Baars, J. (2012a). Aging and the art of living. Baltimore: Johns Hopkins University Press.

Baars, J. (2012b). Critical turns of aging, narrative and time. International journal of ageing and later life 7(2), 143-165.

Baars, J. (2016). Aging: learning to live a finite life. The Gerontologist. doi: 10.1093/geront/gnwo89

Baars, J., Dannefer, D., Phillipson, C. \& Walker, A. (2006). Introduction: Critical perspectives in social gerontology. In J. Baars, D. Dannefer, C. Phillipson \& A. Walker (Eds.), Aging, globalization and inequality. The new critical gerontology (pp. 1-16). Amityville, New York: Baywood publishing company, Inc.

Baars, J. \& Phillipson, C. (2013). Connecting meaning with social structure: theoretical foundations. In J. Baars, J. Dohmen, A. Grenier \& C. Phillipson (Eds.), Ageing, meaning and social structure. Connecting critical and humanistic gerontologY (pp. 11-30). Bristol: Policy Press.

Baier, A. (1985). Postures of the mind: essays on mind and morals. Minneapolis: University of Minnesota Press.

Baltes, P.B. (1991). The many faces of human ageing: towards a psychological culture of old age. Psychological medicine 21, 837-854.

Baltes, P.B. (1997). On the incomplete architecture of human ontogeny. Selection, optimization and compensation as foundation of developmental theory. American Psychologist, 52(4), 366-380.

Baltes, P.B. \& Baltes, M.M. (1990). Successful aging: Perspectives from the behavioural sciences. New York: Cambridge University Press. 
Baltes, P.B. \& Smith, J. (1990). Towards a psychology of wisdom and its ontogenesis. In: R.J. Sternberg (Ed.), Wisdom: its nature, origins and development (pp. 87-120). Cambridge: Cambridge University Press.

Baltes, P.B., Smith, J., Staudinger, U.M. \& Sowarka, D. (1990). Wisdom: one facet of successful aging? In M. Perlmutter (Ed.), Late-life potential (pp. 6381). Washington, DC: Gerontological Society of America.

Baltes, P.B. \& Staudinger, U.M. (2000). Wisdom: a metaheuristic (pragmatic) to orchestrate mind and virtue toward excellence. American Psychologist 55, $122-136$.

Barclay, L. (2000). Autonomy and the social self. In C. Mackenzie, \& N. Stoljar (Eds.), Relational autonomy. Feminist perspectives on autonomy, agency, and the social self (pp. 94-111). New York/Oxford: Oxford University Press.

Bauman, Z. (2001). The individualized society. Cambridge: Polity.

Bauman, Z. (2007). Liquid times. Living in an age of uncertainty. Cambridge: Polity Press.

Bauman, Z. (2008). The art of life. Cambridge: Polity Press.

Baumeister, R. F. (1986). Identity, cultural change and the struggle for self. New York/ Oxford: Oxford University Press.

Baumeister, R.F. (1991). Meanings of life. New York/London: The Guildford Press.

Beauchamp, T.L. \& Childress, J.F. (1984). Principles of bio-medical ethics. New York: Oxford University Press.

Beauvoir, S. de (1947). Pour une morale de l'ambiguité. Paris: Gallimard.

Beauvoir, S. de (1972). Old age. (trans. P. O’Brian). London etc.: André Deutsch Ltd \& George Weidenfeld \& Nicholson Ltd. (Original work published 1970)

Beck, U. (1992). Risk society. towards a new modernity. London: Sage publications.

Beck, U., \& Beck-Gernsheim, E. (2002). Individualization. London: Sage publications.

Bellah, R., Madsen, R., Sullivan, W.M., Swidler, A. \& Tipton, S.M. (1996). Habits of the heart. Individualism and commitment in American life (updated ed.). Berkeley etc.: University of California press.

Bengtson, V.L., Settersten jr., R.A. (Eds.) (2016). Handbook of theories of aging (3rd ed.). New York: Springer Publishing company.

Benson, P. (1991). Autonomy and oppressive socialization. Social theory and practice 17 (3), 385-408.

Benson, P. (1994). Free agency and self-worth. Journal of philosophy 91 (12), 65068.

Berlin, I. (1958). Two concepts of liberty. Oxford: Clarendon Press.

Bieri, P. (2001). Das Handwerk der Freiheit. Über die Entdeckung des eigenen Willens. München: Carl Hanser Verlag. 
Biggs, S. (1997). Choosing not to be old? Masks, bodies and identity management in later life. Ageing and society 17 (5), 553-570.

Biggs, S. (1999). The mature imagination, dynamics of identity in midlife and beyond. Buckingham: Open University Press.

Biggs, S. (2001). Toward critical narrativity. Stories of aging in contemporary social policy. Journal of aging studies 15, 303-316.

Blaikie, A. (1999). Ageing and popular culture. Cambridge: Cambridge University Press.

Blum, L.A. (1994). Moral perception and particularity. New York: Cambridge University Press.

Bolsenbroek, A. \& Laceulle, H. (in press). Setting the scene for later life. Cultural stories for inspiration and resistance. In R. Held (ed.), Social Role Valorization and aging

Braam, A., Bramsen, I., Van Tilburg, T.G., Van der Ploeg, H.M. \& Deeg, D.J. (2006). Cosmic transcendence and framework of meaning in life: patterns among older adults in the Netherlands. The journals of gerontology series $B$ : Psychological sciences and social sciences 61, 121-128.

Bruens, M. T. (2013). Dementia: beyond structures of medicalization and cultural neglect. In: J. Baars, J. Dohmen, A. Grenier \& C. Phillipson (Eds.), Ageing, meaning and social structure. Connecting critical and humanistic gerontology (pp. 81-96). Bristol: Policy Press.

Buber, M. (1958). I and Thou. New York: Scribner.

Butler, R. (1963). The life review: an interpretation of reminiscence in the aged. Psychiatry 26, pp. 65-76.

Caissie, L. (2011). The raging grannies: narrative construction of gender and aging. In G. Kenyon, E. Bohlmeijer \& W.L. Randall (Eds.), Storying later life. Issues, investigations and interventions in narrative gerontology (pp. 126-143). Oxford: Oxford University Press.

Calasanti, T. (2008). A feminist confronts ageism. Journal of aging studies 22, 152-157.

Calasanti, T. M., Slevin, K.F. \& King, N. (2006). Ageism and feminism: From "et cetera" to center. NWSA Journal, 13-30.

Carman, T. (2005). Authenticity. In: H.L. Dreyfus \& M.A. Wrathall (Eds.), A companion to Heidegger (pp. 285-296). Malden, MA etc.: Blackwell Publishing.

Carstensen, L.L. (1991). Selectivity theory: social activity in life-span context. Annual review of gerontology and geriatrics 11, 195-217.

Carstensen, L.L. (1992). Social and emotional patterns in adulthood: Support for socioemotional selectivity theory. Psychology and aging 7, 331-338.

Carstensen, L.L. (1995). Evidence for a life-span theory of socioemotional selectivity. Current directions in psychological science 4, 151-156. 
Carstensen, L.L., Isaacowitz, D.M. \& Charles, S.T. (1999). Taking time seriously. A theory of socioemotional selectivity. The American Psychologist 54 (3), 165-181.

Carstensen, L.L. \& Mikels, J.A. (2005). At the intersection of emotion and cognition. Aging and the positivity effect. Current directions in psychological science 14 (3), 117-121.

Carstensen, L. L., Mikels, J.A. \& Mather, M. (2006). Aging and the intersection of cognition, motivation and emotion. In J. E. Birren, \& K. W. Schaie (Eds.), Handbook of the psychology of aging (6th ed.,) (pp. 343-362). San Diego etc.: Elsevier Academic Press.

Chapman, S.A. (2005). Theorizing about aging well: constructing a narrative. Canadian journal on aging 24 (1), 9-18.

Cicero (2002). On old age (Cato Maior De Senectute). (ed. C. Bennett). Wauconda IL: Bolchazy Carducci Publishers. (Original work published 1467)

Code, L. (1991). What can she know? Feminist theory and the construction of knowledge. Ithaca, N.Y.: Cornell University Press.

Cohen, G.D. (2005). The mature mind. The positive power of the aging brain. Cambridge, MA: Basic Books.

Cohen, G.D. (2010). Creativity and aging: psychological growth, health and well-being. In T.R. Cole, R.E. Ray \& R. Kastenbaum (Eds.), A guide to humanistic studies in aging. What does it mean to grow old? (pp. 182-205). Baltimore: Johns Hopkins University Press.

Cole, T.R. (1992). The journey of life. A cultural history of aging in America. New York: Cambridge University Press.

Cole, T.R., Achenbaum, W.A. \& Carlin, N. (2008). Aging, history and the course of life: social structures and cultural meanings. In: K.W. Schaie \& R.P. Abeles (Eds.). Social structures and aging individuals: continuing challenges (pp. 233-254). New York: Springer Publishing Company.

Cole, T.R. \& Holstein, M. (1996). Ethics and aging. In In: J.H. Schulz (Ed.), Handbook of aging and the social sciences (4 ${ }^{\text {th }}$ ed.) (pp. 481-498). New York: Academic Press.

Collopy, B. (1988). Autonomy and long term care: some crucial distinctions. The Gerontologist 28 (supplement, June), 10-17.

Crisp, R. \& Slote, M. (Eds.) (1997). Virtue ethics. Oxford etc.: Oxford University Press.

Cruikshank, M. (2003). Learning to be old. Gender, culture, and aging. Lanham etc.: Rowman \& Littlefield Publishers.

Cruikshank, M. (2008). Aging and identity politics. Journal of aging studies 22, 147-151.

Crystal, S. \& Shea, D. (2003). Cumulative advantage, cumulative disadvantage, and inequality among older people. The Gerontologist 30, 437-443. 
Cumming, E., \& Henry, W.E. (1961). Growing old. The process of disengagement. New York: Basic Books.

Dannefer, D. (2003). Cumulative advantage/disadvantage and the life course. Cross-fertilizing age and social science theory. Journals of gerontology series B: Psychological sciences and social sciences 58B (6), S327-338.

Dannefer, D. (2008). The waters we swim: Everyday social processes, macrostructural realities, and human aging. In K. W. Schaie, \& R. P. Abeles (Eds.), Social structures and aging individuals: Continuing challenges (pp. 3-22). New York: Springer Publishing company.

Dannefer, D., \& Kelley-Moore, J.A. (2009). Theorizing the life course: New twists in the paths. In V. L. Bengtson, D. Gans, N. M. Putney \& M. Silverstein (Eds.), Handbook of theories of aging (2nd ed.) (pp. 389-411). New York: Springer Publishing company.

Dannefer, D., \& Settersten jr., R.A. (2010). The study of the life course: implications for social gerontology. In D. Dannefer \& C. Phillipson (Eds.), The Sage handbook of social gerontology (pp. 3-19). Los Angeles: Sage.

Dannefer, D. \& Uhlenberg, P. (1999). Paths of the life course: a typology. In V.L. Bengtson \& K.W. Schaie (Eds.), Handbook of theories of aging (pp. 306-326). New York: Springer.

Depp, C.A. \& Jeste, D.V. (2006). Definitions and predictors of successful aging: a comprehensive review of larger quantitative studies. American journal of geriatric psychiatry 14, 6-20.

Derkx, P. (2011). Humanisme, zinvol leven en nooit meer 'ouder worden'. Een levensbeschouwelijke visie op ingrijpende biomedisch-technologische levensverlenging. Brussel: VUB Press.

Deurzen, E. van (2002). Existential counselling and psychotherapy in practice $\left(2^{\text {nd }}\right.$ ed.). London etc.: Sage publications.

Dillon, R. (1992). Toward a feminist conception of self-respect. Hypatia 7, 5269.

Dodds, S. (2000). Choice and control in feminist bioethics. In C. Mackenzie $\&$ N. Stoljar (Eds.), Relational autonomy. Feminist perspectives on autonomy, agency, and the social self (pp. 213-235). New York/Oxford: Oxford University Press.

Dohmen, J. (Ed.) (2002). Over levenskunst. De grote filosofen over het goede leven. Amsterdam: Ambo.

Dohmen, J. (2008). Het leven als kunstwerk. Rotterdam: Stichting Maand van de Filosofie.

Dohmen, J. (2013). My own life: ethics, ageing and lifestyle. In: J. Baars, J. Dohmen, A. Grenier \& C. Phillipson (Eds.), Ageing, meaning and social structure. Connecting critical and humanistic gerontology (pp. 31-54). Bristol: Policy Press. 
Dohmen, J. (2014). Wider die Gleichgültigkeit. Plädoyer für eine moderne Lebenskunst. (trans. B. Jänicke). Zürich: Rüffer \& Rub.

Dohmen, J. \& Baars, J. (Eds.) (2010). De kunst van het ouder worden. De grote filosofen over ouderdom. Amsterdam: Ambo.

Doris, J.M. (1998). Persons, situations and virtue ethics. Nô̂s 32 (4), 504-530.

Edmondson, R. (2009). Wisdom: a humanist approach to valuing older people. In: R. Edmondson \& H-J. von Kondratowitz (Eds.), Valuing older people. A humanist approach to ageing (pp. 201-216). Bristol: Policy Press.

Edmondson, R. (2015). Aging, insight and wisdom. Meaning and practice across the lifecourse. Bristol: Policy Press.

Ekstrom, L.W. (1993). A coherence theory of autonomy. Philosophy and phenomenological research 53, 599-616.

Ekstrom. L. W. (2005). Autonomy and personal integration. In J.S. Taylor (Ed.), Personal autonomy. New essays on personal autonomy and its role in contemporary moral philosophy (pp. 143-161). Cambridge etc.: Cambridge University Press.

Elliott, A. \& Lemert, C. (2006). The new individualism. The emotional costs of globalization. London etc.: Routledge.

Emanuel, E. (2014). Why I hope to die at 75. The Atlantic. Retrieved from http://www.theatlantic.com/features/archive/2014/o9/why-i-hope-to-dieat-75/379329/.

Erikson, E.H. (1963). Childhood and society. London: Imago.

Erikson, E.H. (1997). The life cycle completed (extended version). New York: W.W. Norton \& Company.

Erikson, E.H., Erikson, J.M. \& Kivnick, H.Q. (1986). Vital involvement in old age. New York/London: W. W. Norton \& Company.

Estes, C.L. (1999). Critical gerontology and the new political economy of aging. In M. Minkler \& C.L. Estes (Eds.), Critical gerontology (pp. 17-36). Amityville, NY: Baywood Publishing Company.

Estes, C.L. \& Phillipson, C. (2003). The globalization of capital, the welfare state and old age policy. International journal of health services 32, 279-297.

Ewing, K.P. (1990). The illusion of wholeness: culture, self, and the experience of inconsistency. Ethos 18 (3), 251-278.

Faber, M. von (2002). Maten van succes bij ouderen. Gezondheid, aanpassing en sociaal welbevinden (Doctoral thesis). Amsterdam: University of Amsterdam.

Faber, M. von, Bootsma-van der Wiel, A., Van Exel, A., Gussekloo, J., Lagaay, A.M., Van Dongen, E., Knook, D.L., Van der Geest, S. \& Westendorp, R.G. (2001). Successful aging in the oldest old: Who can be characterized as successfully aged? Archives of Internal Medicine 161 (22), 2694-700.

Featherstone, M. \& Hepworth, M. (1995). Images of positive aging. A case study of Retirement Choice magazine. In M. Featherstone \& M. Wernick (Eds.), 
Images of ageing: cultural representations of later life (pp. 27-46). London/New York: Routledge.

Featherstone, M. \& Hepworth, M. (2005). Images of ageing: cultural representations of later life. In: M. Johnson (Ed.), Cambridge Handbook of Age and Ageing (pp. 354-362). Cambridge: Cambridge University Press.

Featherstone, M., Hepworth, M. \& Turner, B.S. (1991). The body: social process and cultural theory. London etc: Sage publications.

Feinberg, J. (1986). Harm to self. The moral limits of the criminal law. Oxford etc: Oxford University Press.

Feinberg, J. (1992). Freedom and fulfillment. Philosophical essays. Princeton, NJ: Princeton University Press.

Ferrara, A. (1993). Modernity and authenticity. A study of the social and ethical thought of Jean-Jacques Rousseau. Albany: State University of New York Press.

Ferrara, A. (1998). Reflective authenticity. Rethinking the project of modernity. London: Routledge.

Foot, P. (1978). Virtues and vices and other essays in moral philosophy. Oxford: Blackwell.

Foucault, M. (1992). The history of sexuality III: The care of the self. (trans. R. Hurley). New York (etc.): Penguin Books. (Original work published 1984)

Frankfurt, H. (1971). Freedom of the will and the concept of a person. Journal of philosophy 68 (1), 5-20.

Frankfurt, H. (1988a). The importance of what we care about. Philosophical essays. Cambridge/New York: Cambridge University Press.

Frankfurt, H. (1988b). Identification and wholeheartedness. In The importance of what we care about. Philosophical essays (pp. 159-176). Cambridge/New York: Cambridge University Press.

Freeman, M. (2000). When the story's over: narrative foreclosure and the possibility of self-renewal. In: M. Andrews, S. Sclater, C. Squire \& A. Treacher (Eds.), Lines of narrative: psychosocial perspectives (pp. 81-91). London: Routledge.

Freeman, M. (2011). Narrative foreclosure in later life. Possibilities and limits. In: G. Kenyon, E. Bohlmeijer \& W.L. Randall (Eds.), Storying later life. Issues, investigations and interventions in narrative gerontology. (pp. 3-19). Oxford: Oxford University Press.

Freund, A.M. \& Baltes, P.B. (1998). Selection, optimization and compensation as strategies of life management: correlations with subjective indicators of successful aging. Psychology and aging 13 (4): 531-543.

Fried, L.P., Tangen, C.M., Walston, J., Newman, A.B., Hirsch, C., Gottdiener, J., Seeman, T., Tracy, R., Kop, W.J., Burke, G. \& McBurnie, M.A. (2001). Frailty in older adults. Evidence for a phenotype. In: Journals of Gerontology Series A: Medical Sciences 56, 146-156 
Friedman, M. (1992). Feminism and modern friendship: dislocating the community. In E.B. Cole \& S. Coultrap-McQuin (Eds.), Explorations in feminist ethics: theory and practice (pp. 89-100). Bloomington: University of Indiana Press.

Friedman, M. (2000). Autonomy, social disruption, and women. In C. Mackenzie \& N. Stoljar (Eds.) (2000), Relational autonomy. Feminist perspectives on autonomy, agency, and the social self (pp. 35-51). New York/Oxford: Oxford University Press.

Gadamer, H.G. (1989). Truth and method ( $2^{\text {nd }}$ rev. ed.) (trans. J. Weinsheimer \& D.G. Marshall). New York: Crossroad.

Gerhardt, G. (1989). Kritik des Moralverständnisses: Entwickelt am Leitfaden einer Rekonstruktion von "Selbstverwirklichung" und "Volkommenheit". Bonn: Bouvier.

Gerhardt, V. (1999). Selbstbestimmung. Das Prinzip der Individualität. Stuttgart: Philipp Reclam jun.

Gewirth, A. (1998). Self-fulfillment. Princeton, New Jersey: Princeton University Press.

Giddens, A. (1991). Modernity and self-identity. Self and society in the late modern age. Cambridge: Polity Press.

Giddens, A. (1994). Living in a post-traditional society. In U. Beck, A. Giddens \& S. Lash (Eds.), Reflexive modernization. Politics, tradition and aesthetics in the modern social order (pp. 56-109). Cambridge: Polity press.

Giddens, A. (1999). Runaway world. How globalization is reshaping our lives. London: Routledge.

Gilleard, C., \& Higgs, P. (2000). Cultures of ageing: Self, citizen and the body. Harlow: Prentice Hall.

Gilleard, C. \& Higgs, P. (2005). Contexts of ageing. Class, cohort and community. Cambridge: Polity Press.

Gilleard, C. \& Higgs, P. (2011). Frailty, disability and old age. Health (London) $15(5), 475-490$.

Gilligan, C. (1982). In a different voice. Psychological theory and women's development. Cambridge, Mass: Harvard University Press.

Gobbens, R., Luijkx, K., Wijnen-Sponselee, R., Van Assen, M. \& Schols, J. (2011). Scientific definitions and measurements of frailty. In C. van Campen (Ed.), Frail older persons in the Netherlands (pp. 41-50). The Netherlands Institute for Social Research. The Hague: SCP

Goffman, E. (1959). The presentation of self in everyday life. Garden City, NY: Doubleday.

Golomb, J. (1995). In search of authenticity. From Kierkegaard to Camus. London/ New York: Routledge.

Grenier, A. (2012). Transitions and the lifecourse. Challenging the constructions of 'growing old'. Bristol: Policy Press. 
Grenier, A. \& Phillipson, C. (2013). Rethinking agency in late life: structural and interpretive approaches. In: J. Baars, J. Dohmen, A. Grenier \& C. Phillipson (Eds.), Ageing, meaning and social structure. Connecting critical and humanistic gerontology (pp. 55-80). Bristol: Policy Press.

Gubrium, J. F. \& Holstein, J.A. (2000). The self we live by: narrative identity in a post-modern world. New York/Oxford: Oxford University Press

Guignon, C. (2004). On being authentic. London/New York: Routledge.

Gullette, M.M. (1997). Declining to decline. Cultural combat and the politics of the midlife. Charlottesville and London: University Press of Virginia.

Gullette, M.M. (2004). Aged by culture. Chicago: University of Chicago Press.

Gullette, M.M. (2011). Agewise. Fighting the new ageism in America. Chicago: University of Chicago Press.

Gullette, M.M. (2017). Ending ageism, or how not to shoot older people. New Brunswick: Rutgers University Press.

Habermas, J. (1984). The theory of communicative action. Boston: Beacon press. Hadot, P. (1995). Philosophy as a way of life. Spiritual exercises from Socrates to Foucault. Malden, MA: Blackwell publishing.

Harman, G. (1999). Moral philosophy meets social psychology. Virtue ethics and the fundamental attribution error. Proceedings of the Aristotelian Society 119, 316-331.

Harman, G. (2009). Skepticism about character traits. Journal of ethics 13, 235242.

Havighurst, R.J. (1961). Successful aging. The Gerontologist 1 (1), 8-13.

Hazan, H. \& Raz, A.E. (1997). The authorized self: how middle age defines old age in the postmodern. Semiotica 113 (3/4), 257-276.

Heidegger, M. (1996). Being and time. (trans. J. Stambaugh). Albany: SUNY press. (Original work published 1927)

Held, V. (2006). The ethics of care: personal, political and global. Oxford: Oxford University Press.

Hendricks, J. (2010). Age, self and identity in the global century. In D. Dannefer, \& C. Phillipson (Eds.), The Sage handbook of social gerontology (pp. 251-264). London: Sage.

Hendricks, J. \& Hatch, L.R. (2009). Theorizing lifestyle: exploring agency and structure in the life course. In V. L. Bengtson, D. Gans, N. M. Putney \& M. Silverstein (Eds.), Handbook of theories of aging (2nd ed.) (pp. 435-454). New York: Springer Publishing company.

Hillman, J. (1999). The force of character and the lasting life. New York: Random House.

Hockey, J.L. \& James, A. (2003). Social identities across the life course. New York: MacMillan.

Hoffmaster, B. (2006). What does vulnerability mean? The Hastings center report $36(2), 38-45$. 
Holstein, M.B. (1999). Home care, women and aging. A case study of injustice. In M.U. Walker (Ed.), Mother time. Women, aging and ethics (pp. 227-244). Boston: Rowman \& Littlefield publishers.

Holstein, M. B. (2010a). Ethics and aging, retrospectively and prospectively. In T. R. Cole, R. E. Ray \& R. Kastenbaum (Eds.), A guide to humanistic studies in aging (pp. 244-270). Baltimore: Johns Hopkins University Press.

Holstein, M.B. (2010b). Ethics and old age: the second generation. In D. Dannefer, \& C. Phillipson (Eds.), The Sage handbook of social gerontology (pp. 630-641). London: Sage.

Holstein, M.B. (2011). Cultural ideals, ethics, and agelessness: a critical perspective on the Third Age. In D.C. Carr \& K. Komp (Eds.), Gerontology in the era of the Third Age: Implications and next steps (pp. 225-244). New York: Springer Publishing Company.

Holstein, M.B. (2015). Women in late life. Critical perspectives on gender and age. Lanham etc.: Rowman \& Littlefield.

Holstein, M.B., Parks, J.A. \& Waymack, M.H. (2011). Ethics, aging and society: the critical turn. New York: Springer.

Honneth, A. (1995). The struggle for recognition. The moral grammar of social conflicts. Cambridge: Polity Press.

Honneth, A. (2001). Recognition or redistribution? Changing perspectives of the moral order of society. Theory, Culture and Society, 18(2/3), 43-13.

Honneth, A. (2004). Organized self-realization: Some paradoxes of individualization. European Journal of Social Theory, 7(4), 463-478.

Honneth, A. (2008). Reification: a new look at an old idea (ed. M. Jay). Oxford etc.: Oxford University Press.

Honneth, A. (2012). The I in We. Studies in the theory of recognition. Cambridge: Polity Press.

Horney, K. (1950). Neurosis and human growth: the struggle towards self-realization. New York: W.W. Norton \& Company.

Hurd Clarke, L. (2001). Older women's bodies and the self: The construction of identity in later life. Canadian Review of Sociology/Revue canadienne de Sociologie, 441-464.

Hurka, T. (2001). Virtue, vice, and value. Oxford: Oxford University Press.

Hursthouse, R. (1991). Virtue theory and abortion. Philosophy and public affairs $20,223-46$.

Jung, C.G. (1971). Psychological types. Collected Works 6, Princeton, Princeton University Press.

Jung, C.G. (1995). Keerpunt van het leven. In: Mens en cultuur (2nd ed.). Rotterdam, Lemniscaat. (Original work published 1931)

Kant, I. (2002). Groundwork for the metaphysics of morals (ed. A.W. Wood \& J.B. Schneewind). New Haven: Yale University Press. (Original work published $1785)$ 
Kant, I. (2009). An answer to the question: what is Enlightenment? London etc: Penguin books. (Original work published 1784).

Katz, S. (2005). Cultural aging. Life course, lifestyle and senior worlds. Peterborough, Ontario: Broadview Press.

Katz, S. (2010). Sociocultural perspectives on ageing bodies. In: Dannefer, D. \& C. Phillipson (Eds.), The Sage handbook of social gerontology (pp. 357-366). London: Sage.

Kaufman, S. (2010a). Making longevity in an aging society. Linking Medicare policy and the new ethical field. Perspectives on biological medicine 53 (3), 407-424.

Kaufman, S. (2010b).Time, clinic technologies and the making of reflexive longevity: the cultural work of time left in an aging society. Sociology of health and illness 32 (2), 225-237.

Kekes, J. (2002). The art of life. New York: Cornell University Press.

Kendrick, M.J. (2008). Key dimensions of quality in individualised lifestyles and supports. Retrieved from http://www.socialrolevalorization.com/artic les/kendrick/key-dimensions-of-quality-and-individualization.pdf.

Kendrick, M.J. (2009). Personal fulfillment, values and the role of supportive communities. Retrieved from http://www.socialrolevalorization.com/arti cles/kendrick/personal-fulfillment-values-and-community.pdf.

Kenyon, G., Bohlmeijer, E. \& Randall, W.L. (Eds.) (2011). Storying later life. Issues, investigations and interventions in narrative gerontology. Oxford: Oxford University Press.

Kenyon, G., Clark, P. \& De Vries, B. (Eds.) (2001). Narrative gerontology. Theory, research, and practice. New York: Springer Publishing company.

Kierkegaard, S. (1959). Either/Or. (trans. D.F. Swenson \& L.M. Swenson). Garden City, NY: Doubleday. (Original work published 1843)

Kierkegaard, S. (2007). Kierkegaard's journals and notebooks (ed. by N.J. Cappelørn et al.). Princeton: Princeton University Press.

Kitwood, T. (1997). Dementia reconsidered: the person comes first. Buckingham: Open University Press.

Knight, T. \& Ricciardelli, L.A. (2003). Successful aging: perceptions of adults aged between 70 and 101 years. International journal of aging and human development 56, 223-245.

Knipscheer, K. (2010). The early concept of successful ageing in gerontology. In J. Bouwer (Ed.), Successful ageing, spirituality and meaning (pp. 15-28). Leuven: Peeters.

Kohlberg, L. \& Kramer, R. (1969). Continuities and discontinuities in childhood and adult moral development. Human development 12, 93-120.

Krog, A. (2006). Body bereft. Houghton, South Africa: Umuzi, Random House. Kruse, A. (2013). Der gesellschaftlich und individuell verantwortliche Umgang mit Potentialen und Verletzlichkeit im Alter - Wege zu einer Anthropologie 
des Alters. In T. Rentsch, H-P. Zimmermann \& A. Kruse (Eds.), Altern in unsere Zeit. Späte Lebensphasen zwischen Vitalität und Endlichkeit (pp. 2964). Frankfurt etc.: Campus Verlag.

Labouvie-Vief, G. (2009). Dynamic integration theory : emotion, cognition, and equilibrium in later life. In V. L. Bengtson, D. Gans, N. M. Putney \& M. Silverstein (Eds.), Handbook of theories of aging (2nd ed.) (pp. 277-294). New York: Springer Publishing company.

Laceulle, H. (2011). Laatmodern ouder worden: een spiritueel perspectief. In P. Derkx, A. Maas \& A. Machielse (Eds.), Goed ouder worden (pp. 29-46). Amsterdam: SWP

Laceulle, H. (2013). Self-realisation and ageing: a spiritual perspective. In: J. Baars, J. Dohmen, A. Grenier \& C. Phillipson (Eds.), Ageing, meaning and social structure. Connecting critical and humanistic gerontology (pp. 97-118). Bristol: Policy Press.

Laceulle, H. \& Baars, J. (2014). Self-realization and cultural narratives about later life. Journal of aging studies 31, 34-44.

Lange, F. de (2007). De mythe van het voltooide leven. Over de oude dag van morgen. Zoetermeer: Meinema.

Lange, F. de (2008). De armoede van het Zwitserlevengevoel. Pleidooi voor beter ouder worden. Zoetermeer: Meinema.

Larmore, C. (1996). The Romantic legacy. New York: Columbia University Press.

Lasch, C. (1979). The culture of narcissism. American life in an age of diminishing expectations. New York: Norton.

Lash, S. (2003). Reflexivity as non-linearity. Theory, Culture \& Society, 20(2), 49-57.

Laslett, P. (1989). A fresh map of life. The emergence of the Third Age. London: Weidenfeld \& Nicholson.

Lemay, R. (1999). Roles, identities, and expectancies: positive contributions of role theory to normalization and social role valorization. In: R.J. Flynn \& R.A. Lemay (Eds.), A quarter-century of normalization and social role valorization: evolution and impact (pp. 219-240). Ottawa, ON: University of Ottawa Press.

Levinas, E. (2003). Het menselijk gelaat. (ed. A. Peperzak). Amsterdam: Anbo.

Levy, B. (2009). Stereotype embodiment. A psychosocial approach to aging. Current directions in psychological science 18 (6), 332-336.

Lindemann, H. (2014). Holding and letting go. The social practice of personal identities. Oxford etc.: Oxford University press.

Lindemann Nelson, H. (2001). Damaged identities, narrative repair. Ithaca: Cornell University Press.

Locke, J. (1979). An essay concerning human understanding. (Ed. P. Nidditch). Oxford: Clarendon Press. (Original work published 1689) 
Louden, R. (1997). On some vices of virtue ethics. In R. Crisp \& M. Slote (Eds.), Virtue ethics (pp. 201-216). Oxford etc.: Oxford University Press.

MacIntyre, A. (1984). After virtue. A study in moral theory. (3 ${ }^{\text {rd }}$ ed.). Notre Dame, IN.: University of Notre Dame Press.

MacIntyre, A. (1999). Dependent rational animals: why human beings need the virtues. London: Duckworth.

Mackenzie, C. (2000). Imagining oneself otherwise. In C. Mackenzie \& N. Stoljar (Eds.), Relational autonomy. Feminist perspectives on autonomy, agency, and the social self (pp. 124-150). New York/Oxford: Oxford University Press.

Mackenzie, C. \& Poltera, J. (2010). Narrative integration, fragmented selves and autonomy. Hypatia 25 (1), 31-54.

Mackenzie, C., Rogers, W. \& Dodds, S. (2014). Vulnerability. New essays in ethics and feminist philosophy. Oxford etc.: Oxford University Press.

Mackenzie, C. \& Stoljar, N. (Eds.) (2000). Relational autonomy. Feminist perspectives on autonomy, agency, and the social self. New York/Oxford: Oxford University Press.

Markus, H. \& Kitayama, H. (1991). Culture and the self. Implications for cognition, emotion and motivation. Psychological review 98 (2), 224-253.

Markus, H. \& Nurius, P. (1986). Possible selves. American Psychologist 41 (9), 954-969.

McAdams, D. P. (1993). The stories we live by: Personal myths and the making of the self. New York etc.: Guildford Press.

McAdams, D.P. (1996). Narrating the self in adulthood. In: J. Birren, G. Kenyon, J.E. Ruth, J. Schroots \& T. Svensson (Eds.), Aging and biography: Explorations in adult development (pp. 131-148). New York: Springer.

McAdams, D.P., Josselson, R. \& Lieblich, A. (2006). Identity and story: creating self in narrative. Washington, DC: American psychological association.

McLeod, C. \& Sherwin, S. (2000). Relational autonomy, self-trust and healthcare for patients who are oppressed. In C. Mackenzie \& N. Stoljar (Eds.), Relational autonomy. Feminist perspectives on autonomy, agency, and the social self (pp. 259-279). New York/Oxford: Oxford University Press.

Mead, G.H. (2015). Mind, self and society. The definitive edition (ed. C.W. Morris). Chicago: University of Chicago Press. (Original work published 1934)

Medeiros, K. de (2005). The complementary self: multiple perspectives on the aging person. Journal of aging studies 19, 1-13.

Medeiros, K. de (Ed.) (2014). Narrative gerontology in research and practice. New York: Springer Publishing company.

Merleau-Ponty, M. (2012). Phenomenology of perception. (trans. D. Landes) New York: Humanities Press. (Original work published 1945)

Meyers, D.T. (1989). Self, society and personal choice. New York: Columbia University Press. 
Meyers, D.T. (1994). Subjection and subjectivity: psychoanalytic feminism and moral philosophy. New York: Routledge.

Meyers, D.T. (2000). Intersectional identity and the authentic self? Opposites attract! In: C. Mackenzie \& N. Stoljar (Eds.), Relational autonomy. Feminist perspectives on autonomy, agency, and the social self (pp. 151-180). New York/ Oxford: Oxford University Press.

Meyers, D.T. (2002). Gender in the mirror. Cultural imagery and women's agency. Oxford/New York: Oxford University Press.

Meyers, D.T. (2004). Narrative and moral life. In: C. Calhoun (Ed.), Setting the moral compass (pp. 288-308). New York: Oxford University Press.

Minkler, M. \& Estes, C.L. (Eds.) (1999). Critical Gerontology. Amityville, NY: Baywood Publishing Company.

Moen, P., \& Spencer, D. (2006). Converging divergences in age, gender, health and well-being: Strategic selection in the third age. In R. H. Binstock, \& L. K. George (Eds.), Handbook of aging and the social sciences (6th ed.) (pp. 129145). Burlington, MA etc.: Academic Press.

Moody, H. R. (1992). Ethics in an aging society. Baltimore: Johns Hopkins University Press.

Moody, H.R. \& Carroll, D. (1999). The five stages of the soul. For anyone who has ever asked: is this it? London: Rider.

Nehamas, A. (1985). Nietzsche. Life as literature. Cambridge, MA/London: Harvard University Press.

Nehamas, A. (1998). The art of living: Socratic reflections from Plato to Foucault. Berkeley: University of California Press.

Newman, J. \& Tonkens, E.H. (Eds.) (2011). Participation, responsibility and choice. Summoning the active citizen in Western European welfare states. Amsterdam: Amsterdam University press.

Nietzsche, F. (1967). Werke. Kritische Gesamtausgabe (eds. G. Colli \& M. Montinari). Berlin/New York: De Gruyter.

Nietzsche, F. (1995). Schopenhauer as educator. In: Unfashionable observations (ed. R. T. Gray) (pp. 169-255). Stanford: Stanford University Press. (Original work published 1874)

Nietzsche, F. (1996). Human, all too human. A book for free spirits. (trans. R.J. Hollingdale). Cambridge: Cambridge University Press. (Original work published 1878 )

Nietzsche, F. (2001). The gay science. (ed. B. Williams). Cambridge: Cambridge University Press. (Original work published 1882)

Nietzsche, F. (2006). Thus spoke Zarathustra. (ed. A. del Caro \& R. Pippin). Cambridge: Cambridge University Press. (Original work published 1883)

Noddings, N. (1986). Caring: a feminist approach to ethics and moral education. Berkeley: University of California Press. 
Norton, D.L. (1979). Personal destinies. A philosophy of ethical individualism. Princeton, NJ: Princeton University Press.

Nussbaum, M. (2001). The fragility of goodness. Luck and ethics in Greek tragedy and philosophy (rev. ed.). Cambridge etc.: Cambridge University Press.

Osburn, J. (2006). An overview of Social Role Valorization theory. The SRV Journal 1 (1), 4-13.

Parekh, B. (2008). A new politics of identity. Political principles for an interdependent world. New York: Palgrave MacMillan.

Parfit, D. (1984). Reasons and persons. Oxford: Clarendon Press.

Phelan, E.A., Anderson, L.A. La Croix, A.Z. \& Larson, E.B. (2004). Older adults' views of "successful aging" - how do they compare with researchers' definitions? Journal of the American Geriatrical Society 52, 211-216.

Phillipson, C. (1998). Reconstructing old age : New agendas in social theory and practice. London: Sage.

Phillipson, C. (2006). Aging and globalization: issues for critical gerontology and political economy. In In J. Baars, D. Dannefer, C. Phillipson \& A. Walker (Eds.), Aging, globalization and inequality. The new critical gerontology (pp. 43-58). Amityville, NY: Baywood publishing company.

Phillipson, C. (2009). Reconstructing theories of aging: the impact of globalization on critical gerontology. In V. L. Bengtson, D. Gans, N. M. Putney \& M. Silverstein (Eds.), Handbook of theories of aging (2nd ed.) (pp. 615-628). New York: Springer Publishing company.

Phillipson, C. (2013). Ageing. Cambridge: Polity Press.

Polivka, L. \& Longino Jr., C. (2006). The emerging postmodern culture of aging and retirement security. In J. Baars, D. Dannefer, C. Phillipson \& A. Walker (Eds.), Aging, globalization and inequality. The new critical gerontology (pp. 183-204). Amityville, NY: Baywood publishing company.

Polivka, L. \& Moody, H.R. (2001). A debate on the ethics of aging: does the concept of autonomy provide a sufficient framework for aging policy? Journal of aging and identity 6 (4), 223-237.

Randall, W. L. (2011). Memory, metaphor and meaning: reading for wisdom in the stories of our lives. In G. Kenyon, E. Bohlmeijer \& W.L. Randall (Eds.) (2011), Storying later life. Issues, investigations and interventions in narrative gerontology (pp. 20-38). Oxford: Oxford University Press.

Randall, W.L. \& McKim, A.E. (2008). Reading our lives. The poetics of growing old. Oxford: Oxford University Press.

Randall, W.L. \& Kenyon, G. (2001). Ordinary wisdom. Biographical aging and the journey of life. Westport, Conn.: Praeger.

Rawls, J. (1971). A theory of justice. Cambridge, Mass.: Harvard University Press.

Reichstadt, J., Depp, C.A., Palinkas, L.A. (2007). Building blocks of successful aging: a focus group study of older adults perceived contributors to successful aging. American journal of Geriatric Psychiatry 15, 194-201. 
Reichstadt, J., Sengupta, G., Depp, C.A., Palinkas, L.A. \& Jeste, D.V. (2010). Older adults' perspectives on successful aging: qualitative interviews. The American journal of Geriatric Psychiatry 18 (7), 567-575.

Rentsch, T. (2013). Alt werden, alt sein. Philosophische Ethik der späten Lebenszeit. In T. Rentsch, H-P. Zimmermann \& A. Kruse (Eds.), Altern in unsere Zeit. Späte Lebensphasen zwischen Vitalität und Endlichkeit (pp. 163-187). Frankfurt etc.: Campus Verlag.

Rentsch, T., Zimmermann, H.P. \& Kruse, A. (Eds.). (2013). Altern in unsere Zeit. Späte Lebensphasen zwischen Vitalität und Endlichkeit. Frankfurt etc.: Campus Verlag.

Ricoeur, P. (1991). Narrative identity. In D. Wood (Ed.), On Paul Ricoeur: narrative and interpretation (pp. 188-200). London/New York: Routledge.

Ricoeur, P. (1992), Oneself as another (trans. K. Blamey). Chicago/London: University of Chicago Press.

Riley, M.W., Kahn, R.L. \& Foner, A. (Eds.). (1994). Age and structural lag: Society's failure to provide meaningful opportunities in work, family, and leisure. New York: Wiley.

Rousseau, J.J. (1984). A discourse on inequality. (trans. M. Cranston). London: Penguin Books. (Original work published 1754)

Rousseau, J.J. (1996). The confessions. (ed. D. Matravers). Ware, Hertfordshire: Wordsworth editions Ltd. (Original work published 1782)

Rousseau, J.J. (2003). Émile, or treatise on education. (trans. W.H. Payne). Amherst, NY: Prometheus Books. (Original work published 1762)

Rowe, J.W. \& Kahn, R.L. (1987). Human aging: usual and successful. Science 237, 143-149.

Rowe, J.W. \& Kahn, R.L. (1997). Successful ageing. The Gerontologist 37 (4), 433-440.

Rowe, J.W. \& Kahn, R.L. (1998). Successful aging. New York: Random House Large Print.

Ruddick, S. (1999). Virtues and age. In M.U. Walker (Ed.), Mother Time: Women, aging and ethics (pp. 45-6o). Lanham etc.: Rowman \& Littlefield Publishers Inc.

Ryan, R.M. \& Deci, E.L. (2001). On happiness and human potentials. A review of research on hedonic and eudaimonic well-being. Annual review of psychology 52, 141-166.

Ryff, C.D., Friedman, E., Fuller-Rowell, T., Love, G., Miyamoto, Y., Morozink, J., Radler, B. \& Tsenkova, V. (2012). Varieties of resilience in MIDUS. Social and personality psychology compass 6 (11), 792-806.

Ryff, C. D. \& Singer, B.H. (2008). Know thyself and become what you are: a eudaimonic approach to psychological well-being. Journal of happiness studies 9, 13-39. 
Ryff, C. D. \& Singer, B.H. (2009). Understanding healthy aging. Key components and their integration. In V. L. Bengtson, D. Gans, N. M. Putney \& M. Silverstein (Eds.), Handbook of theories of aging (2nd ed.) (pp. 117-144). New York: Springer Publishing company.

Sabat, S R. (2001). The experience of Alzheimer's Disease. Life Through a Tangled Veil. Oxford: Blackwell Publishers.

Sartre, J.P. (1948). Existentialism and humanism (trans. P. Mairet). London: Methuen.

Sartre, J.P. (1956). Being and nothingness (trans. H. Barnes). New York: Philosophical library.

Schechtman, M. (1996). The constitution of selves. Ithaca: Cornell University Press.

Schmid, W. (1998). Philosophie der Lebenskunst. Frankfurt: Suhrkamp.

Schneewind, J.B. (1990). The misfortunes of virtue. Ethics 101, 42-63.

Schulz, R. \& Heckhausen, J. (1996). A life-span model of successful aging. The American Psychologist 51 (7), 702-714.

Sennett, R. (1992). The fall of public man. New York: Norton.

Settersten, R.A. \& Trauten, M.E. (2009). The new terrain of old age: hallmarks, freedoms and risks. In V. L. Bengtson, D. Gans, N. M. Putney \& M. Silverstein (Eds.), Handbook of theories of aging (2nd ed.) (pp. 455-470). New York: Springer Publishing company.

Slote, M. (1992). From morality to virtue. New York/Oxford: Oxford University Press.

Slote, M. (2001). Morals from motives. Oxford/New York: Oxford University Press.

Smaling, A. \& Alma, H. (2009). Zingeving en levensbeschouwing: een conceptuele en thematische verkenning. In H. Alma \& A. Smaling (Eds.). Waarvoor je leeft. Studies naar humanistische bronnen van zin (pp. 17-42). Amsterdam: SWP.

Statman, D. (Ed.) (1997). Virtue ethics: a critical reader. Georgetown: Georgetown University Press.

Stoljar, N. (2000). Autonomy and the feminist intuition. In C. Mackenzie \& N. Stoljar (Eds.), Relational autonomy. Feminist perspectives on autonomy, agen$c y$, and the social self (pp. 94-111). New York/Oxford: Oxford University Press.

Strawson, G. (2004). Against narrativity. Ratio (New Series) 17, 428-452.

Swanton, C. (2003). Virtue ethics: a pluralistic view. Oxford: Oxford University Press.

Taylor, C. (1985a). What is human agency? In: Philosophical papers I. Human agency and language (pp. 15-44). Cambridge: Cambridge University Press.

Taylor, C. $(1985$ b), Self-interpreting animals. In: Philosophical papers I. Human agency and language (pp. 45-76). Cambridge: Cambridge University Press. 
Taylor, C. (1989). Sources of the self: The making of the modern identity. Cambridge: Cambridge University Press.

Taylor, C. (1991). The ethics of authenticity. Cambridge: Harvard University Press.

Taylor, C. (2007). A secular age. Cambridge: Belknap Press of Harvard University Press.

Taylor, J. S. (Ed.) (2005). Personal autonomy. New essays on personal autonomy and its role in contemporary moral philosophy. Cambridge etc.: Cambridge University Press.

Thane, P. (2010). The history of aging and old age in "Western" cultures. In T.R. Cole, R.E. Ray \& R. Kastenbaum (Eds.), A guide to humanistic studies in aging. What does it mean to grow old? (pp. 33-56). Baltimore: Johns Hopkins University Press.

Thomä, D. (1998). Erzähle dich Selbst. Lebensgeschichte als philosophisches Problem. Muenchen: Suhrkamp (Beck).

Tongeren, P. van (2012). Leven is een kunst. Over morele ervaring, deugdethiek en levenskunst. Zoetermeer: Klement.

Tornstam, L. (1989). Gerotranscendence: a meta-theoretical reformulation of the disengagement theory. Aging: clinical and experimental research 1 (1), 5563 .

Tornstam, L. (1994). Gerotranscendence: a theoretical and empirical exploration. In L.E. Thomas \& S.A. Eisenhandler (Eds). Aging and the religious dimension (pp. 203-225). Westport, Connecticut: Greenwood.

Tornstam, L. (1997). Gerotranscendence in a broad cross-sectional perspective. Journal of aging and identity 2 (1), 17-36.

Tornstam, L. (2005). Gerotranscendence. A developmental theory of positive aging. New York: Springer Publishing Company.

Torres, S. (2006). Different ways of understanding the construct of successful aging: Iranian immigrants speak about what aging well means to them. Journal of cross-cultural gerontolog $\gamma, 21(1-2), 1-23$.

Townsend, P. (1981). The structured dependency of the elderly: the creation of policy in the twentieth century. Ageing and Society 1, 5-28.

Trilling, L. (1971). Sincerity and authenticity. Cambridge, Mass./London: Harvard University Press.

Tronto, J. (1993). Moral boundaries. A political argument for an ethics of care. New York: Routledge.

Tulle, E. (Ed.) (2004). Old age and agency. New York: Nova Science Publishers.

Twigg, J. (2004). The body, gender and age: Feminist insights in social gerontology. Journal of Aging Studies, 59-73.

Twigg, J. \& Martin, W. (2015a). The challenge of cultural gerontology, The Gerontologist 55 (3), pp. 353-359. 
Twigg, J. \& Martin, W. (Eds.) (2015b). Routledge handbook of cultural gerontology. London/New York: Routledge.

Varga, S. and Guignon, C. (2014). Authenticity. The Stanford Encyclopedia of Philosophy (Fall 2014 Edition), E. N. Zalta (Ed.). Retrieved from http://plato. stanford.edu/archives/fall2014/entries/authenticity/.

Verhoeven, A., Kooiker, S. \& Van Campen, J. (2011). Views of older persons on frailty and quality of life. In C. van Campen (Ed.), Frail older persons in the Netherlands (pp. 27-40). The Netherlands Institute for Social Research. The Hague: SCP

Vincent, J., Phillipson, C. \& Downs, M. (Eds.) (2006). The futures of old age. London: Sage books.

Walker, A. (1980). The social creation of dependency in old age. Journal of social policy 9, 45-75.

Walker, A. (1996). The new generational contract: intergenerational relations, old age and welfare. London: UCL Press.

Walker, A. (2006). Reexamining the political economy of aging: understanding the structure/agency tension. In J. Baars, D. Dannefer, C. Phillipson \& A. Walker (Eds.), Aging, globalization and inequality. The new critical gerontology (pp. 59-80). Amityville, NY: Baywood publishing company.

Walker, M.U. (1999a). Getting out of line. Alternatives to life as a career. In M.U. Walker (Ed.), Mother Time: Women, aging and ethics (pp. 97-112). Lanham etc.: Rowman \& Littlefield Publishers.

Walker, M. U. (Ed.). (1999b). Mother Time: Women, aging and ethics. Lanham etc.: Rowman \& Littlefield Publishers.

Walker, M. U. (2007). Moral understandings. A feminist study in ethics (2nd ed.). Oxford etc.: Oxford University Press.

Weber, M. (1989). Science as a vocation. In: P. Lassman, I. Velody and H. Martins (Eds), Max Weber's 'Science as a vocation' (pp. 3-32). London etc.: Unwin Hyman Inc. (Original work published 1922)

Westendorp, R. (2014). Oud worden zonder het te zijn. Over vitaliteit en veroudering. Amsterdam: Atlas Contact.

Williams, B. (1981). Moral luck. Cambridge: Cambridge University Press.

Williams, B. (2002). Truth and truthfulness. An essay in genealogy. Princeton, NJ: Princeton University Press.

Winnicott, D.W. (1965). The maturational processes and the facilitating environment: studies in the theory of emotional development. London: Hogarth Press and the Institute of Psychoanalysis.

Wolf, S. (2005). Freedom within reason. In J.S. Taylor (Ed.), Personal autonomy. New essays on personal autonomy and its role in contemporary moral philosophy (pp. 258-276). Cambridge etc.: Cambridge University Press. 
Wolfensberger, W. (2013). A brief introduction to Social Role Valorization: A high-order concept for addressing the plight of societally devalued people, and for structuring human services. (4th ed.) Plantagenet, ON: Valor Press. 


\section{Cultural Studies}

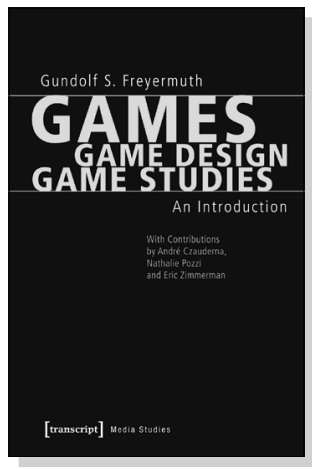

Gundolf S. Freyermuth

\section{Games | Game Design | Game Studies}

An Introduction

(With Contributions by André Czauderna,

Nathalie Pozzi and Eric Zimmerman)

2015, 296 p., pb.

$19,99 €(D E), 978-3-8376-2983-5$

E-Book: 17,99 € (DE), ISBN 978-3-8394-2983-9

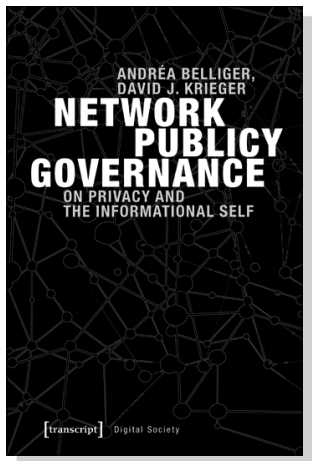

Andréa Belliger, David J. Krieger

\section{Network Publicy Governance}

On Privacy and the Informational Self

February 2018, 170 p., pb.

$29,99 €(D E), 978-3-8376-4213-1$

E-Book: 26,99 € (DE), ISBN 978-3-8394-4213-5

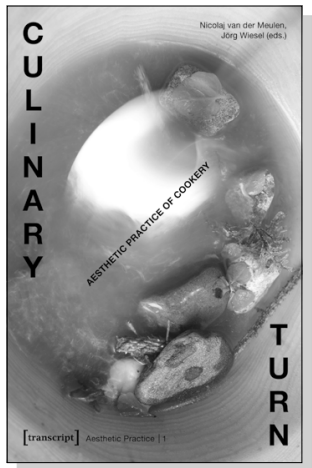

Nicolaj van der Meulen, Jörg Wiesel (eds.)

\section{Culinary Turn}

Aesthetic Practice of Cookery

(In collaboration with Anneli Käsmayr

and in editorial cooperation with Raphaela Reinmann)

2017, 328 p., pb., col. ill.

$29,99 €(D E), 978-3-8376-3031-2$

E-Book available as free open access publication

ISBN 978-3-8394-3031-6 


\section{Cultural Studies}

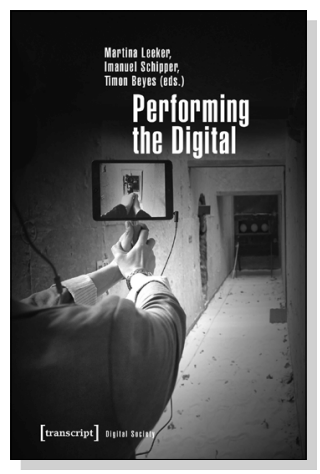

Martina Leeker, Imanuel Schipper, Timon Beyes (eds.)

\section{Performing the Digital}

Performativity and Performance Studies in Digital Cultures

2016, 304 p., pb.

$29,99 €(D E), 978-3-8376-3355-9$

E-Book available as free open access publication

ISBN 978-3-8394-3355-3

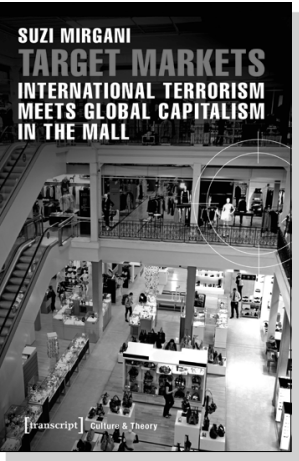

Suzi Mirgani

Target Markets -

International Terrorism

Meets Global Capitalism in the Mall

2016, 198 p., pb.

$29,99 €(D E), 978-3-8376-3352-8$

E-Book available as free open access publication

ISBN 978-3-8394-3352-2

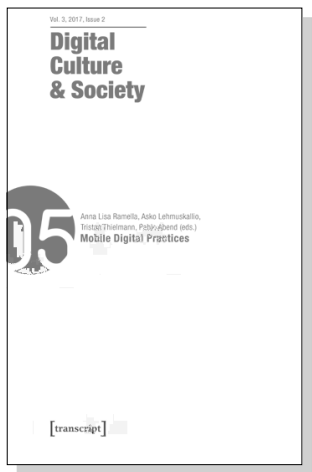

Ramón Reichert, Annika Richterich,

Pablo Abend, Mathias Fuchs, Karin Wenz (eds.)

Digital Culture \& Society (DCS)

Vol. 3, Issue 2/2017 - Mobile Digital Practices

January 2018,272 p., pb.

$29,99 €(D E), 978-3-8376-3821-9$

E-Book: 29,99€ (DE), ISBN 978-3-8394-3821-3 
